RINA HUAMANRAYME BUSTAMANTE

FABRICAÇÃO DE NANOESTRUTURAS DE ALUMINA ANÓDICA POROSA E SUAS APLICAÇÕES NA SÍNTESE DE NANOMATERIAIS 


\section{FABRICAÇÃO DE NANOESTRUTURAS DE ALUMINA ANÓDICA POROSA E SUAS APLICAÇÕES NA SÍNTESE DE NANOMATERIAIS}

Dissertação apresentada à Escola

Politécnica da Universidade de São Paulo para obtenção do Título de Mestre em Ciências.

Área de concentração:

Microeletrônica

Orientador: Prof. Dr. Walter Jaimes

Salcedo 
Este exemplar foi revisado e alterado em relação à versão original, sob responsabilidade única do autor e com a anuência de seu orientador.

São Paulo, de junho de 2012.

Assinatura do autor

Assinatura do orientador

FICHA CATALOGRÁFICA

Huamanrayme Bustamante, Rina

Fabricação de nanoestruturas de alumina anódica porosa e suas aplicações na síntese de nanomateriais / R. Huamanrayme Bustamante. -- ed.rev. -- São Paulo, 2012.

$142 \mathrm{p}$.

Dissertação (Mestrado) - Escola Politécnica da Universidade de São Paulo. Departamento de Engenharia de Sistemas Eletrônicos.

1. Eletrodeposição 2. Materiais nanoestruturados 3. Alumínio 4. Anodização I. Universidade de São Paulo. Escola Politécnica. Departamento de Engenharia de Sistemas Eletrônicos II. t. 


\section{DEDICATÓRIA}

Dedico este trabalfo a Deus, que me ajudou a concluir este trabalho... 


\section{AGRADECIMENTOS}

Agradeço...

... A Deus, por Sua intervenção na minha vida, especialmente quando cheguei ao ponto em que me senti impotente. A Ele sou grata por ter aproximado de mim pessoas especiais, tão importantes para mim quanto seus ensinamentos, as quais marcaram a minha vida desde que cheguei ao Brasil, especialmente ao meu orientador Prof. Dr. Walter Jaimes Salcedo. Obrigada, Professor, por confiar em mim e por todas as suas orientações.

... Aos meus pais, Luciano Huamanrayme e Benedicta Bustamante que me incentivaram a estudar em todo momento da minha vida, sua influência se refletiu na perseverança que exerci para concluir este trabalho.

... Aos meus irmãos, Nilton, German, Margot, Gretta, Alicia, pelo carinho e motivação para continuar estudando.

... Aos meus colegas, dando o melhor de si - me levaram a fazer o melhor que podia. Especialmente aos meus amigos Danilo, Daniel, Mauro, Felipe, Fátima, Vitor, e demais amigos e colegas que de alguma forma me acompanharam durante a minha caminhada.

... Ao meu colega e parceiro de atividades, Alan, que não economizou esforços para colaborar de diversas maneiras no desenvolvimento deste trabalho e apoiar-me nos momentos difíceis.

... Aos funcionários da sala limpa, e do laboratório de materiais magnéticos do IF-USP, em especial a Cristina, Teresa, Rita, João, Marco e Fabiana, pela dedicação e auxílio na preparação das minhas amostras.

... A meu amigo Adir pela sua ajuda na obtenção das imagens MEV.

... e a todos aqueles que de certa forma não foram citados.

... Finalmente, tenho de agradecer ao CNPq pelo suporte econômico da bolsa. 


\section{EPÍGRAFE}

"U m professor sempre aftea a eternidade. E le nunca saberá ondesua influencia termina."

- H enry B rookeA dam 


\section{RESUMO}

Nanoestructuras de alumina anódica porosa (AAP) têm sido tradicionalmente fabricadas por duas etapas de anodização a temperaturas relativamente baixas (de 0 até $5^{\circ} \mathrm{C}$ ), e usadas como máscaras ideais para formação de vários materiais nanoestruturados. Neste sentido, o objetivo do trabalho foi estudar sistematicamente a formação e a fabricação de nanoestruturas de AAP autoorganizadas por uma só etapa de anodização e posterior aplicação na síntese de nanopartículas e nanofios metálicos. As nanoestruturas auto-organizadas de AAP foram obtidas por apenas uma etapa de anodização em ácido oxálico $\left(\mathrm{H}_{2} \mathrm{C}_{2} \mathrm{O}_{4}\right)$ a temperatura ambiente; diferentemente dos processos convencionais onde são utilizados duas ou mais etapas de anodização. As características estruturais dos filmes de AAP foram moduladas através do controle dos parâmetros da concentração da solução, temperatura e potencial de polarização. O procedimento principal, para a obtenção de AAP auto-organizadas apenas por uma etapa de anodização, foi o pós-processamento de abertura dos poros através de um processo de corrosão química. Os resultados obtidos neste trabalho mostraram que o diâmetro médio dos poros apresentou uma dependência linear com a temperatura, potencial e tempo de corrosão química e foi constante em relação à concentração da solução eletrolítica. No entanto, a análise estrutural via microscopia eletrônica de varredura (MEV), mostrou que a circularidade e a ordem dos nanoporos sobre a superfície anodizada melhoraram com o aumento da concentração do eletrólito. A estrutura de AAP com um arranjo hexagonal de poros regularmente distribuídos foi obtida quando a anodização foi realizada em $0,3 \mathrm{M}$ de $\mathrm{H}_{2} \mathrm{C}_{2} \mathrm{O}_{4}$, a $45 \mathrm{~V}$ e $20^{\circ} \mathrm{C}$ de temperatura seguido de uma corrosão química a temperatura de $17^{\circ} \mathrm{C}$ por 102 minutos. Adicionalmente foram obtidos nanopartículas e nanofios metálicos utilizando-se as nanoestruturas de AAP como moldes. Como os filmes de AAP são isolantes a obtenção das nanopartículas e nanofios foi realizado através de um processo de eletrodeposição de corrente alternada (CA). Os resultados deste trabalho mostraram que nanoestruturas de AAP autoorganizadas podem ser fabricadas por uma etapa de anodização controlando o tempo de corrosão química. Os resultados apresentados neste trabalho mostram-se vantajosos em relação aos reportados na literatura, já que normalmente as nanoestruturas de AAP são obtidas mediante processos de anodização em duas etapas e tempos longos de anodização.

Palavras-chave: Alumina Anódica Porosa, Eletrodeposição CA, Corrosão química. 


\begin{abstract}
Nanostructures of porous anodic alumina (PAA) have been traditionally manufactured by two steps anodization at relatively low temperatures $\left(0\right.$ to $\left.5^{\circ} \mathrm{C}\right)$ and used as templates suitable for the formation of various nanostructured materials. In this sense, the goal of this work was the fabrication of self-organized porous Anodic alumina nanostructures (AAP) by a one anodization step and subsequent application in the synthesis of metal nanowires and nanoparticles. The self-organized nanostructures of PAA were obtained by just one anodization step in oxalic acid $\left(\mathrm{H}_{2} \mathrm{C}_{2} \mathrm{O}_{4}\right)$ at ambient temperature unlike to conventional processes where they are used two or more anodization steps. The structural characteristics of PAA films were modulated through control of the solution concentration, temperature and potential of polarization. The key procedure to obtain the periodic organized PAA by only one step anodization was the post-processing of pore opening through a process of corrosion chemistry. The results of this work showed that the average diameter of pores presented a linear dependence with temperature, time of chemical corrosion, polarization potential and it was constant relative to the concentration of the electrolyte solution. However, the structural analysis via scanning electron microscopy (SEM) showed that the roundness and the order of nanoporos over the anodized surface improved with the electrolyte concentration increasing. The PAA structure with a hexagonal arrangement of pores was obtained when the anodization was held in $0.3 \mathrm{M}$ of $\mathrm{H}_{2} \mathrm{C}_{2} \mathrm{O}_{4}, 45 \mathrm{~V}$, and $20{ }^{\circ} \mathrm{C}$ of temperature followed by a chemical corrosion at $17{ }^{\circ} \mathrm{C}$ of temperature for 102 minutes. Additionally it was obtained nano particles and nano metal wires using the PAA structures as molds. Since the PAA films are insulating, the nanoparticles and nanowire were obtained through an electrodeposition process using alternating current. The results of this work have shown that self-organized PAA nanostructures can be fabricated by one anodization step controlling the time of chemical etching process. The results presented in this work are advantageous in relation to reported in the literature, since normally the structures of PAA are obtained by two step anodization and for long anodization time.
\end{abstract}

Key-words: Porous Anodic Alumina, Electrodeposition AC, Chemical Etching. 


\section{LISTA DE FIGURAS}

Figura 2.1. (A) Imagem MET da superfície anodizada, e (B) vista transversal mostrando a camada de óxido tipo poroso e tipo barreira. (Ref. [84]) . . . . . . . 11

Figura 2.2. Estrutura idealizada da $A A P(A)$. Vista da seção transversal da camada de óxido (B) com $D_{p}$ : diâmetro do poro, $W$ : espessura da parede do poro, $D_{c}$ : distância interporo e $B$ : espessura da camada tipo barreira. . . . . . . . . . 12

Figura 2.3. Influência do potencial de anodização sobre a espessura da camada tipo barreira da AAP formada em vários ácidos. (Ref. [81]) . . . . . . . . . . . . 16

Figura 2.4. Parâmetros de "anodização" que podem influenciar as características

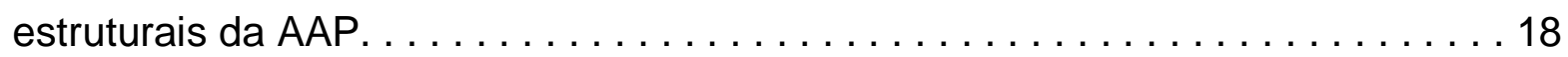

Figura 2.5. Perfil esquemático de profundidade da concentração de ânions no filme de óxido tipo poroso (A) e tipo barreira (B) formado por anodização do alumínio em diferentes soluções eletrolítcas. (Ref. [104]) . . . . . . . . . . . . . . 20

Figura 2.6. Representação esquemática da vista seccional e plano da esturtura de AAP de parede celular duplex. . . . . . . . . . . . . . . . . . 21

Figura 2.7. Representação esquemática da vista seccional e plano da esturtura de AAP de parede celular triplex. . . . . . . . . . . . . . . . . . . . 21

Figura 2.8. Curvas cinéticas de crescimento da AAP em regime galvanostático (A) e potenciostático $(B)$, com suas zonas de anodização . . . . . . . . . . . 24

Figura 2.9. Curvas cinéticas de crescimento da $A A P$ anodizadas em regime galvanostático, 0,5 $\mathrm{M} \mathrm{H}_{2} \mathrm{SO}_{2}(\mathrm{~A}), 0,2 \mathrm{M} \mathrm{H}_{2} \mathrm{C}_{2} \mathrm{O}_{4}$ (B) e 0,4 $\mathrm{M} \mathrm{H}_{3} \mathrm{PO}_{4}$ (C): J=25mA/cm² (A), $\mathrm{J}=10 \mathrm{~mA} / \mathrm{cm}^{2}$ (B), $\mathrm{J}=5 \mathrm{~mA} / \mathrm{cm}^{2}$ (C). (Ref. [143]) $\ldots \ldots \ldots \ldots \ldots \ldots \ldots \ldots \ldots$

Figura 2.10. Curvas cinéticas de crescimento da AAP anodizadas em regime potenciostático para $0,3 \mathrm{M} \mathrm{H}_{2} \mathrm{C}_{2} \mathrm{O}_{4}$ e diferentes temperaturas. (Ref. [36]) . . . . .26

Figura 2.11. Curvas cinéticas de crescimento da AAP em regime galvanostático $(A)$ e potenciostático (B), estágios de crescimento da AAP (C), estrutura da AAP sem 
células hexagonais (D) e estrutura da AAP com células hexagonais (E). (Ref.[113]). .28

Figura 2.12. Imagens $M E V$ de ocorrência natural para um longo período de tempo de anodização de AAP formado em três tipos de eletrólitos: (A) ácido sulfúrico, (B) ácido oxálico e (C) ácido fosfórico. (Ref. $[71,74,75]) \ldots \ldots \ldots \ldots \ldots \ldots \ldots . \ldots \ldots$

Figura 2.13. Dependência da ordenação do arranjo dos poros da AAP anodizadas em 0,5 M de ácido sulfúrico a $25 \mathrm{~V}: 9 \mathrm{~min}$ (A), $36 \min (B)$ e $710 \mathrm{~min}$ (C). (Ref. [74]). .

Figura 2.14. Diagrama esquemático de anodização em duas etapas para a preparação de AAP auto-organizada. 33

Figura 2.15. Imagens $M E V$ vistas no fundo dos poros após a remoção do substrato de alumínio. Estas estruturas de AAP foram preparadas por anodização em ácido sulfúrico $(A)$, ácido oxálico (B) e ácido fosfórico (C). (Ref. [158]). . . . . . . . . 33

Figura 2.16. Imagens MEV-EC da superfície do filme de AAP anodizada em $0,3 \mathrm{M}$ de $\mathrm{H}_{2} \mathrm{C}_{2} \mathrm{O}_{4}, 140 \mathrm{~V}$ e $-5^{\circ} \mathrm{C}$ por 20 minutos $(\mathrm{A})$ e $1 \mathrm{M}$ de $\mathrm{H}_{3} \mathrm{PO}_{4}, 140 \mathrm{~V}$ e $5^{\circ} \mathrm{C}$ por 3

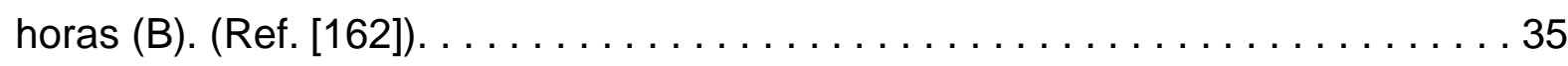

Figura 2.17. Imagens MEV-EC da superfície anodizada (A), e de vista transversal (B) da AAP sob a anodização melhorada. (Ref. [162]). . . . . . . . . . . 35

Figura 2.18. Desenho esquemático da preparação de AAP auto-organizada usando

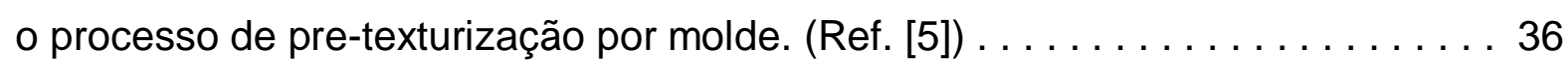

Figura 2.19. Imagens $M E V$ da configuração celular com diferentes intervalos entre os canais $100 \mathrm{~nm}(\mathrm{~A}), 150 \mathrm{~nm}$ (B) e $200 \mathrm{~nm}$ (C). Os potenciais de anodização foram de $40 \mathrm{~V}(\mathrm{~A}), 60 \mathrm{~V}(\mathrm{~B})$ e $80 \mathrm{~V}(\mathrm{C})$. $A$ anodização foi realizada em 0,3 $\mathrm{M}$ de ácido oxálico a $17^{\circ} \mathrm{C}$ para $(\mathrm{A})$ e (B), e $0,04 \mathrm{M}$ de ácido oxálico a $3^{\circ} \mathrm{C}$ para (C). (Ref. [73]). . 
Figura 2.20. Imagens $M E V$ das configurações celulares da AAP formado por indentação de moldes: estrutura de grafite $(A)$, estrutura triangular $(B)$ e estrutura

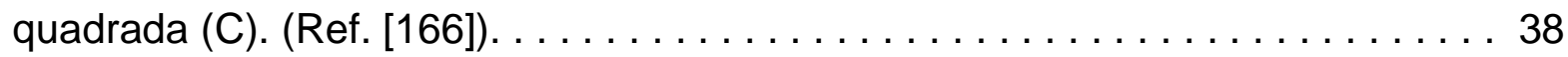

Figura 2.21. Imagens $\mathrm{MEV}$ de $\mathrm{AAP}$ formada em $3,3 \mathrm{M} \mathrm{H}_{2} \mathrm{SO}_{4}$ a $-8^{\circ} \mathrm{C}$ para vários potenciais: 15V (A), 19V (B) e 25V (C). Diâmetro médio dos poros (D), distância interporo $(E)$ e porosidade $(F)$ em função do potencial de anodização para várias temperaturas. (Ref. $[91,93]) \ldots \ldots \ldots \ldots \ldots \ldots \ldots \ldots \ldots \ldots \ldots \ldots \ldots \ldots$

Figura 2.22. Imagens MEV de AAP formada em $0,3 \mathrm{M} \mathrm{H}_{2} \mathrm{C}_{2} \mathrm{O}_{4}$ por 1 hora a $30^{\circ} \mathrm{C}$ para vários potenciais: $30 \mathrm{~V}(\mathrm{~A}), 40 \mathrm{~V}$ (B) e 50V (C). Diâmetro médio dos poros (D), distância interporo $(E)$ e porosidade $(F)$ em função do potencial de anodização para

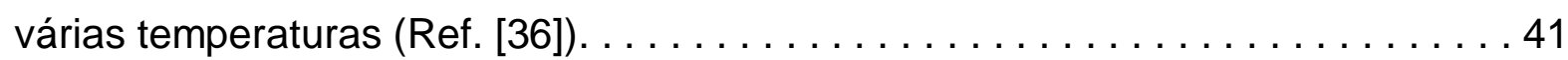

Figura 2.23. Fabricação de nanofios via membranas "free-standing" de AAP por eletrodeposição CC: (A) dissolução do $\mathrm{Al}$, (B) remoção de camada barreira, (C)

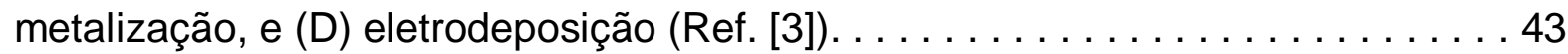

Figura 2.24. Fabricação de nanofios via máscaras de AAP por eletrodeposição $C A$ : (A) afinamento da camada barreira e (B) electrodeposição (Ref. [3]) . . . . . . . 44

Figura 2.25. Fabricação de nanofios via máscaras de AAP por eletrodeposição pulsada. (A) Estrutura porosa ordenada, (B) processo de ataque químico, (C) formação de dendrites devido a redução exponencial do potencial de anodização, (D) e (E) Electrodeposição Pulsada de Corrente. (Ref. [175]) . . . . . . . . . . 45

Figura 2.26. Nanopartículas de Ouro (A), nanofios de Prata $(B)$ e nanotubos de Níquel (C) eletrodepositadas numa membrana de AAP (Ref. $[177,179,180]$ ) . . . .46

Figura 3.1. Célula eletrolítica simples (A) e um diagrama esquemático de

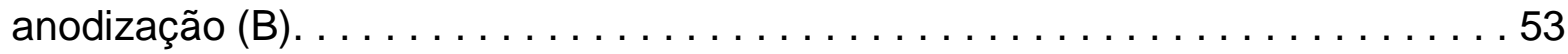

Figura 3.2. Diagrama de blocos do processo de fabricação de nanoestruturas de

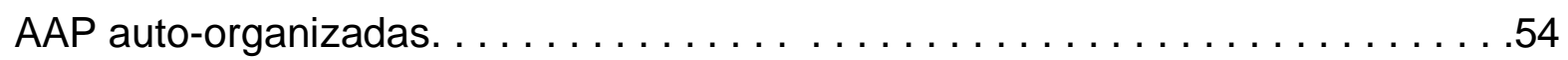

Figura 3.3 Diagrama esquemático do processo de eletrodeposição CA. . . . . 56 
Figura 3.4 Amostras colocadas em solução de $1 \mathrm{M}$ de $\mathrm{H}_{3} \mathrm{PO}_{4}$ para o processo de

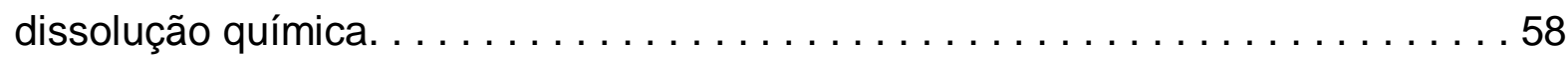

Figura 4.1. Curvas cinéticas de crescimento da AAP no regime potenciostático das amostras $\mathrm{O}_{7}$ e $\mathrm{O}_{8}$ durante a anodização em $0,5 \mathrm{M}$ de $\mathrm{H}_{2} \mathrm{C}_{2} \mathrm{O}_{4}$, a um potencial de 45 $V$ e a temperatura de 15 e $25^{\circ} \mathrm{C}$, respectivamente, junto com suas respectivas regiões de anodização (a,b,c,d) e etapas do desenvolvimento da estrutura porosa. .

Figura 4.2. Imagens MEV da superfície anodizada das amostras $O_{7}(A)$ e $O_{8}(B)$ depois de uma corrosão química de 60 minutos a $23^{\circ} \mathrm{C}$. A anodização foi realizada em $0,5 \mathrm{M}$ de acido oxálico, $45 \mathrm{~V}, 15$ e $25^{\circ} \mathrm{C}$ respectivamente.

Figura 4.3. Imagens $M E V$ das amostras $O_{7}(A, B, C)$ e $O_{8}(D, E, F)$ de vista superior com rachadura e clivada $(A, D)$. Imagem transversal mostrando a camada interna e externa $(B)$, imagem com poros perfeitamente paralelos $(E)$, e imagens transversais das espessuras dos óxidos crescidos $(\mathrm{C}, \mathrm{F}) \ldots \ldots \ldots \ldots \ldots \ldots \ldots \ldots \ldots \ldots$

Figura 4.4. Imagens MEV das superfícies anodizadas das amostras $O_{3}, O_{1}, R_{8}$ e $\mathrm{O}_{2}$. A anodização foi realizada a $20^{\circ} \mathrm{C}$ e $45 \mathrm{~V}$, para várias concentrações de ácido oxálico: 0,05M (A), 0,15M (B), 0,3M (C) e 0,5M (D) . . . . . . . . . . . . 64

Figura 4.5. Curvas cinéticas de crescimento para as amostras $O_{3}, O_{1}, R_{8}$ e $O_{2}$ correspondentes às várias concentrações de ácido oxálico . . . . . . . . . .66

Figura 4.6. Densidade de corrente em estado estacionário em função da concentração do eletrólito, registradas das curvas cinéticas de anodização das amostras $\mathrm{O}_{3}, \mathrm{O}_{1}, \mathrm{R}_{8}, \mathrm{O}_{2}\left(20^{\circ} \mathrm{C}\right)$ e $\mathrm{K}_{1}, \mathrm{O}_{6}, \mathrm{P}_{6}, \mathrm{O}_{9}\left(30^{\circ} \mathrm{C}\right)$ para um potencial de anodização constante de $45 \mathrm{~V}$.

Figura 4.7. Densidade de corrente em estado estacionário em função da concentração do eletrólito, registradas das curvas cinéticas de anodização das amostras $\mathrm{O}_{3}, \mathrm{O}_{1}, \mathrm{R}_{8}, \mathrm{O}_{2}(45 \mathrm{~V})$ e $\mathrm{B}_{2}, \mathrm{~F}_{6}, \mathrm{H}_{2}, \mathrm{H}_{6}(50 \mathrm{~V})$ para uma temperatura constante de $20^{\circ} \mathrm{C}$. 68 
Figura 4.8. Diagrama de distribuição $3 D$ do diâmetro dos poros para as amostras $\mathrm{O}_{3}(0,05 \mathrm{M}), \mathrm{O}_{1}(0,15 \mathrm{M}), \mathrm{R}_{8}(0,3 \mathrm{M})$ e $\mathrm{O}_{2}(0,5 \mathrm{M})$

Figura 4.9. Influência da concentração do eletrólito sobre o diâmetro médio dos

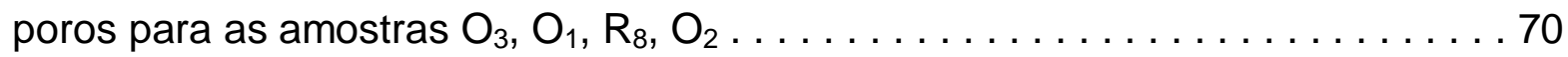

Figura 4.10. Imagens MEV das superfícies anodizadas das amostras $P_{3}(A), R_{8}(B)$, $\mathrm{P}_{4}(C)$ e $\mathrm{P}_{6}(\mathrm{D})$ depois de uma corrosão química de 60 minutos a uma temperatura de $23^{\circ} \mathrm{C}$. A anodização foi realizada em $0,3 \mathrm{M}$ de ácido oxálico a $45 \mathrm{~V}$ para várias temperaturas: $15^{\circ} \mathrm{C}\left(\mathrm{P}_{3}\right), 20^{\circ} \mathrm{C}\left(\mathrm{R}_{8}\right), 25^{\circ} \mathrm{C}\left(\mathrm{P}_{4}\right)$ e $30^{\circ} \mathrm{C}\left(\mathrm{P}_{6}\right) \ldots \ldots \ldots \ldots \ldots . \ldots 71$

Figura 4.11. Curvas cinéticas de crescimento dos poros das amostras $P_{3}, R_{8}, P_{4}$ e $P_{6}$ para os primeiros dois minutos e meio de anodização realizados em $0,3 \mathrm{M}$ de acido oxálico, $45 \mathrm{~V}$, e para várias temperaturas do eletrólito: $15^{\circ} \mathrm{C}\left(\mathrm{P}_{3}\right), 20^{\circ} \mathrm{C}\left(\mathrm{R}_{8}\right)$,

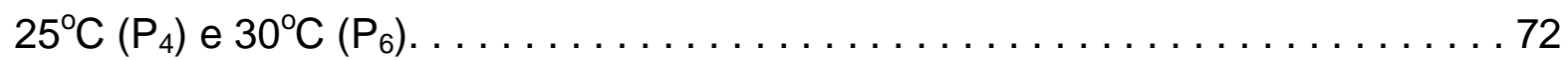

Figura 4.12. Densidade de corrente estacionaria em função da temperatura do eletrólito para duas concentrações diferentes de 0,3 e 0,5M. As curvas correspondem às amostras $\mathrm{P}_{3}, \mathrm{R}_{8}, \mathrm{P}_{4}, \mathrm{P}_{6}(0,3 \mathrm{M})$ e $\mathrm{O}_{7}, \mathrm{O}_{2}, \mathrm{O}_{8}, \mathrm{O}_{9}(0,5 \mathrm{M})$ para um potencial de anodização constante de $45 \mathrm{~V} \ldots \ldots \ldots \ldots \ldots \ldots \ldots \ldots$

Figura 4.13. Densidade de corrente estacionária en função da temperatura do eletrólito para dois potenciais diferentes de 45 e $50 \mathrm{~V}$. As curvas correspondem às amostras $\mathrm{P}_{3}, \mathrm{R}_{8}, \mathrm{P}_{4}, \mathrm{P}_{6}(45 \mathrm{~V})$ e $\mathrm{H}_{1}, \mathrm{H}_{2}, \mathrm{H}_{3}, \mathrm{H}_{4}(50 \mathrm{~V})$ para uma concentração

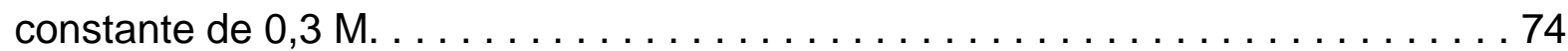

Figura 4.14. Diagrama de distribuição $3 D$ do diâmetro dos poros das amostras $P_{3}$, $R_{8}, P_{4}$ e $P_{6}$ correspondentes as temperaturas do eletrólito de $15^{\circ} \mathrm{C}, 20^{\circ} \mathrm{C}, 25^{\circ} \mathrm{C}$ e $30^{\circ} \mathrm{C}$, respectivamente. . . . . . . . . . . . . . . . . . . . 75

Figura 4.15. Influência da temperatura do eletrólito sobre o diâmetro médio dos

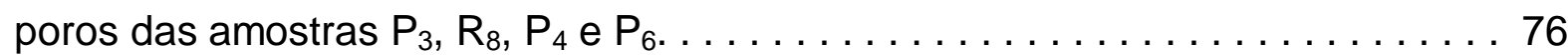

Figura 4.16. Imagens $M E V$ das superfícies anodizadas das amostras $D_{2}(A), P_{7}(B)$, $\mathrm{R}_{8}(\mathrm{C})$ e $\mathrm{H}_{2}(\mathrm{D})$ depois de um tempo de corrosão química de 60 minutos a uma temperatura de $23^{\circ} \mathrm{C}$. A anodização foi realizada em $0,3 \mathrm{M}$ de ácido oxálico a uma 
temperatura de $20^{\circ} \mathrm{C}$ para vários potenciais de anodização: $35 \mathrm{~V}\left(\mathrm{D}_{2}\right), 40 \mathrm{~V}\left(\mathrm{P}_{7}\right), 45 \mathrm{~V}$

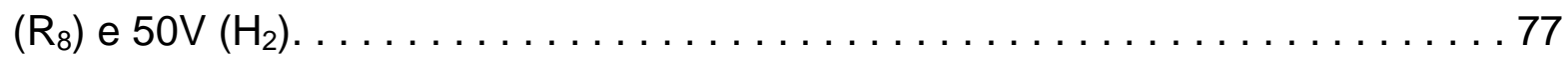

Figura 4.17. Densidade de corrente como função do tempo de anodização das amostras $D_{2}, P_{7}, R_{8}$ e $H_{2}$ para os primeiros dois minutos e meio de anodização, realizados em $0,3 \mathrm{M}$ de acido oxálico e $20^{\circ} \mathrm{C}$ para vários potenciais de anodização de $35,40,45$ e $50 \mathrm{~V}$, respectivamente. . . . . . . . . . . . . . . . 78

Figura 4.18. Densidade de corrente estacionária em função do potencial de anodização, registradas das curvas cinéticas de anodização das amostras $D_{2}, P_{7}$, $\mathrm{R}_{8}, \mathrm{H}_{2}(0,3 \mathrm{M})$ e $\mathrm{D}_{6}, \mathrm{E}_{2}, \mathrm{O}_{2}, \mathrm{H}_{6}(0,5 \mathrm{M})$ para uma temperatura constante de $20^{\circ} \mathrm{C} \ldots \ldots$

Figura 4.19. Densidade de corrente estacionária en função do potencial de anodização obtidas das curvas cinéticas de anodização das amostras $D_{2}, P_{7}, R_{8}, H_{2}$ $\left(20^{\circ} \mathrm{C}\right)$ e $\mathrm{D}_{3}, \mathrm{P}_{8}, \mathrm{P}_{4}, \mathrm{H}_{3}\left(25^{\circ} \mathrm{C}\right)$ para uma concentração de ácido oxálico constante de $0,3 \mathrm{M}$. .80

Figura 4.20. Diagrama de distribuição $3 D$ do diâmetro dos poros das amostras $D_{2}$, $\mathrm{P}_{7}, \mathrm{R}_{8}$ e $\mathrm{H}_{2}$ correspondentes aos potenciais de anodização de $35 \mathrm{~V}, 40 \mathrm{~V}, 45 \mathrm{~V}$ e 50 $\checkmark$, respectivamente. . . . . . . . . . . . . . . . . . 81

Figura 4.21. Influência do potencial de anodização sobre o diâmetro médio dos poros das amostras $D_{2}, P_{7}, R_{8}$ e $H_{2}$. . 82

Figura 4.22. Imagens $M E V$ da superfície anodizada da amostra $R_{8}$ para vários períodos de tempo de corrosão química em $1 \mathrm{M}$ de $\mathrm{H}_{3} \mathrm{PO}_{4}$ : 20 minutos $(\mathrm{A}), 40$ minutos (B), 60 minutos (C) e 80 minutos (D) a uma temperatura de $23^{\circ} \mathrm{C}$. A anodização foi realizada em $0,3 \mathrm{M}$ de ácido oxálico, $20^{\circ} \mathrm{C}$ e $45 \mathrm{~V} \ldots \ldots \ldots . . .83$

Figura 4.23. Influência do tempo de corrosão química sobre o diâmetro médio dos poros da amostra $R_{8}$ para vários períodos de tempo.

Figura 4.24. Imagens $M E V$ da superfície anodizada da amostra $R_{8}$ para vários períodos de tempo de corrosão química em $1 \mathrm{M} \mathrm{H}_{3} \mathrm{PO}_{4}$ : 84 minutos (A), 86 minutos 
(B), 88 minutos (C), 90 minutos (D) a uma temperatura de $23^{\circ} \mathrm{C}$. A anodização foi realizada em $0,3 \mathrm{M}$ de ácido oxálico, $20^{\circ} \mathrm{C}$ e $45 \mathrm{~V} \ldots \ldots \ldots \ldots \ldots \ldots$

Figura 4.25. Imagens $M E V$ da superfície anodizada da amostra $R_{8}$ para vários períodos de tempo de ataque químico em $1 \mathrm{M} \mathrm{H}_{3} \mathrm{PO}_{4}$ : 88 minutos $(\mathrm{A}), 92$ minutos (B), 97 minutos (C) e 102 minutos (D) a uma temperatura de $17^{\circ} \mathrm{C}$. A anodização foi realizada em $0,3 \mathrm{M}$ de ácido oxálico, temperatura de $20^{\circ} \mathrm{C}$ e para um potencial de

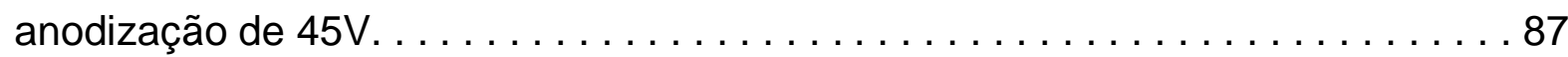

Figura 4.26. Imagens MEV de estruturas auto-organizadas de AAP para as amostras $\mathrm{O}_{6}, \mathrm{O}_{7}$ e $\mathrm{P}_{3}$ após um tempo de corrosão química de 90 minutos aproximadamente.

Figura 4.27. Diagrama de distribuição $3 D$ do diâmetro dos nanoporos da amostra $\mathrm{R}_{8}$ para vários períodos de tempo de corrosão química em $1 \mathrm{M} \mathrm{H}_{3} \mathrm{PO}_{4}$ : 20 minutos (A), 40 minutos (B), 60 minutos (C), 80 minutos (D) a temperatura de $23^{\circ} \mathrm{C}$ e uma distribuição dos poros auto-organizados $(\mathrm{E}) \ldots \ldots \ldots \ldots \ldots \ldots \ldots \ldots . .69$

Figura 4.28. Imagens $M E V$ de nanopartículas e nanofios de Níquel obtidas por electrodeposição utilizando-se um sinal $C A$ de: $(A, B) 100 \mathrm{~Hz}$ de frequência e um tempo de deposição de 2 minutos; (C,D) $300 \mathrm{~Hz}$ de frequência e um tempo de deposição de 2 minutos; (E,F) $300 \mathrm{~Hz}$ de freqüência e um tempo de deposição de 10 min. . . . . . . . . . . . . . . . . . . . . . . . . . . .

Figura 4.29. Espectro EDS da análise química das nanopartículas de Níquel eletrodepositadas numa máscara de AAP . . . . . . . . . . . . . . 92

Figura 4.30. Imagens MEV dos nanofios de prata eletrodepositados numa máscara de AAP utilizando um sinal $C A$ de: $(A, B) 100 \mathrm{~Hz}$ de frequência com um tempo de deposição de 5 minutos; (C,D) $300 \mathrm{~Hz}$ de freqüência com um tempo de deposição de 40 minutos. . . . . . . . . . . . . . . . . . . . . . . . . . . . . . . . . . . 94

Figura 4.31. Espectro EDS da análise química dos nanofios de Prata eletrodepositadas numa máscara de AAP . . . . . . . . . . . . . . 95 
Figura 4.32. Imagens MEV do processo de formação de nanofios de alumina para a amostra $P_{3}$ : (A) 40 minutos, 50 minutos (B), (C) 60 minutos, e 65 minutos (D) de dissolução química a uma temperatura de $27^{\circ} \mathrm{C} \ldots \ldots \ldots \ldots \ldots \ldots \ldots$

Figura 4.33. Espectro EDS da análise química dos nanofios de alumina. . . . . . 97

Figura 4.34. (A) Imagem MEV da formação de nanofios de alumina da amostra $P_{3}$ com um tempo de dissolução química de 65 minutos a uma temperatura de $27^{\circ} \mathrm{C}$. (B) Imagem MEV da superfície depois de uma remoção dos nanofios. . . . . . . 98

Figura 4.35. (A) Imagem MEV de nanofios de alumina formados da amostra $R_{8}$ com um tempo de dissolução química de 104 minutos a temperatura de $23^{\circ} \mathrm{C}$ e (B) Imagem MEV da superfície de alumina depois de uma remoção dos nanofios. ..... 


\section{LISTA DE TABELAS}

Tabela 3.1. Parâmetros eletroquímicos utilizados na formação de estruturas de

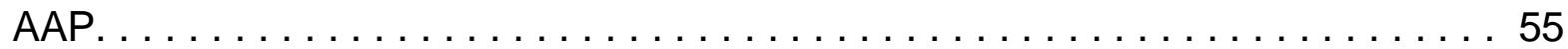




\section{LISTA DE SIGLAS E ABREVIATURAS}
AAP
Alumina Anódica Porosa
$\mathrm{CA}$
Corrente Alternada
CC
Corrente Continua
DCA
Dissolução de Campo Assistido
EDS
Espectroscopia por Dispersão de Energia
EEA
Espectroscopia de Elétrons Auger
EEODI
Espectroscopia de Emissão Ótica em Descarga Incandescente
$\mathrm{E} / \mathrm{O}$ Interface Eletrólito-Óxido
EL Eletroluminescência
$\mathrm{FL}$
Fotoluminescência
$\mathrm{F}^{+}$
Impurezas eletrolíticas incorporadas na AAP
GL
Galvanoluminescência
ISE
Ion Sputter Etching
LNE
Litografia de Nanoesferas
MVS
Microscópia de Varredura por Sonda
MFA
Microscópia de Força Atômica
MEV
Microscopia Eletrônica de Varredura
MET
Microscopia Eletrônica de Transmissão
MEV-EC
MEV por Emisão de Campo
NFMs
Nanofios Metálicos
NPs
Nanopartículas
NPMs
Nanopartículas Magnéticas
NFs
Nanofios
NTs
Nanotubos
O/Al
Interface Óxido/Alumínio
$\mathrm{O} / \mathrm{M}$
Interface Óxido-Metal
PDMS
Polidimetilsiloxano
SERS
Espalhamento Raman de Superficie Intensificada 


\section{LISTA DE SÍMBOLOS}

\begin{tabular}{|c|c|}
\hline Al & Alumínio \\
\hline $\mathrm{Al}^{3+}$ & Íon de Alumínio \\
\hline $\mathrm{Al}(\mathrm{OH})_{3}$ & Hidróxido de Alumínio \\
\hline $\mathrm{AlO}(\mathrm{OH})$ & Oxi-hidróxido de Alumínio \\
\hline $\mathrm{Al}_{2} \mathrm{O}_{3}, \mathrm{xH}_{2} \mathrm{O}$ & Óxido de alumínio Hidratado \\
\hline $\mathrm{Al}_{2} \mathrm{O}_{3}$ & Óxido de Alumínio \\
\hline $\mathrm{Au}$ & Ouro \\
\hline $\mathrm{Ag}$ & Prata \\
\hline$B$ & Espessura da Camada tipo Barreira (nm) \\
\hline$B_{U}$ & Espessura de $B$ por unidade de potencial $\left(\mathrm{nmV}^{-1}\right)$ \\
\hline $\mathrm{C}_{2} \mathrm{HCl}_{3}$ & Tricloretileno \\
\hline $\mathrm{CH}_{3}(\mathrm{CO}) \mathrm{CH}_{3}$ & Acetona \\
\hline $\mathrm{C}_{3} \mathrm{H}_{8} \mathrm{O}\left(\mathrm{H}_{3} \mathrm{C}-\mathrm{HCOH}-\mathrm{CH}_{3}\right)$ & Isopropanol \\
\hline${ }^{\circ} \mathrm{C}$ & Graus Centígrados \\
\hline$D_{p}$ & Diâmetro do poro (nm) \\
\hline$D_{c}$ & Distância Interporo (nm) \\
\hline$d_{c}$ & Espessura Crítica da camada tipo Barreira (nm) \\
\hline $\mathrm{Fe}_{2} \mathrm{O}_{3}$ & Óxido de Ferro \\
\hline $\mathrm{H}_{2} \mathrm{SO}_{3}$ & Ácido Sulfúrico \\
\hline $\mathrm{H}_{2} \mathrm{C}_{2} \mathrm{O}_{4}$ & Ácido Oxálico \\
\hline $\mathrm{H}_{3} \mathrm{PO}_{4}$ & Ácido Fosfórico \\
\hline $\mathrm{H}_{2} \mathrm{CrO}_{4}$ & Ácido Crómico \\
\hline $\mathrm{HgCl}_{2}$ & Cloreto de Mercúrio \\
\hline $\mathrm{HAuCl}_{4}$ & Ácido Cloroáurico \\
\hline $\mathrm{H}_{3} \mathrm{BO}_{3}$ & Ácido Bórico \\
\hline$H^{+}$ & Íon de Hidrogênio \\
\hline $\mathrm{H}_{2} \mathrm{O}$ & Água \\
\hline$j_{e}$ & Densidade de Corrente Eletrônica $\left(\mathrm{mA} / \mathrm{cm}^{2}\right)$ \\
\hline$k$ & Constante de Proporcionalidade $\left(2,5 \mathrm{nmV}^{-1}\right)$ \\
\hline$L$ & Espessura da camada de óxido poroso \\
\hline $\mathrm{Ni}$ & Níquel \\
\hline
\end{tabular}


$\mathrm{N}_{2}$

$\mathrm{NiSO}_{4} \cdot 6 \mathrm{H}_{2} \mathrm{O}$

$\mathrm{NiCl}_{2} \cdot 6 \mathrm{H}_{2} \mathrm{O}$

$\mathrm{O}^{2-}$

$\mathrm{OH}^{-}$

$P$

$p$

$\mathrm{SiC}$

$\mathrm{Si}_{3} \mathrm{~N}_{4}$

$U$

W

$W_{U}$

$\lambda_{p}$

$\lambda_{c}$
Gás Nitrogênio

Sulfato de Níquel

Cloreto de Níquel

Íon de Oxigênio

Hidroxila

Porosidade (\%)

Densidade Porosa (poros $/ \mathrm{cm}^{2}$ )

Carbeto de Silício

Nitreto de Silício

Potencial de Anodização (V)

Espesura da Parede do Poro (nm)

Espessura de $W$ por unidade de Potencial $\left(\mathrm{nm} \mathrm{V}^{-1}\right)$

Constante de Proporcionalidade $\left(1,29 \mathrm{nmV}^{-1}\right)$

Constante de Proporcionalidade $\left(2,5 \mathrm{nmV}^{-1}\right)$ 


\section{SUMÁRIO}

RESUMO

ABSTRAC

LISTA DE FIGURAS

LISTA DE TABELAS

LISTA DE SIGLAS E ABREVIATURAS

LISTA DE SIMBOLOS

1 Introdução. . . . . . . . . . . . . . . . . . . . . . . .

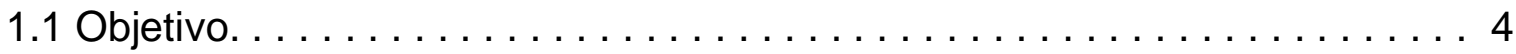

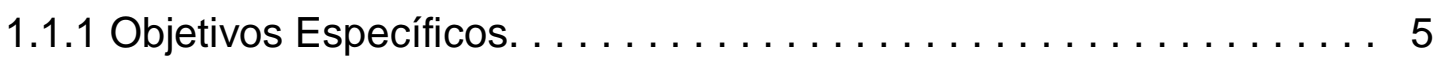

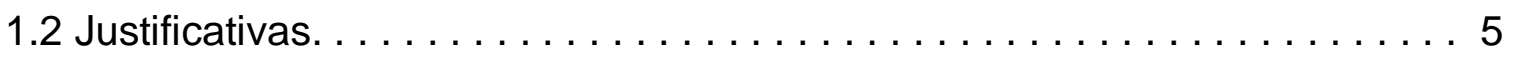

2 Fundamentos Teóricos e Revisão Bibliográfica $\ldots \ldots \ldots \ldots \ldots \ldots \ldots$

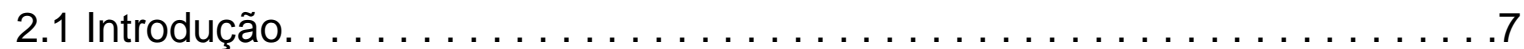

2.2 Anodização do Alumínio e Estrutura da AAP. . . . . . . . . . . . 8

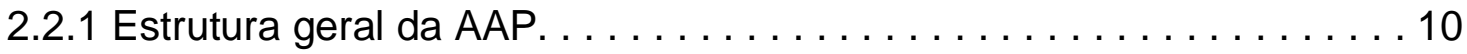

2.2.2 Cinética de Formação de estruturas de AAP . . . . . . . . . . . . 23

2.2.3 Anodização Auto-organizada e Pré-texturizada. . . . . . . . . . . . 30

2.2.4 Características Estruturais da AAP Auto-organizada. . . . . . . . . . . 39

2.3 Síntese Eletroquímica de Materiais em Máscaras de AAP . . . . . . . . . . 42

2.3.1 Nanopartículas, Nanofios e Nanotubos . . . . . . . . . . . . . . . . . . 45

2.3.2 Aplicações Principais. . . . . . . . . . . . . . . . . . . . 47

2.4 Conclusões parciais. . . . . . . . . . . . . . . . . . . 49

3 Procedimentos Experimentais. . . . . . . . . . . . . . . . 51

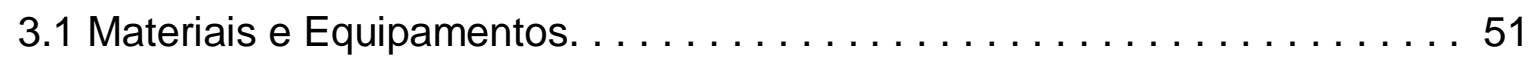

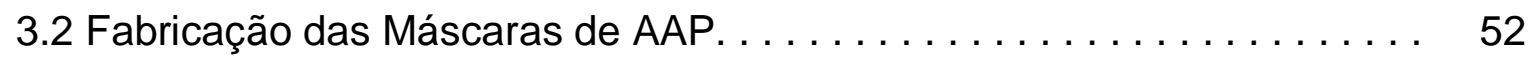

3.2.1 Limpeza e Preparação das Amostras. . . . . . . . . . . . . . . . . . . . 52

3.2.2 Obtenção de Estruturas de AAP por uma Etapa de Anodização. . . . . 53

3.3 Fabricação de Nanopartículas e Nanofios Metálicos. . . . . . . . . . . . . 56

3.4 Fabricação de Nanofios de Alumina. . . . . . . . . . . . . . . . 57 
3.5 Caracterização das Estruturas. . . . . . . . . . . . . . . 58

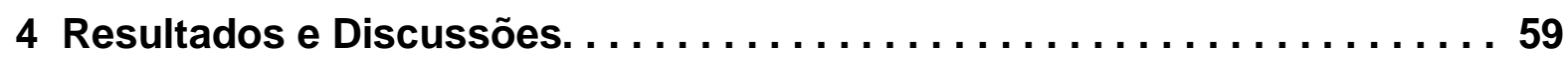

4.1 Anodização em uma só Etapa e Configurações Morfológicas. . . . . . . . . 59

4.1.1 Cinética de Formação das Estruturas de AAP . . . . . . . . . . 59

4.1.2 Efeito da Concentração a Temperatura e Potencial Constantes. . . . 64

4.1.3 Efeito da Temperatura a Concentração e Potencial Constantes. . . . 70

4.1.4 Efeito do Potencial a Temperatura e Concentração Constantes. . . . 76

4.1.5 Efeito da Corrosão Química sob as Estruturas de AAP. . . . . . . . . 82

4.2 Fabricação de Nanopartículas e Nanofios por Eletrodeposição CA. . . . . 90

4.2.1 Nanopartículas e Nanofios de Níquel. . . . . . . . . . . . . . 90

4.2.2 Nanofios de Prata. . . . . . . . . . . . . . . . . . . 93

4.3 Fabricação de Nanofios de Alumina por Dissolução Química. . . . . . . . 95

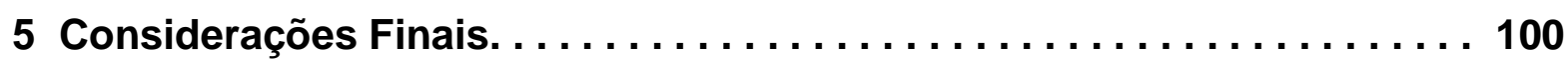

5.1 Conclusões. . . . . . . . . . . . . . . . . 100

5.2 Perspectivas Futuras. . . . . . . . . . . . . . . . . . . 102

Referências Bibliográficas. ......................... 103

Anexo A: Publicação durante o Programa de Mestrado. . . . . . . . . . . . . 120 


\section{Capítulo 1}

\section{Introdução}

Nos últimos anos, a ciência dos nanomateriais junto com a tecnologia representou um dos assuntos mais atraentes para os físicos, químicos, biólogos, médicos e engenheiros. Estes nanomateriais apresentam um interesse especial do ponto de vista da compreensão científica, mas também as suas aplicações potenciais são muito atraentes [1]. Como é descrito a seguir, os nanomateriais representam a base para o desenvolvimento de novas tecnologias, sistemas e equipamentos. O contínuo desenvolvimento de dispositivos miniaturizados para diferentes aplicações está exigindo novos materiais multifuncionais que possam executar diferentes funções simultaneamente. Nanomateriais tais como nanopartículas [1,2], nanofios [1,3], nanotubos [1,4], nanoporos [5] etc. exibem novas oportunidades únicas para tal propósito. Em particular, as nanopartículas e nanofios estão entre os nanomateriais que desempenham um papel importante no domínio da nanociência e da nanotecnologia devido ao seu comportamento específico, bem como ao número de suas aplicações potenciais em componentes ópticos e eletrônicos [6,7], dispositivos de armazenamento por meio magnético [8], metamateriais [9], biosensores [10], nanoeletrodos [11] etc. Arranjos ordenados de nanopartículas e nanofios podem ser produzidos usando diferentes métodos, sendo um deles a deposição eletroquímica em filmes nanoporosos bidimensionais. A fabricação de tais arranjos por eletrodeposição, principalmente em máscaras de policarbonato [12] e alumina anódica porosa (AAP) [13], abriu novos horizontes no que diz respeito à produção e aplicações de tais materiais nanoestruturados complexos.

Experimentalmente tem-se desenvolvido diferentes métodos de síntese que permitiram a fabricação de nanomateriais. Em geral, existem duas aproximações, "top-down" e "bottom-up" que são duas abordagens completamente diferentes na sua concepção. A abordagem "top-down", frequentemente usa métodos tradicionais de microfabricação, onde ferramentas extremamente controladas são usadas para dar forma aos materiais [14-17]. Por outro lado, a abordagen "bottom-up" utiliza as 
propriedades químicas de moléculas individuais para formarem componentes e sistemas moleculares para alguma aplicação específica. A síntese de nanoestruturas periodicamente ordenadas é obtida quer utilizando os procedimentos das técnicas "top-down" ou "botton-up", respectivamente. Entre as principais nanoestruturas organizadas reportadas pela literatura pode-se mencionar os nanoporos altamente ordenados, nanotubos e nanofios regularmente distribuídos $[3,4,5]$. A fabricação de nanoestruturas organizadas por meio de processos totalmente controláveis (top-down) requerem geralmente poderosas técnicas litograficas não-óticas, tais como: litografia de feixe de elétrons [14], litografia de feixe de íons [15], litografia de raios-X [16] e litografia de interferência holográfica [17]. Com o auxílio destas técnicas litográficas avançadas podem ser fabricados materiais nanoestruturados com resolução de poucos nanometros, mas suas aplicações são limitadas pelo alto custo dos equipamentos de laboratório. Neste sentido, os processos "bottom-up", que são de baixo custo e processamento escalonável, apresentam-se como alternativas altamente viáveis para a fabricação de nanoestruturas organizadas. Entre eles, a síntese de máscaras empregando membranas de alumina anodica porosa (AAP) demonstrou ser uma abordagem eficaz, de baixo custo e tecnicamente simples para a fabricação de diversos materiais em escala nanométrica [3,5,13]. A fabricação de máscaras de AAP autoorganizada pode ser realizado de três maneiras diferentes. O primeiro procedimento está baseado em uma anodização pré-texturizada do alumínio, resultando em um arranjo perfeitamente ordenado de nanoporos sobre a área da superfície previamente pré-texturizada. A pré-texturização do alumínio é realizada por uma indentação direita da superfície com uma ponta do microscópio de varredura por sonda (MVS) [18] ou microscópio de força atômica (MFA) [19], ou por litografia de feixe de elétrons [20], litografia holográfica [21] e litografia de feixe de íons [22]. Uma segunda alternativa para fabricar moldes ou máscaras de AAP considera o procedimento de litografia de impressão utilizando um selo mestre (molde) com um conjunto organizado de esferas convexas é comumente usado para texturizar o alumínio. Os moldes podem ser feitos de carbeto de silício (SiC) [23], nitreto de silício $\left(\mathrm{Si}_{3} \mathrm{~N}_{4}\right)$ [24], Níquel (Ni) [25] ou polidimetilsiloxano (PDMS) [26]. Recentemente, uma grade de difração óptica $\left(5 \mathrm{~mm} \times 5 \mathrm{~mm}, 1200\right.$ linhas $\left./ \mathrm{mm}^{2}\right)$ [27] e litografia de nanoesferas (LNE) empregando matrizes empacotadas $\mathbf{2 D}$ de esferas 
de poliestireno [28] e esferas de óxido de ferro $\left(\mathrm{Fe}_{2} \mathrm{O}_{3}\right)$ [29] têm sido usados com sucesso para a pré-texturização do substrato de alumínio antes da anodização. A principal desvantagem da anodização guiada pela pré-texturização é que a formação está limitada a pequenas áreas onde o alumínio é texturizado. Esta área de trabalho depende das dimensões do molde e, geralmente, não ultrapassa os $\mathrm{mm}^{2}$. Este limite em relação à superfície da amostra anodizada pode ser facilmente evitado por uma terceira opção, a anodização do alumínio efetuando duas etapas [30]. Este processo de anodização conduz a uma estrutura nanoporosa autoorganizada, quase-monodomínio sendo atualmente o procedimento mais utilizado pela comunidade científica. As características periódicas côncavas formadas na superfície do alumínio durante a primeira anodização servem como sítios de nucleação para a formação dos nanoporos durante a segunda anodização. A anodização auto-organizada permite a preparação de uma só vez de arranjos de nanoporos ordenados sob uma área superfícial relativamente grande (vários $\mathrm{cm}^{2}$ ). As máscaras de AAP feitos em laboratório e utilizados para a fabricação de nanomateriais são geralmente preparados pela anodização de duas etapas utilizando comumente soluções eletrolíticas tais como: ácido sulfúrico $\left(\mathrm{H}_{2} \mathrm{SO}_{4}\right)$ [31], ácido oxálico $\left(\mathrm{H}_{2} \mathrm{C}_{2} \mathrm{O}_{4}\right)$ [32] e ácido fosfórico $\left(\mathrm{H}_{3} \mathrm{PO}_{4}\right)$ [33]. Contudo, o ácido oxálico como eletrólito de anodização é o mais utilizado, e a faixa da temperatura de anodização geralmente está próxima de $0^{\circ} \mathrm{C}$ e a duração da anodização excede várias horas de processo ( $>7$ horas). Dentro deste cenário, a anodização do alumínio em altas temperaturas pode ser uma alternativa interessante para uma redução significativa do tempo de preparação das máscaras de AAP. Do ponto de vista industrial, a redução do tempo de fabricação e a redução de custos são muito vantagosas. Apesar disso, há poucos estudos de anodização do alumínio em temperaturas altas [34-36]. Uma análise detalhada da influência da temperatura e do potencial de anodização sobre as características estruturais da AAP foram recentemente realizadas por Sulka e colaboradores [36].

Por outro lado, existem poucos trabalhos reportando a fabricação de estruturas de AAP por uma única etapa de anodização [37,38], já uma análise detalhada deste processo para altas temperaturas e a influência dos parâmetros de anodização sobre as características estruturais da AAP não foram reportadas. Nesse sentido, 
no presente projeto foi realizado um estudo sistemático da formação de estruturas de AAP com apenas um processo de anodização e em altas temperaturas, já que o procedimento proposto apresenta-se como uma alternativa interessante para reduzir o custo e o tempo de fabricação das máscaras de AAP e sua posterior aplicação na síntese de nanomateriais. Importante mencionar que o êxito deste procedimento depende de um pós-processamento de corrosão química que também foi estudado sistematicamente no presente trabalho.

A literatura reporta vários trabalhos relacionados à aplicação das nanoestruturas de AAP como máscaras ou moldes para a deposição de metais e/ou formação de nanomateriais. Os estudos nesta área estão voltados principalmente à funcionalização e deposição de materiais orgânicos e metais, dentro da estrutura porosa, visando às aplicações na área de sensores, dispositivos plasmónicos e nanoantenas ópticas $[42,52,174,177,178]$. Portanto, a proposta de pesquisa deste trabalho é a fabricação de nanoestruturas de AAP por uma etapa de anodização a altas temperturas (de 15 até $30^{\circ} \mathrm{C}$ ) e suas aplicações na síntese de nanomateriais. A fabricação dos nanomateriais foi realizada através de processos químicos e eletroquímicos respectivamente. Esta é uma tecnologia de baixo custo, uma vez que não requer equipamentos sofisticados nem materiais caros e tóxicos para sua fabricação, facilitando assim processos de produção em massa. Os nanomateriais foram obtidos usando as máscaras de AAP como material de partida obtidas através de um processo de eletrodeposição de corrente alternada (CA).

\subsection{Objetivo}

O objetivo principal do presente projeto foi a fabricação de máscaras de AAP por uma etapa de anodização e suas aplicações na síntese de nanopartículas e nanofios metálicos por eletrodeposição CA. Este objetivo envolveu desafios de interesse científico e tecnológico nas áreas de nanociência e nanotecnologia, porque as nanopartículas, nanofios e nanoporos organizados apresentam propriedades especiais em virtude de sua escala nanométrica. Nanopartículas, nanofios e outros materiais nanoestruturados são nanomateriais de interesse 
fundamental por apresentarem aplicações em campos tão diversificados como a mecânica, a óptica, a eletrônica, a química e a bioquímica. Neste sentido, o presente trabalho traz contribuições ao desenvolvimento da nanofabricação e da nanotecnologia.

As nanoestruturas de AAP auto-organizadas foram obtidas por uma etapa de anodização a temperatura ambiente, e suas características morfológicas foram moduladas através do controle dos parâmetros de anodização, assim como também por um pós-tratamento de corrosão química. A obtenção de nanopartículas e nanofios metálicos foi realizada mediante um processo de deposição eletroquímica CA nas estruturas de AAP utilizados como molde. Por último, nanofios de alumina foram fabricados por um processo de dissolução química das nanoestruturas de AAP em solução de acido fosfórico.

\subsubsection{Objetivos Específicos}

- Obtenção de nanoestruturas de AAP por uma etapa de anodização.

- Estudo da cinética de formação de estruturas de AAP.

- Estudo do efeito dos parâmetros de anodização (concentração, temperatura e potencial) na formação de estruturas de AAP.

- Formação de estruturas de AAP com diferentes diâmetros através do controle do tempo de corrosão química em ácido fosfórico.

- Processamentos de imagens MEV utilizando o software GRANUL [183], para a contagen dos poros e cálculos do diâmetro médio dos poros das estruturas de AAP.

- Fabricação de nanopartículas e nanofios metálicos por eletrodeposição CA.

- Estudo do processo de formação de nanofios de alumina em função do tempo de corrosão química em ácido fosfórico para diferentes temperaturas.

\subsection{Justificativas}

A nanotecnologia é uma área de grande interesse da comunidade científica atual e apresenta-se como uma das áreas mais promissoras ao desenvolvimento da 
ciência e da tecnologia. O estudo de novos materiais na área de microeletrônica é de grande interesse para o desenvolvimento tecnológico e científico.

Dentro do campo da nanotecnologia aplicada à fabricação de dispositivos miniaturizados, existem diversos processos envolvidos na fabricação de nanoestruturas, mas muitos deles são muito custosos e exigem alta infra-estrutura. A fabricação de nanomateriais e nanoestruturas auto-organizadas por métodos eletroquímicos são processos que não exigem grande infra-estrutura e são relativamente simples de serem realizados. Neste contexto, os sistemas com arranjos periódicos de nanoporos, nanopartículas e nanofios estão sendo intensamente investigados devido à grande expectativa com relação as suas aplicações.

O principal desafio das pesquisas é fabricar nanoestruturas porosas autoorganizadas em um curto período de tempo e que possam ser utilizados como máscaras (moldes) para a fabricação de nanopartículas e nanofios metálicos, utilizando técnicas químicas e eletroquímicas. Neste sentido, o presente trabalho apresenta uma alternativa de desenvolvimento de novos materiais que está inserido no contexto do desenvolvimento tecnológico na área de dispositivos plasmônicos e nanonatenas ópticas, que é assunto de relevância científica. O presente trabalho visa trazer contribuições para a fabricação rápida destas nanoestruturas através de métodos relativamente simples, além de reportar a fabricação de nanopartículas e nanofios usando esta nanoestrutura porosa como material sacrificial. 


\section{Capítulo 2}

\section{Fundamentos Teóricos e Revisão Bibliográfica}

\subsection{Introdução}

As propriedades dos nanomateriais e suas funcionalidades tendem a ser diferentes relativas aos seus correspondentes propriedades no substrato, quando um ou mais dimensões são reduzidas na faixa de 1 a 100 nm, o chamado "regime de tamanho nanométrico". Filmes finos (materiais bidimensionais, ou 2D), nanofios/nanotubos (matérias unidimensionais, ou 1D), e nanopartículas/pontos quânticos (materiais zero dimensional, ou 0D) constituem as classes básicas dos nanomateriais. Entre estas, especialmente os materiais 1D são altamente desejáveis, devido a sua forma geométrica e elevada área superficial 2D que resulta funcionalmente interessante na aplicação de diversos dispositivos. Por exemplo, os nanofios metálicos (NFMs) são susceptíveis a se tornarem parte integrante de nanodispositivos futuros, pelo menos, como elementos de interligação de componentes funcionais, tais como nanotransistores [39], dispositivos moleculares [40], etc. Além da conexão elétrica para nanocircuitos, os NFMs podem ser utilizados como componentes funcionais em várias aplicações que vão desde o armazenamento de dados de alta densidade até nanosensores de alta sensibilidade assim como também metamateriais e nanoantenas ópticas [8-11,41,42]. Por outro lado, os materiais OD ou nanoparticulas (NPs) estão sendo atualmente utilizados para aplicações em catálise química [43-45], biosensores [46-50] e baterias recarregáveis [51], mais também podem ser utilizadas em nanosistemas e nanorobôs para a veiculação de drogas e tratamento de inúmeras doenças [52], como os que se baseiam em lipossomos e nanopartículas. Estes sistemas ficam especialmente interessantes se forem construídos a partir de nanopartículas magnéticas (NPMs) [1,2].

Sínteses de matrizes de NPs e nanofios (NFs) utilizando máscaras de AAP são obtidas através da redução eletroquímica dos íons de um ou mais metais no interior dos canais de nanoporos de um filme de AAP fabricado através de anodização auto-organizada [3,5]. Devido a sua relação custo-efetividade, 
versatilidade e alto rendimento, este método oferece a promessa significativa para uma produção versátil de nanomateriais.

Para a maioria das aplicações, é desejável que os NFs apresentem uma elevada razão de aspecto (razão entre o comprimento do fio e seu diâmetro) e elevada área superficial bem como a uniformidade no tamanho e a forma do nanofio junto com uma distribuição espacial periódica. Portanto, máscaras de AAP autoorganizadas tornaram-se o centro do foco para a síntese de muitos nanomateriais.

Nos seguintes items serão apresentados com maiores detalhes os fundamentos teóricos da anodização do alumínio e as propriedads estruturais da AAP. Em seguida, se apresentará às técnicas utilizadas na síntese eletroquímica de nanomateriais utilizando os filmes da AAP, onde as NPs, NFs e nanotubos (NTs) são obtidos, dando ênfase nas suas principais aplicações.

\subsection{Anodização do Alumínio e Estrutura da AAP}

A anodização do alumínio é um processo de formação de um filme de óxido sobre o alumínio por meio da imersão em um banho eletrolítico onde o metal é ligado ao eletrodo positivo de uma fonte de tensão, transformando-se no ânodo da cuba eletrolítica. A história da oxidação eletroquímica do alumínio é anterior ao inicio do século XX. O tratamento anódico do alumínio foi intensamente investigado para obter camadas protetoras e decorativas sobre sua superfície [53]. Mais recentemente, aplicações do óxido de alumínio com elevada área superficial e uma distribuição de tamanho de poro estreita tem sido exploradas [54]. Embora membranas inorgânicas como moldes tenham sido reportadas [55,56], sem dúvida alguma, a AAP é uma das nanoestruturas mais promissoras, por sua característca de auto-organização, fácil fabricação e baixo custo para a síntese de NPs, NFs e NTs com diâmetro controlado e propriedades geométricas desejáveis [57]. Além disso, ela também pode ser usada como cristal fotónico bidimensional [58].

Existem muitas patentes que foram apresentadas antes de 1950 com relação à anodização do alumínio. Desde então, processos anódicos baseados em $\mathrm{H}_{2} \mathrm{SO}_{4}$, 
$\mathrm{H}_{2} \mathrm{C}_{2} \mathrm{O}_{4}$ e $\mathrm{H}_{3} \mathrm{PO}_{4}$ como eletrólitos vem sendo cuidadosamente explorados [59]. Uma patente britânica registrada em 1923, em nome de Bengough e Stuart é reconhecida como o primeiro trabalho sobre o uso do tratamento anódico para proteger o alumínio e suas ligas da corrosão [60]. Em 1936, Caboni inventou o método de colorir o alumínio usando dois processos eletroquímicos consecutivos: anodização em $\mathrm{H}_{2} \mathrm{SO}_{4}$ seguido pela aplicação de $\mathrm{CA}$ em uma solução contendo íons metálicos [61].

O desenvolvimento da técnica de Microscopia Eletrônica e Varredura (MEV) levou a uma maior compreensão da estrutura da AAP. Em 1953, Keller e colaboradores apresentaram o famoso artigo onde à estrutura da AAP é descrita como um arranjo de células hexagonais consistindo de uma camada tipo "barreira" e uma camada tipo "porosa" [62]. Ainda neste trabalho foi demonstrada a relação entre o potencial aplicado e as características geométricas da estrutura porosa, tais como a espessura da parede do poro. Este modelo foi à base para estudos iniciais que permitiram uma melhor compreensão das propriedades químicas e físicas do sistema da AAP, muito embora este sistema, apesar dos anos de investigação, apresente grandes desafios para a comunidade científica.

Em 1969, um artigo de revisão tratando de filmes de óxido anódico sobre alumínio foi publicado por Diggle [53]. Aspectos estruturais com relação à incorporação de ânions e quantidade de água no óxido e modelos teóricos dos mecanismos de formação do óxido do tipo "barreira" e do tipo "poroso" estão descritos em detalhes neste trabalho. Recentemente, Sulka [63] apresentou uma extensa revisão sobre a formação de AAP.

Entre 1970 e 1990, destacam-se os trabalhos liderados por Thompson e Wood sobre o mecanismo de crescimento de filmes de alumina utilizando Microscopia Eletrônica de Transmissão (MET). Os autores usaram métodos de marcadores para a determinação do número de íons $\mathrm{Al}^{3+}$ e $\mathrm{O}^{2-}$ transportados, e inferir sobre a distribuição aniônica dentro do filme de óxido ao longo da anodização [64-66]. Um dos trabalhos resultantes destas investigações, publicado por O'Sullivan e Wood, é um dos artigos mais citados sobre anodização de alumínio para obter alumina porosa [67]. Muitos grupos de pesquisa dedicaram-se paralelamente ao estudo do 
mecanismo de formação da AAP [68-70]. De uma maneira geral, um mecanismo de instabilidade em termos do campo elétrico na interface óxido/metal $(O / M)$ é considerado ser o responsável pela formação dos poros no óxido de alumínio do tipo "barreira". Os autores defendem que a modelagem teórica do mecanismo de formação de poro em alumina é análoga àqueles para outros materiais porosos que podem ser obtidos via um tratamento anódico, por exemplo, silício poroso. Baseando-se em um processo de replicação em duas etapas, uma membrana de AAP altamente ordenada foi preparada por Masuda e Fukuda em 1995 [71]. Esta descoberta foi um marco na preparação de nanoestruturas de AAP com multidomínios de estreita distribuição de tamanho de poro e razão de aspecto extremamente elevadas. Dois anos mais tarde, combinando anodização e metodologias de nanoidentação (processo de indentar com uma ponta nanométrica para criar padrões na superficie), estes autores apresentaram, pela primeira vez, a preparação de uma nanoestrutura porosa com monodomínio. Os trabalhos do grupo de Masuda [71-75] colocaram o sistema AAP em uma posição de destaque dentre as máscaras para a preparação dos diversos nanomateriais. Atualmente, dezenas de grupos, independentemente, utilizam o método relatado por Masuda e Fukuda, a anodização potenciostática em duas etapas, para a preparação de AAP.

\subsubsection{Estrutura Geral da Alumina Anódica Porosa}

Em geral, a anodização do alumínio pode resultar em dois tipos diferentes de filmes de óxido: um filme anódico tipo "barreira", e um filme de óxido poroso (Figura 2.1). Normalmente a natureza química do eletrólito, usado para a anodização do alumínio, é um fator importante que determina o tipo de óxido crescido sobre a superfície do alumínio [76]. No entanto, experimentalmente, notou-se que o filme anódico tipo "barreira" é um filme extremamente fino, dieletricamente compacto e sem estrutura porosa. Estes filmes podem ser formados por anodização em soluções neutras ( $\mathrm{pH}=5-7)$, onde a camada de óxido anódico não é químicamente afetado e permanece praticamente insolúvel. O grupo de eletrólitos utilizados para a formação de filmes anódicos tipo "barreira" inclui ácido bórico, borato de amônio, tartarato de amônio, tetraborato em etileno glicol, ácido perclórico com etanol e alguns eletrólitos orgânicos, como ácido cítrico, ácido málico, ácido succínico e ácido glicólico $[53,77,78,79]$. No entanto, os filmes de óxido poroso foram 
reportados principalmente para a anodização do alumínio em soluções eletróliticas fortemente ácidas, tais como $\mathrm{H}_{2} \mathrm{SO}_{4}, \mathrm{H}_{2} \mathrm{C}_{2} \mathrm{O}_{4}, \mathrm{H}_{3} \mathrm{PO}_{4}$ e ácido crômico $\left(\mathrm{H}_{2} \mathrm{CrO}_{4}\right)$, onde o filme de óxido poroso resultante é apenas moderadamente solúvel $[62,67]$. Recentemente, também foi reportado para ácido malônico [80], ácido tartárico [81], ácido cítrico [82] e ácido glicólico [81]. A formação de nanoporos por anodização auto-organizada também tem sido estudado em uma mistura de $\mathrm{H}_{2} \mathrm{SO}_{4}$ e $\mathrm{H}_{2} \mathrm{C}_{2} \mathrm{O}_{4}$ [83]. De fato, estes resultados mostram que não existe diferença distintiva na seleção de um eletrólito utilizado para a formação de filmes de tipo "barreira" ou porosa durante a anodização do alumínio. Além disso, a transição de um filme do tipo "barreira" para o tipo poroso ocorre facilmente. O tempo de anodização é um fator importante e responsável pelo desenvolvimento de uma estrutura porosa, anteriormente formada o filme tipo "barreira". A Figura 2.1 mostra as imagens MET de uma estrutura de AAP o qual foi anodizada em uma solução de ácido fosfórico [84].
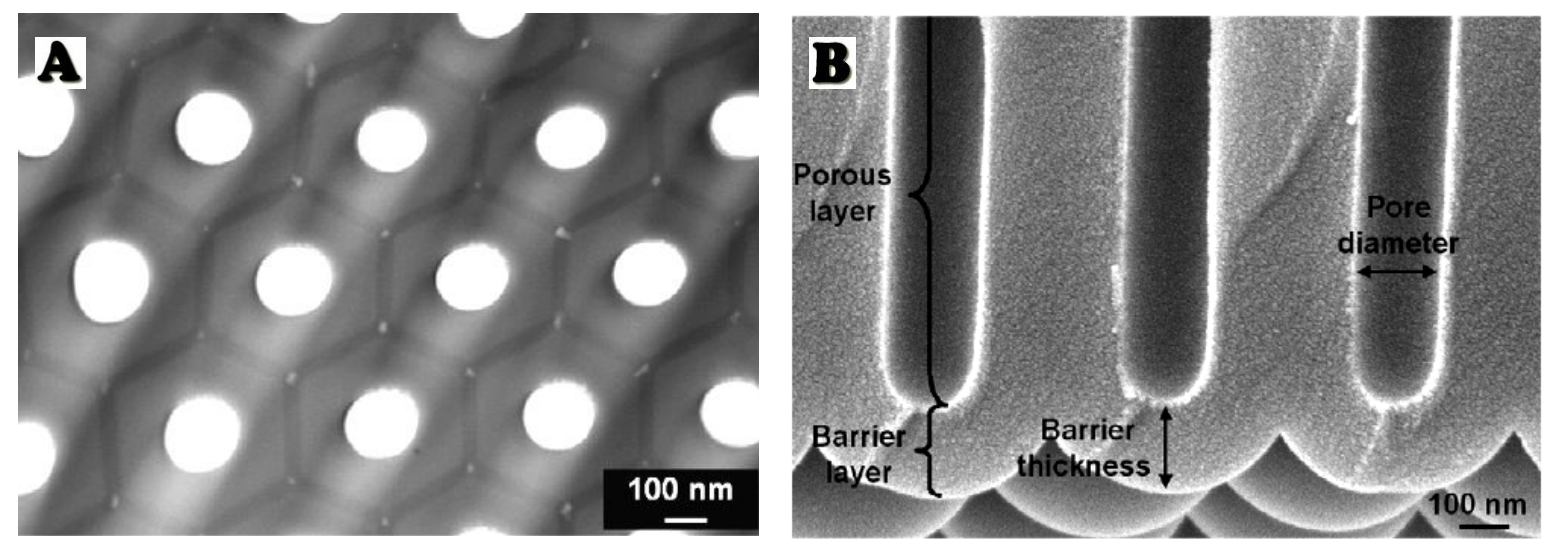

Figura 2.1. (A) Imagem MET da superfície anodizada, e (B) vista transversal mostrando a camada de óxido tipo poroso e tipo barreira. (Ref. [84])

A Figura 2.1A mostra uma vista da sua superfície anodizada com os poros ordenados. A Figura 2.1B mostra uma vista transversal com os dois tipos de filmes anódicos formados, a camada tipo "barreira" e a camada tipo "poroso".

Assim a estrutura da AAP auto-organizada produzida pela anodização do alumínio em soluções eletrolíticas específicas pode ser representado 
esquematicamente como um arranjo empacotado de células organizadas hexagonalmente, contendo um poro em cada célula conforme mostra a Figura 2.2.

(A)

$$
\text { Poro }
$$

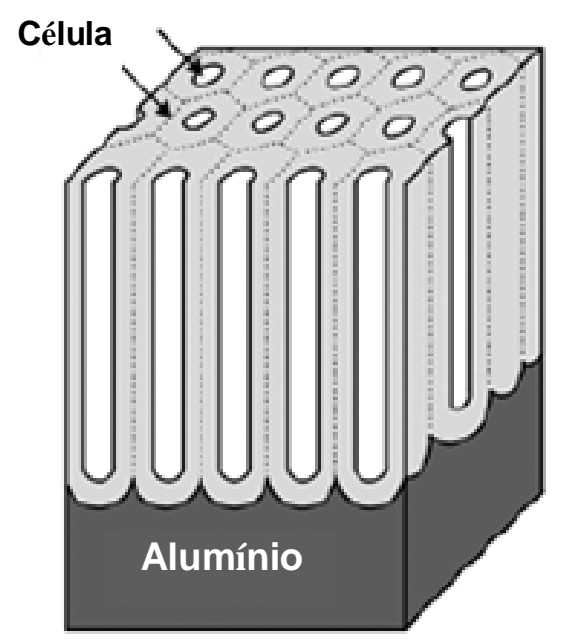

(B)

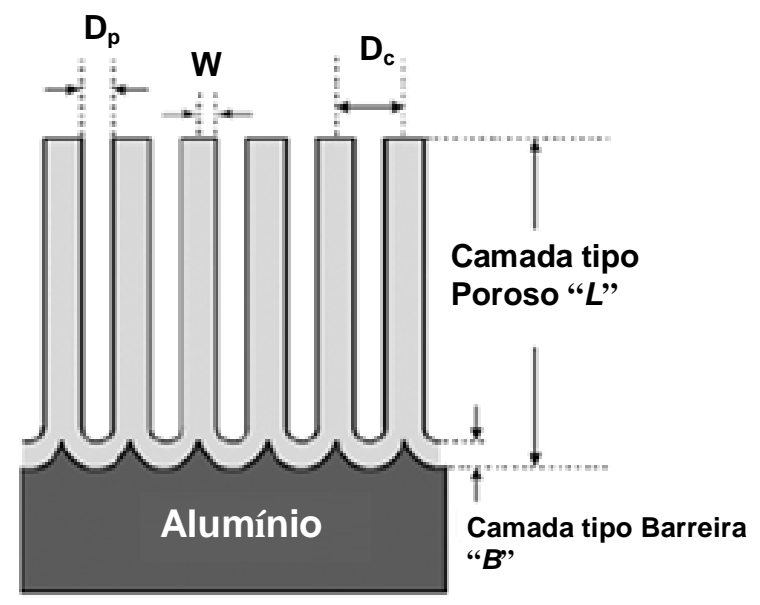

Figura 2.2. Estrutura idealizada da $A A P(A)$. Vista da seção transversal da camada de óxido $(B)$ com $D_{p}$ : diâmetro do poro, $W$ : espessura da parede do poro, $D_{c}$ : distância interporo e $B$ : espessura da camada tipo barreira.

Estas nanoestruturas altamente ordenadas são freqüentemente caracterizadas por determinados parâmetros geométricos, tais como diâmetro do poro $D_{p}$, espessura da parede do poro $W$, espessura da camada tipo barreira $B$, distância interporo $D_{c}$ (diâmetro da célula) e espessura da camada de óxido poroso $L$. Estes parâmetros geométricos podem ser controlados através da alteração das condições de anodização e que o diâmetro dos poros pode variar de alguns nanômetros até centenas de nanômetros [63]. A profundidade dos canais paralelos pode ultrapassar as $100 \mu \mathrm{m}$, uma característica que torna à AAP uma das nanoestruturas mais desejadas com uma elevada razão de aspecto e alta densidade porosa.

Os trabalhos de O'Sullivan e Wood reportaram que o diâmetro do poro da AAP é linearmente proporcional ao potencial de anodização, com uma constante de proporcionalidade $\lambda_{p}$ en torno de $1,29 \mathrm{nmV}^{-1}$ [67]: $D_{p}=\lambda_{p} U$, onde $D_{p}$ é o diâmetro 
do poro (nm) e $U$ denota o potencial de anodização. Por outro lado, o diâmetro do poro para uma anodização realizado a um potencial de anodização constante pode ser calculado também pela relação: $D_{p}=D_{c}-2 W_{U} U$, onde $D_{c}$ é o diâmetro da célula $(\mathrm{nm})$ e $W_{U}$ é a espessura da parede por unidade de potencial $(\mathrm{nm} / \mathrm{V})$. Uma dependência empírica do diâmetro do poro sobre o potencial de anodização para $\mathrm{H}_{2} \mathrm{SO}_{4}$ tem sido reportada por Palibroda [85]: $D_{p}=4,986+0,709 U$. Desde então, muitos trabalhos têm sido focados para encontrar a relação entre o diâmetro do poro e o potencial de anodização nas melhores condições de auto-organização dos nanoporos. Ao descrever a regra de porosidade de 10\%, Nielsch e colaboradores [86] sugeriram que o diâmetro do nanoporo formado pela anodização do alumínio nas melhores condições de auto-organização pode ser calculado a partir da seguinte equação:

$$
D_{p}=\sqrt{\frac{2 \sqrt{3} P}{\pi}} k U
$$

onde $P$ (em \%) é a porosidade (10\%, melhor condição de anodização) e $k$ é uma constante de proporcionalidade $\left(k=2,5 \mathrm{~nm}^{-1}\right)$. Obviamente, a temperatura e a concentração do eletrólito também tem alguma influência no diâmetro dos poros. Dados experimentais mostraram que o efeito da temperatura e a concentração sobre o diâmetro dos poros pode ser totalmente diferente para as condições potenciostática e galvanostáticas de anodização $[67,87,88]$. Por exemplo, foi reportado que o diâmetro do poro depende da temperatura para um potencial de anodização constante em solução de $\mathrm{H}_{3} \mathrm{PO}_{4}$ e que a concentração do eletrólito não influencia significativamente o diâmetro dos poros [67], embora mais recentemente tenha sido sugerido que o diâmetro dos poros diminui com a diminuição do $\mathrm{pH}$ da solução [69] e que um processo químico de abertura dos poros permite controlar seu diâmetro [89]. Por outro lado, é geralmente aceito que a distância interporo da estrutura de AAP, $D_{c}$, é linearmente proporcional ao potencial de anodização em estado estacionário de crescimento da AAP com uma constante de proporcionalidade $\lambda_{c}$ cerca de $2,5 \mathrm{nmV}^{-1}$ [86]: $D_{c}=\lambda_{c} U$. De acordo com Keller e colaboradores [62], o diâmetro da célula pode ser calculada precisamente a partir 
da seguinte equação: $D_{c}=D_{p}+2 W_{U} U$. Neste caso, a dependência linear da distância interporo sobre o potencial de anodização foi assumida na hipótese de que o diâmetro do poro é independente do potencial de anodização. O'Sullivan e Wood [67] constataram que a espessura da parede do poro é de cerca de $71 \%$ da espessura da camada barreira. Tendo em conta este fato, eles encontraram a seguinte expressão para a distância interporo: $D_{c}=D_{p}+1,42 B$. Ebihara e colaboradores [88] reportaram uma equação empírica que descreve a relação entre a distância interporo e o potencial de anodização para $\circ \mathrm{H}_{2} \mathrm{SO}_{4}: D_{c}=12,1+1,99 U$, $(U=3-18 V)$. Mas para $\mathrm{H}_{2} \mathrm{C}_{2} \mathrm{O}_{4}$, Hwang e colaboradores [90] reportaram a dependência do potencial de anodização sobre a distância interporo expressada por: $D_{c}=-5,2+2,75 U, \quad(U=20-60 \mathrm{~V})$ independentemente da temperatura do eletrólito. Contrário a isso, para anodização auto-organizada em $\mathrm{H}_{2} \mathrm{SO}_{4}$, a influência da temperatura sobre a distância interporo tem sido observada [91]. No caso, quando a anodização é realizada em $\mathrm{H}_{3} \mathrm{PO}_{4}$ a densidade de corrente constante, $\mathrm{o}$ aumento da temperatura, bem como o aumento da concentração do eletrólito causa uma diminuição na distância interporo [67]. Por último, a distância interporo também pode ser calculada a partir da transformada de Fourier 2D da estrutura hexagonal da AAP. A transformada de Fourier 2D fornece informações únicas sobre da periodicidade da estrutura no espaço reciproco.

Entre outras características morfológicas da estrutura de AAP, a espessura da parede do poro foi descrito por Keller e colaboradores [62], que pode ser calculado como:

$$
W=\frac{D_{c}-D_{p}}{2}
$$

De acordo com O'Sullivan and Wood [67], a espessura da parede do nanoporo construída durante a anodização em $\mathrm{H}_{3} \mathrm{PO}_{4}$ está relacionada com a espessura da camada barreira como: $W=0,71 B$. Para anodização realizada em solução de $\mathrm{H}_{2} \mathrm{C}_{2} \mathrm{O}_{4}$, Ebihara e colaboradores [87] reportaram que a proporcionalidade entre a espessura da parede do nanoporo e a espessura da camada barreira varia ligeiramente com o potencial de anodização na faixa de 5 a 40V. Para potenciais de 
anodização entre 5 e 20V, uma relação entre $W$ e $B$ foi encontrada com uma constante de proporcionalidade de 0,66, enquanto que para potenciais de anodização altos um incremento gradual na constante de proporcionalidade de 0,89 foi determinado.

Durante o processo de anodização do alumínio, uma camada dielétrica muito fina, densa e compacta é formada na base dos poros. Esta camada chamada de camada tipo "barreira" tem a mesma natureza como o filme de óxido formado naturalmente na atmosfera, e permite a passagem de corrente apenas devido às falhas existentes em sua estrutura. Esta camada dielétrica existente no fundo dos poros torna impossível a deposição eletroquímica de metais dentro dos nanoporos, já que não permite a passagem de corrente elétrica. Devido a este problema, a espessura da camada tipo "barreira" é extremamente importante e é muito estudada. A espessura da camada tipo "barreira" depende diretamente do potencial de anodização. Esta dependência é de cerca de $1,15 \mathrm{nmV}^{-1}$ para estruturas porosas [92]. Uma análise dos resultados experimentais reportados na literatura mostra que a variação da espessura da camada tipo barreira por unidade de potencial depende do tipo de regime de anodização, isto é, se a anodização é efetuada no regime potenciostático (potencial constante) ou galvanostático (corrente constante) [67]. Por exemplo, o aumento da temperatura de anodização diminui a espessura da camada barreira para anodização potenciostática, no entanto, uma relação oposta foi observada para a anodização galvanostática. A influência do potencial de anodização sobre a espessura da camada tipo barreira para uma estrutura de AAP formada em vários eletrólitos é mostrado na Figura 2.3. 


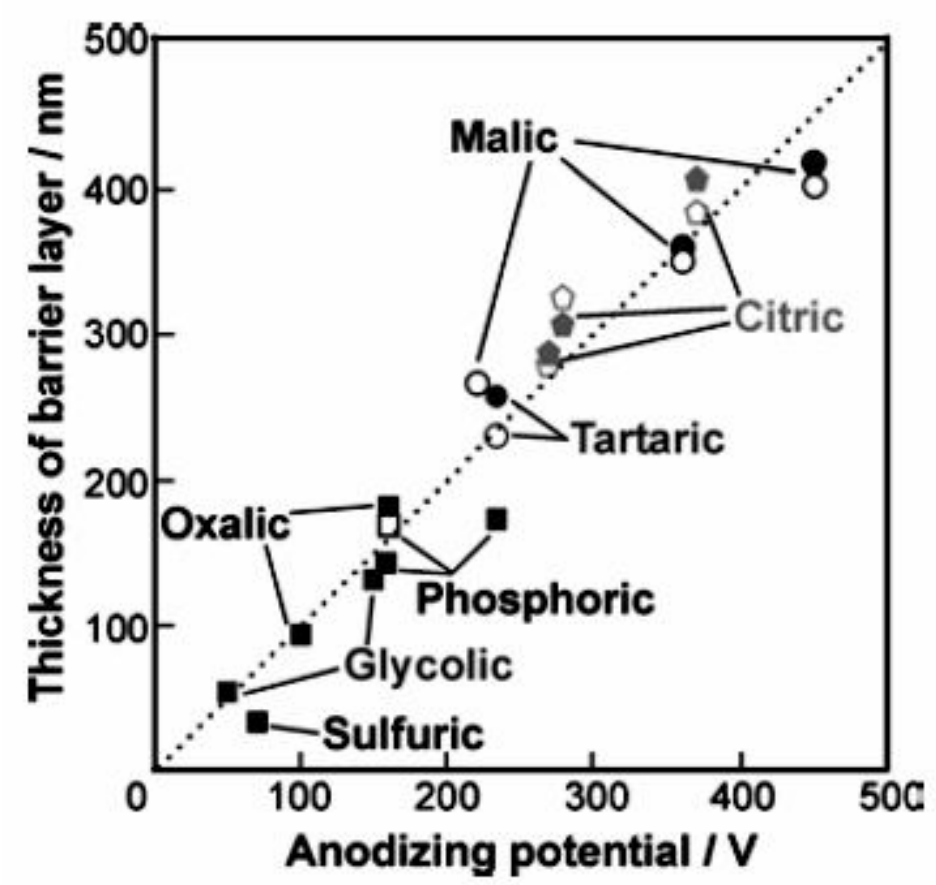

Figura 2.3. Influência do potencial de anodização sobre a espessura da camada tipo barreira da AAP formada em vários ácidos. (Ref. [81])

Em geral, a espessura da camada tipo barreira por unidade de potencial, $B_{U}$, determinado para vários eletrólitos de anodização é muito próximo de $1 \mathrm{nmV}^{-1}$ (linha diagonal pontilhada da Figura 2.3) ao longo de toda a faixa do potencial de anodização. Estes resultados sugerem uma relação linear geral entre a espessura da camada tipo barreira e o potencial de anodização. Por outro lado, é importante mencionar também que as paredes dos nanoporos assim como a espessura da camada tipo "barreira" em nanoestruturas de AAP, formado por anodização, podem ser facilmente alteradas por procedimentos de pós-tratamento que envolve 0 ataque químico isotrópico, conhecido geralmente na literatura como corrosão química [89].

Por outro lado, a porosidade das nanoestruturas de AAP é outro dos parâmetros geométricos importantes que fazem da AAP uma das estruturas desejáveis nas aplicações tecnológicas. A porosidade é definida como a razão de área de superfície ocupada pelos poros em relação à área da superfície inteira. Para um hexágono regular com um único poro dentro, a formulação de porosidade 
de uma nanoestrutura com células dispostas em forma hexagonal pode ser escrita da seguinte forma:

$$
P=90,7\left(\frac{D_{p}}{D_{c}}\right)^{2}
$$

O fator mais importante que define a porosidade de uma nanoestrutura é o potencial de anodização e $\mathrm{o} \mathrm{pH}$ da solução. Uma diminuição exponencial da porosidade com o aumento do potencial de anodização foi reportada para anodização em $\mathrm{H}_{2} \mathrm{SO}_{4}$ [88,93] e $\mathrm{H}_{2} \mathrm{C}_{2} \mathrm{O}_{4}$ [87]. Nielsch e colaboradores [86] informaram que, para um arranjo hexagonal perfeito de nanoporos formado nas melhores condições de anodização, a relação entre o diâmetro do poro e a distância interporo é quase constante, e é igual a 0,33-0,34. Conseqüentemente, a porosidade ótima para a melhor condição de anodização deveria ser 10\%. Ainda que a regra de porosidade foi derivada apenas da auto-organização da AAP nas condições ótimas de anodização, em geral, a AAP auto-organizada requer uma porosidade de $10 \%$ independentemente do potencial de anodização, tipo de eletrólito e outras condições de anodização.

Devido à simetria hexagonal dos poros, a AAP é uma das nanoestruturas com alta densidade porosa e, conseqüentemente, o número de poros formados durante a anodização representa uma das características mais importantes desta nanoestrutura. Para uma distribuição hexagonal das células da nanoestrutura, a densidade porosa é definida como o número total de poros que ocupam uma área de superfície de $1 \mathrm{~cm}^{2}$, e pode ser expressa como:

$$
p=\frac{2 \times 10^{14}}{\sqrt{3} D_{c}^{2}} ; \quad D_{c}>D_{p}>0
$$

A substituição de $D_{c}=2,5 U$ na equação 4 leva à seguinte expressão:

$$
p=\frac{18,475 \times 10^{12}}{U^{2}}
$$


Da equação 5 é possível observar que o aumento do potencial de anodização ou da distância interporo leva a uma diminuição no número de poros formados dentro da estrutura $[87,88,94]$. Para a anodização em $\mathrm{H}_{2} \mathrm{C}_{2} \mathrm{O}_{4}$, o aumento da temperatura faz com que a densidade dos poros diminua [95]. Pakes e colaboradores [96] estudaram a variação da densidade dos poros com o tempo de anodização em uma solução de tetraborato dissódico $(\mathrm{pH}=9,2)$ a $60 \mathrm{~V}$ e $60^{\circ} \mathrm{C}$, e encontraram que a densidade porosa diminui ligeiramente com o tempo de anodização nos estágios iniciais de anodização. Este comportamento foi atribuído ao rearranjo dos poros, sendo esta uma conseqüência da transformação de poros incipiente aos poros verdadeiros.

Contudo, é possível observar que as características estruturais da AAP quantificado pelos seus parâmetros geométricos dependem dos parâmetros de "anodização". Na Figura 2.4 é mostrado um diagrama esquemático representando os parâmetros químicos e eletroquímicos que podem influenciar nas caracterisiticas estruturais e morfologicas das camadas de AAP.

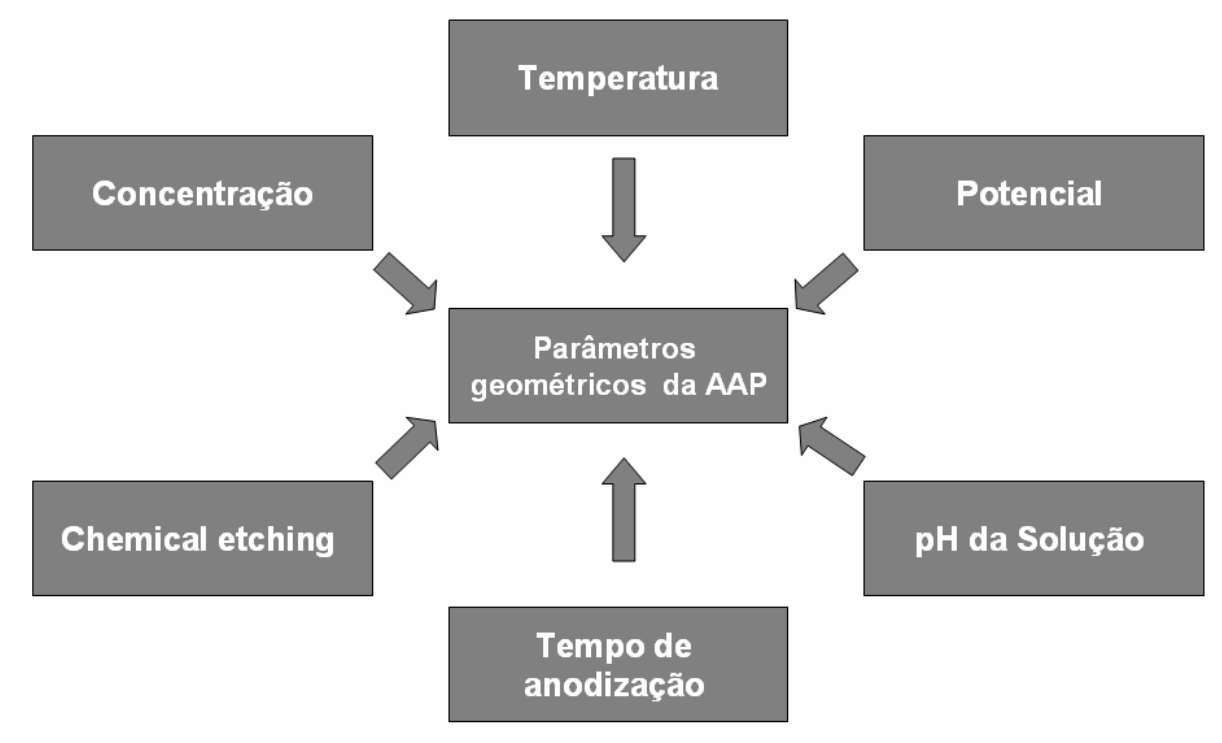

Figura 2.4. Parâmetros de "anodização" que podem influenciar as características estruturais da AAP. 
Por outro lado, o estudo da composição química dos filmes de AAP formados durante o processo de anodização tornou-se muito importante devido a suas aplicações na síntese de nanofios de alumina $[97,98]$. As camadas de óxido na estrutura de AAP são amorfos (não apresenta estrutura cristalina) $[99,100] \mathrm{e}$, de fato, incluem uma mistura variável de compostos de alumínio: hidróxido de alumínio $\mathrm{Al}(\mathrm{OH})_{3}$, oxi-hidróxido de alumínio $\mathrm{AlO}(\mathrm{OH})$, e óxido de alumíno hidratado $\mathrm{Al}_{2} \mathrm{O}_{3}, \mathrm{xH}_{2} \mathrm{O}$.

Em 1979, Thibault e Duchemin [101] reportaram que filmes anódicos obtidos em banhos de $\mathrm{H}_{2} \mathrm{SO}_{4}$ e $\mathrm{H}_{3} \mathrm{PO}_{4}$ contém elementos químicos provenientes do eletrólito tais como, sulfatos e fosfatos. Da mesma forma, em 1989 Farnan e colaboradores [102] reportaram a incorporação de oxalatos nos filmes anódicos, obtidos utilizando banhos de $\mathrm{H}_{2} \mathrm{C}_{2} \mathrm{O}_{4}$. Mas, a incorporação de ânions na estrutura de AAP depende muito do tipo de filme de óxido formado. A formação do óxido tipo poroso durante a anodização leva à incorporação de uma maior quantidade de ânions do que para o filme tipo barreira. Ao longo das últimas décadas, muito esforço tem sido focalizado sobre a determinação de perfis de ânions incorporados ao longo da espessura da camada de óxido e uma grande variedade de técnicas tem sido empregadas para este fim $[66,79,103]$. Uma excelente revisão sobre os métodos utilizados para estudar a distribuição de ânions incorporados em camadas de óxido anódico foi reportado por Despic e Parkhutik [78]. Perfis esquemáticos da concentração de ânions nas camadas de óxido tipo poroso e tipo barreira são mostrados na Figura 2.5. Os perfis de sulfato e cromato foram desenhados com base em dados obtidos pelo método de Espectroscopia de Emissão Óptica em Descarga Incandescente (EEODI) [105-108], enquanto que o perfil de oxalato foi derivado do método de Espectroscopia de Elétrons "Auger" (EEA) [103], e o perfil de concentração de ânions fosfato é um resultado da análise dos perfis obtidos pelos dois métodos. 
(A)

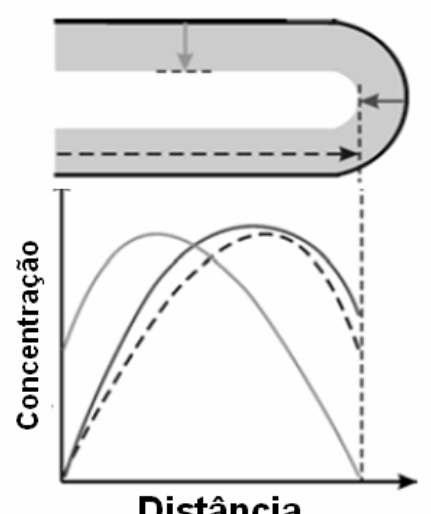

(B)

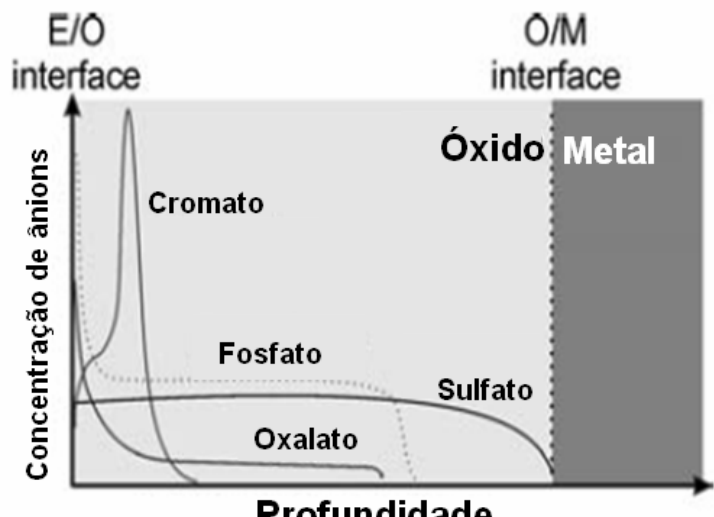

Profundidade

Figura 2.5. Perfil esquemático de profundidade da concentração de ânions no filme de óxido tipo poroso $(A)$ e tipo barreira (B) formado por anodização do alumínio em diferentes soluções eletrolíticas. (Ref. [104]).

As propriedades dos filmes de AAP formada por anodização eletroquímica estão relacionadas com as espécies eletrolíticas incorporadas no óxido. Por exemplo, a incorporação de ânions no óxido modifica a acumulação de carga nos filmes tipo porosa e tipo barreira [78]. Além disso, as propriedades mecânicas do filme da alumina anódica, incluindo a dureza, flexibilidade e resistência à abrasão, são muito influenciadas pela incorporação de ânions na estrutura de AAP [77]. O conteúdo das espécies incorporadas, e sua distribuição, dependem das condições de anodização. Conseqüentemente, diferentes estruturas de parede celular podem ser esperadas em diferentes condições de anodização. Thompson e colaboradores $[77,109]$ propuseram uma parede celular tipo "duplex" com duas regiões distintas uma camada interna contendo alumina relativamente pura e uma camada externa com ânions incorporados - e uma representação esquemática é mostrada na Figura 2.6. 

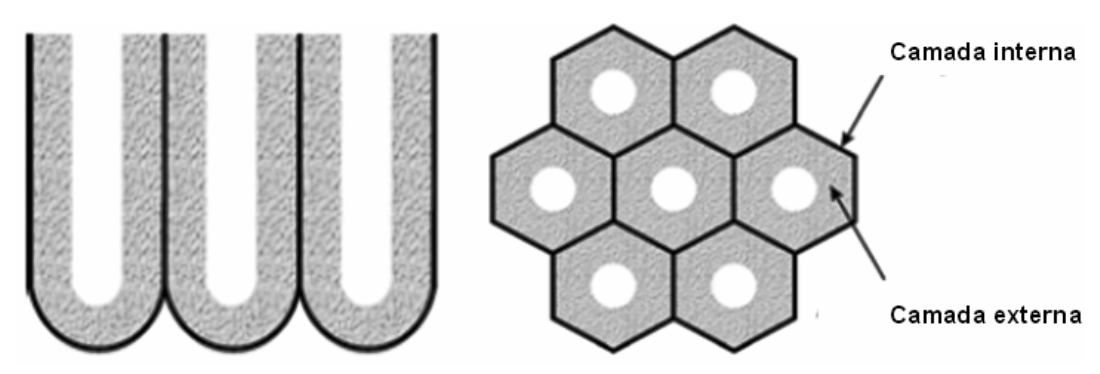

Figura 2.6. Representação esquemática da vista seccional e plano da estrutura de AAP de parede celular duplex.

Foi reportado que a espessura da camada interna aumenta em relação ao eletrólito utilizado na anodização na seguinte ordem: $\mathrm{H}_{2} \mathrm{SO}_{4}<\mathrm{H}_{2} \mathrm{C}_{2} \mathrm{O}_{4}<\mathrm{H}_{3} \mathrm{PO}_{4}<$ $\mathrm{H}_{2} \mathrm{CrO}_{4}$ e que há uma transição do estado sólido para um material tipo gel movendo-se através das paredes das células para o interior dos poros. Reportou-se também que a relação entre a espessura interna com a espessura da camada externa depende do tipo de eletrólito, e é igual a 0,05 para $\mathrm{H}_{2} \mathrm{SO}_{4}, 0,1$ para $\mathrm{H}_{2} \mathrm{C}_{2} \mathrm{O}_{4}$ e 0,5 para $\mathrm{H}_{3} \mathrm{PO}_{4}$ [109]. Recentemente, uma estrutura tipo "triplex" (Figura 2.7) foi reportada para alumina formada por anodização auto-organizada em $\mathrm{H}_{3} \mathrm{PO}_{4}$ [84,110]. A camada externa é rica em ânions e prótons, enquanto a camada intermediária contém principalmente ânions, e a camada interna consiste só de alumina pura.

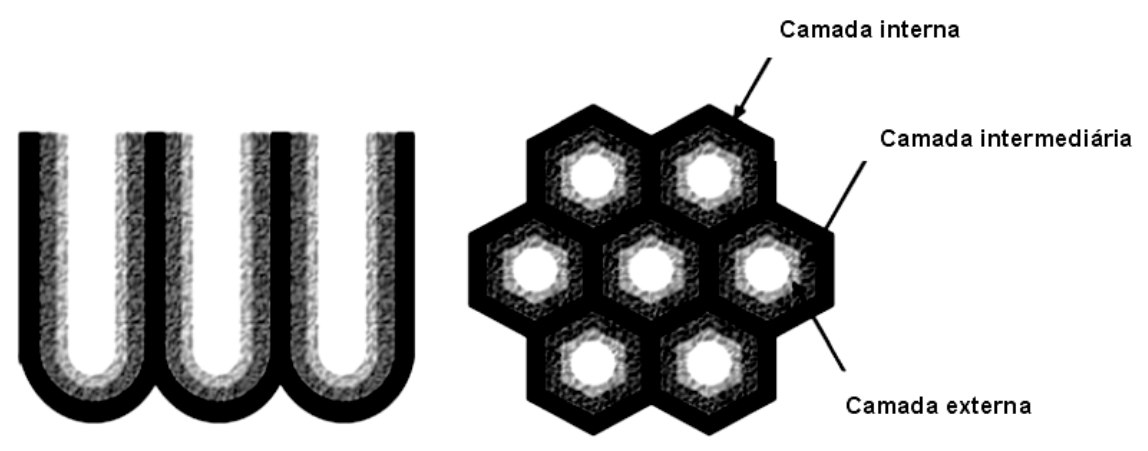

Figura 2.7. Representação esquemática da vista seccional e plano da estrutura de AAP de parede celular triplex. 
Ono e colaboradores [111,112] reportaram vazios na camada interna das paredes das células na alumina anódica e sugeriram que isto pode ocorrer devido à evolução de oxigênio dentro do óxido [111-113], stress existente no filme ou pressão de "electrostriction" (pressão existente no filme devido ao campo elétrico) que faz com que a alumina mude de forma sob a aplicação de um campo elétrico [111,112]. Estes estudos reportaram que o tamanho dos vazios aumenta com o aumento do potencial de anodização e uma explicação clara e exaustiva do processo de quebra do filme e formação de vazios podem ser encontrados na referência [114].

Todos os estudos feitos desde a descoberta da estrutura hexagonal da AAP até os mecanismos mais complicados envolvidos na auto-organização dos nanoporos têm permitido interpretar suas propriedades. Por exemplo, as características térmicas das estruturas altamente ordenadas de AAP formado sobre alumínio têm sido estudadas amplamente [115-120], propriedades estruturais e ópticas [116-118,121], condutividade térmica e difusividade ao longo do eixo dos canais [119], o rearranjo de auto-reparo de matrizes de nanoporos induzida por tratamento térmico [122], propriedades mecânicas [120]. O mecanismo de fratura, módulo de Young, dureza, tenacidade à fratura em AAP cilindricamente ordenados também foram investigados [120,123]. Também foram pesquisadas as propriedades elétricas dos filmes de AAP [124-128], perda de energia de elétrons associados à radiação Cherenkov de feixes de elétrons viajando paralelamente aos poros de uma membrana de AAP [129], e os fatores de rugosidade do filme [130]. Estudos do ângulo de contato em nanoestruturas de AAP foram empregados para caracterizar as interações líquido/superfície nas propriedades em nanoescala e capilaridade dos nanoporos em contato com diferentes solventes e líquidos [131]. A caracterização óptica de materiais porosos altamente ordenados pode fornecer uma variedade de informações sobre suas propriedades estruturais, especialmente sobre a fração do empacotamento dos poros, a forma dos poros, diâmetro dos poros, espessura da camada anódica e a incorporação de aditivos que ocorrem durante a anodização [132,133]. Também é amplamente reconhecido que a AAP apresenta uma banda azul de fotoluminescência (FL) [134-139], com as bandas de emissão (465 nm) a ser atribuído à transição óptica nas vacâncias de oxigênio ionizado (centros $\mathrm{F}^{+}$) ou 
impurezas eletrolíticas incorporadas nas membranas de AAP. Radiação óptica fraca, na faixa visível do espectro emitido durante a anodização do alumínio em eletrólitos ácidos [conhecido como galvanoluminescência (GL) ou eletroluminescência (EL)] também foi estudada [140-142]. A concentração de impurezas e o pré-tratamento das amostras de alumínio, incluindo processos de desengorduramento, limpeza química e eletropolimento, são fatores importantes que afetam fortemente a intensidade GL. Além disso, a intensidade da GL depende das condições de anodização, tais como densidade de corrente, temperatura e concentração do eletrólito. Foi sugerido também que, dependendo da natureza do eletrólito - seja orgânico ou inorgânico - há dois mecanismos diferentes, ou dois tipos diferentes de centros de luminescência responsável pela GL.

\subsubsection{Cinética de Formação da AAP Auto-organizada}

Arranjos hexagonais de nanoporos podem facilmente ser formados por anodização do alumínio aplicando uma determinada corrente elétrica constante (regime galvanostático) ou um potencial elétrico constante (regime potenciostatico). A Figura 2.8 mostra uma ilustração esquemática da cinética de crescimento da AAP em regime galvanostático $(A)$ e regime potenciostático $(B)$, juntamente com suas zonas de anodização, a, b, c, d. O crescimento do óxido anódico inclui quatro etapas que são facilmente detectáveis através do monitoramento da dependência da corrente ou potencial com o tempo de anodização. Quando uma corrente constante é aplicada para o crescimento da AAP, o potencial aumenta com o tempo até atingir um máximo, e depois diminui gradualmente até atingir um potencial estacionário (Figura 2.8A). Mas, quando um potencial constante é aplicado para o crescimento da AAP, a corrente sofre uma queda rápida com o tempo de anodização até atingir um mínimo, e depois aumenta gradualmente até atingir uma corrente estacionária (Figura 2.8B). No decorrer do presente trabalho será analizada cada zona de anodização (a,b,c,d) e sua relação com os estágios do desenvolvimento da AAP. 


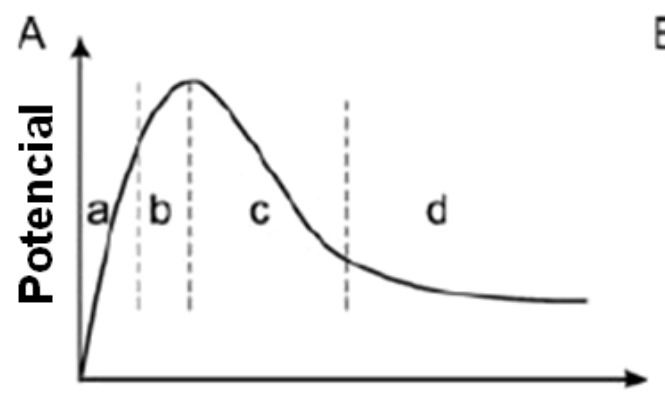

Tempo

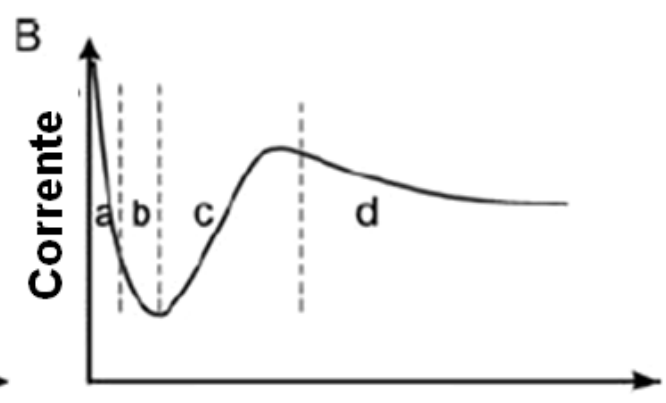

Tempo

Figura 2.8. Curvas cinéticas de crescimento da AAP em regime galvanostático $(A)$ e potenciostático (B), com suas zonas de anodização.

Em 1986, Parkhutik [143] estudou a cinética de incorporação de ânions durante os estágios iniciais de formação de estruturas de AAP em $\mathrm{H}_{2} \mathrm{SO}_{4}, \mathrm{H}_{2} \mathrm{C}_{2} \mathrm{O}_{4} \mathrm{e}$ $\mathrm{H}_{3} \mathrm{PO}_{4}$ utilizando a técnica EEA combinado com a técnica ISE - "Íon sputter etching". Ele descreveu que o oxigênio e o alumínio estão distribuídos homogeneamente no óxido, e que as regiões externas estão contaminadas com ânions eletrolíticos. Reportou também que existe uma correlação entre a cinética de incorporação de ânions no óxido crescido e as zonas de anodização de desenvolvimento da estrutura de AAP. A Figura 2.9 mostra as curvas cinéticas de crescimento das estruturas de AAP anodizadas em regime galvanostático em 0,5 M de $\mathrm{H}_{2} \mathrm{SO}_{2}$ (A); 0,2 $\mathrm{M} \mathrm{H}_{2} \mathrm{C}_{2} \mathrm{O}_{4}$ (B); e 0,4 $\mathrm{M} \mathrm{H}_{3} \mathrm{PO}_{4}$ (C) aplicando densidades de corrente de 25, 10 e $5 \mathrm{~mA} / \mathrm{cm}^{2}$, respectivamente, junto com suas zonas de anodização 1,2,3,4 e uma ilustração esquemática do desenvolvimeto da AAP para cada zona de anodização e mostrado no interior da Figura 2.9 [143]. 


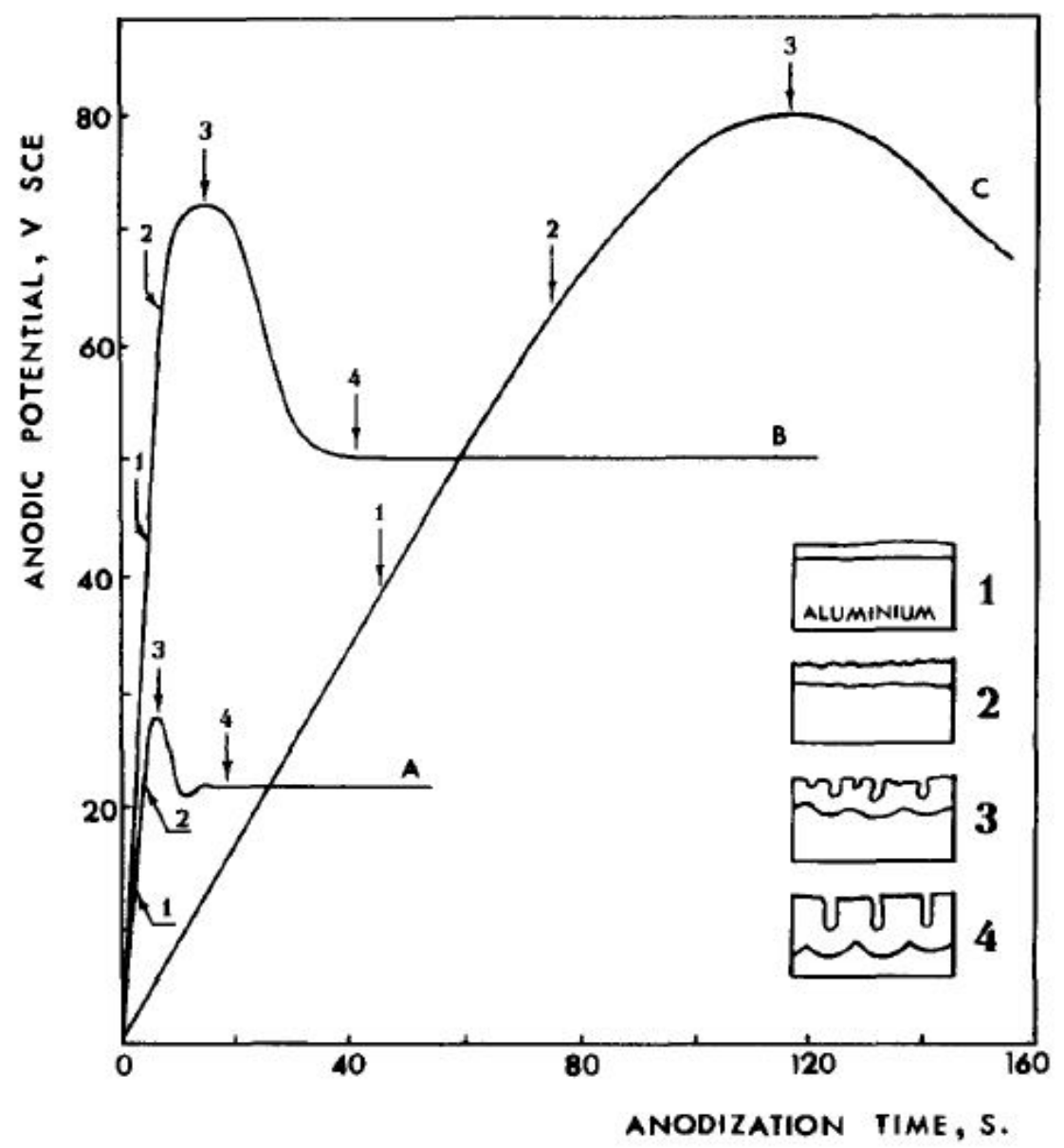

Figura 2.9. Curvas cinéticas de crescimento da AAP anodizadas em regime galvanostático, $0,5 \mathrm{M}$ $\mathrm{H}_{2} \mathrm{SO}_{2}(\mathrm{~A}), 0,2 \mathrm{M} \mathrm{H}_{2} \mathrm{C}_{2} \mathrm{O}_{4}$ (B) e $0,4 \mathrm{M} \mathrm{H}_{3} \mathrm{PO}_{4}(\mathrm{C}): \mathrm{J}=25 \mathrm{~mA} / \mathrm{cm}^{2}(\mathrm{~A}), \mathrm{J}=10 \mathrm{~mA} / \mathrm{cm}^{2}$ (B), J=5mA/cm ${ }^{2}$ (C). (Ref. [143]).

O procedimento de anodização que Parkhutik utilizou foi para distinguir os estágios característicos de crescimento da AAP. Na etapa 1, uma camada de óxido começa a ser formada. Logo depois, na etapa 2, aparecem algumas falhas e rachaduras na superfície do óxido formado, e na etapa 3 aparecem poros precursores muito irregulares. Finalmente, na etapa 4, uma estrutura porosa em estado estacionário é formado, constituído por células cilíndricas muito juntas, cada uma contendo um poro no centro e separado do alumínio por uma camada de óxido tipo "barreira" de forma semiesférica. 
Ao contrário da anodização no regime galvanostático, a anodização no regime potenciostático tem sido comumente utilizado para a fabricação de filmes de AAP altamente ordenados. Recentemente, Sulka e colaboradores reportaram curvas cinéticas de crescimento da AAP para $\mathrm{H}_{2} \mathrm{SO}_{4}$ [31,91], $\mathrm{H}_{2} \mathrm{C}_{2} \mathrm{O}_{4}$ [36] e $\mathrm{H}_{3} \mathrm{PO}_{4}$ [144]. A Figura 2.10, mostra curvas cinéticas de crescimento da AAP anodizadas em 0,3 $\mathrm{M}$ de $\mathrm{H}_{2} \mathrm{C}_{2} \mathrm{O}_{4}$ em regime potenciostático e para várias temperaturas de 20,25 e 30 .

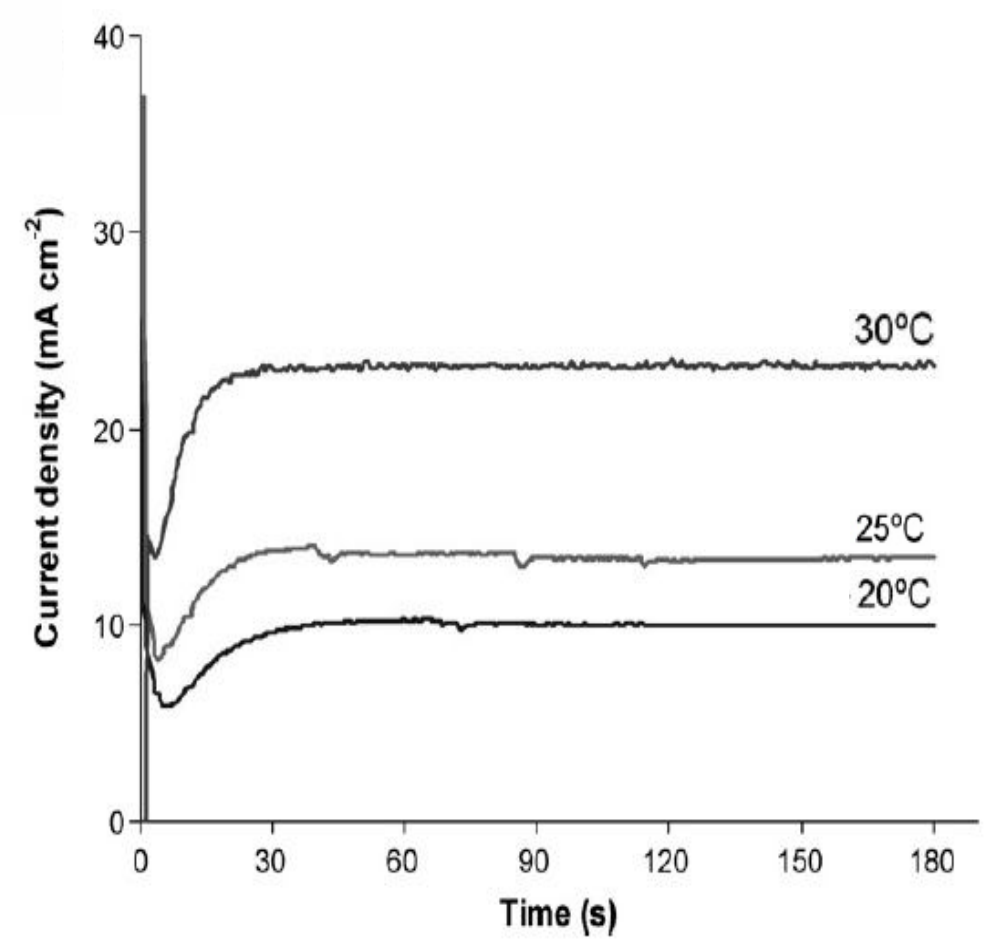

Figura 2.10. Curvas cinéticas de crescimento da AAP anodizadas em regime potenciostático para 0,3 $\mathrm{M} \mathrm{H}_{2} \mathrm{C}_{2} \mathrm{O}_{4}$ e diferentes temperaturas. (Ref. [36])

Como pode ser observado na Figura 2.10, as aparências destas curvas cinéticas revelam os estágios característicos de desenvolvimento da estrutura de AAP, independentemente da temperatura do eletrólito, isto é, elas apresentam uma queda na densidade de corrente até atinguir um mínimo, para logo aumentar e permanecer constante. Similar comportamento foi reportado para $\mathrm{H}_{2} \mathrm{SO}_{4}$ e $\mathrm{H}_{3} \mathrm{PO}_{4}$ [31,144]. Também foram reportados que o perfil das curvas cinéticas é independente do potencial de anodização [36]. Em geral, existe uma mudança nas 
curvas cinéticas de crescimento da AAP quando as condições de anodização são mudadas, por exemplo, para potenciais de anodização baixos (anodização dévil, $40 \mathrm{~V}$ ) as curvas cinéticas de desenvolvimento da AAP apresentam os estágios característicos de formação da estrutura porosa independente das outras condições de anodização, no entanto que para potenciais de anodização altos (anodização forte, $140 \mathrm{~V}$ ) se reportou que as curvas cinéticas de crescimento não apresentam os estágios característicos de desenvolvimento da AAP, mas o óxido formado no alumínio apresenta estrutura porosa auto-organizada [145].

Zhu e colaboradores [113], recentemente, estudaram em detalhe o processo de formação de estruturas de AAP, e reportaram que a formação de nanoporos pode ser atribuída à evolução de oxigênio dentro do óxido e que as diferenças entre a formação dos óxidos tipo "poroso" e tipo "barreira" é, devido à magnitude da densidade corrente eletrônica $j_{e}$ ou a continuidade da evolução de oxigênio. Um resumo do trabalho de Zhu é mostrado na Figura 2.11. A Figura mostra as curvas cinéticas de crescimento da AAP durante os processos de anodização galvanostática (Figura 2.11A) e potenciostática (Figura 2.11B), os estágios de desenvolvimento da estrutura de AAP (Figura 2.11C), estrutura da AAP sem formação de um arranjo hexagonal de poros (Figura 2.11D) e estrutura da AAP com formação de um arranjo hexagonal de poros (Figura 2.11E). Baseado no modelo de dissolução assistida pelo campo local (DCA), o crescimento de nanoestruturas de AAP, inclui quatro etapas no desenvolvimento da AAP (Figura 2.11C) relacionada às quatro zonas de anodizacão (Figura 2.11A-B) $[69,146,147]$.

A camada de óxido tipo "barreira" (BAA na Figura 2.11) se forma nas duas interfaces eletrólito/óxido (E/O) e óxido/Alumínio (O/Al) por ingresso de ions $\mathrm{O}^{2-}$ e egresso de ions $\mathrm{Al}^{3+}$ (segmento 1 da Figura 2.11A-B, e estágio 1 da Figura 2.11C). Em seguida, as curvas começam a declinar, e a eficiência de formação do óxido começa a diminuir no ponto "C" (Figura 2.11A-B). Posteriormente, algumas trincheiras locais e poros embriões sofrem a DCA na superfície da camada tipo barreira (segmento 2 da Figura 2.11A-B, e estagio 2 da Figura 2.11C) e uma interação com o eletrólito resulta em poros precursores irregulares [69,146,147]. Como uma conseqüência do desenvolvimento dos poros, o campo elétrico se torna concentrada nas bases dos poros maiores (segmento 3 da Figura 2.11A-B, e 
estágio 3 da Figura 2.11C), onde uma migração de íons $\mathrm{Al}^{3+}$ são ejetados para o eletrólito exclusivamente devido à intensificação do campo elétrico nas bases dos poros. Isto implica o ingresso contínuo de ions $\mathrm{O}^{2-}$ para formar óxido apenas na interface O/Al. Agora o aprofundamento dos poros é apenas pela DCA no fundo dos poros (segmento 4 da Figura 2.11A-B, e estagio 4 da Figura 2.11C) $[69,146,147,148,149]$.

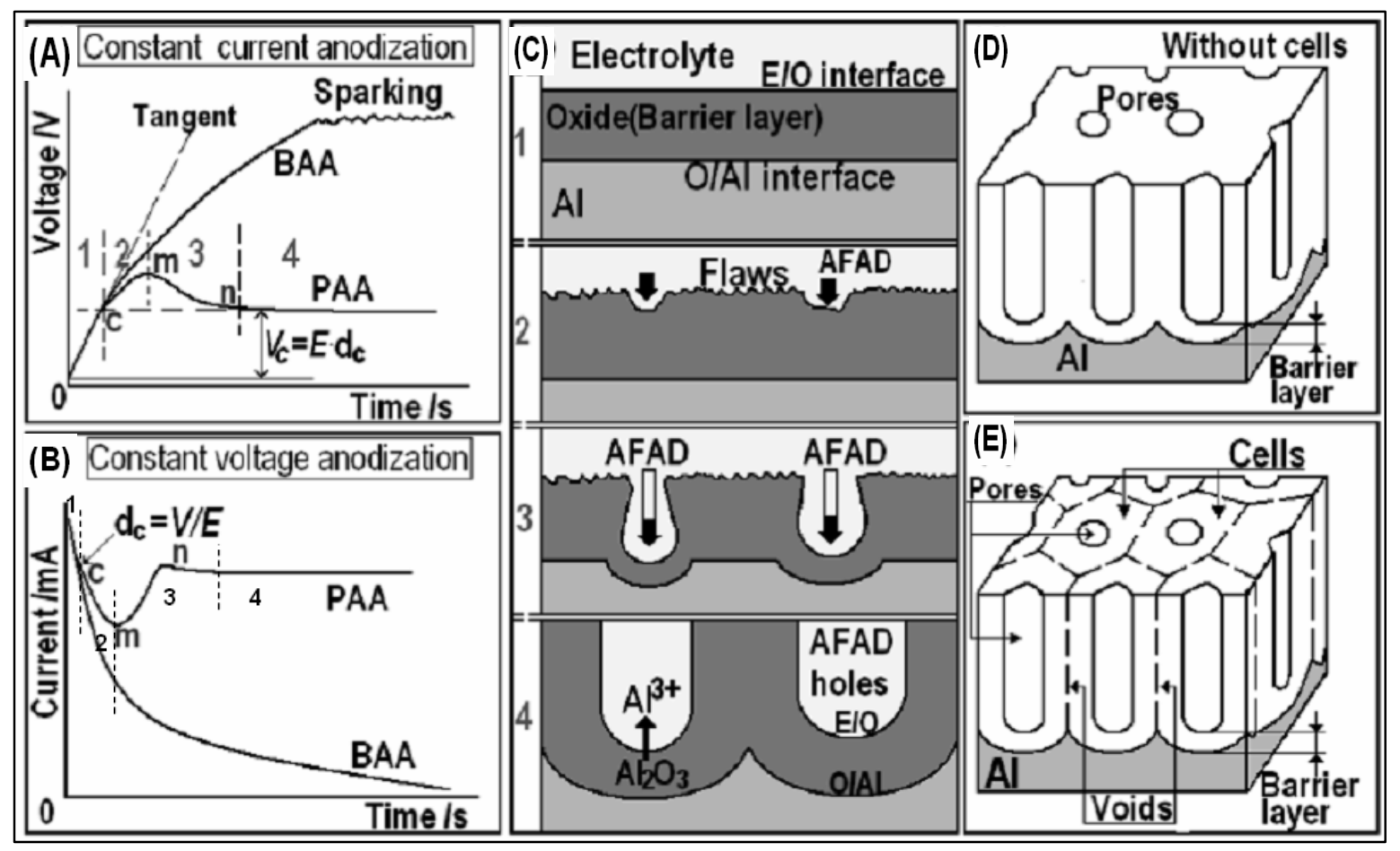

Figura 2.11. Curva cinética de crescimento da $A A P$ em regime galvanostático $(A)$, potenciostático (B), estágios de crescimento da AAP $(C)$, estrutura da AAP sem células hexagonais (D) e estrutura da AAP com células hexagonais (E). (Ref.[113])

As reações correspondentes do modelo DCA envolve [147]:

$$
\mathrm{Al}_{2} \mathrm{O}_{3}+6 \mathrm{H}^{+} \rightarrow 2 \mathrm{Al}^{3+}+3 \mathrm{H}_{2} \mathrm{O} \quad(\text { interface } \mathrm{E} / \mathrm{O})
$$

Este processo é ácido-catalizado, e um grande número de prótons são necessários incessantemente para esta dissolução perto do ânodo. Mas os prótons devem mover-se para o catodo, onde $\mathrm{H}_{2}$ (gás) deve ser gerado. É difícil ou impossível fornecer tal quantidade de prótons perto do ânodo no eletrólito. 
Recentemente, Su e colaboradores propuseram uma nova reação para explicar o aprofundamento dos poros [148].

$$
\mathrm{Al}_{2} \mathrm{O}_{3}+n \mathrm{H}_{2} \mathrm{O} \rightarrow \mathrm{Al}^{3+}+\mathrm{O}^{2-}+\mathrm{OH}^{-}+\mathrm{H}^{+} \text {(interface E/O) }
$$

e

$$
2 \mathrm{Al}^{3+}+3 \mathrm{O}^{2-} \rightarrow \mathrm{Al}_{2} \mathrm{O}_{3} \quad(\text { interface O/Al) }
$$

As reações (6) e (7) podem transformar o óxido de alumínio $\left(\mathrm{Al}_{2} \mathrm{O}_{3}\right)$ em $\mathrm{Al}^{3+}$. Estas reações de dissolução podem dissolver a camada tipo "barreira" e aprofundar os poros na parte inferior (etágio 4 da Figura 2.11C). De acordo com o modelo DCA, os poros se aprofundam para baixo perpendicular a superfície do alumínio, e uma estrutura porosa deveria-se formar com uma camada inteira sem apresentar estrutura hexagonal como mostrado na Figura 2.11D. Ou seja, é impossível que células individuais hexagonais possam ser formadas como mostrado na Figura 2.11E [147,148,150]. Por isso, Lee e colaboradores [151] manifestaram que o mecanismo de formação de células hexagonais não está claro no momento. Portanto, Li e colaboradores concluíram que o modelo DCA ainda não pode explicar os poros colunares e as células hexagonais [147]. Estudos anteriores demonstraram que os processos de crescimento do óxido tipo "poroso" e tipo "barreira" são diferentes. Para filmes tipo "barreira", o $\mathrm{Al}_{2} \mathrm{O}_{3}$ pode ser formado tanto na interface $\mathrm{E} / \mathrm{O}$ como O/AI [53,146,147], mas para filmes tipo "poroso", o $\mathrm{Al}_{2} \mathrm{O}_{3}$ é formado apenas na interface O/Al durante o período de aprofundamento dos poros. Das curvas cinéticas de crescimento, Figura 2.11A-B, observa-se que as duas curvas começam a divergir no ponto $C$. As teorias tradicionais não têm dado uma interpretação razoável para esta divergência. Alías, alguns pesquisadores acreditam que os defeitos e os poros embriões começam a aparecer no ponto C. Diggle e colabradores [53] fizeram uma interpretação da divergência destas curvas cinéticas e sugeriram que a iniciação dos poros ocorre em algum ponto próximo ao ponto $\mathrm{C}$, e que também este processo de iniciação dos poros requer uma espessura crítica $\left(d_{c}\right)$ da camada tipo "barreira" para logo diminuir. Tendo este dado, Zhu e colaboradores consideraram que o aumento na densidade de corrente no filme de AAP origina-se a partir da geração de densidade de corrente eletrônica, $j_{e}$, no 
ponto C. Além disso, o gás oxigênio começa a ser liberado também no ponto C. Por tanto, a densidade de corrente eletrônica dá origem ao gás oxigênio ou "sparking" (Figura 2.11A). Eles também reportaram que a formação dos poros resulta a partir da evolução de oxigênio dentro do óxido formado, e concluíram que as diferenças entre o óxido tipo "poroso" e o óxido tipo "barreira" é a magnitude da densidade de corrente eletrônica ou a contínua evolução de oxigênio, sugerindo que existem duas reações competitivas:

$$
2 \mathrm{Al}^{3+}+3 \mathrm{O}^{2-} \rightarrow \mathrm{Al}_{2} \mathrm{O}_{3} \text { (crescimento do óxido) }
$$

e

$$
2 \mathrm{O}^{2-} \rightarrow \mathrm{O}_{2} \uparrow+4 e^{-} \quad \text { (evolução de oxigênio) }
$$

a primeira reação (9) mantém a parede do canal alongado, e a segunda (10) mantém o canal aberto.

\subsubsection{Anodização Auto-organizada e Pré-texturizada}

Filmes de AAP formados pela anodização do alumínio em soluções eletrolíticas ácidas ou básicas atraíram recentemente muito interesse como ponto de partida para a fabricação de vários tipos de nanodispositivos devido à sua fina estrutura porosa e alta razão de aspecto. A recente melhoria no grau de ordenação de filmes de AAP aumentou a sua importância do ponto de vista da nanofabricação. A configuração organizada dos nanoporos destes filmes é essencial para aperfeiçoar o desempenho dos dispositivos. Masuda e seus colaboradores estudaram as melhores condições para a ocorrência natural da ordenação dos nanoporos em AAP para vários tipos de eletrólitos $[71,75]$. A ordenação para um longo tempo de anodização ocorre sob condições adequadas de anodização. Estas condições de anodização estão caracterizados por um longo período de anodização sob potenciais de anodização constantes (regime potenciostático) que são específicos para cada solução eletrolítica. A ordenação a longo tempo ocorre entre 25-27 $\mathrm{V}$ em $\mathrm{H}_{2} \mathrm{SO}_{4}$ [74], $40 \mathrm{~V}$ em $\mathrm{H}_{2} \mathrm{C}_{2} \mathrm{O}_{4}$ [30,71] e $195 \mathrm{~V}$ em $\mathrm{H}_{3} \mathrm{PO}_{4}$ [75] a temperatura de $0^{\circ} \mathrm{C}$. A Figura 2.12 mostra imagens MEV da configuração dos poros com ocorrência natural para um longo período de anodização (160 horas) nos três 
tipos de eletrólitos mencionados. Estas imagens MEV foram obtidas no fundo dos poros após a remoção do substrato de alumínio, e é observado que a configuração dos nanoporos são altamente ordenados.

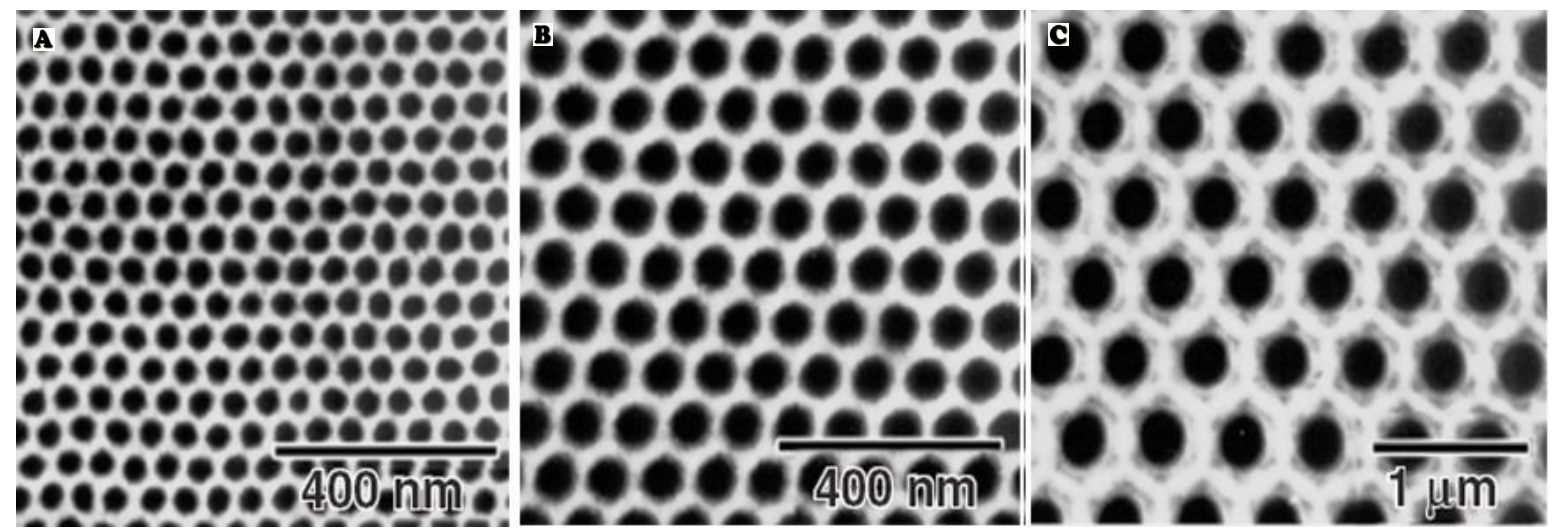

Figura 2.12. Imagens $M E V$ de ocorrência natural para um longo período de tempo de anodização de AAP formado em três tipos de eletrólitos: (A) ácido sulfúrico, (B) ácido oxálico e (C) ácido fosfórico. (Ref. $[71,74,75])$

Para se ter uma idéia de como o tempo de anodização afeta a ordenação dos poros, a Figura 2.13 mostra a dependência da ordenação do arranjo dos poros, no fundo da estrutura porosa após a remoção do substrato de alumínio, sob o período

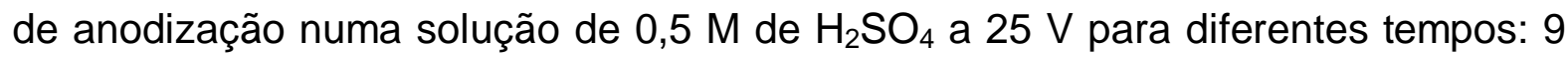
minutos $(A), 36$ minutos $(B)$ e 710 minutos $(C)$ respectivamente [74].

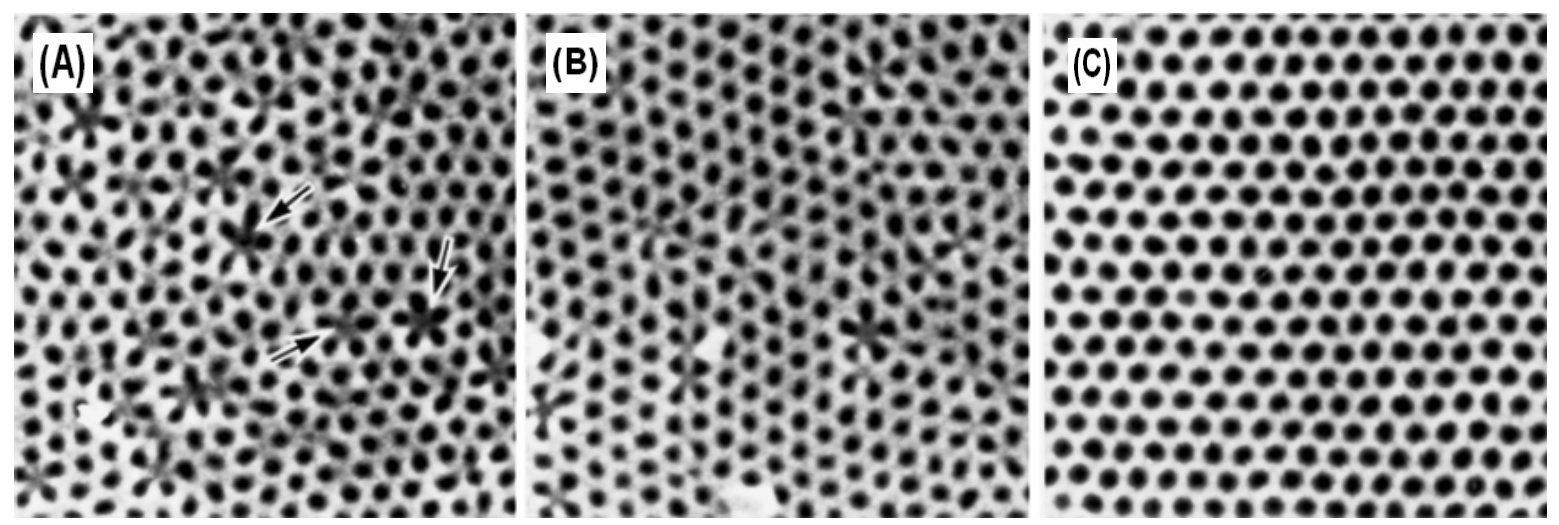

Figura 2.13. Dependência da ordenação do arranjo dos poros da AAP anodizadas em $0,5 \mathrm{M}$ de ácido sulfúrico a $25 \mathrm{~V}$ : 9 min (A), 36 min (B) e 710 min (C). (Ref. [74]) 
$\mathrm{Na}$ fase inicial de anodização, os poros se desenvolvem aleatoriamente sobre a superfície do óxido formado. Durante o crescimento da camada de óxido, a ordenação dos poros acontece gradualmente ao longo tempo a partir de uma configuração aleatória na fase inicial de anodização. Quando a ordenação dos poros começa, o número dos poros defeituosos (indicado pelas setas na Figura 2,13a) diminuiu e finalmente poros quase ordenados são obtidos [152-157].

O modo de auto-organização dos poros durante a anodização é quase o mesmo em $\mathrm{H}_{2} \mathrm{C}_{2} \mathrm{O}_{4}$ [71,30] e $\mathrm{H}_{3} \mathrm{PO}_{4}$ [75]. O tamanho do domínio organizado é dependente do tamanho das células que compõem o domínio, ou seja, ela é maior em $\mathrm{H}_{3} \mathrm{PO}_{4}$ porque a anodização é conduzida sob potênciais mais altos.

O grau de ordenação da configuração dos poros na superfície da AAP é muito baixo porque os poros se desenvolvem aleatoriamente na fase inicial da anodização. Para melhorar a ordenação dos poros na superfície de AAP, Masuda e colaboradores relataram um processo de anodização de duas etapas [30]. O processo envolve dois processos de anodização separados: o primeiro processo de anodização consiste de um longo período de anodização para formar uma configuração de poros altamente ordenados na interface O/Al e a segunda anodização é realizada após a remoção do óxido formado na primeira etapa de anodização (Figura 2.14). Após a remoção do óxido, uma matriz de ondulações altamente ordenada é formada no alumínio, e estas ondulações atuam como sítios de iniciação para o desenvolvimento dos poros na segunda anodização. Este processo gera um arranjo ordenado de poros em toda a camada de óxido.

A técnica de anodização de duas etapas é amplamente utilizada pela comunidade científica para a preparação de nanoestruturas auto-organizadas de AAP devido a sua simples implementação, mas atualmente existe o desafio de obter nanoestruturas de AAP em curtos períodos de anodização. 


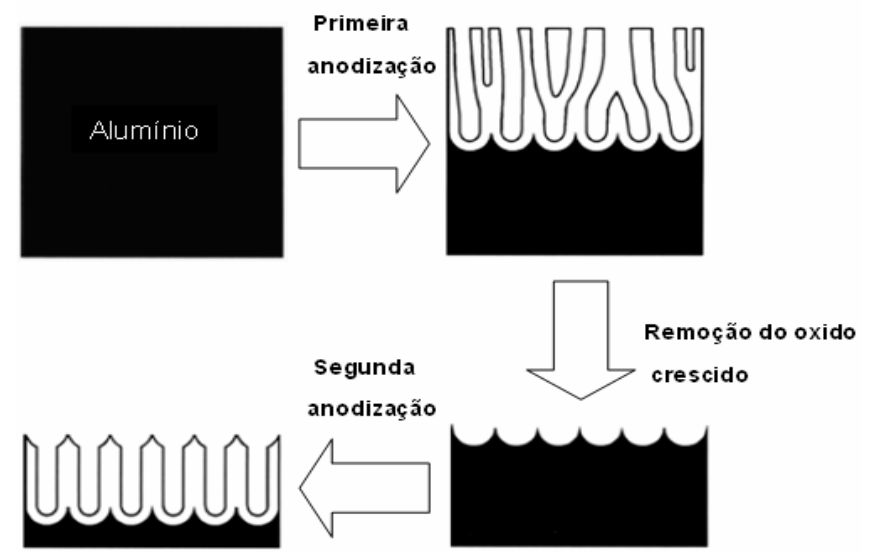

Figura 2.14. Diagrama esquemático de anodização em duas etapas para a preparação de AAP autoorganizada.

A Figura 2.15 mostra imagens MEV das camadas porosas com estrutura hexagonal, vistas no fundo dos poros após a remoção do substrato de alumínio. Estas camadas de AAP foram preparadas por anodização em 0,3 $\mathrm{M}$ de $\mathrm{H}_{2} \mathrm{SO}_{4} \mathrm{a}$ $10^{\circ} \mathrm{C}$ e $25 \mathrm{~V}(\mathrm{~A}) ; 0,5 \mathrm{M}$ de $\mathrm{H}_{2} \mathrm{C}_{2} \mathrm{O}_{4}$ a $5^{\circ} \mathrm{C}$ e $40 \mathrm{~V}(\mathrm{~B})$; e $1,6 \mathrm{M}$ de $\mathrm{H}_{3} \mathrm{PO}_{4}$ a $3^{\circ} \mathrm{C}$ e $160 \mathrm{~V}$ (C), respectivamente. Após a segunda anodização os poros foram abertos do lado da interface $\mathrm{O} / \mathrm{Al}$, por imersão em $1 \mathrm{M}$ de ácido fosfórico a $30^{\circ} \mathrm{C}$ por $30 \min (\mathrm{A}), 35$ ${ }^{\circ} \mathrm{C}$ por $30 \mathrm{~min}(\mathrm{~B})$ e em $45^{\circ} \mathrm{C}$ por $30 \mathrm{~min}(\mathrm{C})$, respectivamente.

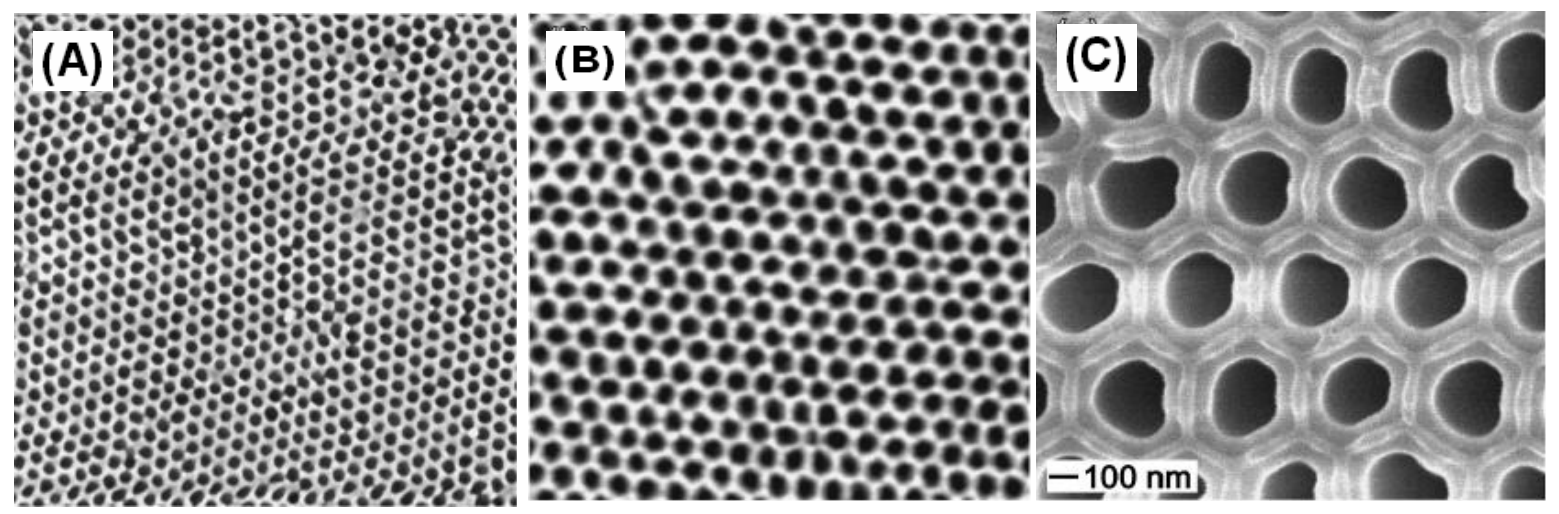

Figura. 2.15. Imagens MEV vistas no fundo dos poros após a remoção do substrato de alumínio.

Estas estruturas de AAP foram preparadas por anodização em ácido sulfúrico (A), ácido oxálico (B) e ácido fosfórico (C). (Ref. [158]) 
Domínios quase perfeitos em forma hexagonal podem ser vistos e poros hexagonalmente ordenados são cercados por seis colunas hexagonais, que estão interligados para formar uma estrutura de rede hexagonal.

Atualmente muitos trabalhos têm sido desenvolvidos para aperfeiçoar a técnica de Masuda e sua aplicação na obtenção de novas nanoestruturas de AAP. Entre eles está um método simples e robusto para fabricar membranas porosas auto-organizadas de óxido de alumínio anódico com nanocanais fechados por anodização em solução de $\mathrm{H}_{3} \mathrm{PO}_{4}$ [159], fabricação de nanoestruturas obtidas por anodização de alumínio em $\mathrm{H}_{3} \mathrm{PO}_{4}$ em potenciais moderados [160], estudo do efeito de $n$-álcoois na formação de AAP formada por anodização auto-organizada do alumínio em duas etapas em soluçao de $\mathrm{H}_{3} \mathrm{PO}_{4}$ [144], fabricação de novas membranas de AAP por anodização forte de duas etapas [161], fabricação rápida de membranas de alumina porosa por anodização forte [145], engenharia de estruturas de óxido de alumínio nanoporoso por anodização pulsada de anodização de alumínio [150] e a formação de AAP auto-organizada por anodização forte em $\mathrm{H}_{2} \mathrm{SO}_{4}$ [163].

Recentemente Han and Shen [162] melhoraram a técnica de anodização de duas etapas proposta por Masuda. Eles combinaram a anodização forte em $\mathrm{H}_{2} \mathrm{C}_{2} \mathrm{O}_{4}$ com a anodização convencional em $\mathrm{H}_{3} \mathrm{PO}_{4}$, e conseguiram superar as irregularidades superficiais que se apresentam na anodização de duas etapas convencional em $\mathrm{H}_{2} \mathrm{C}_{2} \mathrm{O}_{4}$ e $\mathrm{O}$ arranjo de poros desordenados na anodização convencional em $\mathrm{H}_{3} \mathrm{PO}_{4}$. A Figura 2.16 mostra as imagens MEV por emissão de campo (MEV-EC) de filmes de AAP que foram fabricadas sob condições de anodização forte em duas etapas, tanto para anodização em $\mathrm{H}_{2} \mathrm{C}_{2} \mathrm{O}_{4}$ (Figura 2.16A) como para $\mathrm{H}_{3} \mathrm{PO}_{4}$ (Figura 2.16B). A Figura 2.16(A) mostra uma imagen do filme de AAP anodizado em $0,3 \mathrm{M}$ de $\mathrm{H}_{2} \mathrm{C}_{2} \mathrm{O}_{4}, 140 \mathrm{~V} \mathrm{e}-5^{\circ} \mathrm{C}$ por 20 minutos, no entanto que a Figura 2.16(B) mostra uma imagen da superficie do filme de AAP anodizado em $1 \mathrm{M}$ de $\mathrm{H}_{3} \mathrm{PO}_{4}, 140 \mathrm{~V}$ e $5^{\circ} \mathrm{C}$ por 3 horas. 

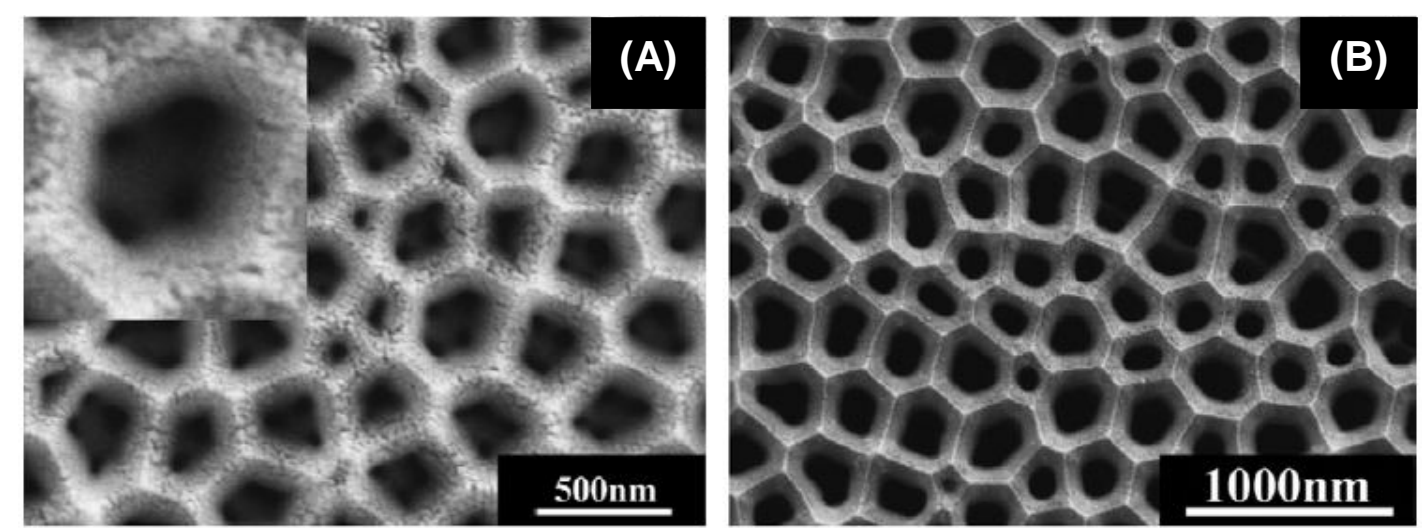

Figura 2.16. Imagens MEV-EC da superfície do filme de AAP anodizada em 0,3M de $\mathrm{H}_{2} \mathrm{C}_{2} \mathrm{O}_{4}, 140 \mathrm{~V}$

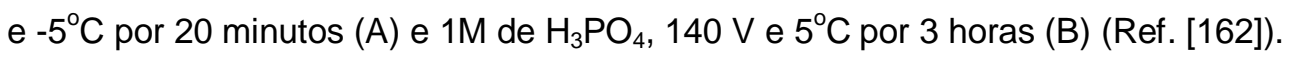

Por outro lado, a Figura 2.17 mostra as imagems MEV-EC da superfície anodizada (A) e de vista transversal (B) da AAP sob a anodização melhorada: a primeira anodização foi realizado em $0,3 \mathrm{M}$ de $\mathrm{H}_{2} \mathrm{C}_{2} \mathrm{O}_{4}, 140 \mathrm{~V}$ e $-5^{\circ} \mathrm{C}$ por 20 minutos, seguido por uma remoção do oxido pré-formado e uma segunda anodização em $1 \mathrm{M}$ de $\mathrm{H}_{3} \mathrm{PO}_{4}, 140 \mathrm{~V}$ a $0^{\circ} \mathrm{C}$ por 1 hora. A melhoria é obvia, e a chave do método está na primeira anodização forte que afeta a orientação dos poros crescidos na segunda anodização.
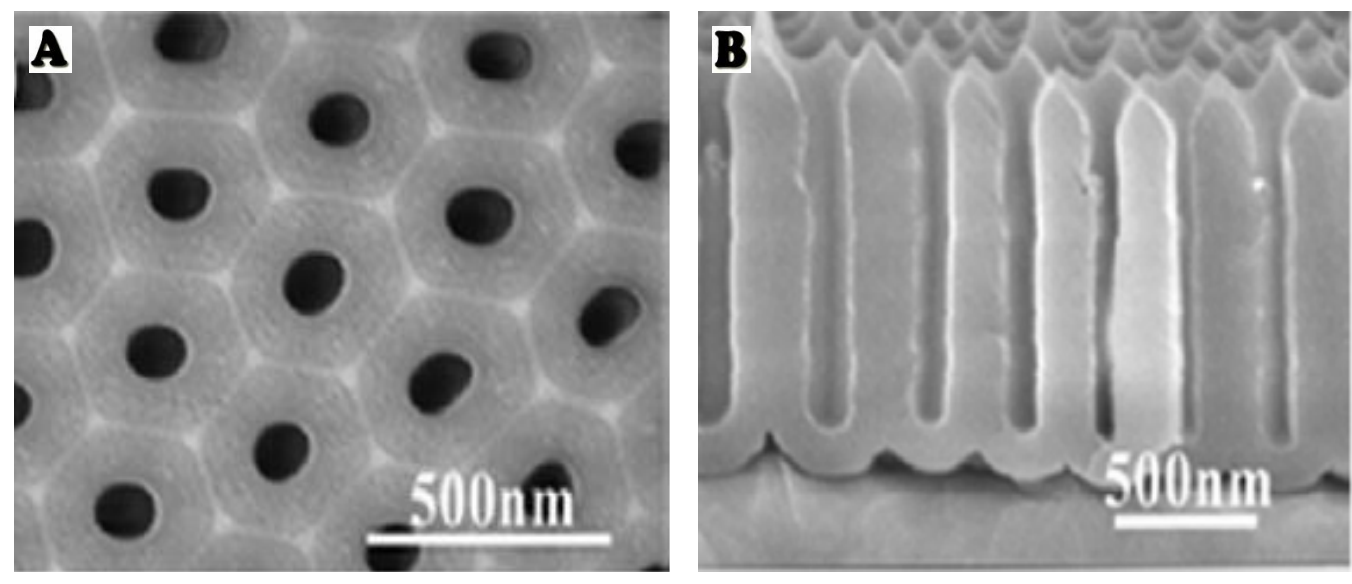

Figura. 2.17. Imagens MEV-EC da superfície anodizada (A), e de vista transversal (B) da AAP sob a anodização melhorada. (Ref. [162]). 
Como foi observado, no caso da ocorrência natural de longo tempo, técnicas de anodização forte e de duas anodizações, a ordenação dos poros da AAP ainda não é ideal, porque poros com defeitos formam parte do domínio da estrutura. Para formar uma estrutura ideal com um único domínio sobre a amostra, um novo processo usando "pré-texturização" do alumínio foi desenvolvido [73,164,165]. Neste processo, um arranjo de cavidades concavas é formado sobre o alumínio por impressão usando um molde mestre, e estas cavidades côncavas servem como sítios de nucleação para o desenvolvimento dos poros na fase inicial da anodização. Um desenho esquemático do processo é mostrado na Figura 2.18. O molde mestre com arranjo hexagonal de pontas convexas pode ser preparado por litografia de feixe de elétrons. O substrato utilizado para o molde geralmente é um cristal de SiC que tem a resistência mecânica e plasticidade necessários para o molde. Após a impressão, o padrão é totalmente transferido para a superfície do alumínio devido à maleabilidade suficiente do alumínio para a moldagem mecânica. Subseqüentemente, um processo de anodização é feito para obter poros autoorganizados.

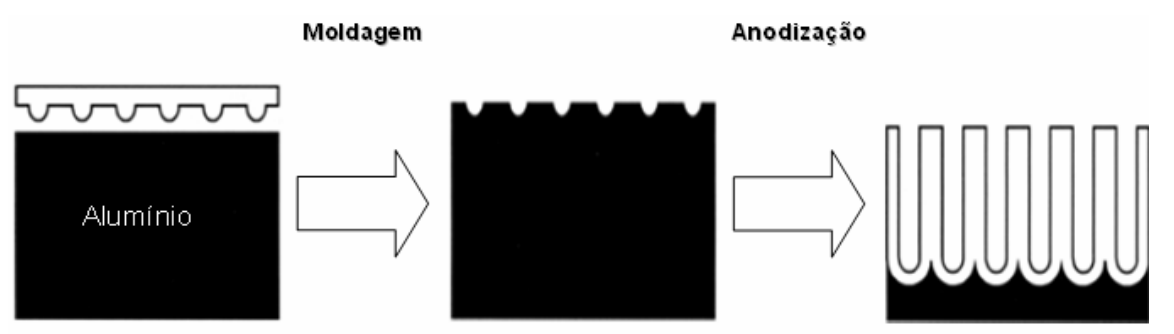

Figura 2.18. Desenho esquemático da preparação de AAP auto-organizada usando o processo de pré-texturização por molde (Ref. [5]).

A Figura 2.19 mostra os resultados obtidos por Masuda e colaboradores na obtenção de AAP auto-organizada por pré-texturização, eles obtiveram arquiteturas da alumina anódica com diferentes intervalos entre os canais: $100 \mathrm{~nm}$ para $(\mathrm{A}), 150$ $\mathrm{nm}$ para (B) e $200 \mathrm{~nm}$ para (C). Os potenciais de anodização foram de 40V (A), 60V (B), e $80 \mathrm{~V}(\mathrm{C})$ respectivamente. $\mathrm{A}$ anodização foi realizada em $0,3 \mathrm{M}$ de $\mathrm{H}_{2} \mathrm{C}_{2} \mathrm{O}_{4} \mathrm{a}$ $17^{\circ} \mathrm{C}$ para $(A)$ e $(B)$, e $0,04 \mathrm{M}$ de $\mathrm{H}_{2} \mathrm{C}_{2} \mathrm{O}_{4}$ a $3^{\circ} \mathrm{C}$ para $(\mathrm{C})$, respectivamente. $\mathrm{A}$ espessura dos filmes do óxido crescido foram de aproximadamente $3 \mu \mathrm{m}$ em todos os casos. Essas arquiteturas foram formados usando o padrão pré-determinado de 
pontas concavas com periodicidade idêntica à das células formadas, com uma subseqüente anodização. Por exemplo, a menor arquitetura formada foi em 40V, o diâmetro do poro foi de 70nm, e a distância interporo foi de $100 \mathrm{~nm}$, que corresponde a uma densidade de porosa de $10^{10} / \mathrm{cm}^{2}$. Para observar a configuração celular dessas arquiteturas, o alumínio foi removido em uma solução de cloreto de mercúrio $\left(\mathrm{HgCl}_{2}\right)$ saturada e, em seguida, a camada tipo barreira foi removido por tratamento de dissolução química em uma solução de $\mathrm{H}_{3} \mathrm{PO}_{4}$. A escala das imagens MEV da Figura 2.19 é de $1 \mu \mathrm{m}$ para todas elas.

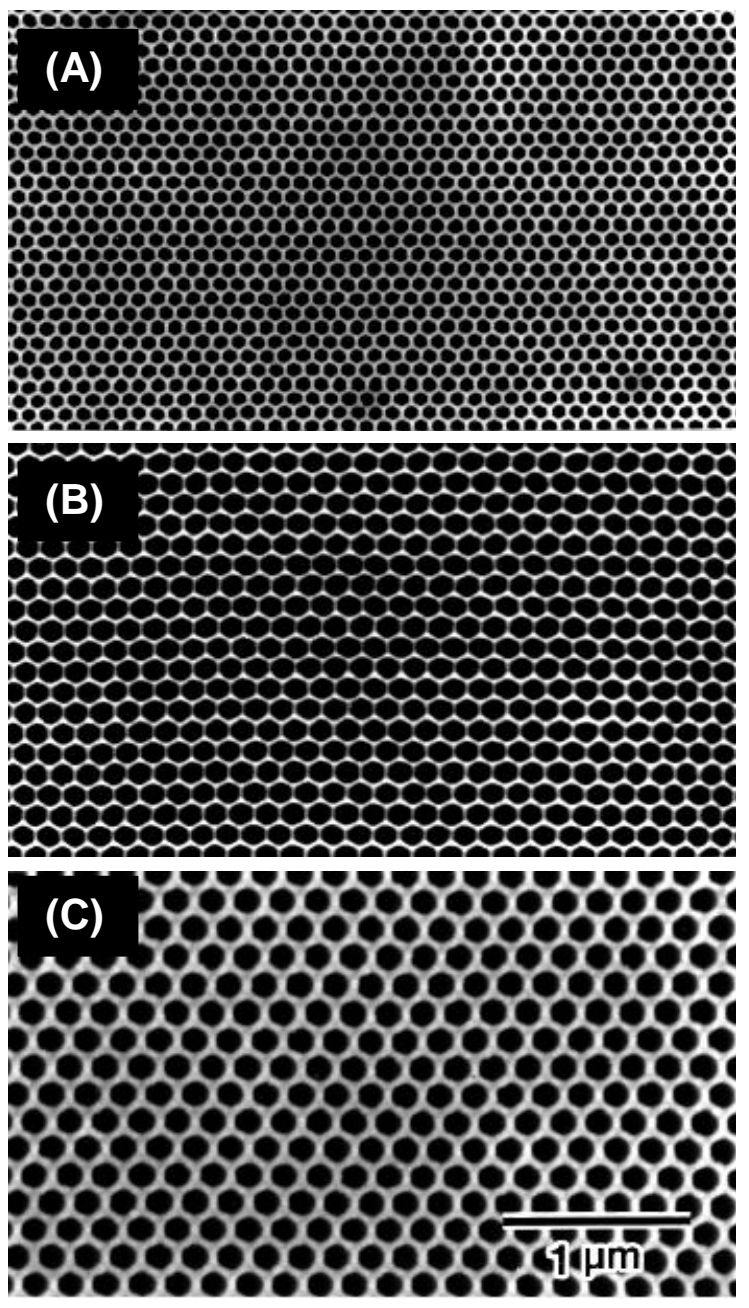

Figura 2.19. Imagens MEV da configuração celular com diferentes intervalos entre os canais, 100 $\mathrm{nm}(\mathrm{A}), 150 \mathrm{~nm}(\mathrm{~B})$, e $200 \mathrm{~nm}$ (C). Os potenciais de anodização foram de $40 \mathrm{~V}$ (a), $60 \mathrm{~V}$ (b), e $80 \mathrm{~V}$ (c). A anodização foi realizada em $0,3 \mathrm{M}$ de ácido oxálico a $17^{\circ} \mathrm{C}$ para (a) e (b), e 0,04 $\mathrm{M}$ de ácido oxálico a $3^{\circ} \mathrm{C}$ para (c). (Ref. [73]). 
A impressão de alumínio com um carimbo mestre resultou em boas nanoestruturas de AAP auto-organizadas. Depois da impressão, a matriz gerada de cavidades côncavas na superfície de alumínio é uma réplica negativa do selo mestre. Por procedimentos de impressão semelhantes, diferentes formas e disposições no molde mestre levam a várias formas dos poros na AAP. A Figura 2.20 mostra algumas dessas arquiteturas: estruturas de grafite (semelhante aos poros de $A A P)(A)$, estruturas triangulares $(B)$ e estruturas quadradas $(C)$ são boms exemplos de indentação utilizando AAP [166].
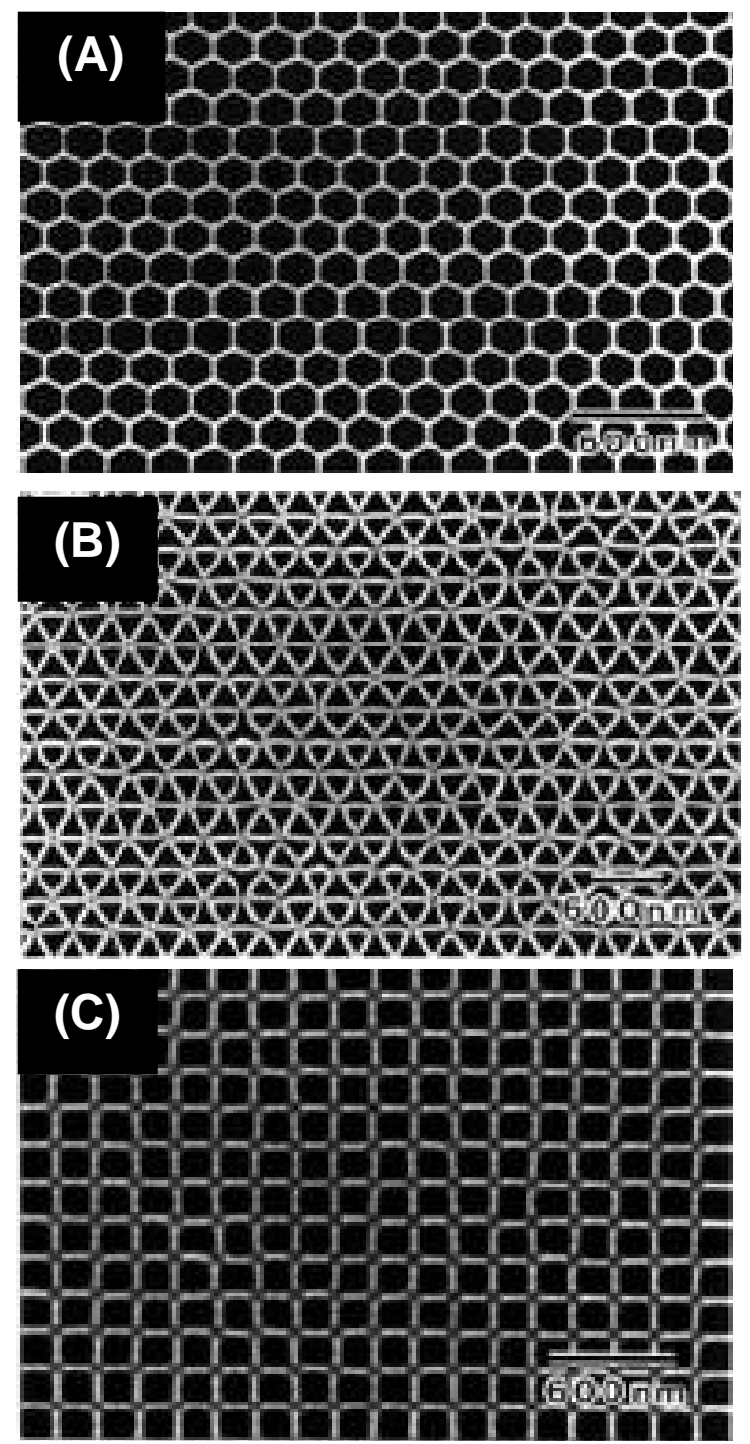

Figura 2.20. Imagens MEV das configurações celulares da AAP formado por indentação de moldes: estrutura de grafite (A), estrutura triangular (B), e estrutura quadrada (C). (Ref. [166]). 
Recentemente, a superfície do alumínio pré-padronizada foi obtida também utilizando litografia de nanoesferas (LNE) empregando um arranjo 2D hexagonal de esferas de poliestireno [28,167] e esferas de $\mathrm{Fe}_{2} \mathrm{O}_{3}$ [168] formado sobre um substrato de silício o vidro. Uma camada de alumínio é depositada sobre o arranjo auto-organizado de nanopartículas esféricas monodispersas. Após a remoção das nanoesferas, as formas côncavas na superfície do alumínio servem como pontos de nucleação para a formação de nanoestruturas de AAP auto-oganizadas.

\subsubsection{Características Estruturais da AAP Auto-organizada}

As características estruturais da AAP formada por anodização sob o regime potenciostático ou galvanostático dependem em geral das condições de anodização $[31,36,63,91,93,144,160,169]$. Recentemente, Sulka e colaboradores fizeram um estudo profundo das propriedades estruturais da AAP obtidas em $\mathrm{H}_{2} \mathrm{SO}_{4}$ [31,63,91,93], $\quad \mathrm{H}_{2} \mathrm{C}_{2} \mathrm{O}_{4}$ [36,63] e $\mathrm{H}_{3} \mathrm{PO}_{4}$ [144,160] utilizando dua etapas de anodização. As Figuras 2.21(A), (B) e (C) mostram as imagens MEV das superfícies anodizadas em 3,3M de $\mathrm{H}_{2} \mathrm{SO}_{4}$ para três diferentes potenciais de anodização 15, 19 e $25 \mathrm{~V}$ a uma temperatura de $-8^{\circ} \mathrm{C}$. As análises das imagens MEV mostram que a regularidade do arranjo dos poros, bem como o tamanho dos domínios ordenados aumenta com o incremento do potencial de anodização. Observe-se que para $25 \mathrm{~V}$, 0 arranjo dos poros apresenta uma estrutura nanoporosa perfectamente hexagonal com uma distância interporo e diâmetro do poro regular. Portanto, a ordem dos nanoporos depende fortemente do potencial de anodização, temperatura, e processo de síntese. O diâmetro médio e sua distância interporo apresentam uma dependência linear com o potencial de anodização, e estas relações estão mostradas nas Figuras 2.21(D) e 2.21 (E). No entanto que a porosidade diminui com o potencial para as temperaturas de 1 e $10^{\circ} \mathrm{C}$, esta aumenta ligeramente para $8^{\circ} \mathrm{C}$ [Figura 2.21(F)]. 

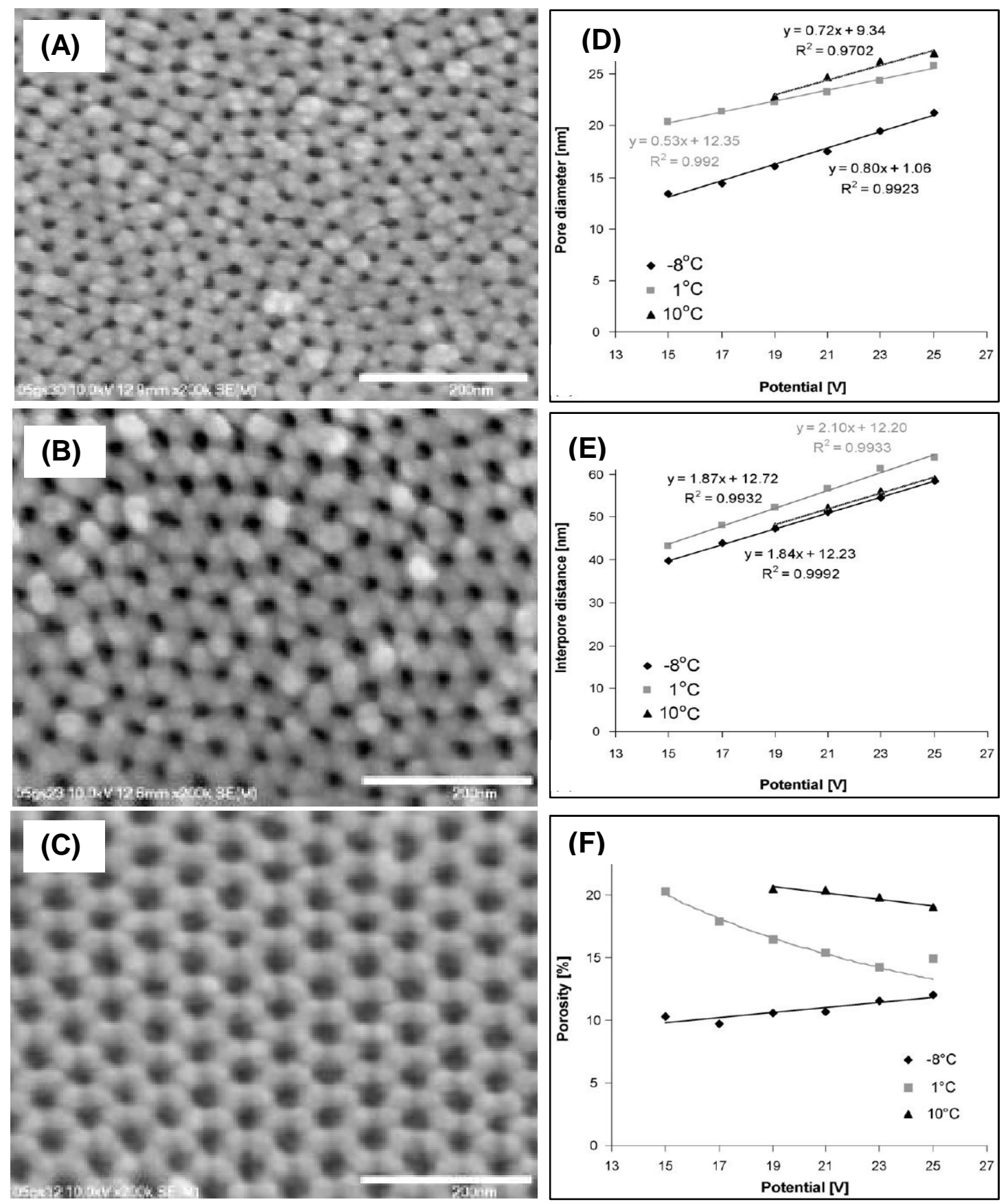

Figura 2.21. Imagens $\mathrm{MEV}$ da AAP formada em $3,3 \mathrm{M}$ de $\mathrm{H}_{2} \mathrm{SO}_{4}$ a $-8^{\circ} \mathrm{C}$ para vários potenciais: $15 \mathrm{~V}$ (A), 19V (B) e 25V (C). Diâmetro meio dos poros (D), distância interporo (E) e porosidade (F) em função do potencial de anodização para várias temperaturas. (Ref. [91,93]).

Por outro lado, a Figura 2.22 mostra resultados recentes em relação à anodização em $\mathrm{H}_{2} \mathrm{C}_{2} \mathrm{O}_{4}$ para altas temperaturas [36]. Nesse trabalho, nanoestruturas de AAP foram fabricados em $0,3 \mathrm{M} \mathrm{H}_{2} \mathrm{C}_{2} \mathrm{O}_{4}$ por 1 hora (duração da 
segunda etapa de anodização) sob uma faixa de potencial de anodização entre 30$65 \mathrm{~V}$ e em temperaturas relativamente elevadas $\left(20-30^{\circ} \mathrm{C}\right)$ em comparação com a anodização clássica $\left(0-5^{\circ} \mathrm{C}\right)$.

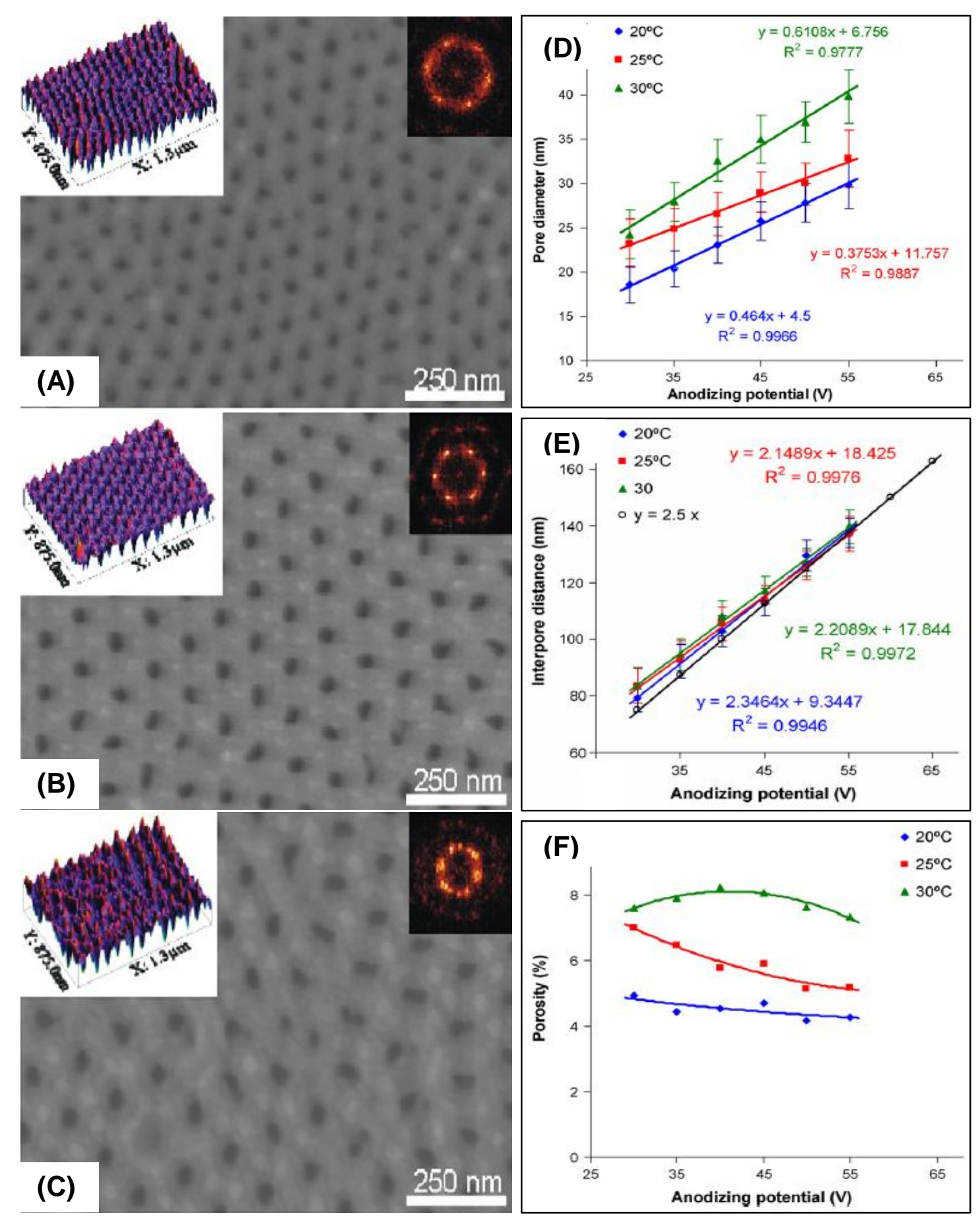

Figura 2.22. Imagens $M E V$ de $A A P$ formada em $0,3 \mathrm{M} \mathrm{H}_{2} \mathrm{C}_{2} \mathrm{O}_{4}$ por 1 hora a $30^{\circ} \mathrm{C}$ para vários potenciais: 30V (A), 40V (B) e 50V (C). Diâmetro do poro meio (D), distância interporo (E) e porosidade $(F)$ em função do potencial de anodização para várias temperaturas (Ref. [36]). 
As imagens MEV da superfície anodizada para vários potenciais de anodização 30V, 40V e 50V são mostrados nas Figuras 2.22(A), 2.22(B) e 2.22(C), respectivamente. As análises destas imagens MEV mostraram que a melhor condição para a obtenção de poros regularmente distribuídos numa simetria hexagonal, é para um potencial de anodização de $40 \mathrm{~V}$ independentemente da temperatura. Também é observado que o arranjo de nanoporos depende do tempo de anodização e que o diâmetro meio e sua distância interporo apresentam uma dependência linear com o potencial de anodização como mostrados nas Figuras 2.22(D) e 2.22 (E), respectivamente. A porosidade diminui com o potencial para as temperaturas de 20 e $25^{\circ} \mathrm{C}$, no entanto, um comportamento totalmente diferente é observado para $30^{\circ} \mathrm{C}$ [Figura 2.22(F)]. O processo de anodização realizada a altas temperaturas tem algumas vantagens em relação aos realizados em baixas temperaturas $\left(0^{\circ} \mathrm{C}\right)$. Como, por exemplo, a taxa de crescimento do óxido é cerca de 5 a 10 vezes maior do que a anodização a baixas temperaturas [36]. Com isso, o tempo de fabricação de máscaras de AAP pode ser reduzido significativamente. Do ponto de vista industrial, o procedimento de anodização a altas temperaturas pode ser tratado como um processo alternativo que permita diminuir custos, já que não será necessário o uso de sistemas de refrigeração.

\subsection{Síntese Eletroquímica de Materiais em máscaras de AAP}

A deposição eletroquímica em filmes de AAP pode ser realizada se existir um caminho condutor formado através dos canais dos nanoporos e o metal alumínio. Isso é particularmente difícil para os filmes de AAP crescidos sobre o alumínio, já que esses filmes apresentam inerentemente uma camada de óxido tipo "barreira" (isolante elétrico) que separa os poros do metal alumínio.

Neste sentido, a literatura reportou três abordagens eletroquímicas clássicas que permitem processos de eletrodeposição no interior dos poros da AAP. Na primeira abordagem, chamada de eletrodeposição de corrente contínua (CC) [3], um filme de AAP com alta razão de apecto é formado sob a folha de alumínio e em seguida é liberado do substrato metálico e da camada tipo "barreira", obtendo-se 
assim uma membrana porosa livre - membrana "free-standing". Este processo é realizado através de um ataque químico sequencial do alumínio (Figura 2.23A) e seguidamente da camada tipo "barreira" (Figura 2.23B). Após a obtenção da membrana "free-standing", é realizado uma deposição física de um filme de metal muito fino em uma das superfícies da membrana (Figura 2.23C) completando-se o processo de obtenção da amostra desejada para iniciar a deposição eletroquímica. A obtenção de nanofios pode então ser realizada utilizando uma célula eletroquímica convencional com CC (Figura 2.23D). O comprimento dos nanofios pode ser controlado simplesmente através do tempo de deposição. Para um tempo de deposição de alguns minutos pode também ser fabricado nanopartículas. $O$ processo pode ser explicado pela equação de Faraday, que leva em conta os parâmetros das máscaras de AAP (tamanho dos poros, densidade dos poros, porosidade, etc), bem como a eficiência de enchimento [170].

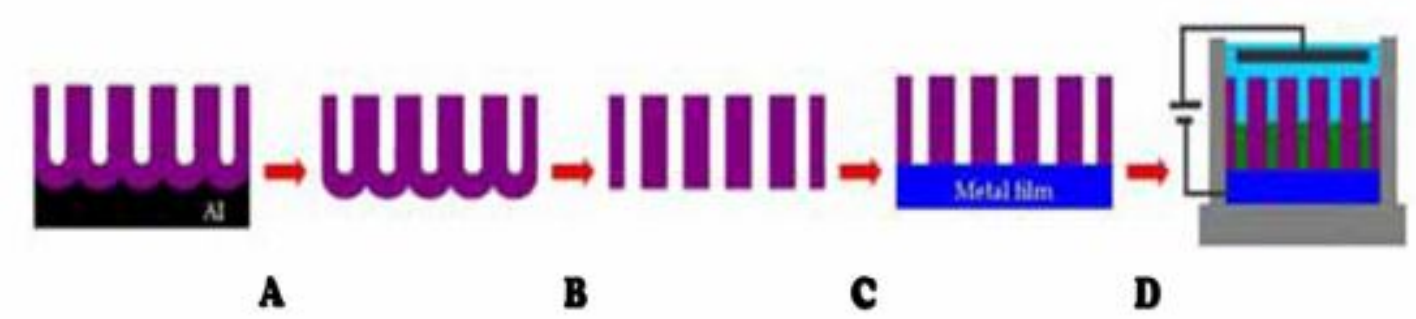

Figura 2.23. Fabricação de nanofios via membranas "free-standing" de AAP por eletrodeposição CC:

(A) dissolução do Al, (B) remoção de camada barreira, (C) metalização, e (D) eletrodeposição (Ref.[3]).

Usando membranas "free-standing" de AAP, é possível aumentar substancialmente os diâmetros dos poros pelo ataque químico em solução de $\mathrm{H}_{3} \mathrm{PO}_{4}$, o que fornece mais flexibilidade no ajuste do diâmetro dos nanofios.

No segundo caso, eletrodeposição de CA [3], o filme de AAP é mantida no substrato de alumínio enquanto que a camada tipo "barreira" é afinada utilizando o método de redução de potencial (Figura 2.24A) [171], de modo a facilitar a sua condutividade elétrica. No entanto, como a camada barreira não pode ser eliminada totalmente, é necessário o uso de CA, ao invés de CC. Neste caso, a deposição 
(Figura 2.24B) emprega voltagens entre 10 a $25 \mathrm{~V}$ e freqüências de algumas centenas de $\mathrm{Hz}[172,173]$. Uma das vantagens deste método é que camadas tipo "barreira" de diferentes tamanhos podem ser usados para preparar nanofios. Este processo é relativamente simples em comparação com aquele que utiliza membranas "free-standing". No entanto, os nanofios sintetizados por este método são frequentemente porosos e policristalinos e não estão bem aderidos ao eletrodo de alumínio, o que dificulta a caracterização elétrica dos mesmos. Além disso, devido à existência de uma camada barreira muito fina, não é possível obter matrizes de nanofios sobre o substrato de alumínio pela remoção da AAP. Mas, é muito útil no que concerne na sua caracterização óptica [174].

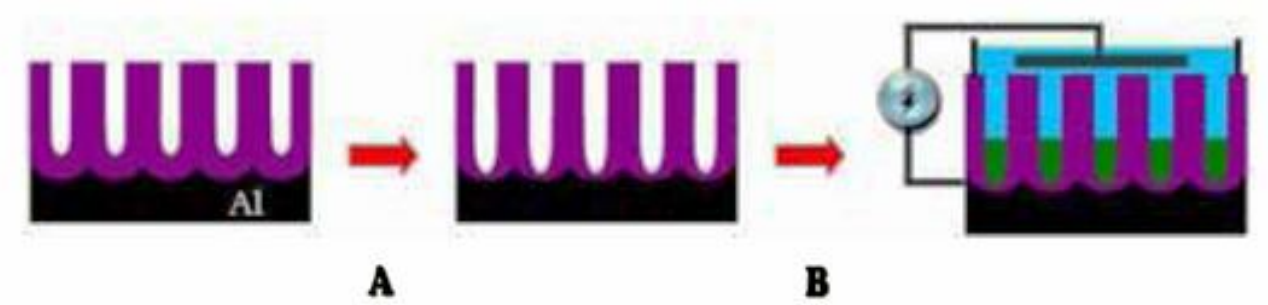

Figura 2.24. Fabricação de nanofios via máscaras de AAP por eletrodeposição $C A$ : $(A)$ afinamento da camada barreira, e (B) electrodeposição. (Ref. [3])

Por último, o método de eletrodeposição pulsada $[175,176]$ tem recebido muita atenção nos últimos anos, devido à melhoria das propriedades mecânicas e químicas dos depósitos. A Figura 2.25 mostra uma sequência do processo de eletrodeposição pulsada. Depois do substrato de alumínio ser anodizado em condições adequadas, uma estrutura porosa ordenada é obtida (Figura 2.25A). Em seguida, a camada tipo "barreira" é afinada e o diâmetro dos poros alargados por ataque químico isotrópico (Figura 2.25B). Para afinar ainda mais a camada barreira, o potencial de anodização aplicado é reduzido de forma exponencial (Figura 2.25C) e formação de dendrites no fundo dos poros na camada tipo "barreira" ocorre (Figura 2.25D). Finalmente, os poros são preenchidos por eletrodeposição pulsada (Figura 2.25E). 

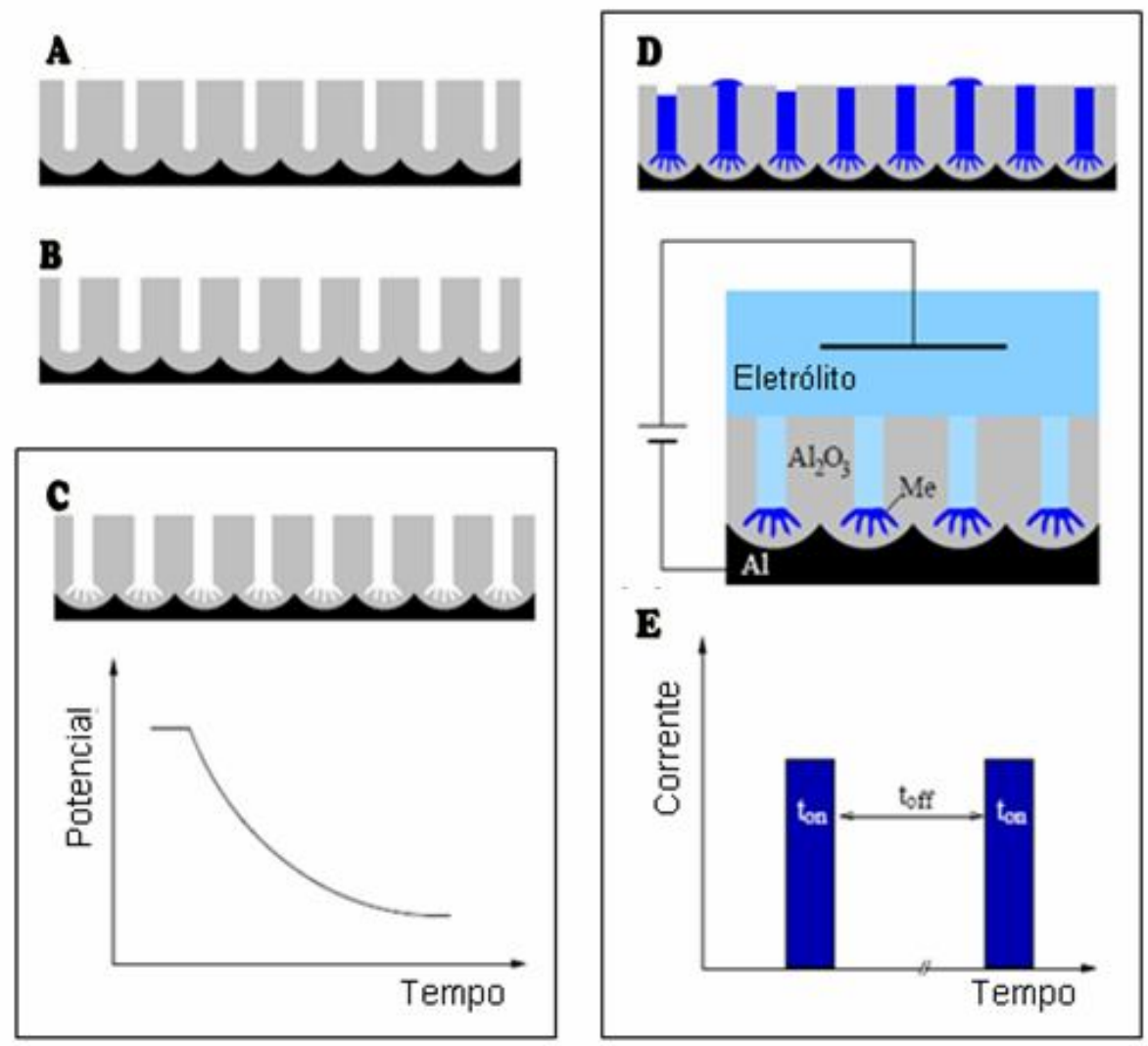

Figura 2.25. Fabricação de nanofios via máscaras de AAP por eletrodeposiçao pulsada. (A) Estrutura porosa ordenada, (B) processo de ataque químico, $(C)$ formação de dendrites devido a redução exponencial do potencial, (D) e (E) Electrodeposição Pulsada de Corrente. (Ref. [175]).

\subsubsection{Nanopartículas, Nanofios e Nanotubos}

O termo "Nanopartícula" é usado para descrever uma partícula com tamanho no intervalo de $1 \mathrm{a} 100 \mathrm{~nm}$, pelo menos em uma das três dimensões [2]. Nesta faixa de tamanho, as propriedades físicas, químicas das nanopartículas mudam em comparação com as propriedades do material de substrato "bulk" correspondente. As nanopartículas podem ser feitos de materiais de natureza química diversa, os mais comuns são os metais, óxidos metálicos, silicatos, cerâmicos, polímeros e carbono. As nanopartículas possuem várias morfologias diferentes, tais como esféricas, cilíndricas, fios, plaquetas, tubos, etc. Como o termo nanopartícula é muito geral, neste trabalho será feita uma distinção entre nanopartículas e nanofios. Será utilizado o termo nanopartícula para nano-objetos esféricos e nanofios para nano-objetos que apresentarem forma de fios cumpridos. 
A enorme diversidade das nanopartículas, nanofios e nanotubos decorrem da sua variada natureza química, formas e morfologias, meio em que as partículas estão presentes, estado de dispersão das partículas e o mais importante, as inúmeras modificações da sua superfície o que torna num importante campo ativo na nanociência. A seguir serão apresentados alguns exemplos de nanopartículas, nanofios e nanotubos devido a sua importância e aplicações. A Figura 2.26 mostra imagens MEV de nanopartículas de ouro $(A)$, nanofios de prata $(B)$ e nanotubos de Níquel (C) sintetizados por eletrodeposição numa membrana de AAP.
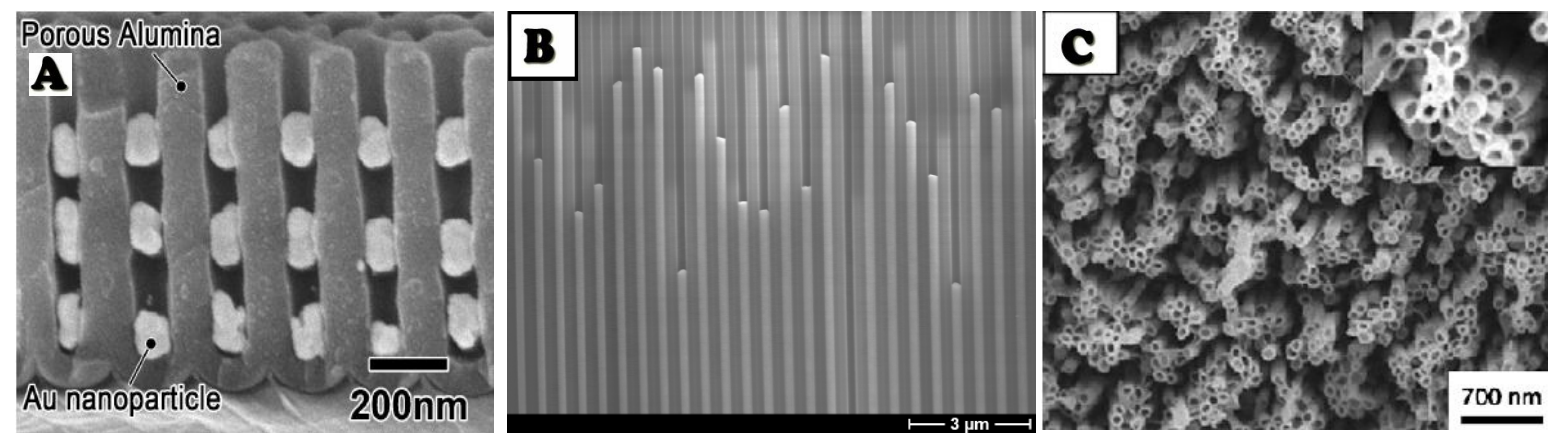

Figura 2.26. Nanopartículas de Ouro (A), nanofios de Prata (B), e nanotubos de Níquel (C) eletrodepositadas em membranas de AAP. (Ref. [177,179,180]).

Nestes exemplos, o método utilizado para preparar as estruturas 3D de nanopartículas de ouro $(\mathrm{Au})$ foi a eletrodeposição $\mathrm{CA}$. A deposição de ouro foi realizada numa máscara de AAP a $25 \mathrm{~V}$ por 3 minutos em um eletrólito contendo ácido cloroáurico $\left(\mathrm{HAuCl}_{4}\right)$ [177]. A frequência do sinal da $\mathrm{CA}$ foi de $50 \mathrm{~Hz}$, e o número de camadas das nanopartículas de $\mathrm{Au}$ foi determinado pelo número de repetições deste processo. A principal aplicação desta estrutura 3D de nanopartíulas de $A u$ foi na utilização como substrato para a medição do espalhamento Raman de superfície intensificada (SERS) baseado na intensificação do campo elétrico por plásmon de superfície localizada [177], semelhantes efeitos SERS foram observados com nanopartículas de prata $(\mathrm{Ag})$ [178].

A Figura 2.26(B) mostra nanofios de Ag depositados eletroquimicamente numa membrana de AAP monodomínio (as membranas de AAP foram preparadas por indentação seguido de uma anodização). Um banho de eletrodeposição comercial 
sob condições de CC $\left(10 \mathrm{~mA} / \mathrm{cm}^{2}\right)$ foi usada para a infiltração dos átomos de $\mathrm{Ag}$ nos poros da AAP. O potencial da célula durante a eletrodeposição foi em torno de $2,5 \mathrm{~V}$, potencial significativamente maior do que o potencial de quebra da camada barreira. Sob tais condições a eletrodeposição CC foi possível. Durante a deposição, a temperatura foi mantida a $25^{\circ} \mathrm{C}$ [179]. Estudos atuais mostram que nanocompositos metal-dielétrico (nanofios de $\mathrm{Au}$ ou $\mathrm{Ag}$ depositados em máscaras de AAP) apresentam novas propriedades físicas, isto é, medições de absorbância óptica destes nanocompositos mostram picos de ressonância correspondentes aos modos plasmônicos transversal e longitudinal [174], o que sugere que estes nanocompositos apresentam comportameto de metamaterial (ou material de índice de refração negativo) [9]. Por outro lado, a Figura 2.26(C) mostra nanotubos de $\mathrm{Ni}$, o eletrólito para a sua preparação continha uma solução misturada de $100 \mathrm{gL}^{-1}$ de sulfato de Níquel $\left(\mathrm{NiSO}_{4} \cdot 6 \mathrm{H}_{2} \mathrm{O}\right), 30 \mathrm{gL}^{-1}$ de cloreto de Níquel $\left(\mathrm{NiCl}_{2} \cdot 6 \mathrm{H}_{2} \mathrm{O}\right)$ e $40 \mathrm{gL}^{-1}$ de ácido bórico $\left(\mathrm{H}_{3} \mathrm{BO}_{3}\right)$, e o valor de $\mathrm{pH}$ da solução foi ajustado para 2,5 com $1 \mathrm{M}$ de $\mathrm{H}_{2} \mathrm{SO}_{4}$, a deposição foi realizado utilizando eletrodeposição $\mathrm{CC}$ nos poros da AAP com um potencial de deposição de 1,4V a temperatura ambiente [180]. Estes nanotubos magnéticos são importantes devido a sua aplicação na fabricação de dispositivos de gravação magnética de alta densidade e sensores de detecção de apenas uma molécula [181,182].

\subsubsection{Aplicações Principais}

A Nanotecnologia oferece uma gama extremamente ampla de aplicações potenciais em eletrônica, comunicações ópticas e sistemas biológicos. Diversas aplicações potenciais e novos dispositivos estão sendo propostos na literatura. Neste item serão apresentados alguns exemplos para ilustrar as possibilidades dos usos das nanoestruturas e nanomateriais nos diferentes ramos da ciência atual.

É interessante notar que as aplicações da nanotecnologia em diversas áreas têm exigências muito diferentes e, assim, enfrentam desafios diferentes, e exigem abordagens diferentes. Por exemplo, para aplicações na medicina ou em nanomedicina, o maior desafio é a "miniaturização": novos instrumentos para analisar tecidos, literalmente, até o nível molecular, sensores menores do que uma célula permitindo medir e monitorear várias funções em curso, e máquinas 
pequenas que, literalmente, circulam dentro de um corpo humano buscando patógenos e neutralizando toxinas químicas [52]. Aplicações de nanoestruturas e nanomateriais são baseadas em (i) propriedades físicas peculiares de materiais em tamanho nanométrico, por exemplo, nanopartículas de Ag são usados como corante inorgânico para introduzir cores em vidro e como catalisador de baixas temperaturas [43-45], (ii) a enorme área de superfície, tais como titânio mesoporoso para células fotoeletroquímicas, e nanopartículas para fabricar nano e biosensores [11,46-50], e (iii) o tamanho pequeno oferece possibilidades extras para manipulação e o espaço para acomodar múltiplas funcionalidades. A seguir, serão apresentadas algumas aplicações principais nas diversas áreas da ciência e da engenharia que têm sido exploradas para ilustrar o uso das nanoestruturas e nanomateriais:

a) Eletrônica Molecular e Nanoeletrônica [1,2,3,6,7,8,10,11,39,40,182]

b) Nanorrobôs e Nanosensores [1,2,3,11,41,46,50,52]

c) Aplicações Biológicas de Nanopartículas [1,2,3,10,52]

d) Catálise por nanopartículas de ouro [1,2,43-45]

e) Engenharia de "Bang Gap" e dispositivos Quânticos [1,14,30,182]

f) Nanomecânica [1]

g) Células fotoeletroquimicas [1,51]

h) Cristais fotônicos e Guias de onda Plasmónico [1,3,6,37,42,58,101]

i) Nanoantenas Ópticas [42]

j) Substratos para espalhamento Raman intensificado $[178,179]$

k) Metamaterials $[3,9,175]$. 


\subsection{Conclusões parciais}

A revisão bibliográfica do estado da arte atual sobre a fabricação de nanoestruturas de AAP, síntese de nanopartículas e nanofios tem nos fornecido as seguintes conclusões:

- As nanoestruturas de AAP fabricadas por anodização apresentam arranjos de poros auto-organizados, o que fazem da AAP uma das estruturas mais desejáveis e é visto como um "nanomaterial ideal" para a indústria da microeletrônica.

- As características estruturais da AAP, quantificado pelos seus parâmetros geométricos, dependem dos parâmetros de anodização.

- A composição química dos filmes de AAP, tanto da camada porosa como da camada barreira, são importantes para os processos de dissolução da AAP e deposição de metais dentro dos poros da AAP.

- A cinética de formação de estruturas de AAP auto-organizada, está dividida em quatro zonas de anodização correspondentes às quatro etapas do desenvolvimento da AAP sob regime potenciostático ou galvanostático.

- Para a fabricação de nanoestruturas de AAP auto-organizadas, são relatadas duas abordagens importantes, um processo de anodização de duas etapas e um processo usando pré-texturização. Mas ainda estes requerem muitas horas de processo e técnicas litograficas custosas.

- Usando processos de anodização de duas etapas, observa-se que o diâmetro médio e a distância interporo seguem uma dependência linear com o potencial de anodização, independentemente da temperatura do eletrólito.

- Anodização a temperaturas altas $\left(20-30^{\circ} \mathrm{C}\right)$ apresenta maiores vantagens em comparação com a anodização clássica $\left(\sim 0-5^{\circ} \mathrm{C}\right)$, a taxa de crescimento do óxido é cerca de 5-10 vezes maior para anodização a altas temperaturas do que a anodização a baixas temperaturas. Portanto, o tempo de fabricação das máscaras de AAP pode ser reduzido significativamente.

- Existem três abordagens clássicas para a deposição eletroquímica nos canais dos poros da AAP. Estas são: Eletrodeposição CC, Eletrodeposição CA e Eletrodeposição Pulsada. 
- As nanopartículas e os nanofios, fabricados por eletrodeposição, são muito importantes na nanotecnologia, devido a suas aplicações que vão desde o armazenamento de dados de alta densidade até dispositivos plasmônicos, de nanoeletrodos de alta sensibilidade, metamateriais e nanoantenas ópticas.

- A grande diversidade de nanomateriais permite inúmeras aplicações nos diferentes ramos da ciência atual.

Assim, segundo o estado da arte, apesar de ter uma técnica padrão de fabricação de estruturas de AAP (anodização em duas etapas) ainda existe um grande desafio para reduzir o tempo e o custo de fabricação dessas nanoestrururas. Embora se tenha sugerido trabalhar com altas temperaturas e/ou altos potenciais, poucos estudos focaram sua atenção na fabricação de estruturas de AAP por uma única etapa de anodização e uma análise deste processo a altas temperaturas e à influência dos parâmetros de anodização sobre as características estruturais da AAP não foi realizada ainda. Nesse sentido, a proposta de pesquisa é a fabricação de máscaras de AAP por uma etapa de anodização e suas aplicações na síntese eletroquímica de nanomateriais. Esta é uma tecnologia de baixo custo e poderia ser uma alternativa interessante para reduzir o custo e o tempo de fabricação das máscaras de AAP e, por tanto, na síntese de nanopartículas e nanofios metálicos. 


\section{Capítulo 3}

\section{Procedimentos Experimentais}

Neste capítulo são descritos os procedimentos experimentais desenvolvidos durante o presente trabalho. Inicia-se apresentando os materiais e equipamentos empregados no processo de fabricação das diferentes estruturas. Seguidamente, os procedimentos para a obtenção das nanoestruturas de AAP auto-organizadas, nanopartículas e nanofios metálicos, e nanofios de alumina são apresentados detalhamente, juntamente com os procedimentos de caracterização química e morfológica das estruturas obtidas.

\subsection{Materiais e Equipamentos}

Os materiais empregados para a obtenção de máscaras de AAP, nanopartículas e nanofios são apresentados a seguir:

- Alumínio metálico em tiras da MERCK com uma espessura de 0,3mm.

Al: 99,9568\%; N: 0,005\%; As: 0,0002\%; Cu: 0,005\%; Fe: 0,006\%; Mn: 0,002\%; Si: 0,02\%; Zn: 0,005\%.

- Célula eletrolítica simples de dois eletrodos, com uma área efetiva de trabalho de $0,5 \mathrm{~cm}^{2}$ (copo de vidro com $0,5 \mathrm{dm}^{3}$ de capacidade).

- Ácido Oxálico $\left(\mathrm{H}_{2} \mathrm{C}_{2} \mathrm{O}_{4}\right)$.

- Ácido Sulfúrico $\left(\mathrm{H}_{2} \mathrm{SO}_{4}\right)$.

- Ácido Fosfórico $\left(\mathrm{H}_{3} \mathrm{PO}_{4}\right)$.

- $\quad$ Sulfato de Níquel $\left(\mathrm{NiSO}_{4}: 6 \mathrm{H}_{2} \mathrm{O}\right)$.

- Nitrato de Prata $\left(\mathrm{AgNO}_{3}\right)$.

- Acido Bórico $\left(\mathrm{H}_{3} \mathrm{BO}_{3}\right)$.

- Água Deionizada.

- Eletrodo de platina (grade) com uma área de trabalho de $1 \mathrm{~cm}^{2}$

- $\quad$ Agitador Mecânico (1490 rpm)

- $\quad$ Fonte de alimentação DC (Keithley 236 Source-Measure Unit). 
- Gerador de funções modelo HP-33120A

- Amplificador operacional bipolar modelo BOP20-KEPCO

- Controlador de temperatura - Banho Criostático da LÁCTEA.

- Microscopia Eletrônica de Varredura (MEV) - FEI Nova NanoSEM-400.

- Programa GRANUL [183].

- $\quad$ pH-Metro modelo PM-602 ANALION

\subsection{Fabricação das Máscaras de AAP}

O procedimento experimental para a obtenção das nanoestruturas de AAP auto-organizadas passa por dois estágios: (1) Limpeza inicial, recozimento térmico e eletropolimento das amostras (Pré-tratamento) e (2) Obtenção das nanoestruturas de AAP por uma só etapa de anodização e um pós-tratamento de corrosão química. Os detalhes são apresentados a seguir.

\subsubsection{Limpeza e Preparação das Amostras}

As amostras foram obtidas a partir de folhas de alumínio com alta pureza (99,9568\%). Iniciamente as amostras foram submetidas a uma limpeza de desengorduramento sequencial, em uma solução misturada de tricloretileno $\mathrm{C}_{2} \mathrm{HCl}_{3}$, acetona $\mathrm{CH}_{3}(\mathrm{CO}) \mathrm{CH}_{3}$ e isopropanol $\mathrm{C}_{3} \mathrm{H}_{8} \mathrm{O}\left(\mathrm{H}_{3} \mathrm{C}-\mathrm{HCOH}-\mathrm{CH}_{3}\right)$, fervido a uma temperatura de $70^{\circ} \mathrm{C}$ durante 10 minutos. Em seguida, as amostras foram submetidas a um tratamento de recozimento térmico a uma temperatura de $500^{\circ} \mathrm{C}$ em ambiente de nitrogênio $\left(\mathrm{N}_{2}\right)$ durante 3 horas. Este tratamento térmico tem a finalidade de diminuir os defeitos da estrutura cristalina no filme de $\mathrm{Al}$, pois tais defeitos poderiam contribuir para a formação de regiões desorganizadas em meio ao sistema auto-organizado. Outra etapa importante para se evitar a formação de poros irregularmente distribuídos é o processo de eletropolimento da superfície irregular do filme de Al.

$O$ processo de eletropolimento foi realizado numa área efetiva de $0,5 \mathrm{~cm}^{2}$ (Figura 3.1A, letra "a") da folha de alumínio. Para essa finalidade foi utilizado um 
suporte de teflon. Na célula eletroquímica (Figura 3.1A, letra "b"), a superfície exposta do filme de alumínio atuou como eletrodo de trabalho (ánodo) e uma grade de platina como contra eletrodo (cátodo), a solução eletrolítica a ser utilizada foi uma mistura de $\mathrm{H}_{2} \mathrm{SO}_{4}+\mathrm{H}_{3} \mathrm{PO}_{4}+\mathrm{H}_{2} \mathrm{O}$ na proporção de 4:4:2 em volume. A célula eletroquímica foi polarizada com uma corrente contínua de $95 \mathrm{~mA}$ por 7 minutos, utilizando-se uma fonte de tensão/corrente Keithley modelo 236. Um agitador mecânico com 1490 rpm foi utilizado para agitação do eletrólito durante o processo de eletropolimento para a eliminação das bolhas formadas durante o processo eletroquímico. Após o eletropolimento, as amostras foram lavadas em água deionizada durante 10 minutos e em seguida foi realizada a anodização do alumínio para a formação de AAP auto-organizadas.
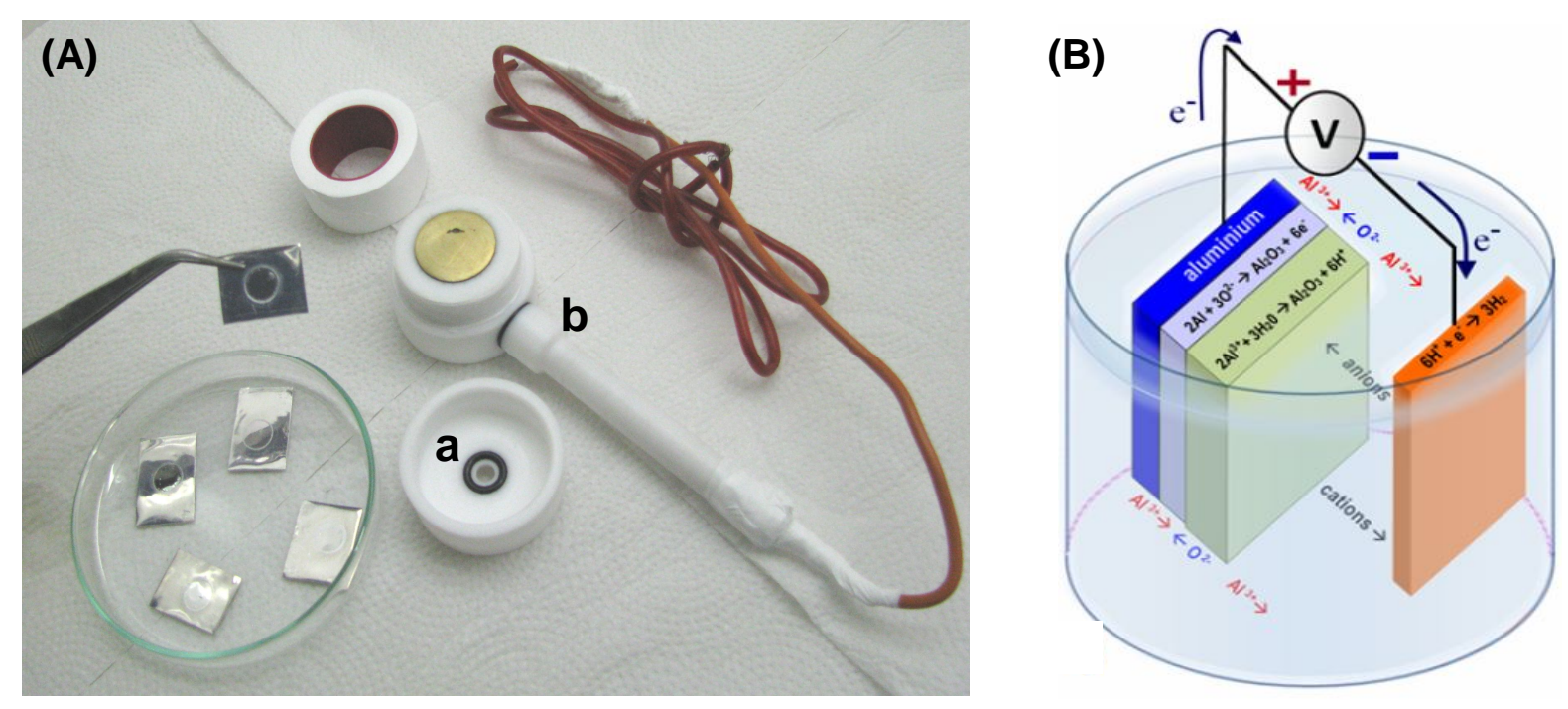

Figura. 3.1. Célula eletrolítica simples (A) e um diagrama esquemático de anodização (B).

\subsubsection{Obtenção de Estruturas de AAP por uma Etapa de Anodização}

A anodização auto-organizada do Al foi realizada numa solução aquosa de $\mathrm{H}_{2} \mathrm{C}_{2} \mathrm{O}_{4}$ durante duas horas para todas as amostras, um diagrama esquemático do processo de anodização é mostrado na Figura 3.1(B). Para analisar as características estruturais e propriedades geométricas da AAP foi preciso estudar o efeito da concentração, temperatura e potencial no processo de anodização. Para 
ter o controle da temperatura $\left(15-30^{\circ} \mathrm{C}\right)$, mantendo a concentração e o potencial constantes, utilizou-se um banho Criostático da LÁCTEA. Durante o processo de anodização, a célula eletroquímica foi polarizada para diferentes potenciais de anodização (35-50V), mantendo a concentração e a temperatura constantes com o objetivo de ter um controle do potencial de anodização. Um agitador mecânico com 1490 rpm foi utilizado no eletrólito para a eliminação das bolhas formadas durante o processo de anodização. Após a anodização, as amostras foram mergulhadas numa solução de $1 \mathrm{M} \mathrm{H}_{3} \mathrm{PO}_{4}$ para um período de tempo de 60 minutos com 0 objetivo de abrir os canais dos nanoporos. $O$ processo de abertura dos poros geralmente conhecida na literatura como corrosão química (ataque químico isotrópico) é um processo muito simples, e será muito importante neste trabalho. Após a corrosão química as amostras foram lavadas em água deionizada por 10 minutos, posteriomente secadas com um jato de nitrogênio.

Como um resumo, a Figura 3.2 mostra um diagrama de blocos dos procedimentos envolvidos na fabricação de nanoestruturas de AAP por uma etapa de anodização em ácido oxálico.

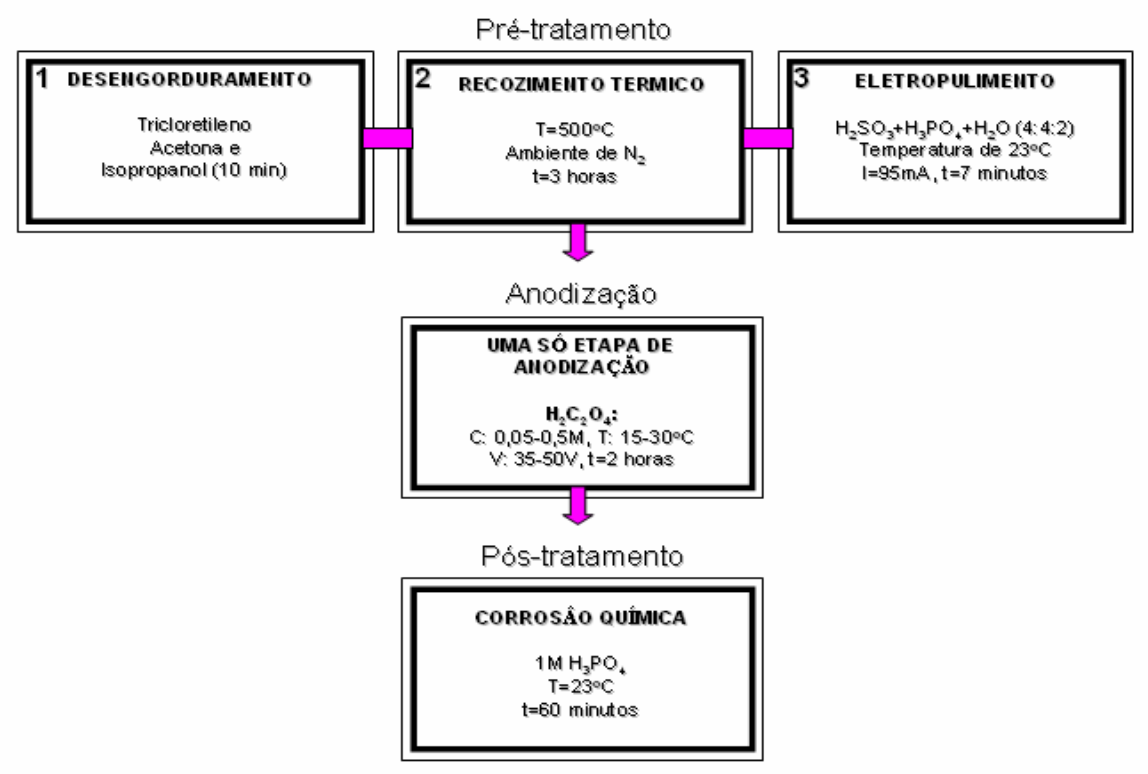

Figura 3.2. Diagrama de blocos do processo de fabricação de nanoestruturas de AAP autoorganizadas. 
A Tabela 3.1 mostra os parâmetros de anodização utilizados na formação de estruturas de AAP, assim como também os nomes das amostras.

Tabela 3.1. Parâmetros eletroquímicos utilizados na formação de estrutura de AAP.

\begin{tabular}{|c|c|c|c|}
\hline Amostra & Concentração (M) & Temperatura $\left({ }^{\circ} \mathbf{C}\right)$ & Potencial (V) \\
\hline $\mathrm{B}_{2}$ & 0,05 & 20 & 50 \\
\hline $\mathrm{D}_{2}$ & 0,30 & 20 & 35 \\
\hline $\mathrm{D}_{3}$ & 0,30 & 25 & 35 \\
\hline $\mathrm{D}_{6}$ & 0,50 & 20 & 35 \\
\hline $\mathrm{E}_{2}$ & 0,50 & 20 & 40 \\
\hline $\mathrm{F}_{6}$ & 0,15 & 20 & 50 \\
\hline $\mathrm{H}_{1}$ & 0,30 & 15 & 50 \\
\hline $\mathrm{H}_{2}$ & 0,30 & 20 & 50 \\
\hline $\mathrm{H}_{3}$ & 0,30 & 25 & 50 \\
\hline $\mathrm{H}_{4}$ & 0,30 & 30 & 50 \\
\hline $\mathrm{H}_{6}$ & 0,50 & 20 & 50 \\
\hline $\mathrm{K}_{1}$ & 0,05 & 30 & 45 \\
\hline $\mathrm{O}_{1}$ & 0,15 & 20 & 45 \\
\hline $\mathrm{O}_{2}$ & 0,50 & 20 & 45 \\
\hline $\mathrm{O}_{3}$ & 0,05 & 20 & 45 \\
\hline $\mathrm{O}_{6}$ & 0,15 & 30 & 45 \\
\hline $\mathrm{O}_{7}$ & 0,50 & 15 & 45 \\
\hline $\mathrm{O}_{8}$ & 0,50 & 25 & 45 \\
\hline $\mathrm{O}_{9}$ & 0,50 & 30 & 45 \\
\hline $\mathrm{P}_{3}$ & 0,30 & 15 & 45 \\
\hline $\mathrm{P}_{4}$ & 0,30 & 25 & 45 \\
\hline $\mathrm{P}_{6}$ & 0,30 & 30 & 45 \\
\hline $\mathrm{P}_{7}$ & 0,30 & 20 & 40 \\
\hline $\mathrm{P}_{8}$ & 0,30 & 25 & 40 \\
\hline $\mathrm{R}_{8}$ & 0,30 & 20 & 45 \\
\hline & & & \\
\hline
\end{tabular}




\subsection{Fabricação de Nanopartículas e Nanofios de Metálicos}

Após o processo de fabricação das estruturas de AAP, estas foram submetidas a um processo de corrosão química com o objetivo de controlar o diâmetro dos nanoporos e reduzir a espessura da camada tipo "barreira" para facilitar a eletrodeposição. As nanopartículas e nanofios metálicos foram fabricados por eletrodeposição CA em moldes de AAP utilizando um gerador de funções modelo HP-33120A e um amplificador operacional bipolar modelo BOP20-KEPCO. O diagrama esquemático da montagem dos equipamentos para a deposição eletroquímica é similar ao processo da anodização e é mostrado na Figura 3.3. Para analisar a relação entre as características estruturais da deposição eletroquímica e os parâmetros utilizados no processo foi necessário controlar a freqüência da tensão alternada e o tempo de deposição, mantendo os demais parâmetros de deposição constantes. Após a deposição, as amostras foram clivadas e mergulhadas numa solução de $1 \mathrm{M} \mathrm{H}_{3} \mathrm{PO}_{4}$ com objetivo de dissolver a alumina e ter boas imagens MEV dos depósitos. Finalmente as amostras foram lavadas em água deionizada por 10 minutos e posteriomente secadas com um jato fino de nitrogênio.

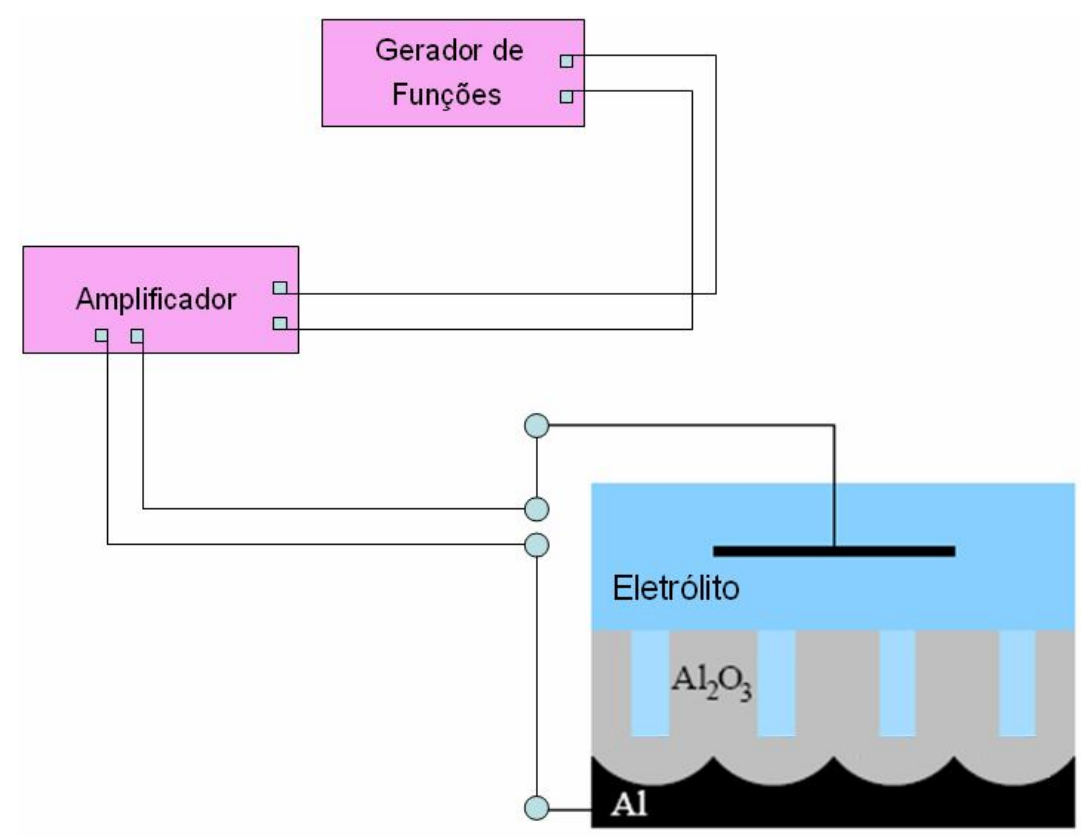

Figura 3.3. Diagrama esquemático do processo de eletrodeposição CA. 
Para a preparação das soluções eletrolíticas na deposição foram utilizados os seguintes compostos:

- $\quad$ Sulfato de níquel $\left(\mathrm{NiSO}_{4}: 6 \mathrm{H}_{2} \mathrm{O}\right)$.

- $\quad$ Nitrato de prata $\left(\mathrm{AgNO}_{3}\right)$.

- $\quad$ Acido Bórico $\left(\mathrm{H}_{3} \mathrm{BO}_{3}\right)$.

A solução eletrolítica usada para fabricar nanopartículas e nanofios de níquel foi $0,1 \mathrm{M}$ de NiSO $4: 6 \mathrm{H}_{2} \mathrm{O}$ e $45 \mathrm{~g} / \mathrm{L} \mathrm{H}_{3} \mathrm{BO}_{3}$, em todos os casos a célula foi polarizada com uma tensão de $20 \mathrm{~V}$, para as freqüências do sinal de 100 e $300 \mathrm{~Hz}$ respectivamente. Também foi variado o tempo de deposição de 2 a 60 minutos. $A$ mistura da solução foi mantida num pH constante de 3,5.

A solução eletrolítica usada para fabricar nanofios de prata foi de $0,05 \mathrm{M}$ $\mathrm{AgNO}_{3}$ e $1,5 \mathrm{~g} / \mathrm{L} \mathrm{H}_{3} \mathrm{BO}_{3}$ mantendo uma tensão de $25 \mathrm{~V}$, para as freqüências de 100 e $300 \mathrm{~Hz}$ e um tempo de deposição variável de 5 a 40 minutos. A mistura da solução foi mantida num pH constante de 2,5.

\subsection{Fabricação de Nanofios de Alumina}

Após o processo de fabricação das estruturas de AAP, estas foram submetidas a um processo de dissolução química para diferentes períodos de tempo em uma solução de $1 \mathrm{M}$ de $\mathrm{H}_{3} \mathrm{PO}_{4}$ a temperaturas de 23 e $27^{\circ} \mathrm{C}$ respectivamente. Após o processo de dissolução as amostras foram lavadas em água deionizada por 10 minutos e posteriomente secadas com um jato de nitrogênio. 


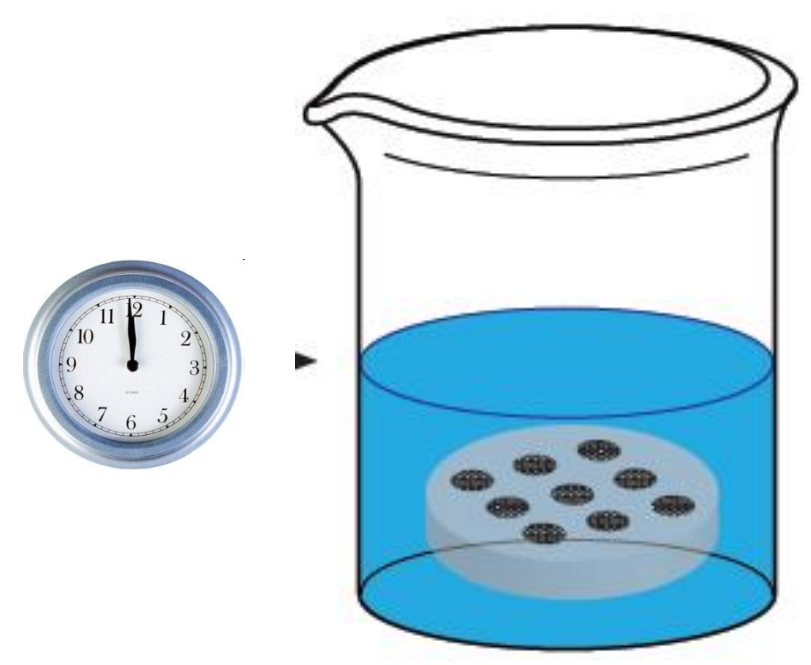

Figura 3.4. Amostras colocadas em solução de $1 \mathrm{M}$ de $\mathrm{H}_{3} \mathrm{PO}_{4}$ para o processo de dissolucão química.

\subsection{Caracterização das Estruturas}

A etapa de caracterização das nanoestruturas de AAP auto-organizadas, nanopartículas e nanofios compreendem a caracterização morfológica e a caracterização química. As caracterizações foram realizadas por Microscopia Eletrônica de Varredura (MEV) no Laboratório de Sistemas Integráveis (LSI) e no Laboratório de Microscopia Eletrônica da Engenharia de Materiais da Escola Politécnica da USP, Brasil. Os microscópios utilizados foram: a) um Microscópio Eletrônico de Varredura FEI Nova NanoSEM-400 e; b) um Microscópio Eletrônico de Varredura PHILIPS XL-30 com espectrômetro de dispersão de energia. Para as análises de Microscopia Eletrônica foi utilizada a técnica de elétrons secundários.

Adicionalmente, uma análise quantitativa das estruturas porosas foi realizada a partir das imagens MEV utilizando o software GRANUL [183] desenvolvido para este propósito pelo grupo do professor Hae. 


\section{Capítulo 4}

\section{Resultados e Discussões}

Neste capítulo, estão apresentados resultados experimentais obtidos durante 0 desenvolvimento deste trabalho. Os resultados obtidos estão divididos em três etapas. Na primeira etapa serão apresentadas as configurações morfológicas das nanoestruturas de AAP auto-organizadas fabricadas por uma etapa de anodização a temperaturas altas. Serão discutidas e analisadas as curvas cinéticas de formação das estruturas de AAP, o efeito dos parâmetros de anodização na formação dessas estruturas e a influência da corrosão química sobre as nanoestruturas formadas. Na segunda etapa estão apresentadas as nanopartículas e nanofios metálicos usando as nanoestruturas de AAP como molde. Estas nanoestruturas metálicas foram obtidas por um processo de deposição eletroquímica CA. Na última etapa, a formação dos nanofios de alumina foi realizada por um processo de dissolução química das estruturas de AAP em ácido fosfórico e para duas temperaturas diferentes 23 e $27^{\circ} \mathrm{C}$ respectivamente. A caracterização estrutural foi realizada basicamente mediante o emprego do microscópio eletrônico de varredura (MEV), enquanto que a caracterização da composição química foi realizada através da técnica de EDS.

\subsection{Anodização em uma só Etapa e Configurações Morfológicas da AAP}

\subsubsection{Cinética de Formação das Estruturas de AAP}

Durante todos os processos de anodização das diferentes amostras, foram obtidas curvas da evolução da densidade de corrente elétrica em relação ao tempo, estas curvas apresentam comportamentos semelhantes aos reportados na literatura [31,36,144]. Em geral, estas curvas apresentam inicialmente um decaimento muito rápido da densidade de corrente até atingir um mínimo e depois um crescimento da mesma até atingir um máximo para logo ficar quase constante. Na Figura 4.1 são mostradas as curvas de anodização potenciostática (densidade de corrente vs. 
tempo de anodização) das amostras $\mathrm{O} 7$ e $\mathrm{O} 8$, onde são mostradas também as diferentes regiões de anodização (letras a,b,c,d nas curvas cinéticas). As diferentes regiões estão relacionadas a diferentes etapas do processo de formação da estrutura porosa como se mostra no lado direito da Figura 4.1. Essas amostras (O7 e O8) foram anodizadas em $0,5 \mathrm{M}$ de $\mathrm{H}_{2} \mathrm{C}_{2} \mathrm{O}_{4}$, a um potencial de $45 \mathrm{~V}$ e a temperaturas de 15 e $25^{\circ} \mathrm{C}$, respectivamente.

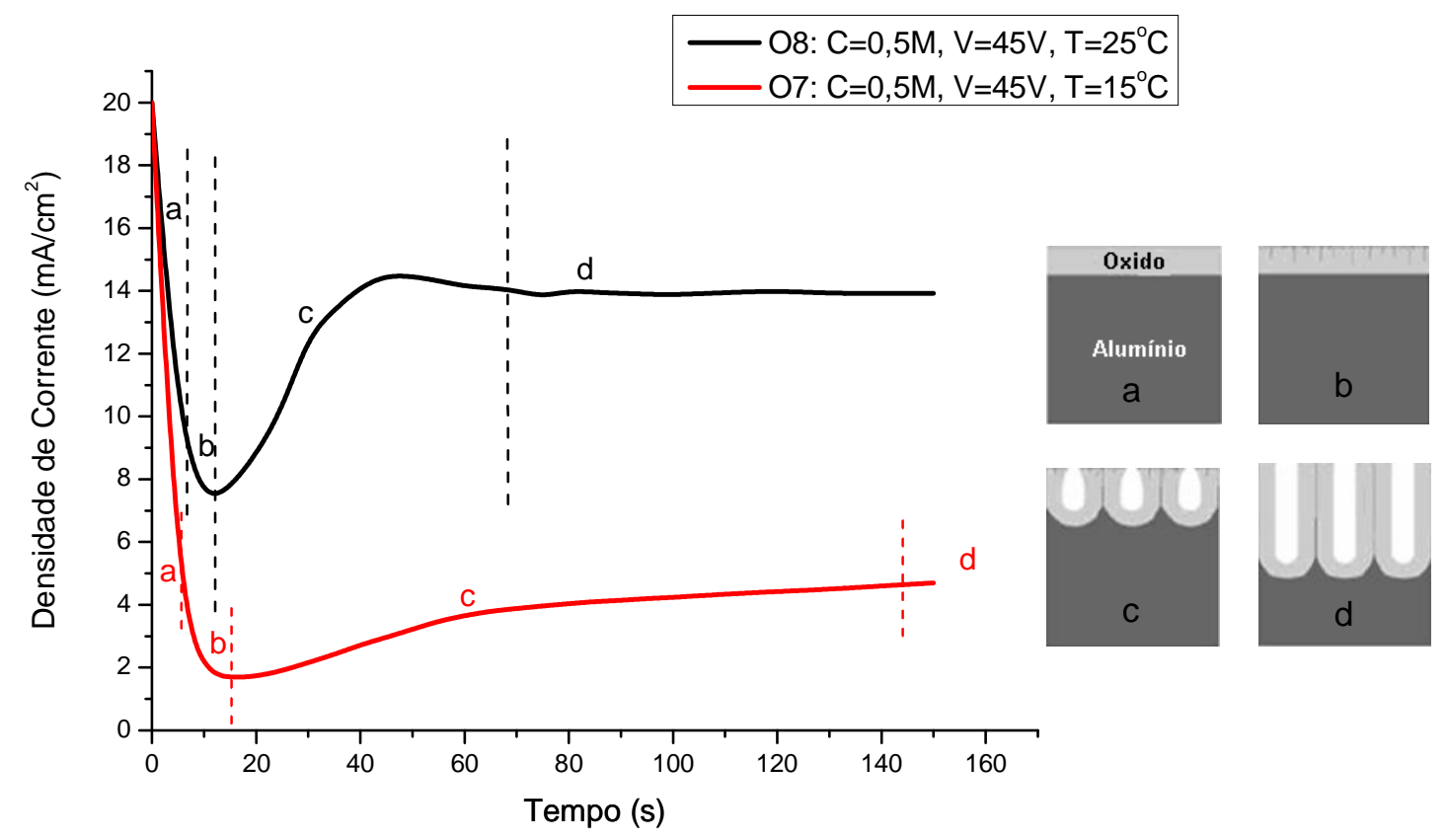

Figura 4.1. Curvas cinéticas de crescimento da AAP no regime potenciostático das amostras $\mathrm{O}_{7}$ e $\mathrm{O}_{8}$ durante a anodização em $0,5 \mathrm{M}$ de $\mathrm{H}_{2} \mathrm{C}_{2} \mathrm{O}_{4}$, a um potencial de $45 \mathrm{~V}$ e a temperaturas de 15 e $25^{\circ} \mathrm{C}$, respectivamente, junto com suas respectivas regiões de anodização (a,b,c,d) e etapas do desenvolvimento da estrutura porosa.

Como pode ser observado na Figura 4.1, as duas curvas cinéticas não apresentam as mesmas regiões de anodização devido a que as condições de anodização são diferentes (neste caso a temperatura). Para a amostra 08, a densidade de corrente em estado estacionario (letra "d" da Figura 4.1) é maior do que para a amostra 07 , devido ao aumento da temperatura. Observa-se também que a amostra O8 alcança o máximo valor de corrente antes do que O7. Por tanto, na amostra $\mathrm{O} 8$ o processo de formação dos poros é mais rápido do que na amostra 
O7. Em geral, a cinética de crescimento da estrutura de AAP é diferente para diferentes condições de anodização.

A relação entre as diferentes regiões de anodização na curva de densidade de corrente, $J(t)$, e a evolução do processo de formação da estrutura porosa foi modelada teoricamente pelo modelo dissolução de campo assistido "FAD-Field assisted dissolution", este modelo considera quatro fases na evolução de corrente para a formação de óxido de alumínio. Durante o período inicial de anodização, etapa (a) um filme de óxido compacto de alta resistência (filme tipo "barreira") é formado sobre o substrato de alumínio razão pela qual a densidade de corrente diminui rapidamente. A eficiência de formação do óxido é também mais alta nesta etapa. Já na etapa (b), a densidade de corrente começa a diminuir lentamente até chegar a um mínimo. A eficiência de formação do óxido também começa a diminuir. Nesta mesma etapa, algumas falhas e propagação de trincheiras locais são formadas, estas trincheiras atuaram posteriomente como poros precursores sob a superfície da camada tipo "barreira" (etapa b). Como conseqüência do desenvolvimento dos poros precursores, o campo elétrico se torna mais concentrado na base dos poros principais e os íons de alumínio $\mathrm{Al}^{3+}$ são ejetados para o eletrólito devido ao campo elétrico intensificado e simultaneamente acontece a difusão de íons $\mathrm{O}^{2-}$ desde a interface eletrolito/óxido até a interface óxido/alumínio para a formação de óxido apenas na interface óxido/alumínio. É geralmente aceito que a corrente de anodização está relacionada com o movimento dos íons $\mathrm{O}^{2-}$ e $\mathrm{Al}^{3+}$ através da camada de óxido, portanto, um aumento na densidade de corrente é observado até atingir um máximo local, onde ocorre um rearranjo dos poros (etapa c). Após atingir o valor máximo, a densidade de corrente não se altera significativamente com o tempo e a camada de óxido poroso começa a crescer no alumínio (etapa d). A densidade de corrente em estado estacionário registrada para todo o processo de anodização, mostrou uma ligeira diminuição exponencial em função do tempo.

A Figura 4.2 mostra imagens MEV das superfícies anodizadas das amostras $\mathrm{O}_{7}(\mathrm{~A})$ e $\mathrm{O}_{8}(\mathrm{~B})$ após duas horas de anodização seguida de uma corrosão química em $1 \mathrm{M}$ de $\mathrm{H}_{3} \mathrm{PO}_{4}$ por 60 minutos a $23^{\circ} \mathrm{C}$. A anodização foi realizada em $0,5 \mathrm{M}$ de ácido oxálico, $45 \mathrm{~V}$ e temperaturas de 15 e $25^{\circ} \mathrm{C}$, respectivamente. $\mathrm{O}$ processo de 
corrosão química foi realizado com o objetivo de abrir os poros, já que inicialmente a superfície anodizada apresentava uma superfície com poros fechados não permitindo a visualização da estrutura porosa da amostra.

Observa-se que estas imagens não apresentam uma distribuição espacial periódica dos poros, isso se deve ao fato de que, no início da anodização, os sítios de nucleação de formação dos poros sobre o filme de óxido inicialmente formado são aleatórios. Por tanto, poros defeituosos são formados na superfície anodizada, o que dá uma aparência de formação de poros irregulares.
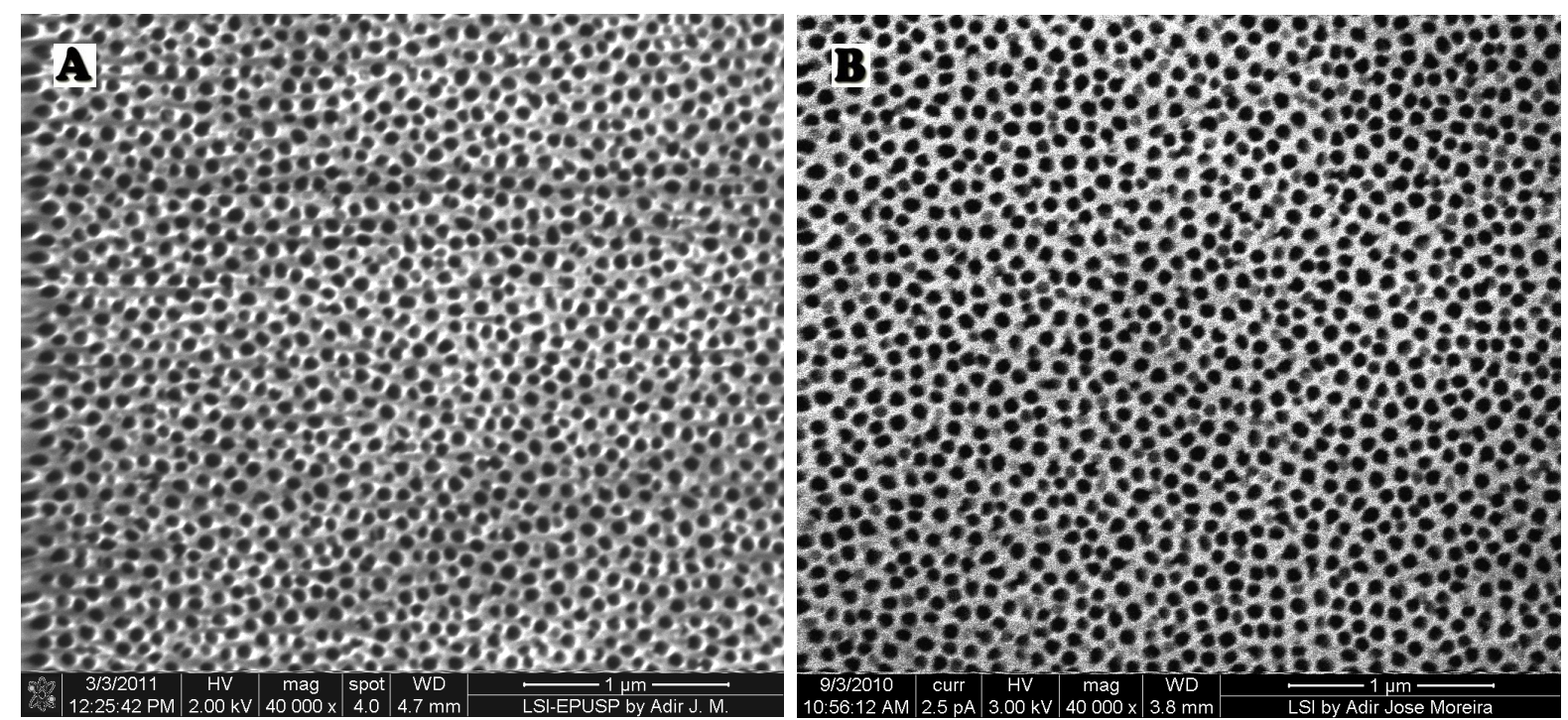

Figura 4.2. Imagens MEV da superfície anodizada das amostras $\mathrm{O}_{7}(\mathrm{~A})$ e $\mathrm{O}_{8}(\mathrm{~B})$ depois de uma corrosão química de 60 minutos a $23^{\circ} \mathrm{C}$. A anodização foi realizada em $0,5 \mathrm{M}$ de ácido oxálico, $45 \mathrm{~V}$, 15 e $25^{\circ} \mathrm{C}$ respectivamente.

Os poros formados no processo de anodização das amostras $\mathrm{O}_{7}$ e $\mathrm{O}_{8}$ apresentam uma regularidade espacial no interior da estrutura porosa, a Figura 4.3 mostra imagens MEV das amostras $\mathrm{O}_{7}(A, B, C)$ e $\mathrm{O}_{8}(D, E, F)$ respectivamente. As Figuras 4.3(A) e (D) mostram que na superfície anodizada das amostras $\mathrm{O}_{7}$ e $\mathrm{O}_{8}$ os poros não apresentam uma distribuição periódica, já na camada interna observa-se poros bem ordenados e abertos, o qual indica que no interior da estrutura porosa apresentam poros auto-organizados. Na imagem da Figura 4.3 (B) verifica-se a existência de duas camadas de óxido, uma externa e outra interna. Já na Figura 4.3 
(E) é mostrado o perfil clivado da camada interna onde é possível obervar que os poros são perfeitamente paralelos. Assim, em resumo, foi observado que a camada externa contém poros distribuídos aleatoriamente e a camada interna contém os poros auto-organizados. Nas Figuras 4.3(C) e (F) mostra-se as imagens transversais dos óxidos crescidos das amostras $\mathrm{O}_{7}$ e $\mathrm{O}_{8}$ durante as duas horas de anodização atingindo cerca de $20 \mu \mathrm{m}$ (C) e $30 \mu \mathrm{m}(\mathrm{F})$, respectivamente. Estes resultados mostram que a espessura atingida em nosso processo é oito vezes maior do que aqueles processos de anodização de duas etapas e a baixas temperaturas $\left(0-5^{\circ} \mathrm{C}\right)$, o que é muito vantajoso com relação ao tempo de fabricação de estruturas com alta razão de aspecto. Assim, os filmes de AAP formados eletroquimicamente apresentam uma camada externa muito fina com poros distribuídos irregularmente e outra camada interna com poros regularmente distribuídos.
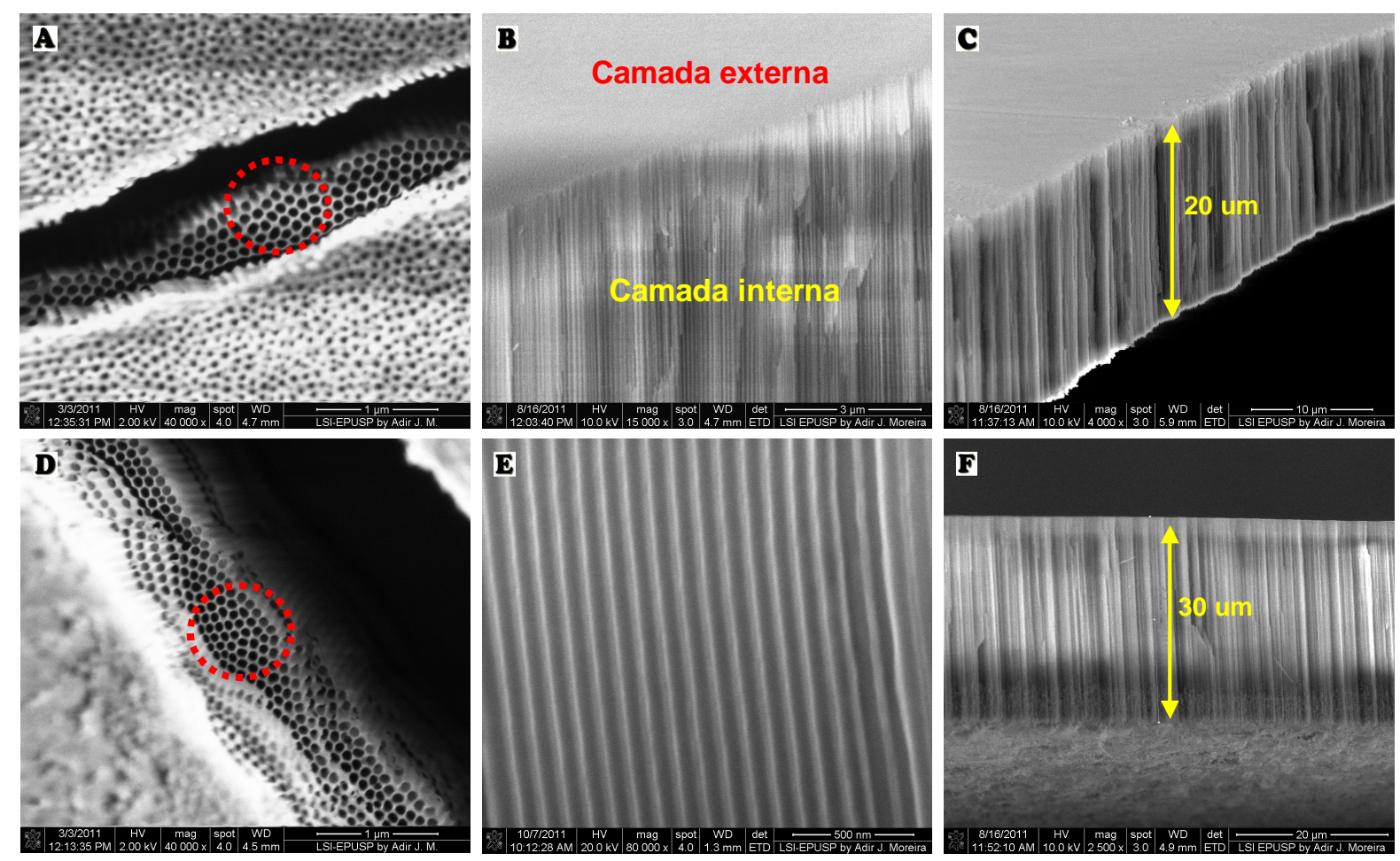

Figura 4.3. Imagens $M E V$ das amostras $\mathrm{O}_{7}(A, B, C)$ e $\mathrm{O}_{8}(D, E, F)$ de vista superior com rachadura e clivada $(A, D)$. Imagen transversal mostrando a camada interna e externa $(B)$, imagem com poros perfeitamente paralelos $(E)$, e imagens transversais das espessuras dos óxidos crescidos (C,F). 


\subsubsection{Efeito da Concentração do Eletrólito a Temperatura e Potencial} Constantes.

A Figura 4.4 mostra imagens MEV das superfícies anodizadas das amostras $\mathrm{O}_{3}, \mathrm{O}_{1}, \mathrm{R}_{8}$ e $\mathrm{O}_{2}$. Estas amostras foram fabricadas por uma etapa de anodização a uma temperatura de $20^{\circ} \mathrm{C}$, um potencial de $45 \mathrm{~V}$ e para várias concentrações de ácido oxálico: 0,05M (A); 0,15M (B); 0,3M (C) e 0,5M (D) respectivamente. Após a anodização de duas horas, as amostras foram submetidas a um processo de corrosão química em $1 \mathrm{M}$ de $\mathrm{H}_{3} \mathrm{PO}_{4}$ por um período de 60 minutos a $23^{\circ} \mathrm{C}$. Esse processo tinha como objetivo abrir os canais dos nanoporos.
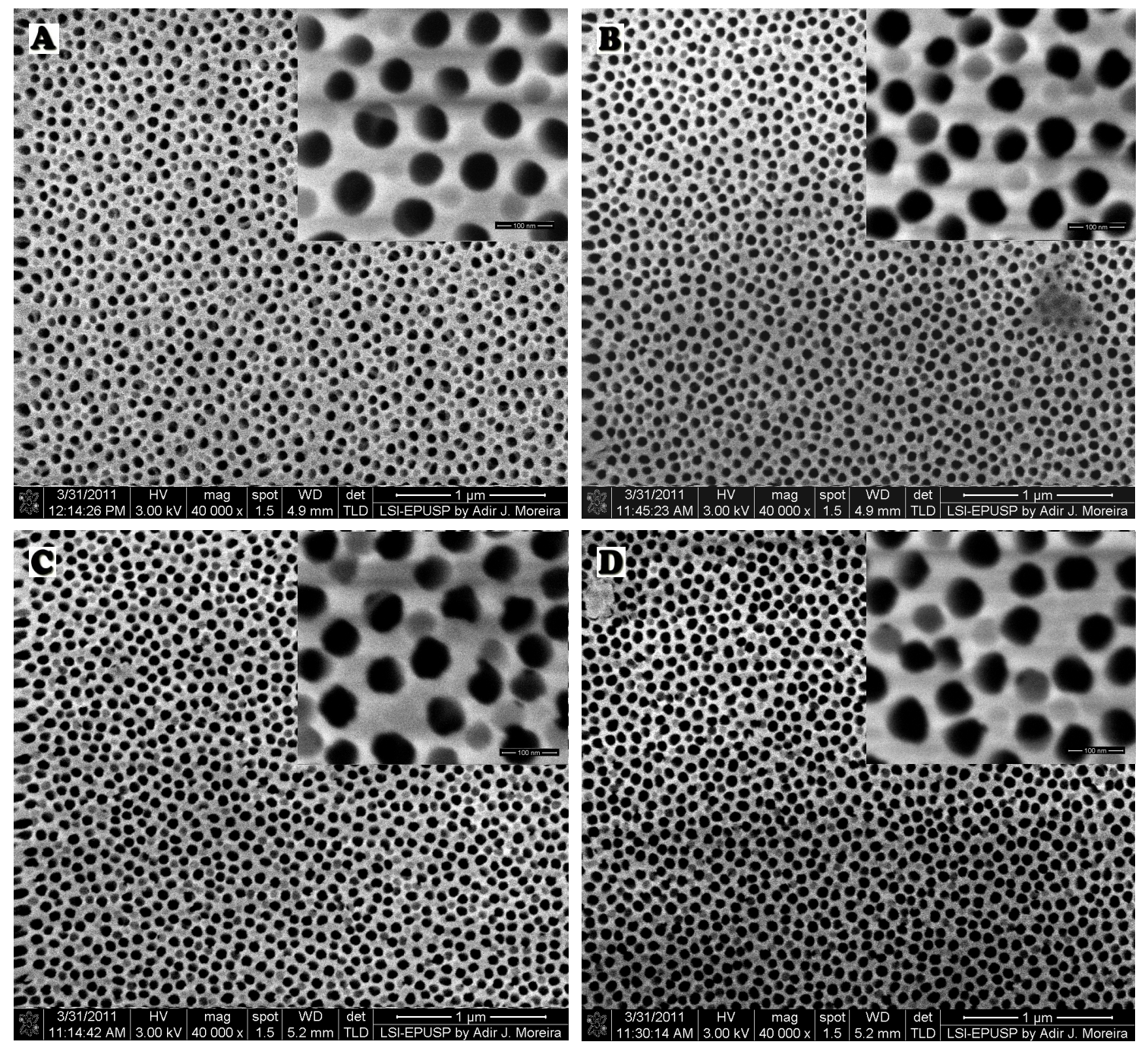

Figura 4.4. Imagens MEV das superfícies anodizadas das amostras $O_{3}, O_{1}, R_{8}$ e $O_{2}$. A anodização foi realizada a $20^{\circ} \mathrm{C}$ e $45 \mathrm{~V}$ para várias concentrações de ácido oxálico: $0,05 \mathrm{M}(\mathrm{A}), 0,15 \mathrm{M}(\mathrm{B}), 0,3 \mathrm{M}$ (C) e $0,5 \mathrm{M}(\mathrm{D})$. 
As imagens MEV mostraram que as estruturas porosas obtidas neste trabalho foram melhores que as reportadas na literatura no que se refere à distribuição espacial e circularidade dos nanoporos [37,38,89]. Esta melhoria foi devido a elevada temperatura de anodização empregada durante o processo eletroquímico $\left(20^{\circ} \mathrm{C}\right)$, se comparada com os processos clássicos de anodização que normalmente são realizados a baixas temperaturas $\left(0-5^{\circ} \mathrm{C}\right)$. O processo de corrosão química também é um fator importante na melhoria da circularidade e da uniformidade dos nanoporos. Este processo foi fundamental no desevolvimento do presente trabalho, especialmente na formação de nanoestruturas auto-organizadas de AAP e nanofios de alumina que serão discutidas mais para frente.

Poucos estudos foram reportados na literatura com respeito ao efeito da concentração sobre a morfologia da AAP. Nossos resultados mostram que quando a concentração do eletrólito aumenta se observa uma redução dos poros defeituosos na superfície anodizada, assim como também, uma melhoria na circularidade e na periodicidade dos nanoporos. Contudo, sua organização espacial começa a ser mais evidente. O surgimento dos poros defeituosos, na camada superficial, como já foi dito, corresponde a sítios de nucleação randomicamente distribuídos sobre a superfície e que posteriormente darão origem à formação dos poros. Essa aleatoriedade dos sítios de nucleação, onde os poros precursores começam a nascer, é o responsável pela não organização dos nanoporos na camada superficial.

A Figura 4.5 mostra as curvas cinéticas de crescimento no regime potenciostático das amostras $\mathrm{O}_{3}, \mathrm{O}_{1}, \mathrm{R}_{8}$ e $\mathrm{O}_{2}$ para os primeiros dois minutos e meio do tempo de anodização correspondentes às concentrações de 0,05M,0,15M,0,3M e 0,5M, respectivamente. Estas curvas cinéticas mostram um aumento na densidade de corrente quando a concentração da solução eletrolítica aumenta, mantendo a temperatura e o potencial constantes $\left(20^{\circ} \mathrm{C}, 45 \mathrm{~V}\right)$. De acordo com a lei de Faraday, a espessura da camada de óxido formado durante a anodização é diretamente proporcional à densidade de corrente e ao tempo de anodização, quando a eficiência faradaica é igual a 100\% [36]. Então, para um período de tempo de anodização de duas (2) horas, que é o nosso caso, a espessura da camada de óxido deve aumentar só com a densidade de corrente estacionária e, 
consequentemente, com a concentração do eletrólito. Portanto, concluímos que a taxa de crescimento do poro (que está relacionada à densidade de corrente em estado estacionário) aumenta com o aumento da concentração do eletrólito, mantendo a temperatura e o potencial de anodização constantes.

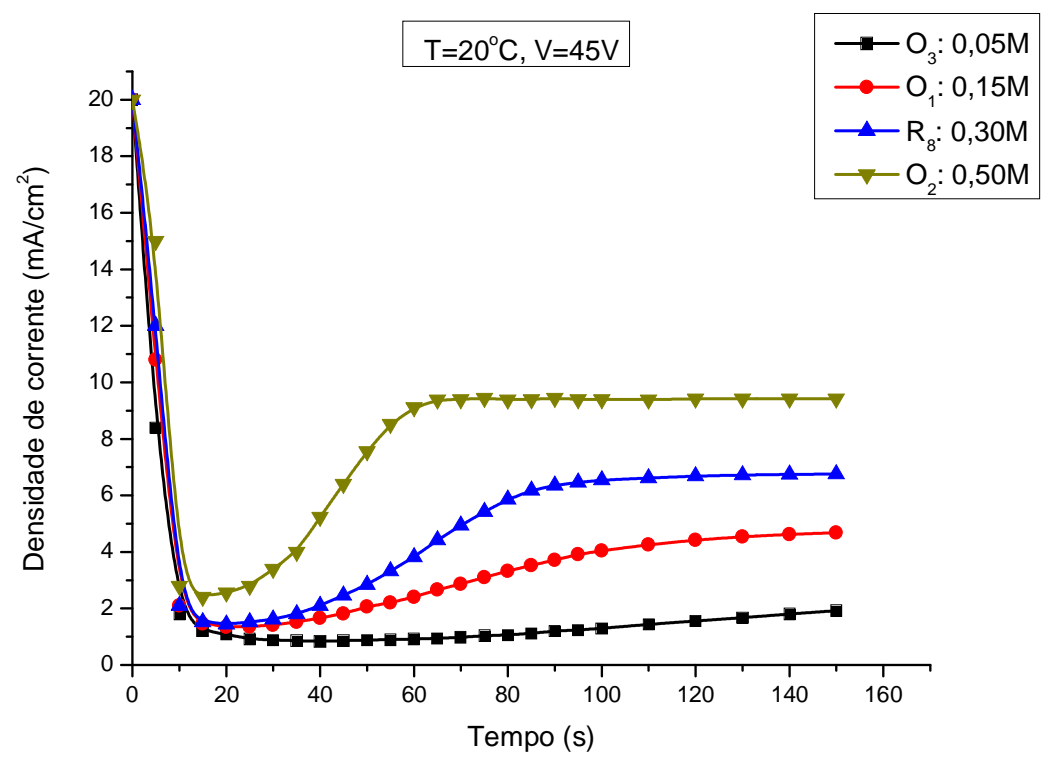

Figura 4.5. Curvas cinéticas de crescimento para as amostras $O_{3}, \mathrm{O}_{1}, \mathrm{R}_{8}$ e $\mathrm{O}_{2}$ correspondentes às várias concentrações de ácido oxálico.

Para mostrar a dependência da densidade de corrente estacionária com a concentração, na Figura 4.6 foi registrado as densidades de corrente em estado estacionário em função da concentração do eletrólito para duas temperaturas diferentes, $20^{\circ} \mathrm{C}$ e $30^{\circ} \mathrm{C}$ respectivamente, mantendo constante o potencial de anodização $(45 \mathrm{~V})$. As densidades de corrente em estado estacionário das amostras $\mathrm{O}_{3}, \mathrm{O}_{1}, \mathrm{R}_{8}, \mathrm{O}_{2}$ foram registradas na Figura 4.6 (linha tracejada com círculos pretos, $20^{\circ} \mathrm{C}$ ) e das amostras $\mathrm{K}_{1}, \mathrm{O}_{6}, \mathrm{P}_{6}, \mathrm{O}_{9}$ na Figura 4.6 (linha tracejada com triângulos pretos, $30^{\circ} \mathrm{C}$ ), estas densidades de corrente estacionárias mostraram-se constantes durante um período de duas horas. Observou-se uma demorada diminuição na densidade de corrente estacionária quando o tempo de anodização atingiu as duas horas. As curvas ajustadas mostram uma dependência polinomial de segundo grau crescente com a concentração e o perfil da curva mostra ser independente da temperatura do eletrólito. Quando a concentração é mantida constante, um aumento 
na densidade de corrente estacionária é observado ao aumentar a temperatura. Portanto, uma formação de AAP no regime potenciostático ocorre a uma densidade de corrente constante e, como conseqüência, a taxa de crescimento dos poros é constante. A partir do comportamento das curvas analisadas, é possivel afirmar que a taxa de crescimento dos poros cresce com o aumento da concentração e da temperatura do eletrólito.

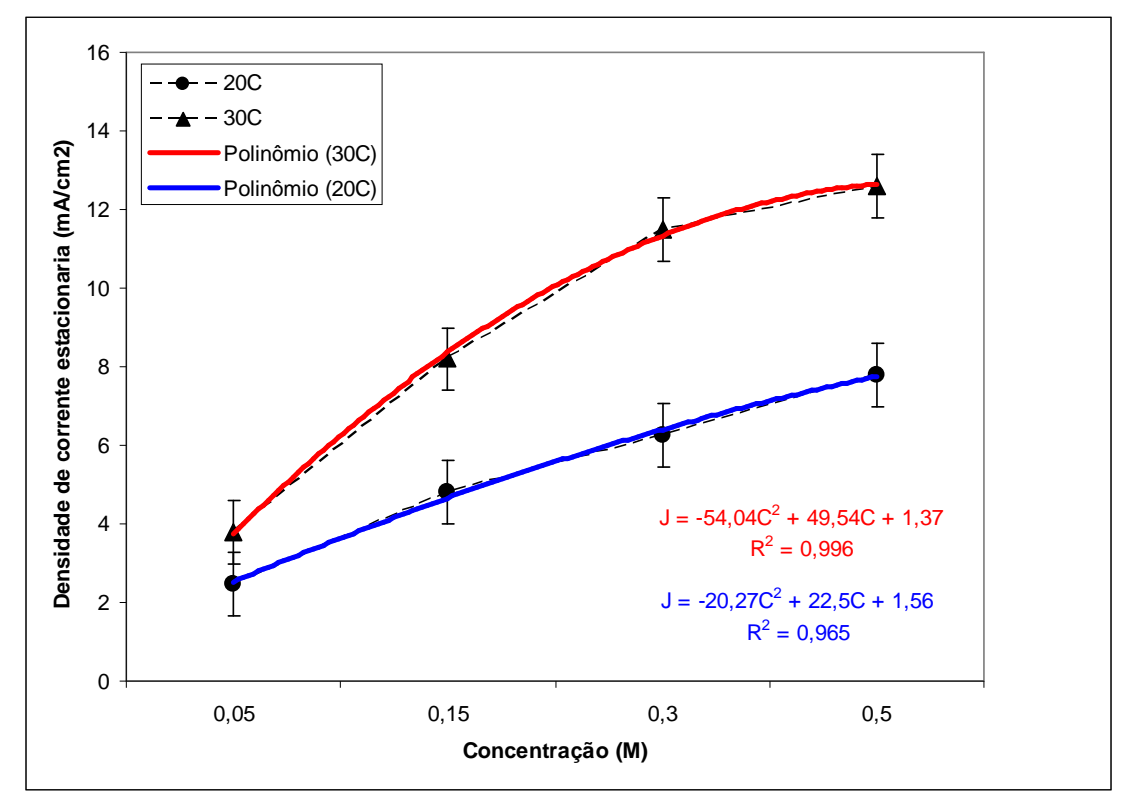

Figura 4.6. Densidade de corrente em estado estacionário em função da concentração do eletrólito, registradas das curvas cinéticas de anodização das amostras $\mathrm{O}_{3}, \mathrm{O}_{1}, \mathrm{R}_{8}, \mathrm{O}_{2}\left(20^{\circ} \mathrm{C}\right)$ e $\mathrm{K}_{1}, \mathrm{O}_{6}, \mathrm{P}_{6}, \mathrm{O}_{9}$ $\left(30^{\circ} \mathrm{C}\right)$ para um potencial de anodização constante de $45 \mathrm{~V}$.

A Figura 4.7 mostra a dependência da densidade de corrente em estado estacionário com a concentração para dois potenciais diferentes de 45 e $50 \mathrm{~V}$, mantendo a temperatura constante de $20^{\circ} \mathrm{C}$. A curva em linha tracejada com círculos pretos corresponde às densidades de corrente estacionárias das amostras $\mathrm{O}_{3}, \mathrm{O}_{1}, \mathrm{R}_{8}, \mathrm{O}_{2}$ e a curva em linha tracejada com triângulos pretos correspondem às densidades de corrente estacionárias das amostras $B_{2}, F_{6}, H_{2}, H_{6}$, respectivamente. O tempo de anodização foi de duas horas para todas as amostras. As curvas ajustadas mostram novamente uma dependência polinomial de segundo grau crescente da densidade de corrente estacionária com a concentração do eletrólito e o perfil da curva mostra ser independente do potencial de anodização. Quando a 
concentração é mantida constante, um aumento na densidade de corrente estacionária é observada ao aumentar o potencial. Portanto, a taxa de crescimento do poro também cresce com o aumento do potencial de anodização.

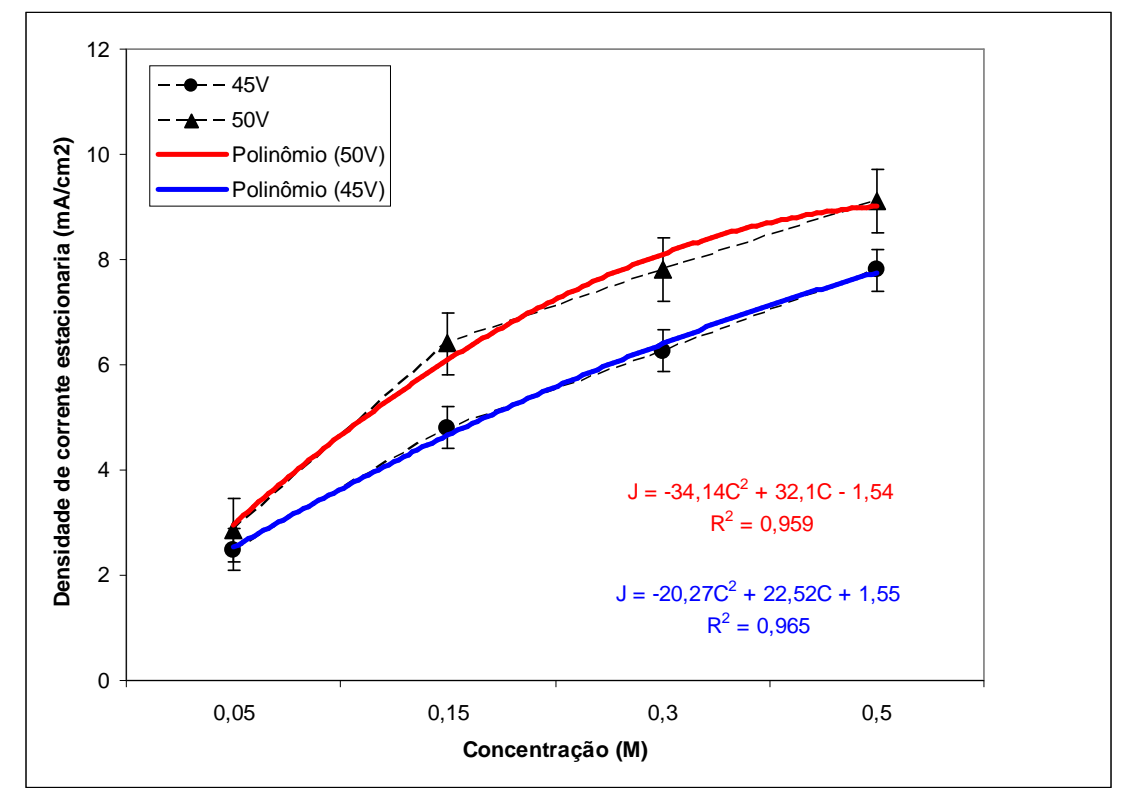

Figura 4.7. Densidade de corrente em estado estacionário en função da concentração do eletrólito registrada das curvas cinéticas de anodização das amostras $\mathrm{O}_{3}, \mathrm{O}_{1}, \mathrm{R}_{8}, \mathrm{O}_{2}(45 \mathrm{~V})$ e $\mathrm{B}_{2}, \mathrm{~F}_{6}, \mathrm{H}_{2}, \mathrm{H}_{6}$ (50V) para uma temperatura constante de $20^{\circ} \mathrm{C}$.

Embora a morfologia dos poros nas superfícies anodizadas das amostras $\mathrm{O}_{3}$, $\mathrm{O}_{1}, \mathrm{R}_{8}, \mathrm{O}_{2}$ (Figura 4.4) não apresentem uma homogeneidade nem uma boa regularidade, uma análise quantitativa das estruturas porosas foi realizada a partir das imagens MEV com o Software GRANUL desenvolvido para este propósito pelo grupo do professor Hae [183]. Os parâmetros extraídos nesta análise foram: o tamanho dos poros, a distribuição dos poros e a classificação dos poros de diferentes tamanhos. A Figura 4.8 mostra o diagrama de distribuição 3D do diâmetro dos poros $\left(D_{p}\right)$ processados a partir das imagens MEV da Figura 4.4. Este gráfico foi construído a partir da classificação de poros distribuídos em sete (7) classes diferentes, onde cada classe corresponde a poros de um diâmetro específico. Para cobrir todos os tamanhos dos poros foi necessário considerar uma faixa de diâmetros compreendida entre 30 e 100 nm. Observa-se na Figura 4.8 que, independentemente da concentração da solução eletrolítica, a maior densidade de 
poros concentra-se em poros com diâmetros entre 65 e $75 \mathrm{~nm}$. As amostras $\mathrm{O}_{3}, \mathrm{O}_{1}$, $\mathrm{R}_{8}$ e $\mathrm{O}_{2}$ apresentaram poros com diâmetros médios iguais a 64, 64, 66 e $67 \mathrm{~nm}$ respectivamente. Para todas as amostras a distância entre poros vizinhos foi da ordem de $110 \mathrm{~nm}$ aproximadamente. Estes resultados mostram pouca ou menhuma dependência do diâmetro médio dos poros sobre a concentração do eletrólito, mas as imagens MEV destas amostras sugerem que a concentração do eletrólito define a circularidade e organização dos poros (Figura 4.4). Na figura 4.9 é estudada a dependência do diâmetro médio dos poros das amostras $O_{3}, O_{1}, R_{8}, O_{2}$ com a concentração do eletrólito. Observa-se que o diâmetro médio não é influenciado pelo aumento na concentração.

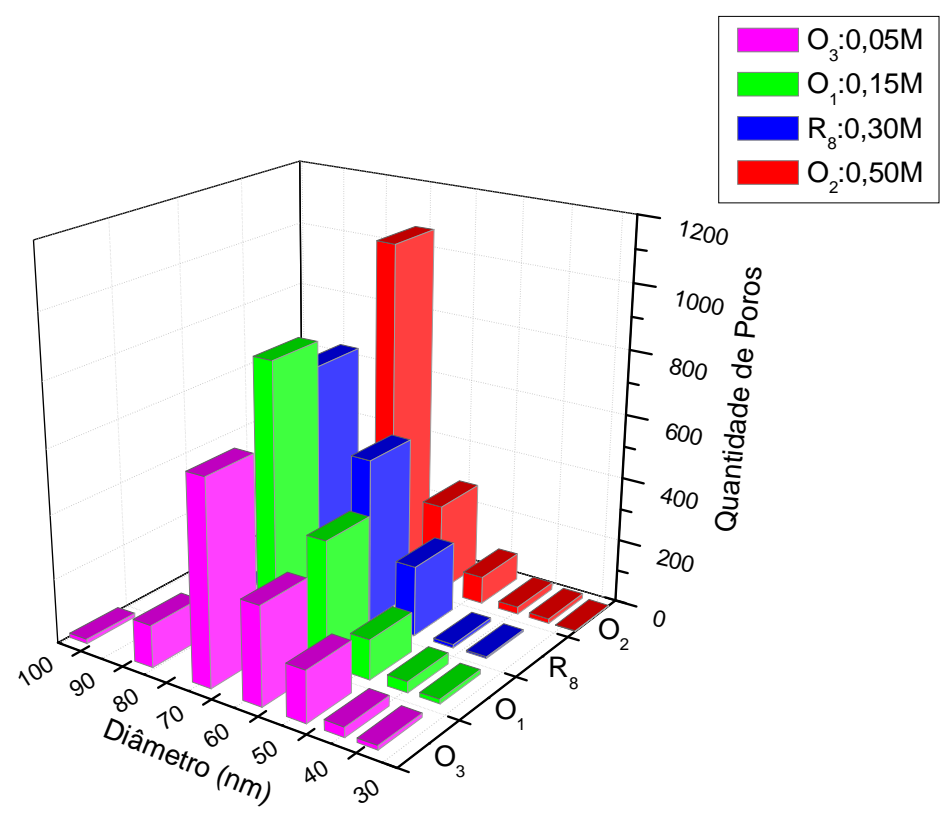

Figura 4.8. Diagrama de distribuição $3 \mathrm{D}$ do diâmetro dos poros para as amostras $\mathrm{O}_{3}(0,05 \mathrm{M}), \mathrm{O}_{1}$ $(0,15 \mathrm{M}), \mathrm{R}_{8}(0,3 \mathrm{M})$ e $\mathrm{O}_{2}(0,5 \mathrm{M})$. 


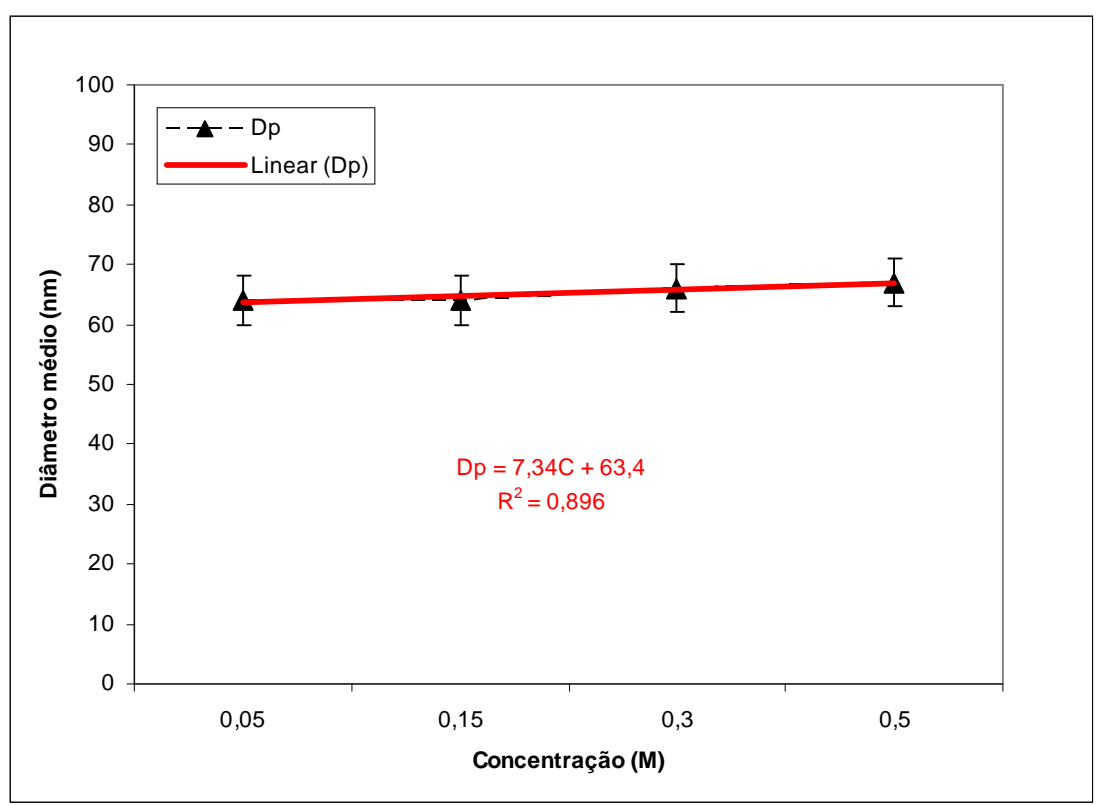

Figura 4.9. Influência da concentração do eletrólito sobre o diâmetro médio dos poros para as amostras $\mathrm{O}_{3}, \mathrm{O}_{1}, \mathrm{R}_{8}, \mathrm{O}_{2}$.

Em conclusão, nenhum efeito da concentração sobre o diâmetro médio dos poros da AAP foi observado, mas existe uma influência na organização e na circularidade dos nanoporos. Em relação à densidade de corrente, esta aumenta com a concentração independentemente da temperatura e do potencial de anodização.

\subsubsection{Efeito da Temperatura a Concentração e Potencial Constantes}

A Figura 4.10 mostra as imagens MEV das superfícies anodizadas das amostras $P_{3}, R_{8}, P_{4}$ e $P_{6}$. Estas estruturas foram fabricadas por uma etapa de anodização utilizando-se uma solução eletrolítica de $\mathrm{H}_{2} \mathrm{C}_{2} \mathrm{O}_{4}(0,3 \mathrm{M})$ e um potencial de $45 \mathrm{~V}$. As temperaturas de anodização utilizadas foram de $15^{\circ} \mathrm{C}(\mathrm{A}), 20^{\circ} \mathrm{C}(\mathrm{B})$, $25^{\circ} \mathrm{C}$ (C) e $30^{\circ} \mathrm{C}$ (D). Após a anodização de duas horas, as amostras foram submetidas a um processo de corrosão química em $1 \mathrm{M} \mathrm{H}_{3} \mathrm{PO}_{4}$ durante um período de 60 minutos a temperatura de $23^{\circ} \mathrm{C}$ com o objetivo de abrir os canais dos nanoporos. 

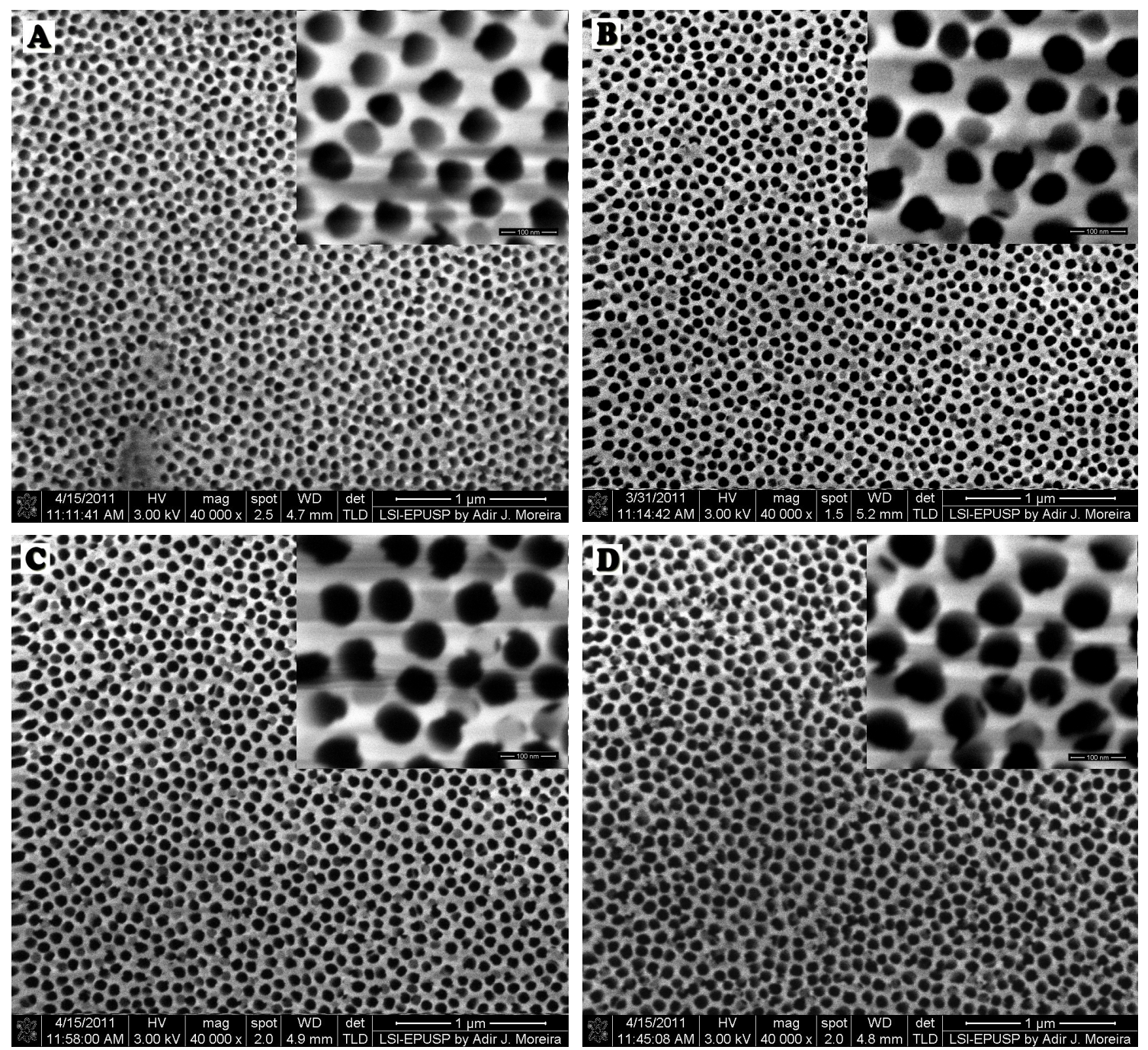

Figura 4.10. Imagens $M E V$ das superfícies anodizadas das amostras $P_{3}(A), R_{8}(B), P_{4}(C)$ e $P_{6}(D)$ depois de uma corrosão química de 60 minutos a uma temperatura de $23^{\circ} \mathrm{C}$. A anodização foi realizada em $0,3 \mathrm{M}$ de acido oxálico a $45 \mathrm{~V}$ para várias temperaturas: $15^{\circ} \mathrm{C}\left(\mathrm{P}_{3}\right), 20^{\circ} \mathrm{C}\left(\mathrm{R}_{8}\right), 25^{\circ} \mathrm{C}\left(\mathrm{P}_{4}\right)$ e $30^{\circ} \mathrm{C}\left(\mathrm{P}_{6}\right)$.

Como pode ser observado na Figura 4.10, os nanoporos sobre a superfície anodizada estão distribuídos randomicamente, e a regularidade dos domínios ordenados não parece melhorar com o aumento da temperatura. Similarmente às amostras anteriormente analizadas a camada superficial apresenta poros randomicamente distribuídos, mas a camada mais profunda apresenta poros regularmente distribuídos. É observado também que o diâmetro dos nanoporos aumenta quando a temperatura do eletrólito aumenta, mesmo que não haja 
nenhuma melhora com respeito à organização e a sua circularidade. $O$ longo período de tempo de corrosão química (60 minutos aproximadamente) a que foram submetidas as amostras, após a anodização, originou uma maior abertura dos poros, facilitando a obtenção de imagens MEV bem definidas.

As curvas cinéticas de crescimento dos poros das amostras $P_{3}, R_{8}, P_{4}$ e $P_{6}$ monitoradas durante os primeiros 150 segundos de anodização são mostradas na Figura 4.11. A anodização foi realizada em $0,3 \mathrm{M}$ de ácido oxálico, um potencial de $45 \mathrm{~V}$ e para várias temperaturas do eletrólito: $15^{\circ} \mathrm{C}\left(\mathrm{P}_{3}\right), 20^{\circ} \mathrm{C}\left(\mathrm{R}_{8}\right), 25^{\circ} \mathrm{C}\left(\mathrm{P}_{4}\right)$ e $30^{\circ} \mathrm{C}$ $\left(\mathrm{P}_{6}\right)$. As curvas mostram que com o aumento da temperatura há um aumento na densidade de corrente estacionária, mantendo a concentração e o potencial de anodização constantes (0,3M e 45V). De acordo com a lei de Faraday, e para um período de tempo de anodização de 2 horas, a espessura da camada de óxido aumenta com a densidade de corrente e, consequentemente, com a temperatura do eletrólito (Figura 4.11). Portanto, a taxa de crescimento dos poros aumenta com a temperatura, mantendo a concentração e o potencial de anodização constantes.

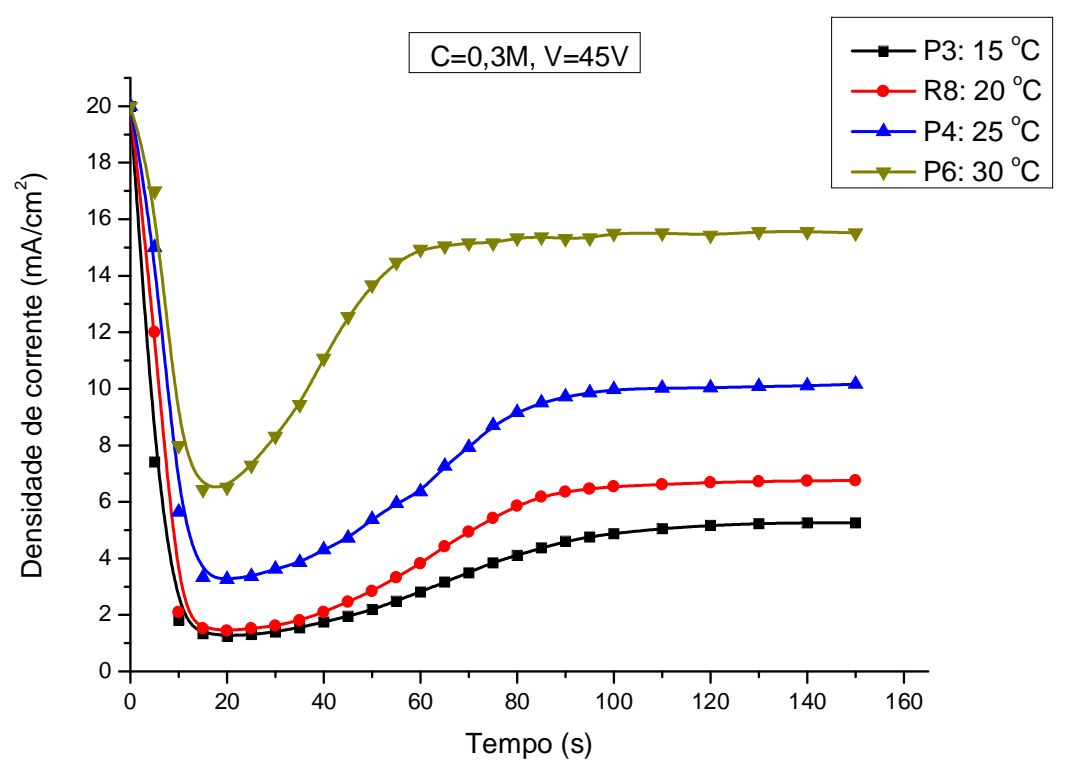

Figura 4.11. Curvas cinéticas de crescimento dos poros das amostras $P_{3}, R_{8}, P_{4}$ e $P_{6}$ para os primeiros dois minutos e meio de anodização realizados em $0,3 \mathrm{M}$ de ácido oxálico, $45 \mathrm{~V}$, e para várias temperaturas do eletrólito: $15^{\circ} \mathrm{C}\left(\mathrm{P}_{3}\right), 20^{\circ} \mathrm{C}\left(\mathrm{R}_{8}\right), 25^{\circ} \mathrm{C}\left(\mathrm{P}_{4}\right)$ e $30^{\circ} \mathrm{C}\left(\mathrm{P}_{6}\right)$. 
A Figura 4.12 mostra a dependência da densidade de corrente estacionária com a temperatura para duas concentrações diferentes $0,3 \mathrm{M}$ e $0,5 \mathrm{M}$, mantendo 0 potencial de anodização constante (45V). As densidades de corrente em estado estacionário foram obtidas das curvas cinéticas de anodização das amostras $P_{3}, R_{8}$, $\mathrm{P}_{4}, \mathrm{P}_{6}$ (curva tracejada com círculos pretos da Figura 4.12) e $\mathrm{O}_{7}, \mathrm{O}_{2}, \mathrm{O}_{8}, \mathrm{O}_{9}$ (curva tracejada com triângulos pretos da Figura 4.12), para um tempo de anodização de duas horas. As curvas ajustadas mostram que a densidade de corrente em estado estacionário tem uma dependência exponencial crescente com a temperatura, e o perfil da curva é independente da concentração do eletrólito. Quando a temperatura é mantida constante, um aumento apreciável na densidade de corrente estacionária é observada ao aumentar a concentração, isso confirma os resultados obtidos anteriormente em relação ao efeito da concentração do eletrólito. Portanto, a taxa de crescimento dos poros cresce exponencialmente com a temperatura do eletrólito mantendo constantes os outros parâmetros de anodização.

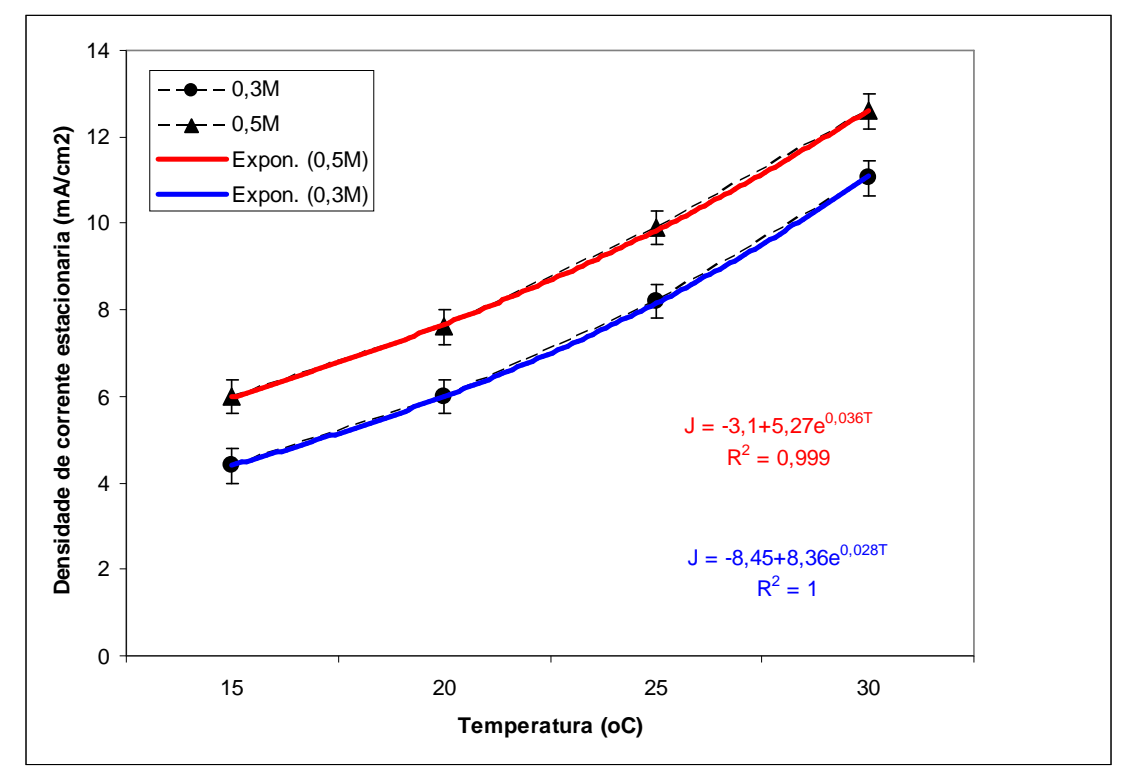

Figura 4.12. Densidade de corrente estacionária em função da temperatura do eletrólito para duas concentrações diferentes de 0,3 e $0,5 \mathrm{M}$. As curvas correspondem às amostras $P_{3}, R_{8}, P_{4}, P_{6}(0,3 \mathrm{M})$ e $\mathrm{O}_{7}, \mathrm{O}_{2}, \mathrm{O}_{8}, \mathrm{O}_{9}(0,5 \mathrm{M})$ para um potencial de anodização constante de $45 \mathrm{~V}$.

Por outro lado, a Figura 4.13 mostra a dependência da densidade de corrente estacionária com a temperatura para dois potenciais de anodização diferentes, 45 e 
$50 \mathrm{~V}$, mantendo a concentração constante de $0,3 \mathrm{M}$. As densidades de corrente em estado estacionário foram obtidas das curvas cinéticas de anodização das amostras $P_{3}, R_{8}, P_{4}, P_{6}$ (curva tracejada com círculos pretos da Figura 4.13) e $\mathrm{H}_{1}, \mathrm{H}_{2}, \mathrm{H}_{3}, \mathrm{H}_{4}$ (curva tracejada com triângulos pretos da Figura 4.13), para um tempo de anodização de duas horas. Estas curvas também mostram uma dependência exponencial crescente com a temperatura e o perfil da curva é independente do potencial de anodização. Quando a temperatura é mantida fixa, um aumento apreciável na densidade de corrente estacionária é observada ao aumentar o potencial. Portanto, a taxa de crescimento do poro também cresce com o aumento do potencial de anodização.

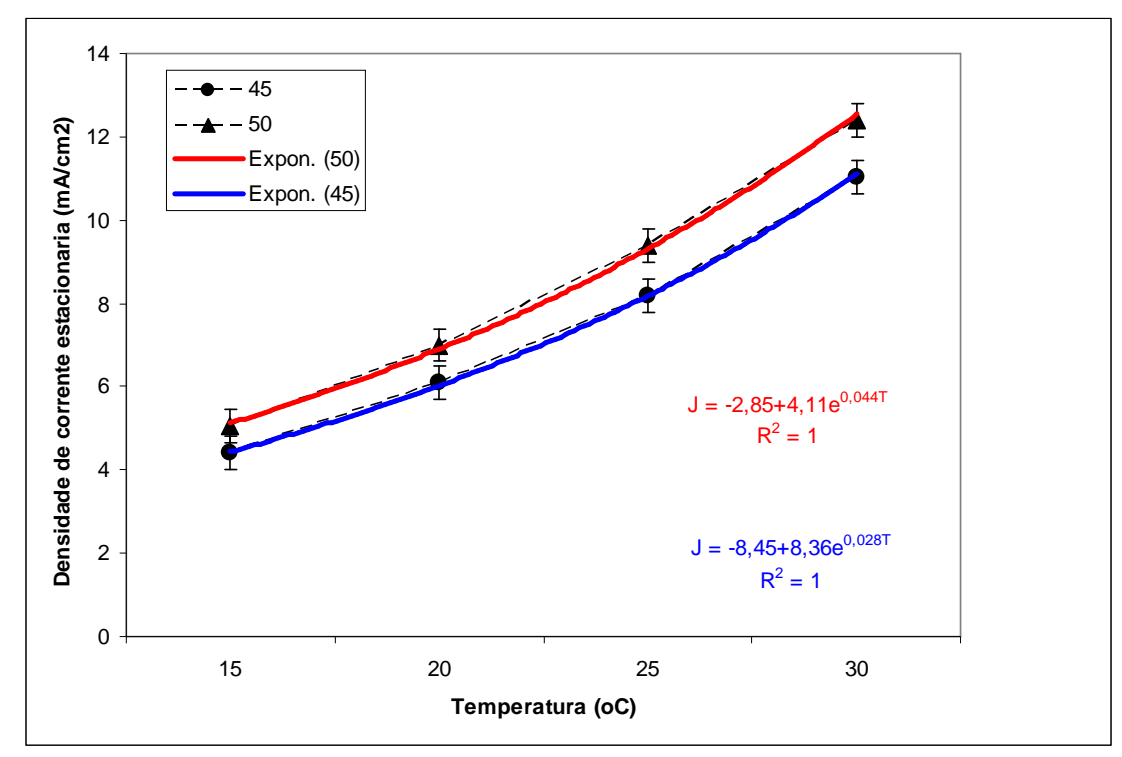

Figura 4.13. Densidade de corrente estacionária em função da temperatura do eletrólito para dois potenciais diferentes de 45 e $50 \mathrm{~V}$. As curvas correspondem às amostras $P_{3}, R_{8}, P_{4}, P_{6}(45 \mathrm{~V})$ e $H_{1}$, $\mathrm{H}_{2}, \mathrm{H}_{3}, \mathrm{H}_{4}(50 \mathrm{~V})$ para uma concentração constante de $0,3 \mathrm{M}$.

A Figura 4.14 mostra o diagrama de distribuição 3D do diâmetro dos poros processados das imagens MEV da Figura 4.10 utilizando o software GRANUL. Todos os valores obtidos de $D_{p}$ foram classificados em oito (8) classes que cobrem toda a faixa de diâmetros dos poros $(30-110 \mathrm{~nm})$. A fração dominante de poros apresenta diâmetros entre 70 e $80 \mathrm{~nm}$. $O$ valor do diâmetro médio dos poros $\left(d_{p}\right)$ para as amostras $P_{3}, R_{8}, P_{4}$ e $P_{6}$ foram de 66, 70, 74 e $79 \mathrm{~nm}$ respectivamente. Como pode ser observado no diagrama de barras 3D da Figura 4.14, só as duas 
primeiras amostras (P3 e R8) apresentam quase a mesma distribuição de poros e um mesmo diâmetro médio. No entanto, para temperaturas superiores a $20^{\circ} \mathrm{C} O$ histograma de distribuição dos nanoporos mostra um deslocamento do diâmetro médio para valores maiores. A dependência do diâmetro médio dos poros das nanoestruturas de AAP correspondentes às amostras $P_{3}, R_{8}, P_{4}$ e $P_{6}$ com a temperatura é mostrado na Figura 4.15, onde é observada uma dependência linear do diâmetro médio dos poros com a temperatura do eletrólito. É importante mencionar que a temperatura não é um parâmetro significativo com relação ao diâmetro médio dos poros, porque os diâmetros dos poros variam lentamente ao aumentar a temperatura.

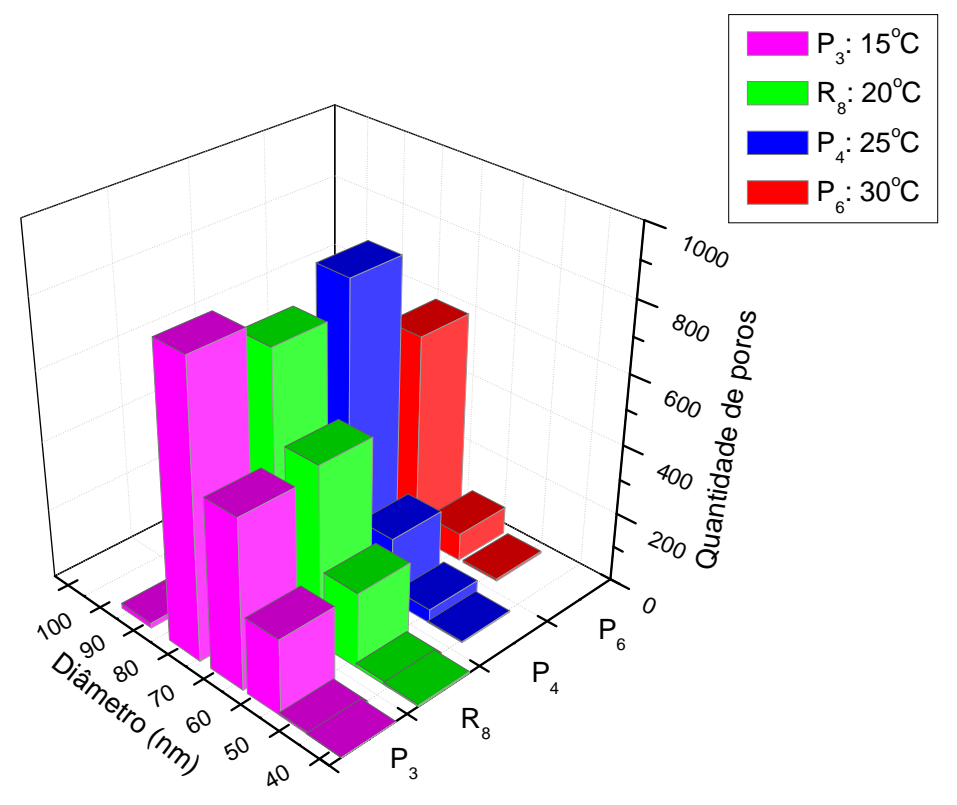

Figura 4.14. Diagrama de distribuição $3 D$ do diâmetro dos poros das amostras $P_{3}, R_{8}, P_{4}$ e $P_{6}$ correspondentes as temperaturas do eletrólito de $15^{\circ} \mathrm{C}, 20^{\circ} \mathrm{C}, 25^{\circ} \mathrm{C}$ e $30^{\circ} \mathrm{C}$, respectivamente. 


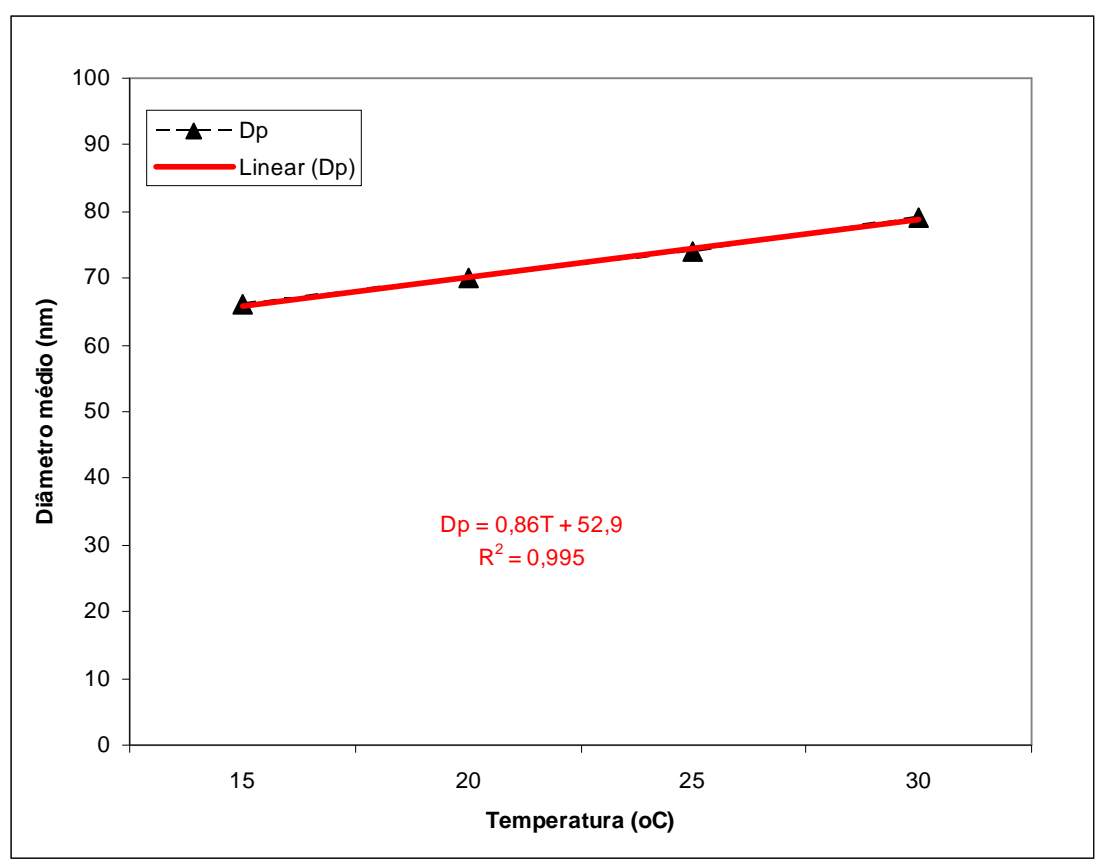

Figura 4.15. Influência da temperatura do eletrólito sobre o diâmetro médio dos poros das amostras $P_{3}, R_{8}, P_{4}$ e $P_{6}$.

Concluímos que a dependência do diâmetro médio dos nanoporos com a temperatura é ligeramente linear e nenhuma influência na organização e na circularidade dos nanoporos foi observado com o aumento da temperatura. Com respeito à densidade de corrente, esta aumenta exponencialmente com a temperatura independentemente da concentração e do potencial de anodização.

\subsubsection{Efeito do Potencial a Temperatura e Concentração Constantes}

A Figura 4.16 mostra imagens MEV das superfícies anodizadas das amostras $D_{2}, P_{7}, R_{8}$ e $H_{2}$. Estas estruturas foram fabricadas por uma etapa de anodização numa solução eletrolítica de $\mathrm{H}_{2} \mathrm{C}_{2} \mathrm{O}_{4}(0,3 \mathrm{M})$, a uma temperatura de $20^{\circ} \mathrm{C}$. Neste caso, foi controlado o potencial de anodização em valores de $35 \mathrm{~V}$ (A), $40 \mathrm{~V}(\mathrm{~B}), 45$ $\mathrm{V}(\mathrm{C})$ e $50 \mathrm{~V}$ (D). Após a anodização de duas horas, as amostras foram submetidas

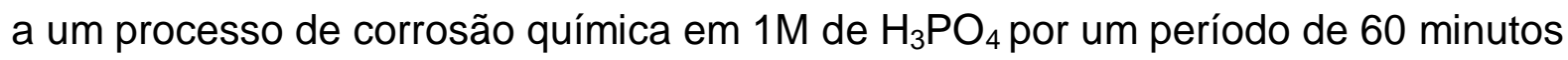
a temperatura de $23^{\circ} \mathrm{C}$ com o objetivo de abrir os canais dos nanoporos. 

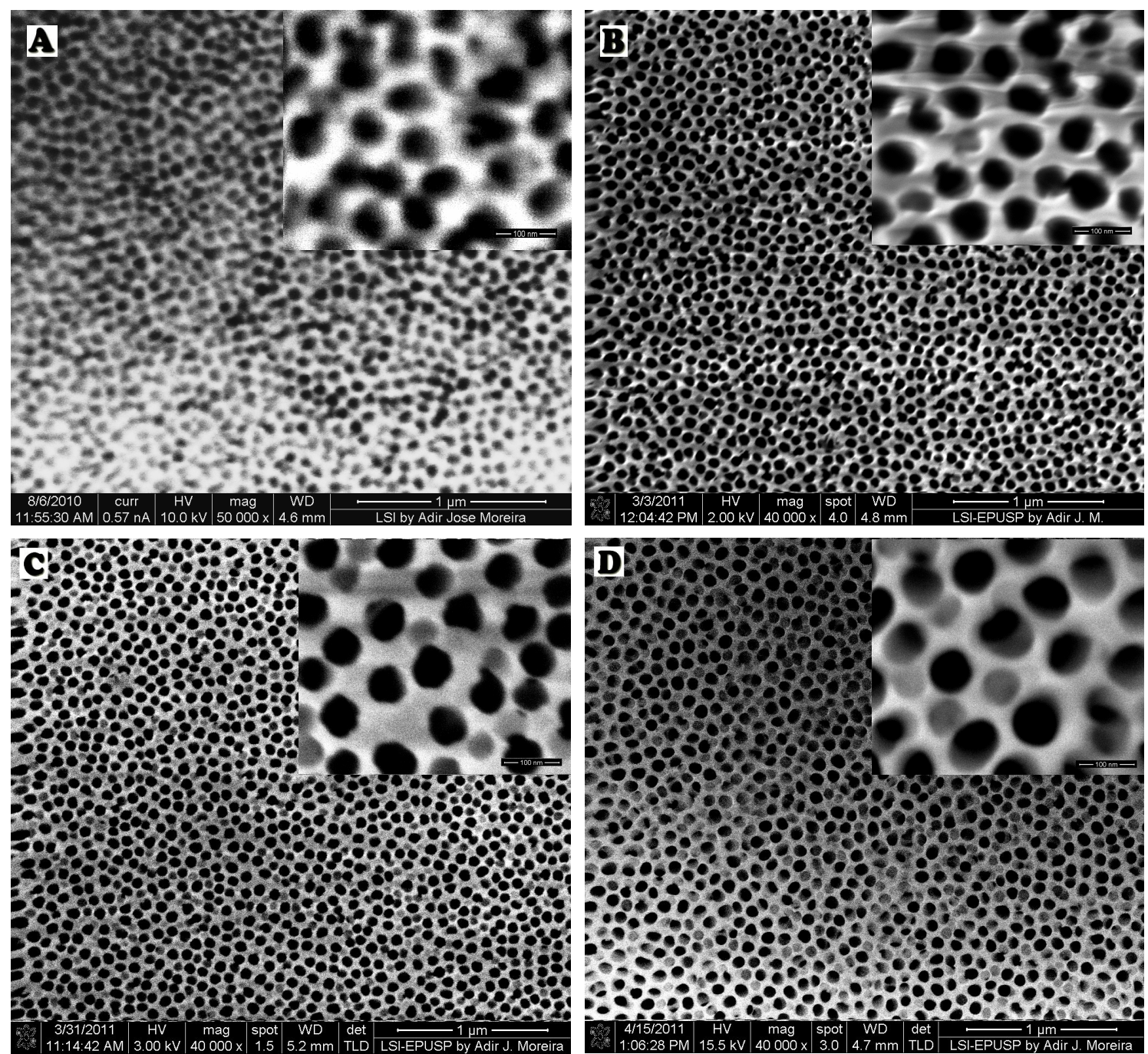

Figura 4.16. Imagens $M E V$ das superfícies anodizadas das amostras $D_{2}(A), P_{7}(B), R_{8}(C)$ e $H_{2}(D)$ depois de um tempo de corrosão química de 60 minutos a temperatura de $23^{\circ} \mathrm{C}$. A anodização foi realizada em $0,3 \mathrm{M}$ de ácido oxálico e uma temperatura de $20^{\circ} \mathrm{C}$ para vários potenciais de anodização: 35V (D2), 40V (P7), 45V (R8) e 50V (H2).

$\mathrm{Na}$ Figura 4.16(A) observa-se que a amostra $D_{2}$ obtida com baixa tensão de polarização (35V) apresenta uma distribuição de poros superficiais muito irregulares se comparado às das outras amostras (Figuras 4.16B, 4.16C e 4.16D). Esse comportamento mostra que as baixas tensões de polarização desfavorecem uma organização regular dos poros superficiais. No caso da amostra $\mathrm{H}_{2}$ (Figura 4.16D) que foi obtida com uma alta tensão de polarização (50V) observa-se que esta apresenta uma estrutura porosa irregular com respeito ao diâmetro dos poros, 
apresentando poros com diâmetros grandes e pequenos não bem definidos em profundidade. Já para potencias intermediários entre 40 e $45 \mathrm{~V}$ (Figuras 4.16B e 4.16C), observa-se uma maior regularidade, uniformidade e circularidade dos nanoporos, especialmente a amostra $R_{8}$. Este resultado sugere a existência de uma faixa de potencial de anodização para a formação de poros regularmente distribuídos na superfície anodizada.

Por outra parte, a Figura 4.17 mostra as curvas cinéticas de anodização no regime potenciostático correspondente às amostras $D_{2}, P_{7}, R_{8}$ e $H_{2}$, respectivamente. A evolução temporal da densidade de corrente foi monitorada durante os primeriros dois minutos e meio, tempo suficiente para observar as diferentes regiões transitórias do processo de anodização. As curvas mostram que com o aumento do potencial de anodização há um aumento na densidade de corrente estacionária. Neste caso, foram mantidas constantes a concentração e a temperatura de anodização $\left(0,3 \mathrm{M}\right.$ e $\left.20^{\circ} \mathrm{C}\right)$. Portanto, a taxa de crescimento dos poros aumenta com o potencial de anodização.

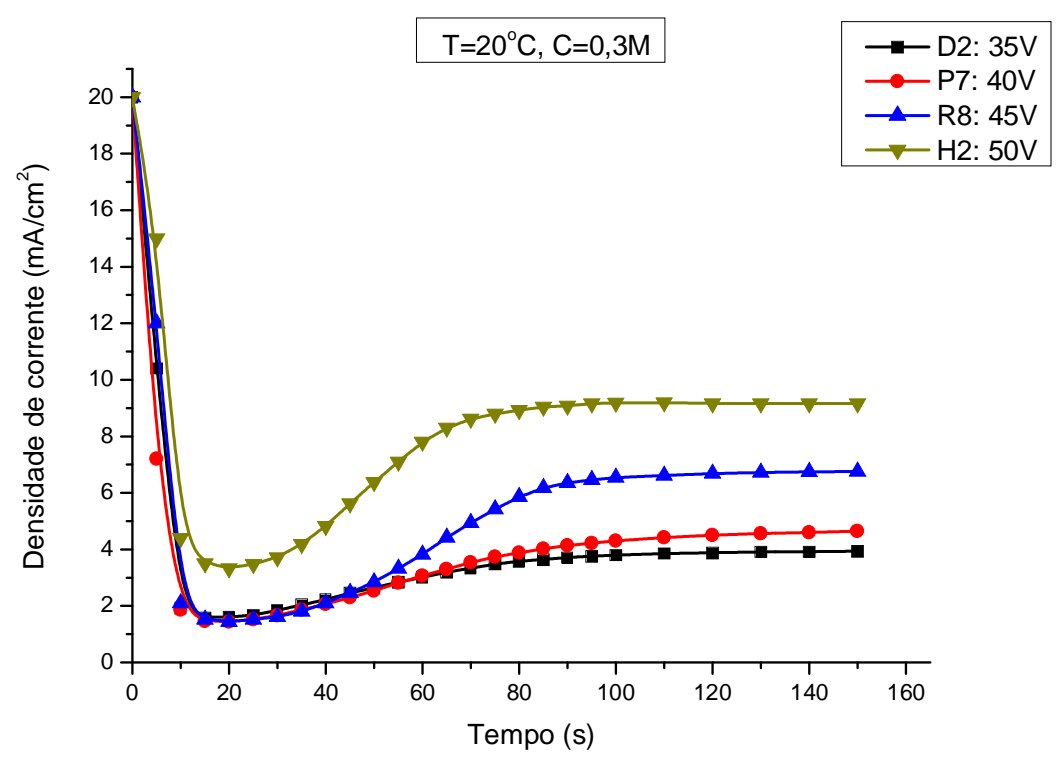

Figura 4.17. Densidade de corrente como função do tempo de anodização das amostras $D_{2}, P_{7}, R_{8}$ e $\mathrm{H}_{2}$ para os primeiros dois minutos e meio de anodização, realizados em $0,3 \mathrm{M}$ de ácido oxálico e $20^{\circ} \mathrm{C}$ para vários potenciais de anodização de $35,40,45$ e 50V, respectivamente. 
Para mostrar a dependência da densidade de corrente em estado estacionário com o potencial de anodização, na Figura 4.18 foi graficado as densidades de corrente estacionária em função do potencial de anodização para duas concentrações diferentes de 0,3 e 0,5M, mantendo constante a temperatura de anodização $\left(20^{\circ} \mathrm{C}\right)$. As densidades de corrente em estado estacionário foram obtidas das curvas cinéticas de anodização das amostras $D_{2}, P_{7}, R_{8}, H_{2}$ (linha tracejada com círculos pretos da Figura 4.18) e $\mathrm{D}_{6}, \mathrm{E}_{2}, \mathrm{O}_{2}, \mathrm{H}_{6}$ (linha tracejada com triângulos pretos da Figura 4.18). As curvas ajustadas mostram uma dependência exponencial crescente com o potencial de anodização, e o perfil da curva é independente da concentração do eletrólito. Quando o potencial é mantido constante, um aumento na densidade de corrente estacionária é observada ao aumentar a concentração do eletrólito, isso confirma os resultados obtidos anteriormente com respeito ao efeito da concentração. Portanto, a taxa de crescimento dos poros aumenta exponencialmente com o potencial de anodização, independente dos outros parâmetros de anodização.

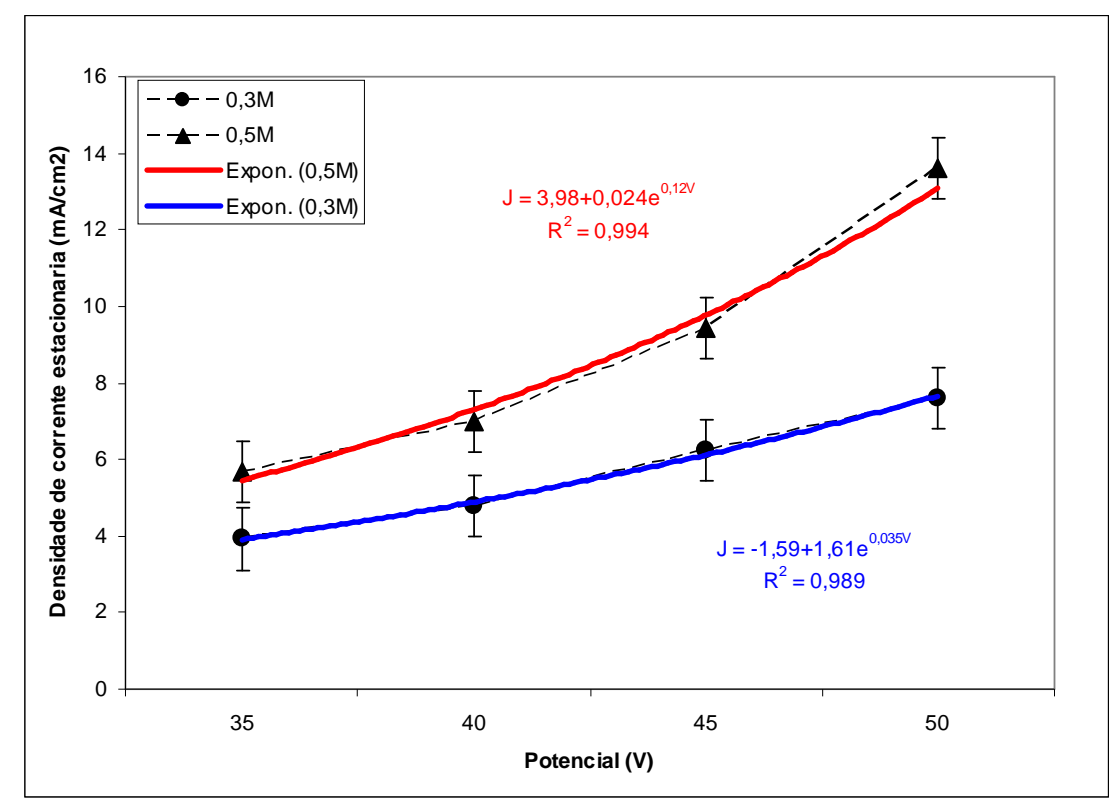

Figura 4.18. Densidade de corrente estacionária em função do potencial de anodização, registradas das curvas cinéticas de anodização das amostras $D_{2}, P_{7}, R_{8}, H_{2}(0,3 M)$ e $D_{6}, E_{2}, O_{2}, H_{6}(0,5 M)$ para uma temperatura constante de $20^{\circ} \mathrm{C}$. 
Por outro lado, a Figura 4.19 mostra a dependência da densidade de corrente estacionária com o potencial de anodização para duas temperaturas diferentes de 20 e $25^{\circ} \mathrm{C}$, mantendo a concentração do eletrólito constante em $0,3 \mathrm{M}$. As densidades de corrente em estado estacionário foram obtidas das curvas cinéticas de anodização das amostras $D_{2}, P_{7}, R_{8}$ e $H_{2}$ (linha tracejada com círculos pretos da Figura 4.19) e $D_{3}, P_{8}, P_{4}, H_{3}$ (linha tracejada com triângulos pretos da Figura 4.19), em todos os casos o tempo de anodização foi de duas horas. Como podem ser observadas, as curvas ajustadas também mostram uma dependência exponencial crescente com o potencial de anodização e o perfil da curva é independente da temperatura. Quando o potencial é mantido fixo, um aumento na densidade de corrente estacionária é observado ao aumentar a temperatura, isso confirma os resultados obtidos anteriormente com respeito ao efeito da temperatura.

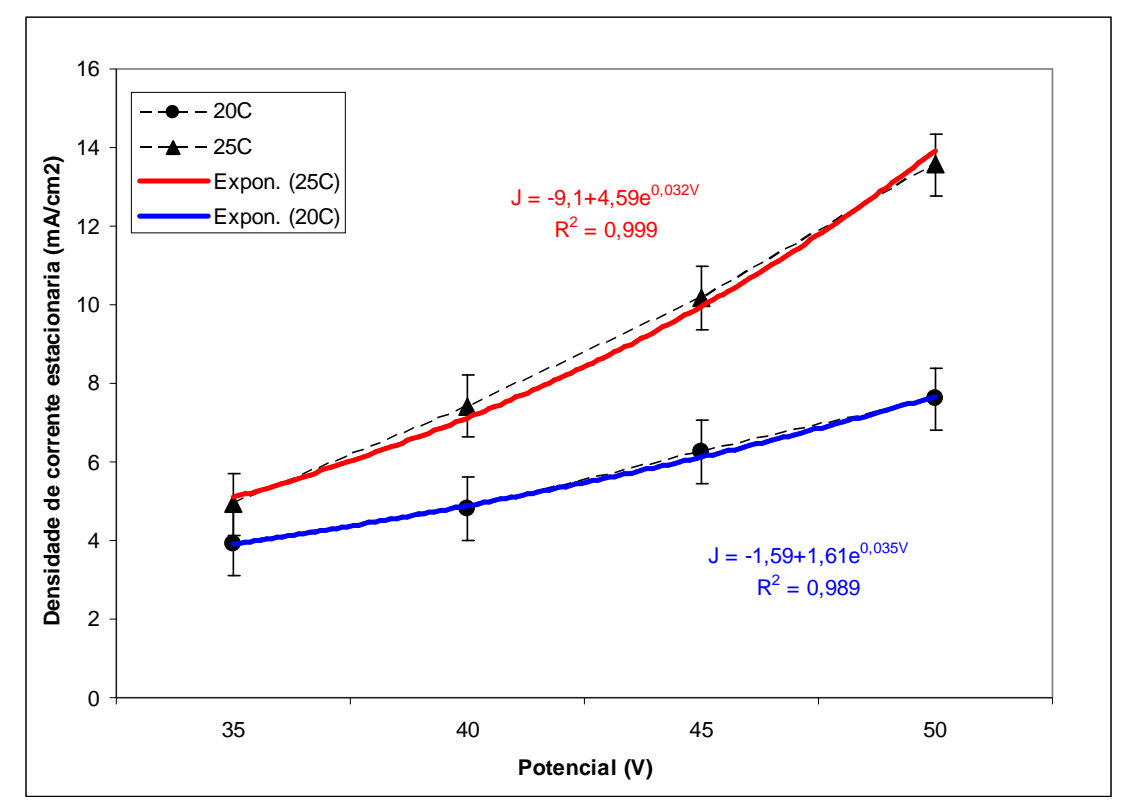

Figura 4.19. Densidade de corrente estacionária en função do potencial de anodização obtidas das curvas cinéticas de anodização das amostras $D_{2}, P_{7}, R_{8}, H_{2}\left(20^{\circ} \mathrm{C}\right)$ e $D_{3}, P_{8}, P_{4}, H_{3}\left(25^{\circ} \mathrm{C}\right)$ para uma concentração de ácido oxálico constante de $0,3 \mathrm{M}$.

A Figura 4.20 mostra o diagrama de distribuição 3D do diâmetro dos poros obtidos a partir do processamento das imagens MEV das amostras $D_{2}, P_{7}, R_{8}$ e $H_{2}$ utilizando o software GRANUL. Os diâmetros dos poros $D_{p}$ foram classificados em dez classes abrangendo uma faixa de valores entre 10 e $110 \mathrm{~nm}$. Os diâmetros 
médios das amostras $D_{2}, P_{7}, R_{8}$ e $H_{2}$ foram de $30 \mathrm{~nm}, 38 \mathrm{~nm}, 66 \mathrm{~nm}$ e $77 \mathrm{~nm}$, respectivamente. Nos cálculos para o diâmetro médio dos poros as formas dos poros foram assumidas como círculos perfeitos. Observa-se que o histograma de distribuição dos nanoporos mostra um deslocamento do diâmetro médio para valores maiores. Uma representação gráfica do comportamento do diâmetro médio dos poros em função do potencial de anodização é mostrada na Figura 4.21, onde se observa uma dependência linear crescente do diâmetro médio dos poros com o potencial de anodização. Portanto, o potencial de anodização é o parâmetro de anodização mais significativo com relação aos outros parâmetros de anodização, devido a que o diâmetro médio aumenta linearmente ao aumentar o potencial de anodização.

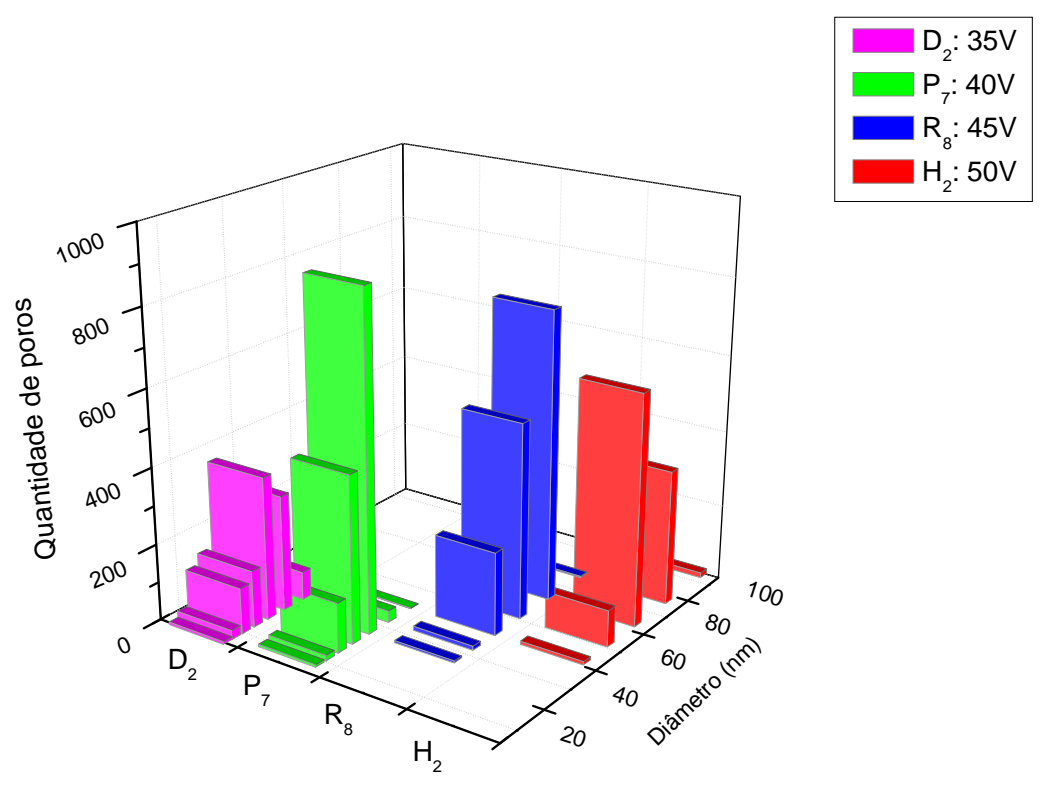

Figura 4.20. Diagrama de distribuição 3D do diâmetro dos poros das amostras $D_{2}, P_{7}, R_{8}$ e $H_{2}$ correspondentes aos potencias de anodização de $35 \mathrm{~V}, 40 \mathrm{~V}, 45 \mathrm{~V}$ e $50 \mathrm{~V}$, respectivamente. 


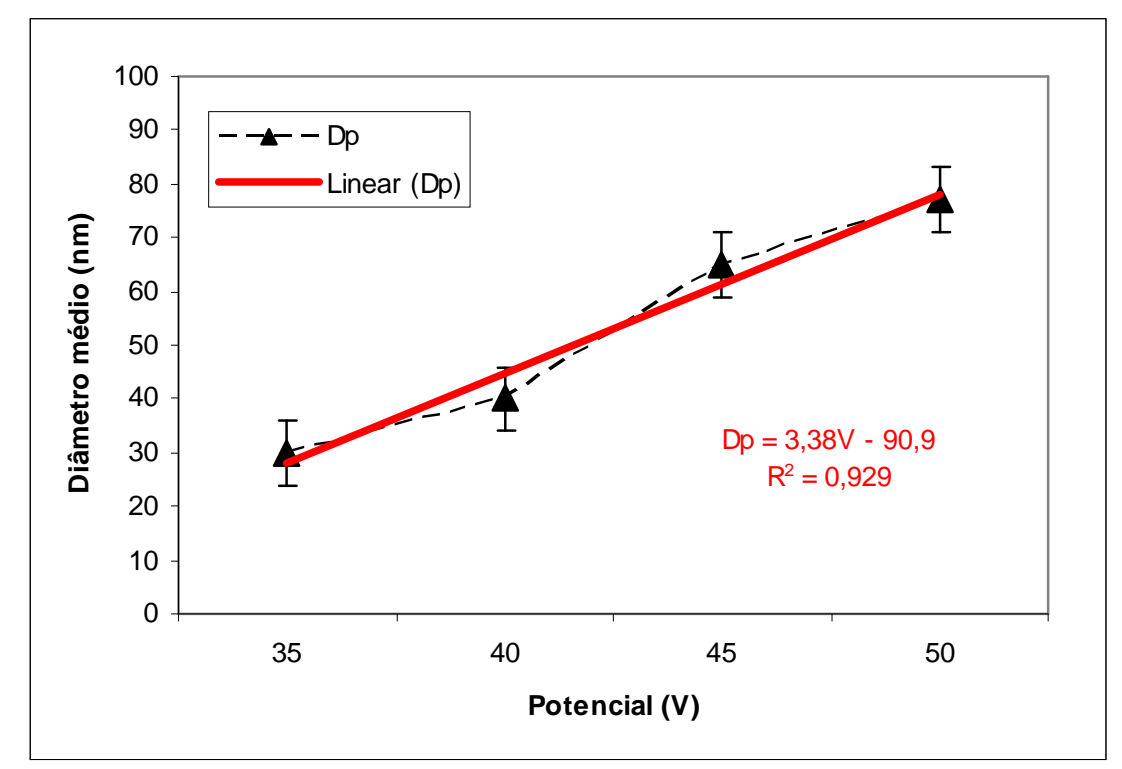

Figura 4.21. Influência do potencial de anodização sobre o diâmetro médio dos poros das amostras $D_{2}, P_{7}, R_{8}$ e $H_{2}$.

Em conclusão, o efeito do potencial de anodização sobre o diâmetro médio dos nanoporos é o parâmetro mais significativo com relação aos outros parâmetros de anodização, este resultado é muito importante na fabricação de máscaras de AAP com diâmetro controlado. O diâmetro médio mostrou ser linearmente dependente do potencial de anodização. Para potenciais baixos e altos observou-se uma irregularidade dos nanoporos, mas para um potencial de anodização intermediário, que neste caso foi de $45 \mathrm{~V}$, encontrou-se uma melhor distribuição, homogeneidade e circularidade dos nanoporos na superfície anodizada. Com respeito à densidade da corrente estacionária, esta aumenta exponencialmente com o potencial de anodização independente da concentração e da temperatura do eletrólito.

\subsubsection{Efeito da Corrosão Química sob as Estruturas de AAP}

A Figura 4.22 mostra as imagens MEV da superfície anodizada da amostra $R_{8}$ a qual foi fabricada por uma etapa de anodização em 0,3 $\mathrm{M}$ de ácido oxálico, a um 
potencial de $45 \mathrm{~V}$ e a uma temperatura de $20^{\circ} \mathrm{C}$. Após a anodização, a amostra foi submetida a um processo de corrosão química em $1 \mathrm{M}$ de $\mathrm{H}_{3} \mathrm{PO}_{4}$. Neste caso, foram realizados ensaios sistemáticos de corrosão química a uma temperatura de $23{ }^{\circ} \mathrm{C}$ durante vários períodos de tempo: 20 minutos (A), 40 minutos (B), 60 minutos $(C)$, e 80 minutos (D). Estes ensaios tiveram o objetivo de estudar o efeito do tempo de corrosão química sobre o diâmetro médio dos nanoporos.
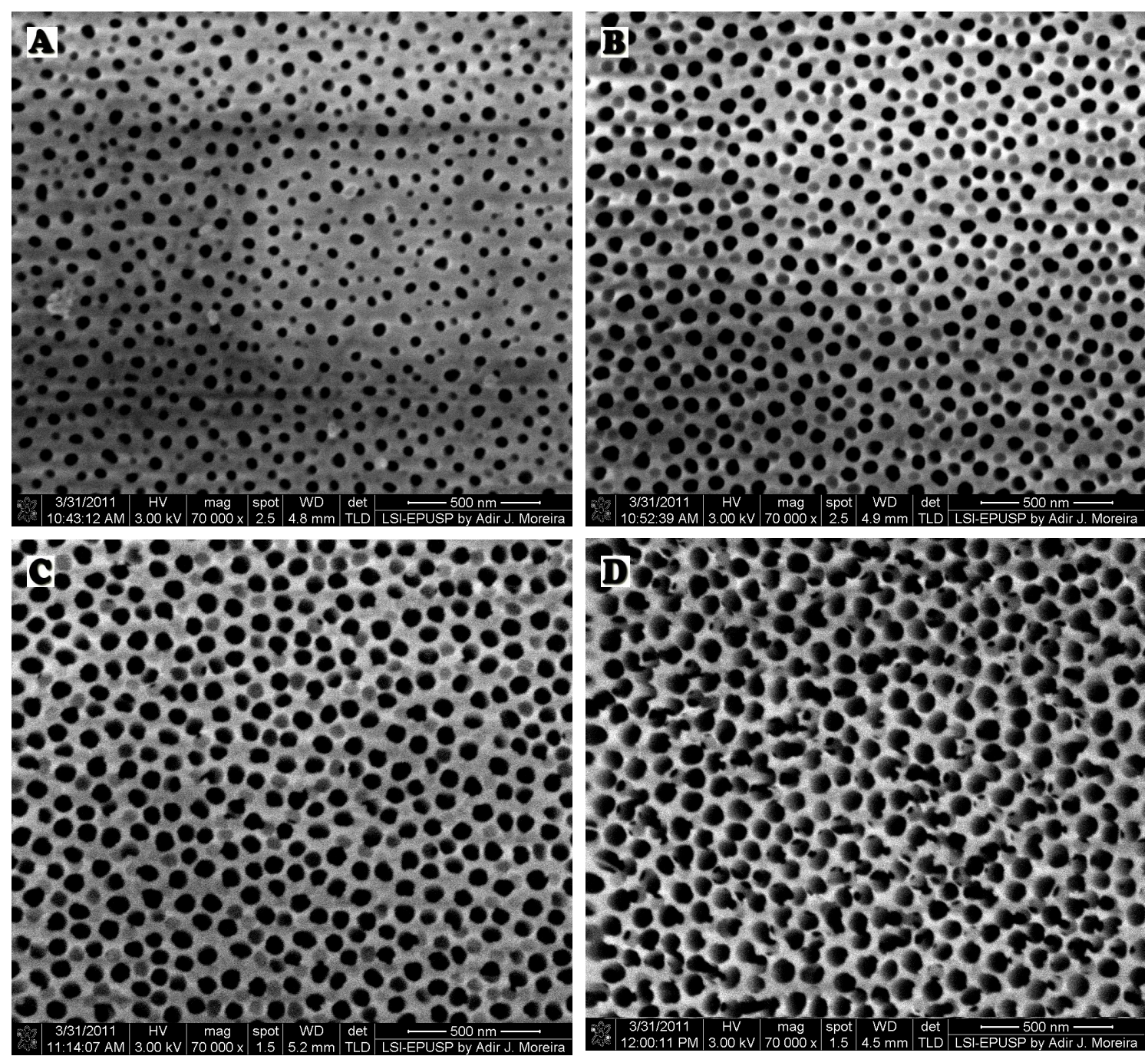

Figura 4.22. Imagens $M E V$ da superfície anodizada da amostra $R_{8}$ para vários períodos de tempo de

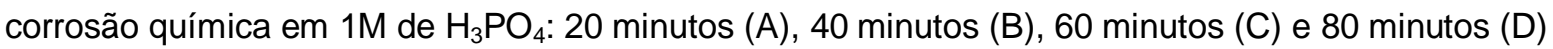
a uma temperatura de $23^{\circ} \mathrm{C}$. A anodização foi realizada em $0,3 \mathrm{M}$ de ácido oxálico, $20^{\circ} \mathrm{C}$ e $45 \mathrm{~V}$.

A superfície da nanoestrutura de AAP para um tempo de corrosão química de 20 minutos (Figura 4.22A) apresentou um diâmetro médio de 44 nm e a imagen 
MEV não mostra indícios de uma distribuição regular dos poros. As Figuras 4.22B, 4.22C e 4.22D mostram as estruturas porosas da amostra $R_{8}$ após ser submetido a uma corrosão química de 40,60 e 80 minutos, respectivamente. Neste caso, os diâmetros médios dos poros foram de 54, 66 e $74 \mathrm{~nm}$, respectivamente, já a distância entre poros vizinhos é da ordem de $110 \mathrm{~nm}$ aproximadamente em todas as imagens. Com o aumento do tempo de corrosão, a uniformidade e a circularidade dos nanoporos melhoram e os padrões hexagonais da distribuição dos poros começam a ser mais evidentes mostrando que as estruturas de AAP formados anodicamente apresentam duas camadas diferentes, onde a camada superficial apresenta uma estrutura porosa irregular e a camada interna apresenta uma distribuição de poros regularmente distribuídos numa simetria hexagonal. Após uma corrosão de 80 minutos (Figura 4.22D), a superfície da estrutura porosa começa a ser destruída, principalmente nos lugares onde os poros defeituosos foram formados, enfraquecendo assim as paredes dos poros vizinhos. No entanto, no interior da estrutura porosa só as paredes dos poros se afinam, aumentando o diâmetro de cada poro.

A dependência do diâmetro medio dos poros das nanoestruturas de AAP (Figura 4.22) com o tempo de corrosão química é mostrado na Figura 4.23, onde é observada uma dependência linear na faixa de 20-80 minutos. É importante mencionar que este processo de pós-tratamento (corrosão química ou processo de abertura dos poros) é mais significativo do que os parâmetros de anodização (concentração, temperatura e potencial), porque o diâmetro médio pode ser modulado simplesmente pelo tempo de corrosão química, mantendo uma distância interporo constante de aproximadamente $110 \mathrm{~nm}$. O diâmetro médio modulado varia na faixa de 40 a $80 \mathrm{~nm}$. 


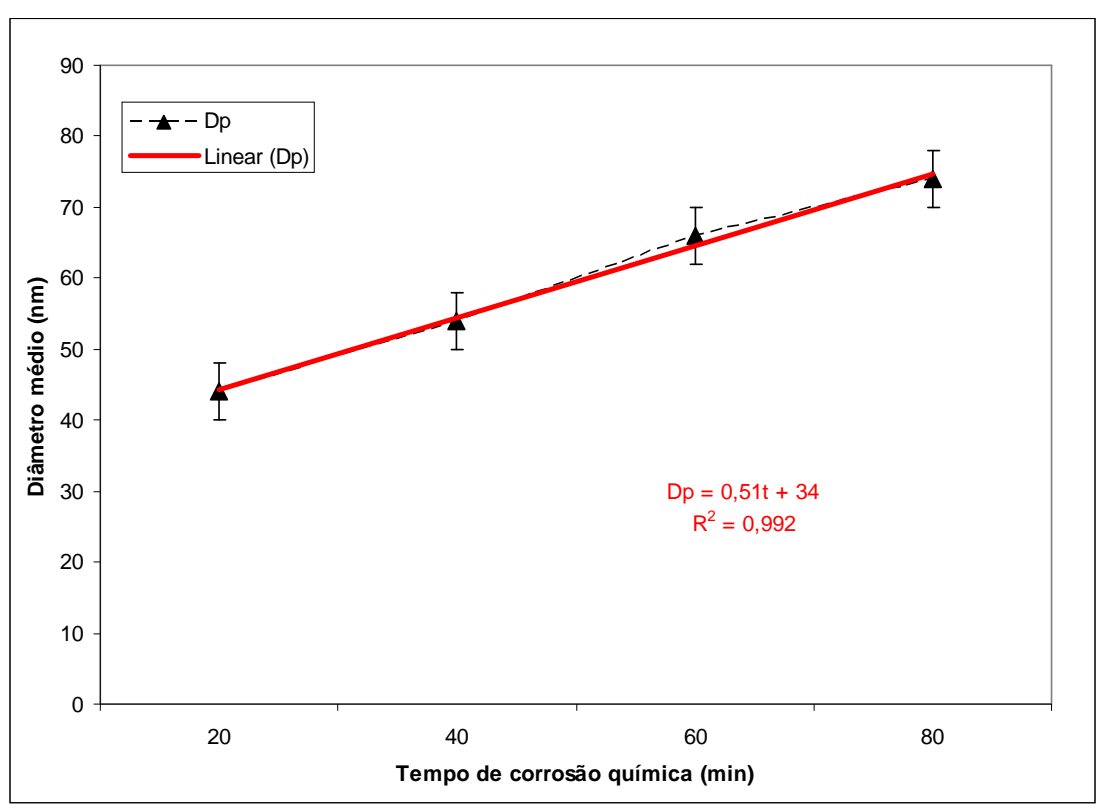

Figura 4.23. Influência do tempo de corrosão química sobre o diâmetro médio dos poros da amostra $\mathrm{R}_{8}$ para vários períodos de tempo.

A Figura 4.24 mostra imagens $M E V$ do processo de dissolução química da estrutura de AAP da amostra $R_{8}$ para vários períodos de tempo: 84 (A), 86 (B), 88 (C) e 90 minutos (D). O processo de dissolução química foi realizado a uma temperatura de $23^{\circ} \mathrm{C}$. Quando o tempo de ataque químico é de 84 minutos (Figura 4.24A), a superficie da estrutura porosa começa a ser destruída, de forma mais pronunciada nos lugares onde os poros defeituosos foram formados, enfraquecendo assim as paredes dos poros vizinhos. A Figura 4.24B, quando o tempo de ataque químico é de 86 minutos, mostra claramente a destruição dos poros superficiais na forma de tubos quebrados (indicado pela seta) com uma altura de aproximadamente $1.4 \mu \mathrm{m}$ em toda a superfície anodizada aparecendo algumas áreas com um arranjo ordenado de nanoporos (indicado pelo círculo tracejado). Da mesma forma, na Figura 4.24C, para um tempo de ataque químico de 88 minutos, pode ser observado o surgimento de áreas maiores com poros auto-organizados e restos dos poros quebrados. Quando se atinge os 90 minutos de dissolução (Figura 4.24D), poros auto-organizados em simetria hexagonal são revelados. 

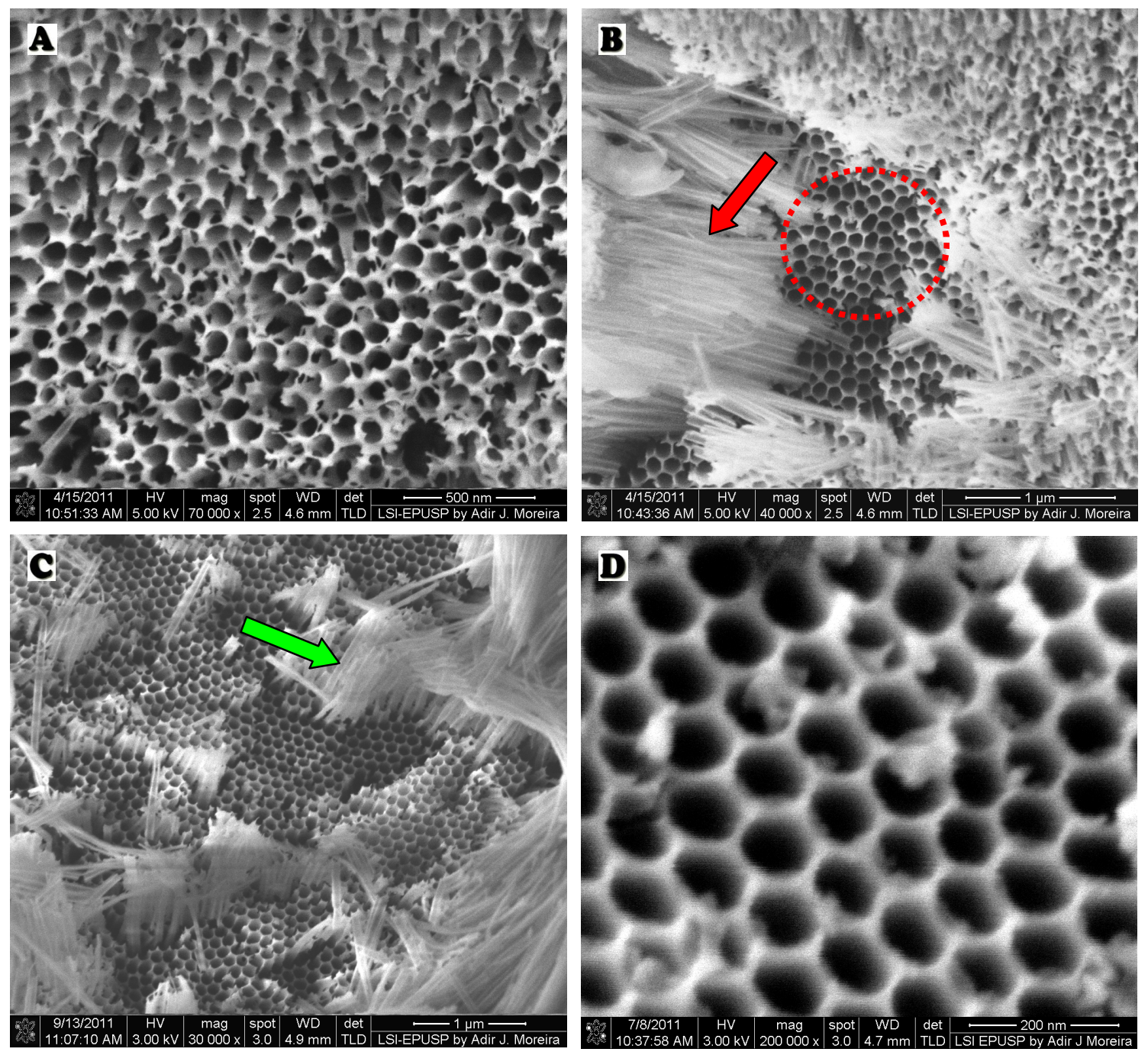

Figura 4.24. Imagens $M E V$ da superfície anodizada da amostra $R_{8}$ para vários períodos de tempo de corrosão química em $1 \mathrm{M} \mathrm{H}_{3} \mathrm{PO}_{4}$ : 84 minutos $(A), 86$ minutos $(B), 88$ minutos $(C), 90$ minutos $(D)$ a uma temperatura de $23^{\circ} \mathrm{C}$. A anodização foi realizada em $0,3 \mathrm{M}$ de ácido oxálico, $20^{\circ} \mathrm{C}$ e $45 \mathrm{~V}$.

Com o objetivo de ter o controle do processo de dissolução química da alumina em ácido fosfórico e sua formação de estruturas de AAP auto-organizadas, será importante considerar a temperatura do processo. A temperatura é um fator importante no processo de dissolução, devido ao fato de que a dissolução da alumina é endotérmica. Isto é, a temperaturas altas $\left(>23^{\circ} \mathrm{C}\right)$ facilita-se a dissolução, aumentando a solubilidade da alumina. No entanto, a baixas temperaturas $\left(<23^{\circ} \mathrm{C}\right)$ dificulta-se a dissolução, diminuindo a solubilidade da alumina. A Figura 4.25 mostra as imagens MEV da superfície anodizada da amostra $R_{8}$ para vários períodos de 
tempo de ataque químico: 88 (A), 92 (B), 97 (C) e 102 minutos (D), a uma temperatura de $17^{\circ} \mathrm{C}$. Esta baixa temperatura favorece um processo de dissolução química mais lenta, permitindo um controle mais preciso da formação de estruturas de AAP auto-organizadas.
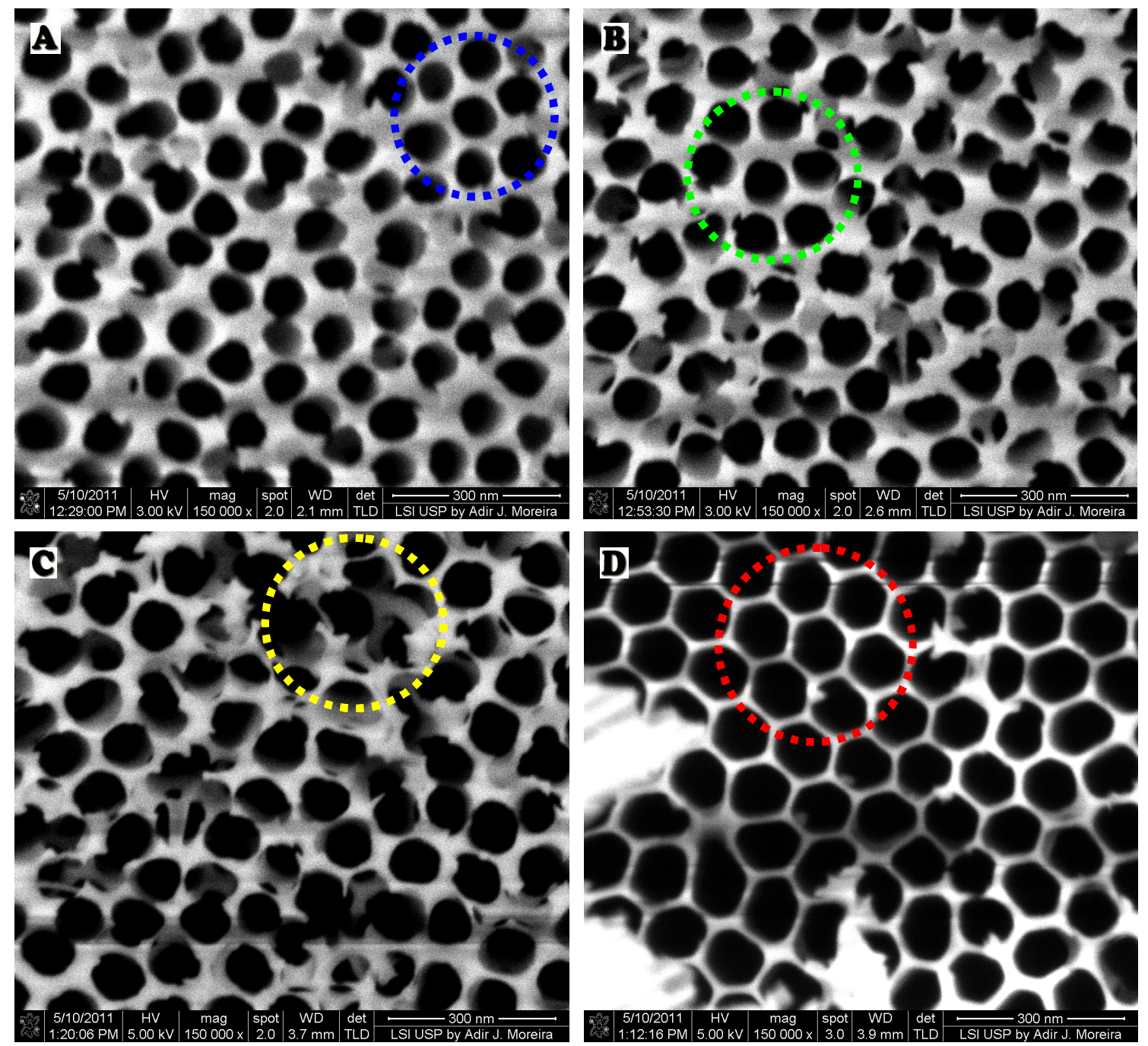

Figura 4.25. Imagens MEV da superfície anodizada da amostra $R_{8}$ para vários períodos de tempo de ataque químico em $1 \mathrm{M} \mathrm{H}_{3} \mathrm{PO}_{4}$ : 88 minutos $(A), 92$ minutos (B), 97 minutos (C) e 102 minutos (D) a uma temperatura de $17^{\circ} \mathrm{C}$. A anodização foi realizada em $0,3 \mathrm{M}$ de ácido oxálico, temperatura de $20^{\circ} \mathrm{C}$ e para um potencial de anodização de $45 \mathrm{~V}$.

A superfície da nanoestrutura para um tempo de ataque químico de 88 minutos é mostrada na Figura 4.25(A). A imagem mostra algumas zonas onde os nanoporos estão ordenados hexagonalmente (círculo azul). A Figura 4.25(B) que 
corresponde à amostra após um tempo de ataque químico de 92 minutos apresenta um processo de dissolução química inicial, onde as paredes dos nanoporos defeituosos começam a se enfraquecer destruindo os arranjos hexagonais dos nanoporos (círculo de verde). Quando o tempo de corrosão química atinge os 97 minutos uma destruição completa dos arranjos hexagonais de nanoporos acontece na superfície da estrutura (círculo amarelo). A Figura 4.25(D) mostra o arranjo hexagonal perfeito da nanoestrutura de AAP (círculo vermelho) quando o tempo de corrosão química atingiu os 102 minutos, após a dissolução dos nanoporos superficiais, surgindo assim uma estrutura auto-organizada. Como já foi descrito, na seção inicial, ainda que a superfície anodizada apresente uma irregularidade dos nanoporos, dentro da estrutura de AAP encontra-se uma estrutura porosa regular composta de um arranjo hexagonal de poros, semelhante a uma estrutura de colméia de abelhas.

A Figura 4.26 mostra imagens MEV das amostras $\mathrm{O}_{6}, \mathrm{O}_{7}$ e $\mathrm{P}_{3}$ quando foram submetidos a um processo de corrosão química de 90 minutos, aproximadamente, em $1 \mathrm{M}$ de $\mathrm{H}_{3} \mathrm{PO}_{4}$ e a temperatura de $23^{\circ} \mathrm{C}$, mostrando arranjos de poros autoorganizados.
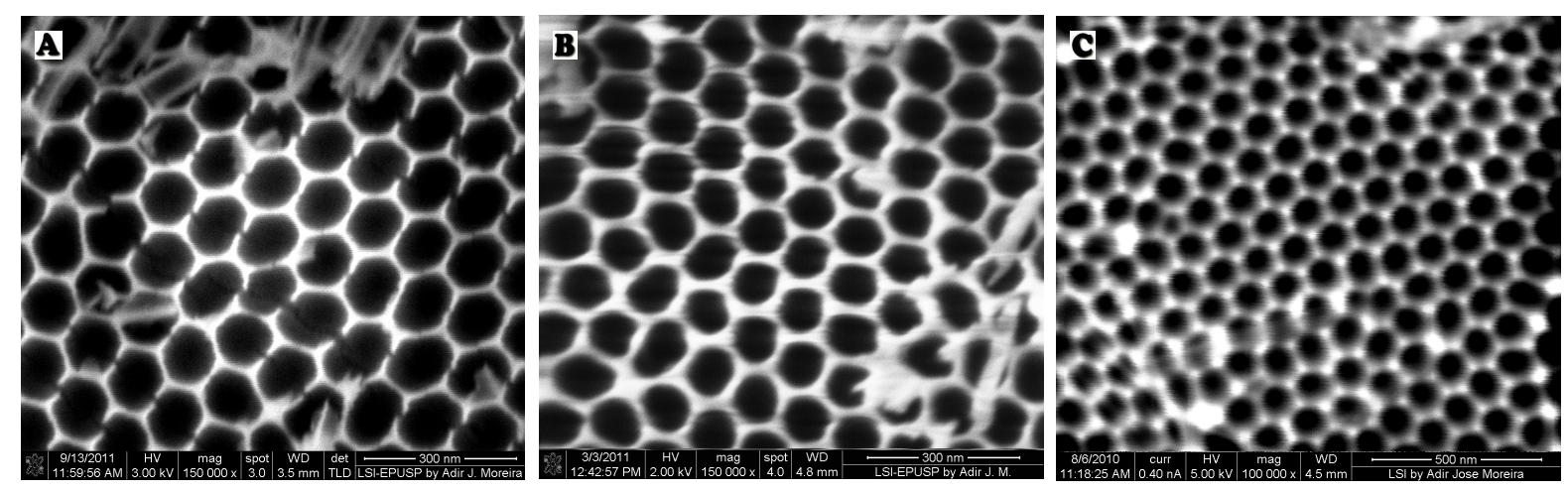

Figura 4.26. Imagens MEV de estruturas auto-organizadas de AAP para as amostras $O_{6}, O_{7}$ e $P_{3}$ após um tempo de corrosão química de 90 minutos aproximadamente.

É importante mencionar que todas estas estruturas auto-organizadas apresentaram um diâmetro médio máximo de $90 \mathrm{~nm}$ aproximadamente com uma distância interporo constante de $110 \mathrm{~nm}$. Nestas condições, utilizando as equações 
(3) e (4) do capítulo 2, a porosidade e a densidade porosa das nanoestruturas são estimadas em torno de $60 \%$ e $10^{10} \mathrm{~cm}^{-2}$, respectivamente, e são independentes das condições de anodização. Estas nanoestruturas de AAP auto-organizadas obtidas por uma etapa de anodização e um processo de corrosão química são semelhantes às nanoestruturas obtidos por processos de nanoindentação utilizando um selo mestre estudado por Masuda e colaboradores [73]. Neste sentido, o processo apresentado neste trabalho é vantajoso em relação aos trabalhos de Masuda.

A Figura 4.27 mostra o diagrama de distribuição dos diâmetros dos nanoporos da amostra $R_{8}$ para vários períodos de corrosão química obtidas das imagens MEV das Figuras 4.22 A-D e das nanoestruturas auto-organizadas das Figuras 4.25 D e 4.26. Como pode ser observado no histograma de distribuição 3D de cada amostra o diâmetro dominante dos poros se desloca para valores maiores à medida que o tempo de corrosão aumenta e que esta distribuição apresenta um perfil estreito (elevada concentração de poros de um único diâmetro de poros) quando os poros começam a apresentar uma distribuição regular na estrutura de AAP.

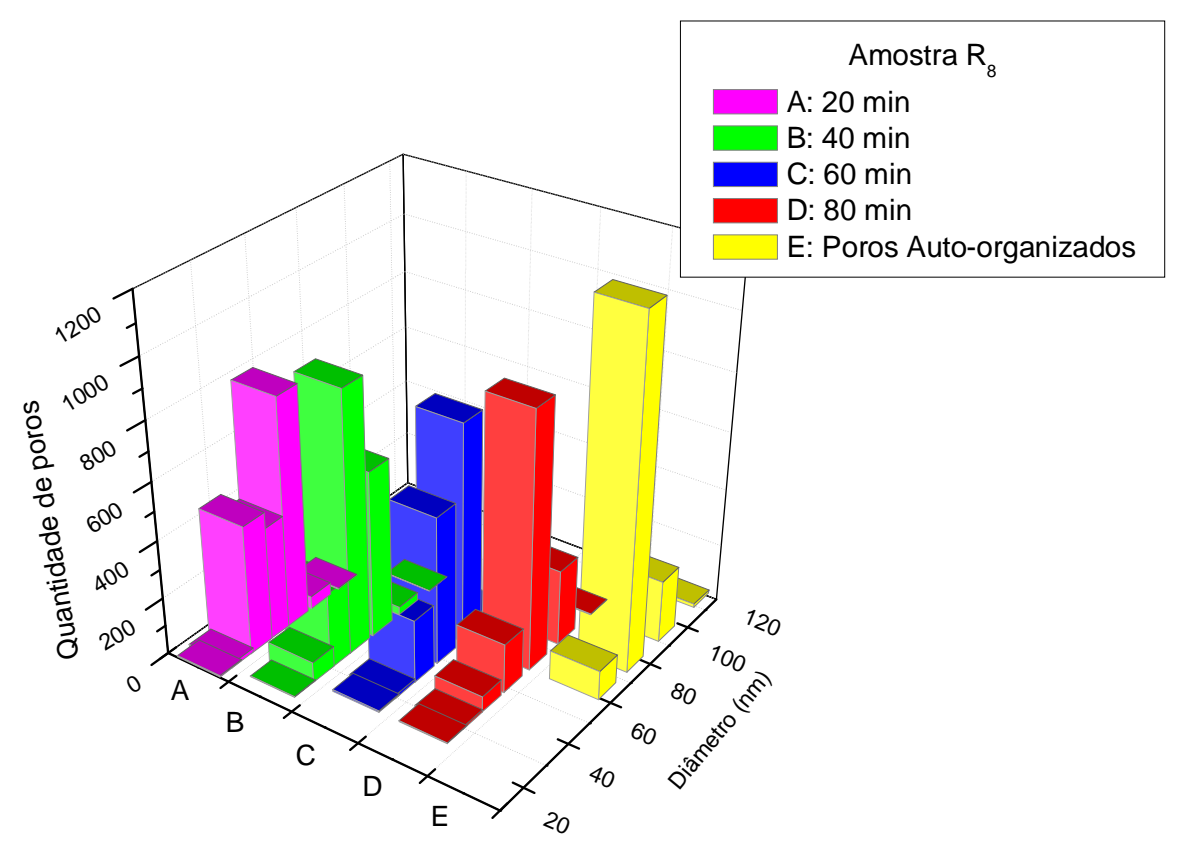

Figura 4.27. Diagrama de distribuição 3D do diâmetro dos nanoporos da amostra $R_{8}$ para vários períodos de tempo de corrosão química em $1 \mathrm{M} \mathrm{H}_{3} \mathrm{PO}_{4}$ : 20 minutos $(\mathrm{A}), 40$ minutos $(\mathrm{B}), 60$ minutos (C), 80 minutos (D) a temperatura de $23^{\circ} \mathrm{C}$ e uma distribuição dos poros auto-organizados (E). 
Como conclusão, o efeito do tempo de corrosão química sobre o diâmetro médio dos nanoporos é o parâmetro mais importante na fabricação de máscaras de AAP e de nanoestruturas auto-organizadas correspondentes, em comparação com os parâmetros de anodização. Estes resultados podem ser usados para fabricar máscaras de AAP com diferentes diâmetros mantendo a distância interporo constante e utilizá-los como moldes na síntese de nanopartículas e nanofios metálicos.

\subsection{Fabricação de Nanopartículas e Nanofios por Eletrodeposição CA}

\subsubsection{Nanopartículas e Nanofios de Níquel}

Após a obtenção das estruturas de AAP, estas foram utilizadas como moldes para a fabricação de nanopartículas e nanofios de níquel. O método utilizado para este propósito foi a deposição eletroquímica $\mathrm{CA}$ em uma solução eletrolítica de 0,1M de sulfato de níquel ( $\left.\mathrm{NiSO}_{4}: 6 \mathrm{H}_{2} \mathrm{O}\right)$ e $45 \mathrm{~g} / \mathrm{L}$ de ácido bórico $\left(\mathrm{H}_{3} \mathrm{BO}_{3}\right)$, mantendo um potencial de 20V. Com o objetivo de estudar as características do depósito, foi necessário trabalhar com duas freqüências, 100 e $300 \mathrm{~Hz}$ e diferentes tempos de deposição. $\mathrm{O}$ pH da solução foi mantido constante num valor de 3,5.

As Figuras 4.28(A) e (B) mostram imagens MEV das nanopartículas de níquel eletrodepositadas numa máscara de AAP. A máscara utilizada para esta finalidade foi à amostra $R_{8}$ com um tempo de corrosão química de 70 minutos em $1 \mathrm{M}$ de $\mathrm{H}_{3} \mathrm{PO}_{4}$ a temperatura de $23^{\circ} \mathrm{C}$, o que deu origem a uma estrutura com poros de diâmetro médio em torno de $70 \mathrm{~nm}$ (Figura 4.23). No processo de eletrodeposição, o sinal senoidal $A C$ teve sua freqüência fixada em $100 \mathrm{~Hz}$ e o tempo de deposição foi de 2 minutos. Como pode ser observado nas imagens MEV, as nanopartículas apresentam uma geometria esférica com diâmetro de $70 \mathrm{~nm}$ aproximadamente (indicado pela seta na Figura 4.28B), este valor é aproximadamente igual ao diâmetro médio dos nanoporos na superfície da estrutura de AAP da amostra $R_{8}$. Também as imagens MEV apresentam canais dos nanoporos perfeitamente paralelos, indicando que a camada interna da estrutura de AAP apresenta um 
arranjo hexagonal ordenado de nanoporos, onde as nanopartículas de níquel foram depositadas apresentando também um arranjo de nanopartículas ordenadas.
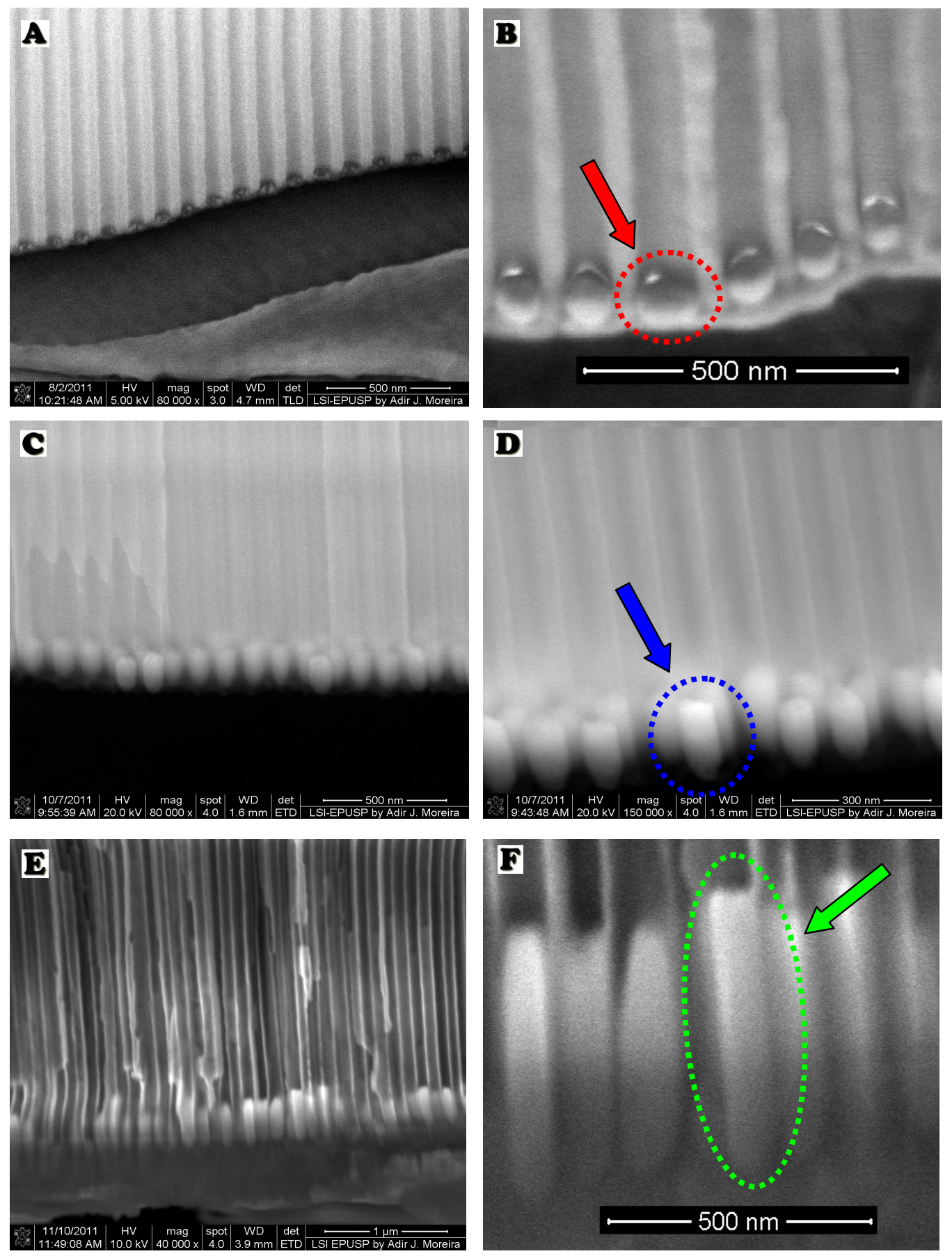

Figura 4.28. Imagens $M E V$ de nanopartículas e nanofios de Níquel obtidas por eletrodeposição utilizando-se um sinal $C A$ de: $(A, B) 100 \mathrm{~Hz}$ de frequência e um tempo de deposição de 2 min, $(C, D)$ $300 \mathrm{~Hz}$ de freqüência e um tempo de deposição de $2 \mathrm{~min}$, (E,F) $300 \mathrm{~Hz}$ de freqüência e um tempo de deposição de 10 min. 
As Figuras 4.28(C) e (D) mostram imagens MEV dos nanofios de Níquel em crescimento com dimensões de $70 \mathrm{~nm}$ de diâmetro e $150 \mathrm{~nm}$ de altura (indicado pela seta), este processo de eletrodeposição foi realizado a uma frequência de 300 $\mathrm{Hz}$ com um tempo de deposição de 2 minutos. Como é observada nesteas imagens a taxa de deposição aumenta com o incremento da freqüência, sugerindo que a maior freqüência, a deposição torna-se mais rápida e uniforme. As Figuras 4.28(E) e (F) mostram nanofios de Níquel com dimensões de $70 \mathrm{~nm}$ de diâmetro e altura de $500 \mathrm{~nm}$ (indicado pela seta). Esse processo foi realizado numa frequência de 300 $\mathrm{Hz}$ e um tempo de deposição de 10 minutos. Como se observa, o tempo de deposição promove o crescimento dos nanofios, sugerindo que nanofios de Níquel com um diâmetro uniforme de $70 \mathrm{~nm}$ aproximadamente e um comprimento desejado pode ser fabricado pelo controle do tempo de deposição, prenchendo assim todos os nanoporos da estrutura de AAP.

$\mathrm{Na}$ Figura 4.29 é mostrado o espectro EDS da análise química das nanopartículas e nanofios de Níquel eletrodepositados. O espectro indica a presença de Níquel, assim como também à composição química da máscara de AAP constituído de óxido de alumínio.

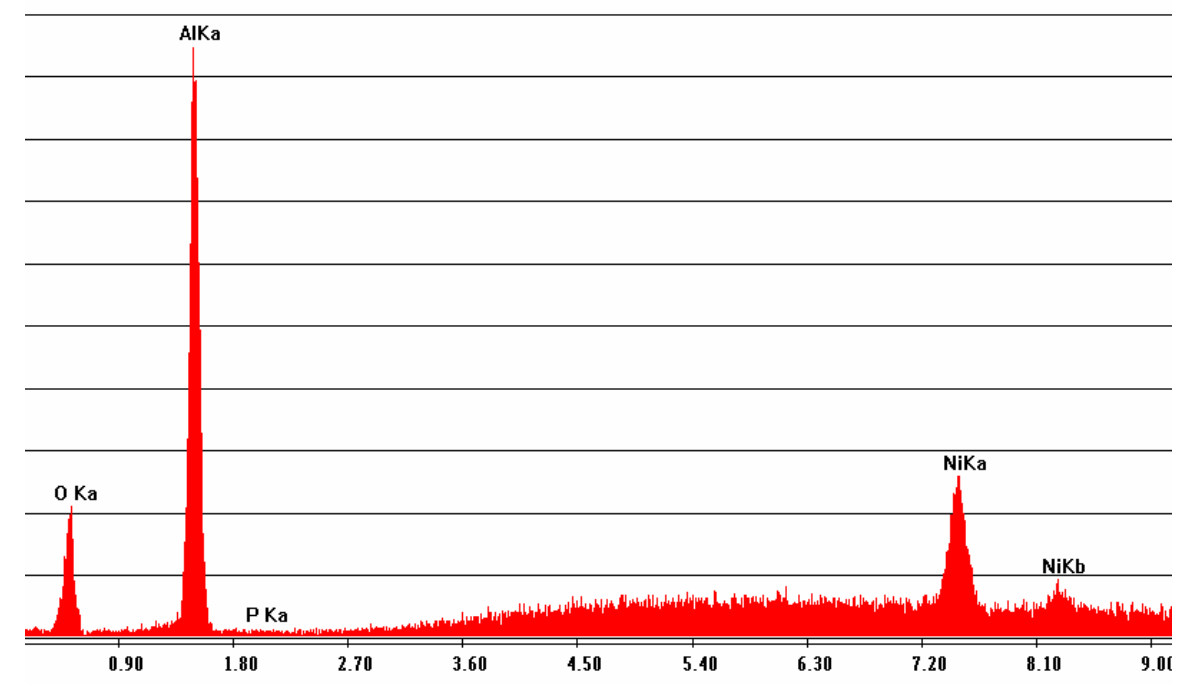

Figura 4.29. Espectro EDS para análise química das nanopartículas de Níquel eletrodepositadas numa máscara de AAP. 


\subsubsection{Nanofios de Prata}

A Figura 4.30 mostra os nanofios de prata eletrodepositados numa máscara de AAP, neste caso também foi utilizada a amostra $R_{8}$ como molde com uma corrosão química de 70 minutos atingindo um diâmetro médio de $70 \mathrm{~nm}$. A solução eletrolítica utilizada para a eletrodeposição $\mathrm{CA}$ foi de $0,05 \mathrm{M}$ de nitrato de prata $\left(\mathrm{AgNO}_{3}\right)$ e $6 \mathrm{~g} / \mathrm{L}$ de ácido bórico $\left(\mathrm{H}_{3} \mathrm{BO}_{3}\right)$, um potencial de $25 \mathrm{~V}$ foi utilizado para o polarizar a célula eletroquímica. Duas frequências do sinal foram utilizadas para observar o efeito do grau de prenchimento dos poros, 100 e $300 \mathrm{~Hz}$, e diferentes tempos de deposição de 5 e 40 minutos. $\mathrm{O}$ pH da solução foi mantida constante num valor de 2,5.

Os resultados da infiltração de prata nos nanoporos alcançada pela eletrodeposição CA para 5 minutos e $100 \mathrm{~Hz}$ de freqüência são mostrados nas Figuras as 4.30 (A) e (B). O depósito de prata é evidenciado pelo contraste de tons de cinza das imagens MEV mostradas nestas Figuras. Estas imagens mostram que os poros foram prenchidos parcialmente com prata até um comprimento de $4 \mu \mathrm{m}$ aproximadamente, mostrando fios incompletos (indicado pela seta na figura 4.30A), observa-se que, na base dos poros, só alguns poros foram prenchidos completamente (indicado pelas setas pretas na figura 4.30B). Portanto, nanofios podem ser fabricados nessas condições, levando-se em conta, porém, que o curto tempo de deposição e a baixa frequência não garante fios com razão de aspecto elevados nem uniformes. Por outro lado, a Figura 3.30(C) e (D) mostra nanofios fabricados a $300 \mathrm{~Hz}$ de freqüência e 40 minutos de deposição. Estes nanofios atingiram um comprimento de $18 \mu \mathrm{m}$ aproximadamente com um diâmetro uniforme de $70 \mathrm{~nm}$ (indicado pelas setas na Figura 4.30C). Como é observado, estes nanofios preenchem quase completamente os poros (setas da Figura 4.30D), isso pode ser observado pelo contraste dos tons de cinza das imagenes MEV. É importante mencionar que com o aumento do tempo de deposição e da frequência são obtidos nanofios mais uniformes que preenchem de melhor forma os poros da estrutura APP em comparação com aqueles fabricados a $100 \mathrm{~Hz}$ de freqüência e 4 minutos de tempo de deposição. Estes resultados sugerem que é possível controlar o cumprimento e uniformidade dos nanofios através da modulação da freqüência do sinal e o tempo de deposição. 

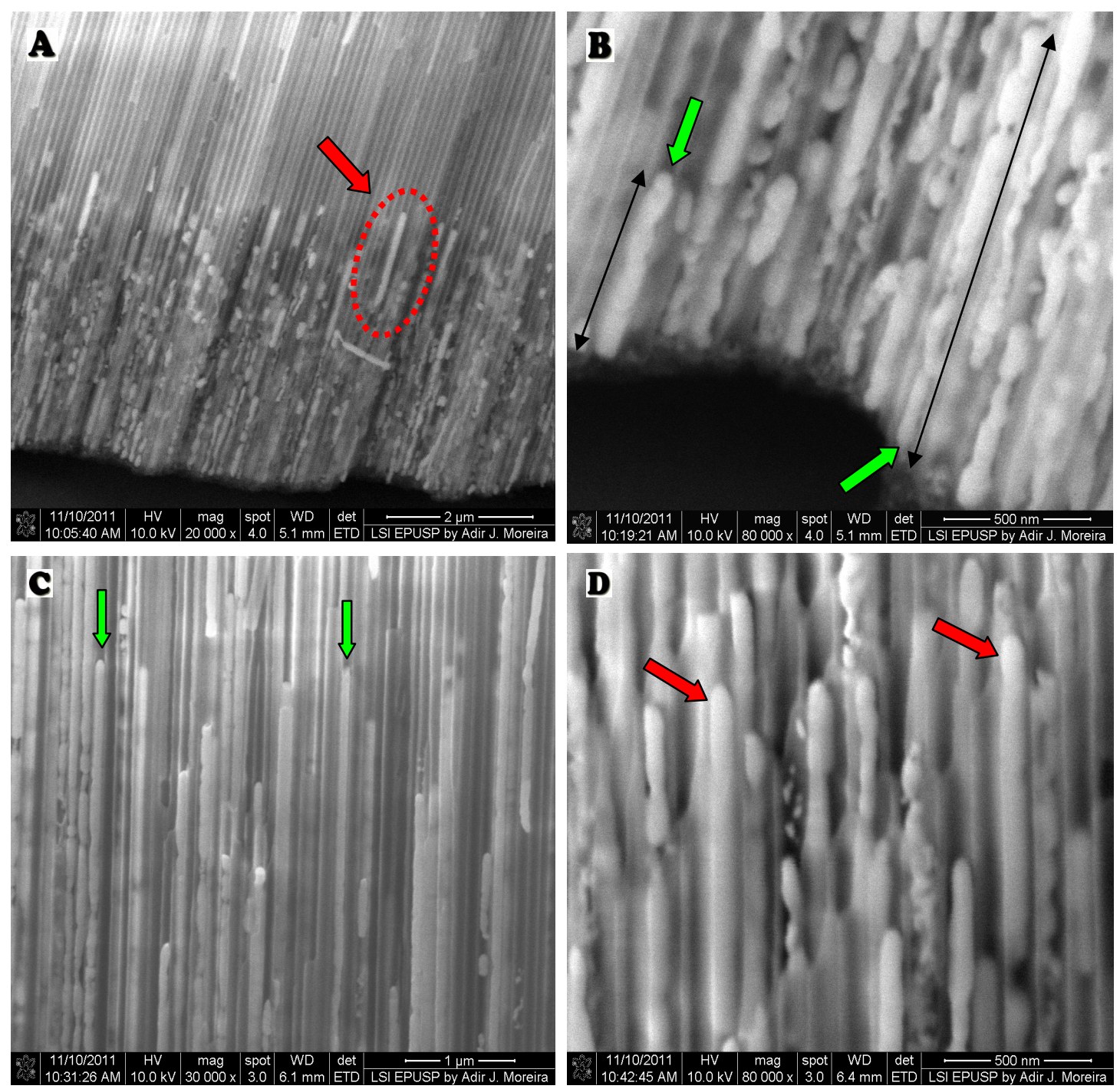

Figura 4.30. Imagens $M E V$ dos nanofios de prata eletrodepositados numa máscara de AAP utilizando um sinal $A C$ de: $(A, B) 100 \mathrm{~Hz}$ de freqüência com um tempo de deposição de 5 minutos; (C,D) $300 \mathrm{~Hz}$ freqüência de com um tempo de deposição de 40 minutos.

Na Figura 4.31 é mostrado o espectro EDS da análise química dos nanofios de Prata eletrodepositados. O espectro indica a presença de Prata, assim como também a composição química da máscara de AAP constituída pelo óxido de alumínio. 


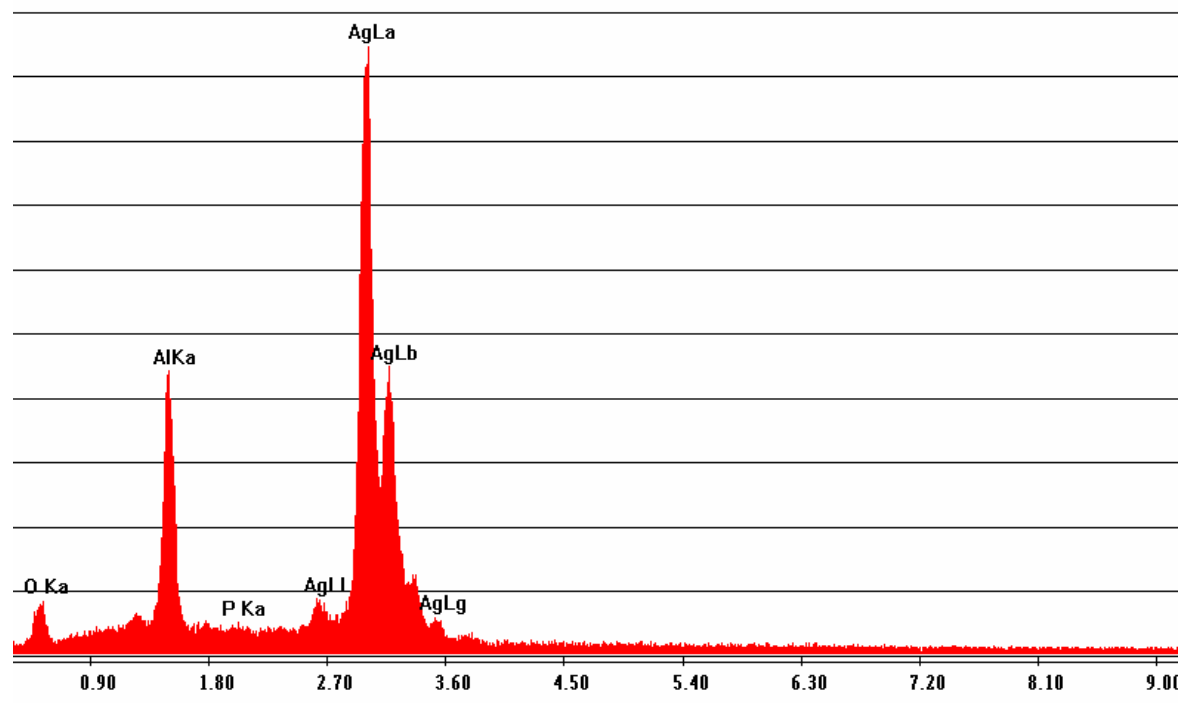

Figura 4.31. Espectro EDS para análise química dos nanofios de Prata eletrodepositadas numa máscara de AAP.

\subsection{Fabricação de Nanofios de Alumina por Dissolução Química}

Após a obtenção das estruturas de AAP, o processo para se obter os nanofios de alumina é relativamente simples. A Figura 4.32 mostra imagens MEV do processo de formação dos nanofios de alumina para a amostra $P_{3}$. Após a anodização da amostra $P_{3}$, esta foi submetida a um processo de dissolução química em $1 \mathrm{M} \mathrm{H}_{3} \mathrm{PO}_{4}$ para vários períodos de tempo. Neste ensaio foi utilizado uma temperatura de $27{ }^{\circ} \mathrm{C}$ com o objetivo de acelerar o processo de dissolução química e assim obter num só passo nanofios de alumina. A Figura 4.32(A) mostra a superfície nanoporosa para um tempo de corrosão química de 40 minutos. Como foi descrito e demonstrado anteriormente, as nanoestruturas de AAP estão formados de um arranjo hexagonal perfeito de nanoporos (Figura 4.26), portanto os poros atuam como colunas no centro da célula hexagonal. Quando o tempo de corrosão química atinge os 50 minutos (Figura 4.32B), as paredes de muitos poros se enfraquecem devido à dissolução da alumina e alta temperatura do processo até que as colunas porosas começam a perder sua sustentabilidade agrupando-se entre eles. A Figura 4.32C mostra uma imagem MEV transversal da amostra após ser submetida a um processo de dissolução por 60 minutos. Observa-se claramente 
a formação de nanofios de alumina com uma razão de aspecto elevado. Observa-se também que esses nanofios são altamente flexíveis, como mostrado na Figura 4.32C e identificado por uma linha amarela contínua. A Figura 4.32 D mostra a imagem MEV dos nanofios completamente formados e separados uns dos outros. Estos nanofios foram formados quando o tempo de corrosão química atingiu os 65 minutos de dissolução química.
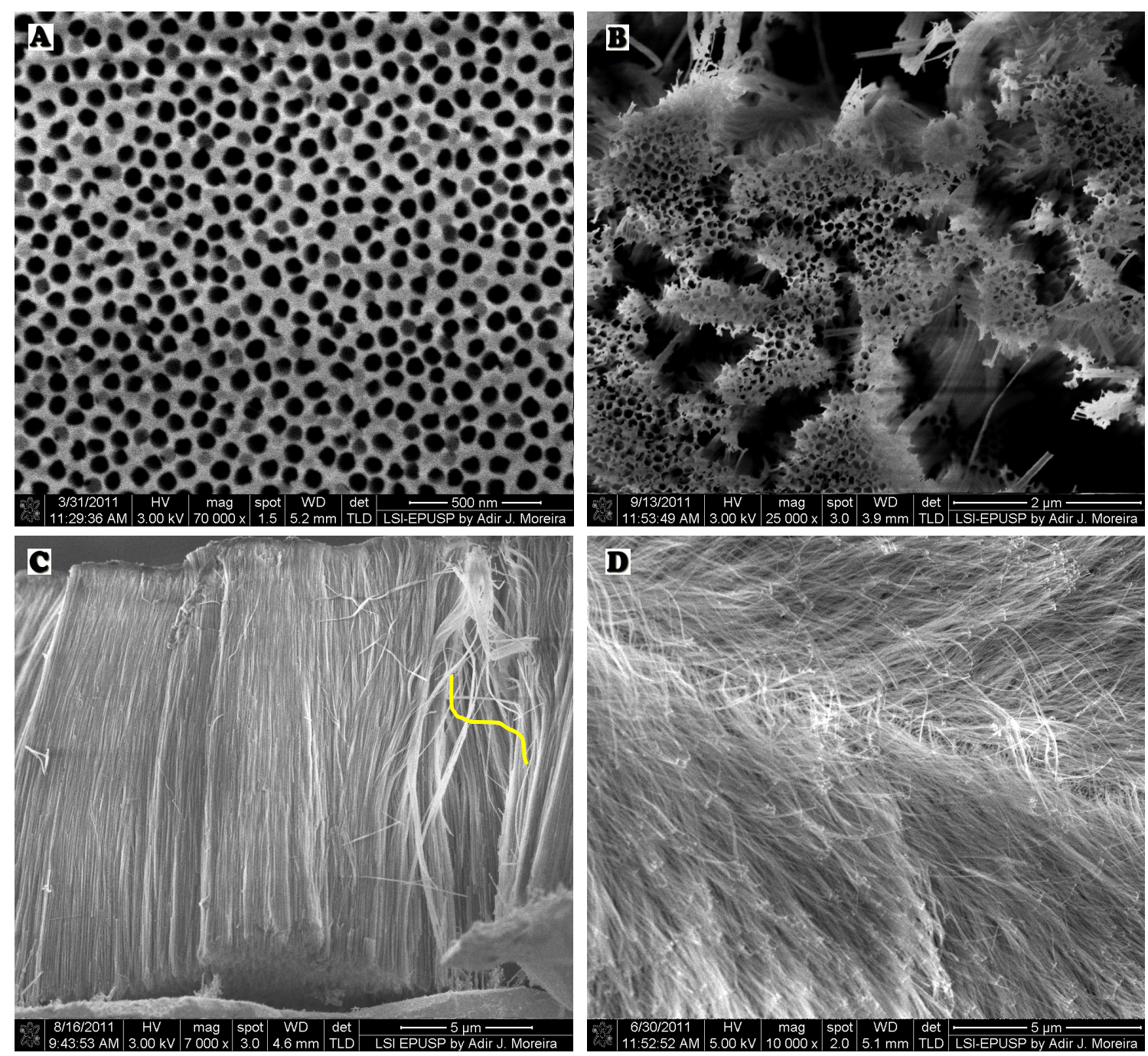

Figura 4.32. Imagens MEV do processo de formação de nanofios de alumina para a amostra $P_{3}:(A)$ 40 minutos, (B), 50 minutos (C) 60 minutos, e (D) 65 minutos de dissolução química a uma temperatura de $27^{\circ} \mathrm{C}$.

A Figura 4.33 mostra o espectro EDS da análise química dos nanofios de alumina. O espectro indica a presença de alumínio e oxigênio, semelhante à 
composição química das máscaras de AAP, implicando que os nanofios de alumina estão formados de alumina pura.

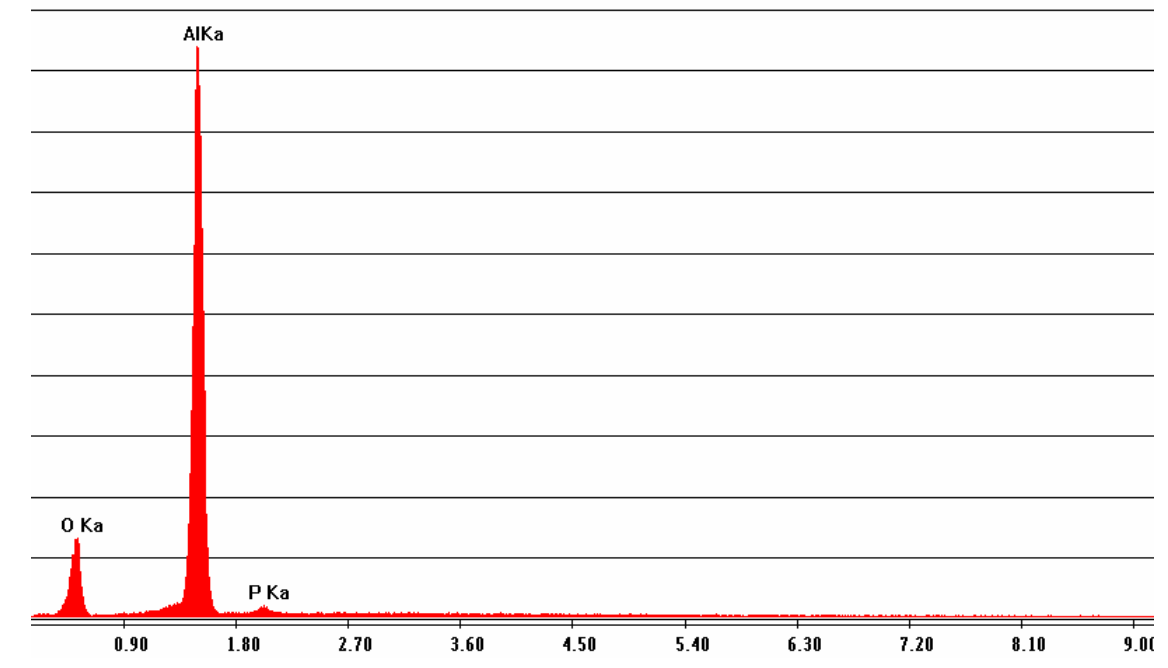

Figura 4.33. Espectro EDS da análise química dos nanofios de alumina.

A evidência experimental que mostra a origem dos nanofios de alumina pode ser observada nas Figuras 4.34(A) e (B). Na Figura 4.34(A) observa-se uma região aumentada onde os nanofios foram formados. Nesta imagem pode ser observado que o tamanho do diâmetro dos nanofios de alumina (indicado pela seta) é menor do que o diâmetro dos poros, e que os vértices do arranjo hexagonal dos poros (Figura 4.34B) foram os responsáveis para a formação dos nanofios. A imagem MEV da Figura 4.34(B) mostra a superfície da alumina depois de uma remoção dos nanofios, e observa-se que os nanofios são formados nos vértices do hexágono (indicado pela seta) que atuam como colunas para a construção dos nanoporos no centro da célula hexagonal.

O diâmetro dos nanofios de alumina formados a partir da amostra $\mathrm{P}_{3}$ (círculo vermelho da Figura 4.34A e indicado pela seta) e o diâmetro dos pontos que fazem parte dos vértices para formar o hexágono regular da figura 4.34B (círculo verde indicado da Figura 4.34B pela seta) são de aproximadamente $20 \mathrm{~nm}$ respectivamente. Este resultado fortalece o argumento de que os nanofios de alumina são formados exatamente na região dos vértices na estrutura hexagonal. É importante mencionar que no processo de dissolução química, só os nanofios não 
foram influenciados pela dissolução, permacendo firmes, as quais atuam como colunas principais na formação dos nanoporos. No entanto, as paredes dos nanoporos sofreram a dissolução permitindo a formação dos nanofios.
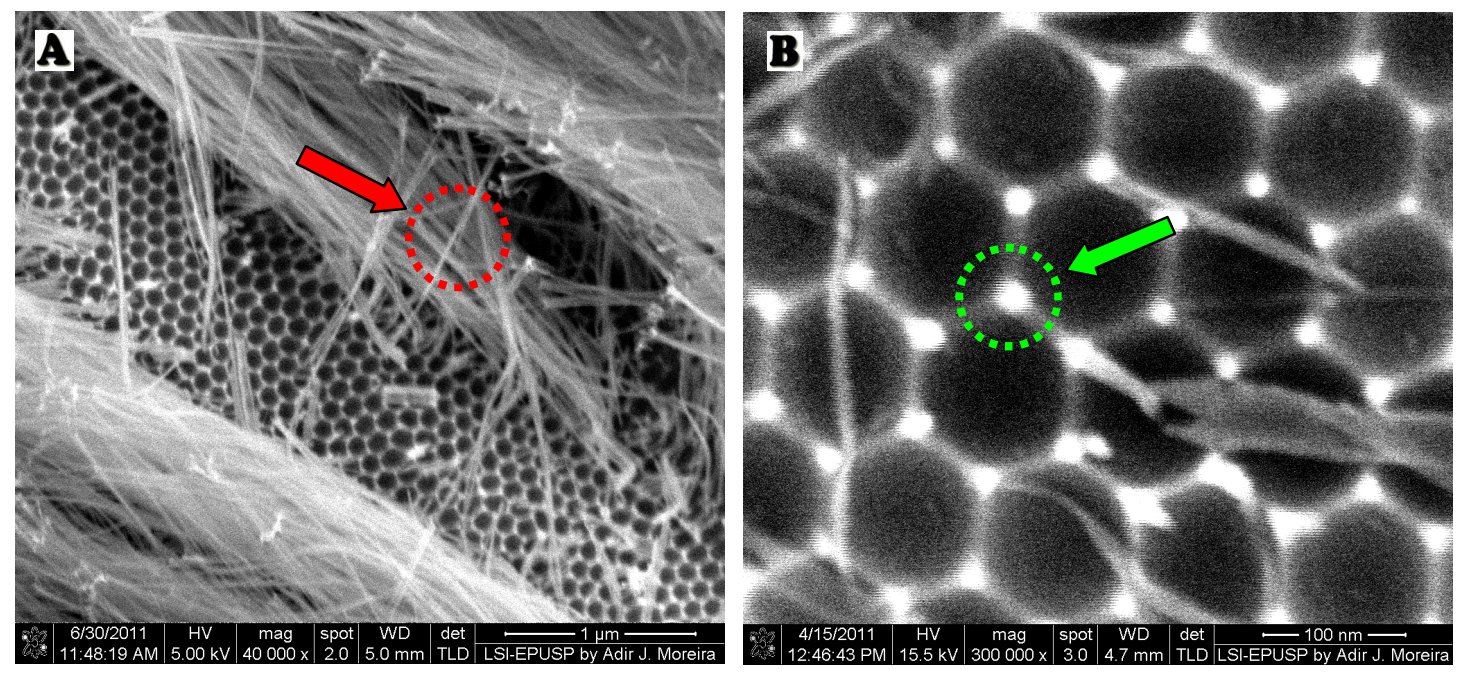

Figura 4.34. (A) Imagem MEV da formação de nanofios de alumina da amostra $P_{3}$ com um tempo de dissolução química de 65 minutos a uma temperatura de $27^{\circ} \mathrm{C}$. (B) Imagem MEV da superfície depois de uma remoção dos nanofios.

Por outro lado, a Figura 4.35 mostra imagens MEV dos nanofios formados para a amostra $R_{8}$. Esta amostra, anodizada por uma etapa, foi submetida a um processo de dissolução química em $1 \mathrm{M} \mathrm{H}_{3} \mathrm{PO}_{4}$ por 104 minutos a temperatura de $23^{\circ} \mathrm{C}$. O diâmetro destes nanofios (círculo vermelho da Figura 4.35A) e o diâmetro dos pontos que fazem de vértices para formar o hexágono regular (círculo verde da Figura 4.35B) são aproximadamente de $20 \mathrm{~nm}$ semelhante a aquele obtido para a amostra $P_{3}$. Por tanto, indepedentemente da temperatura de anodização a que foram submetidas as amostras $P_{3}$ e $R_{8}$ (neste caso, $15^{\circ} \mathrm{C}$ para $P_{3}$ e $20^{\circ} \mathrm{C}$ para $R_{8}$ ) em ambos os casos se obtiveram nanofios de alumina de igual diâmetro, o que sugere que os diâmetros dos nanofios são independentes da temperatura de anodização. Em geral, observou-se que o diâmetro dos nanofios de alumina são indendentes das condições de anodização e da temperatura do processo de dissolução. 

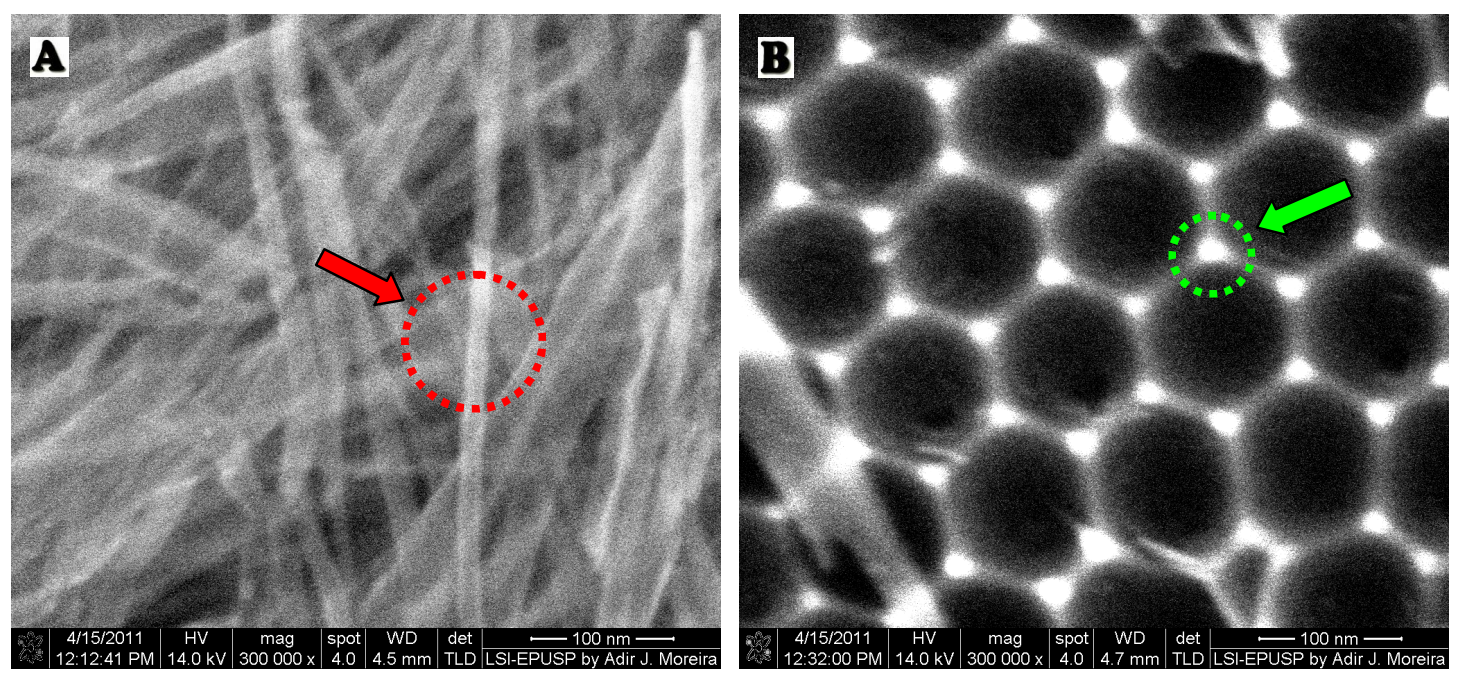

Figura 4.35. (A) Imagem MEV de nanofios de alumina formados da amostra $R_{8}$ com um tempo de dissolução química de 104 minutos a temperatura de $23^{\circ} \mathrm{C}$ e (B) Imagem MEV da superfície de alumina depois de uma remoção dos nanofios.

Em conclusão, os resultados obtidos na fabricação de nanofios de alumina através de técnicas químicas mostram que este método é adequado para obter nanofios de alumina com diâmetro na ordem de $20 \mathrm{~nm}$, mostrando que o diâmetro independe das condições de anodização e da temperatura do processo de dissolução. Além disso, notou-se que para uma temperatura de $23^{\circ} \mathrm{C}$ o processo de dissolução é mais lento do que para uma temperatura de $27^{\circ} \mathrm{C}$. 


\section{Capítulo 5}

\section{Considerações Finais}

\subsection{Conclusões}

Os resultados obtidos no presente trabalho nos conduzem às seguintes conclusões:

- As camadas de óxido de alumínio obtidas por anodização à temperatura ambiente apresentam duas camadas, uma camada superficial onde os poros estão irregularmente distribuídos e com uma faixa elevada de diferentes diâmetros. A camada mais profunda apresenta estruturas de poros organizados numa simetria hexagonal com poros do mesmo diâmetro. Também se encontrou que a espessura do óxido crescido por anodização a temperatura de $30^{\circ} \mathrm{C}$ é oito (8) vezes maior do que a anodização para baixas temperaturas. Este é um resultado muito vantajoso, já que é possível fabricar nanoestruturas de AAP em um curto período de tempo com poros de elevada razão de aspecto.

- Não foi observada uma dependência entre os diâmetros dos poros e a concentração do eletrólito utilizado no processo de anodização. No entanto, a concentração do eletrólito exerce uma influência na circularidade e na organização dos nanoporos.

- O efeito da temperatura sobre o diâmetro médio dos nanoporos é linear e nenhuma influência na organização e na circularidade dos nanoporos foi observada.

- O potencial de anodização mostrou ser um parâmetro importante no processo de fabricação de máscaras de AAP, já que o diâmetro médio dos poros mostrou-se diretamente proporcional ao potencial de anodização. Para potenciais baixos $(35 \mathrm{~V})$ e altos $(50 \mathrm{~V})$ observou-se uma irregularidade dos nanoporos, mas para um potencial de anodização mediano (45V), observouse uma melhor distribuição, homogeneidade e circularidade dos nanoporos. 
- Existe um crescimento polinomial na densidade de corrente estacionária sobre a concentração e é independente do potencial e da temperatura de anodização.

- Existe um crescimento exponencial na densidade de corrente estacionária em função do potencial de anodização e é independente da concentração e da temperatura de anodização.

- Existe um crescimento exponencial na densidade de corrente estacionária sobre a temperatura e é independente da concentração e do potencial de anodização.

- O processo de corrosão química após a anodização é um fator importante no processo de abertura dos poros. Estes resultados mostram que é possível fabricar máscaras de AAP por uma etapa de anodização com diferentes diâmetros médios mantendo a distância interporo constante.

- Os resultados indicam que nanoestruturas de AAP auto-organizadas podem ser fabricadas por uma etapa anodização controlando o tempo de corrosão química.

- Foi possível obter nanopartículas e nanofios metálicos auto-organizados sobre as máscaras de AAP previamente fabricadas, mesmo que estas apresentem uma irregularidade superficial em seus poros. Estes resultados sugerem que é possível fabricar nanopartículas e nanofios com diferentes diâmetros na faixa de 40 a $90 \mathrm{~nm}$.

- O resultado obtido na fabricação de nanofios de alumina através de técnicas químicas mostra que este método é adequado para produzir nanofios com diâmetro na ordem de $20 \mathrm{~nm}$, independente das condições de anodização e da temperatura do processo de dissolução. Além disso, encontrou-se que para uma temperatura de $23^{\circ} \mathrm{C}$ o processo de dissolução é mais lento do que para uma temperatura de $27^{\circ} \mathrm{C}$.

- Em conclusão, os resultados obtidos na fabricação de máscaras de AAP por uma etapa de anodização, nanopartículas e nanofios metálicos através de técnicas químicas e eletroquímicas mostram que este método é adequado para produzir nanomateriais com diâmetros na ordem menor de $100 \mathrm{~nm}$ onde não há necessidade do uso de equipamento sofisticado e de alto custo de manutenção e operação. 


\subsection{Perspectivas Futuras}

As conclusões do presente trabalho abrem muitas sugestões para a realização e continuação de trabalhos paralelos no que se refere à fabricação rápida de nanoestruturas de AAP auto-organizadas com elevada razão de aspecto e nanomateriais artificiais de tamanho nanométrico.

Os sistemas auto-organizados, além de serem utilizados como substratos para monitoramento do espalhamento Raman de moléculas depositadas, podem ser utilizados como cristais fotônicos bidimensionais. Em resumo, nossas pesquisas futuras estão voltadas à fabricação e caracterização de um dispositivo plasmônico, mais especificamente "nanoantenas óticas", onde os depósitos metálicos (Au ou Ag) dentro dos nanoporos de uma máscara de AAP atuariam com nanoantenas numa faixa de frequência de trabalho. Este tipo de trabalho está inserido na pesquisa atual e é um assunto de relevância científica e tecnológica. 
Referências bibliográficas

1. CAO, G., Nanostructures and nanomaterials: synthesis, properties and applications, [s.I.]: Imperial College Press, 2004.

2. NAGARAJAN, R., Nanoparticles: building blocks for nanotechnology. In: Nanoparticles: synthesis, stabilization, passivation, and functionalization, ACS SYMPOSIUM SERIES 996, Editors, R. Nagarajan and T. Alan Hatton, p. 214, 2008.

3. KARTOPU, G. and YALÇIN, O., Fabrication and applications of metal nanowires arrays electrodeposited in ordered porous templates. [s.I.]: Electrodeposited Nanowires and their Applications. [s.I.]: INTECH, p. 113-140, 2010.

4. RAO, C. N. R., GOVINDARAJ, E. A., Nanotubes and nanowires. Norfolk, Reino Unido [s.l.]: RSC Publishing, 2005.

5. MASUDA, H., Highly ordered nanohole arrays in anodic porous alumina. In: Ordered porous nanostructures and applications. [s.l.]: Springer Science New York, Wehrspohn, p. 37-55, 2005.

6. XU Q., BAO J., CAPASSO F. and WHITESIDES G. M., Surface plasmon resonances of free-standing gold nanowires fabricated by nanoskiving. Angew. Chem., 118, p. 3713, 2006.

7. CHOI D. S., RHEEM Y., YOO B., MYUNG N.V., KIM Y.K., I-V characteristics of a vertical single $\mathrm{Ni}$ nanowire by voltage-applied atomic force microscopy, Current Applied Physics, 10, p. 1037, 2010.

8. KAITSU, I.; INAMURA, R.; TODA, J. and MORITA, T., Ultra high density perpendicular magnetic recording technologies. Fujitsu Sci. Tech. J., v. 42, n.1, p. 122, 2006.

9. YAO, J., LIU, Z., LIU, Y., WANG, Y., SUN, C., BARAL, G., STACY, A. M., and ZHANG, $X$. Optical negative refraction in bulk metamaterials of nanowires, Science, 321, p. 930, 2008.

10. LIU S., LIU J., HAN X., CUI Y., Wang W., Electrochemical DNA biosensor fabrication with hollow gold nanospheres modified electrode and its enhancement in DNA immobilization and hybridization, Biosensors and Bioelectronics, 25, p.1640, 2010. 
11. VALIZADEH, S., GEORGE, J. M., LEISNER, P. and HULTMAN, L., Electrochemical deposition of Co nanowire arrays; quantitative consideration of concentration profiles. Electrochim. Acta, 47, 865, 2001.

12. WANG, H-W., SHIEH, C-F., CHEN, H-Y., SHIU, W-C., RUSSO, B. and CAO, G., Standing [111] gold nanotube to nanorod arrays via template growth, Nanotechnology, v. 17, n. 2689, p.111, 2006.

13. OliveirA, C. P., FReitAS, R. G., MATtOSO, L. H. C. and PEREIRA, E. C., Nanostructured Materials synthesized using electrochemical techniques. [s.l.]: Nanostructured Materials in Electrochemistry, WILEY-VCH Verlag GmbH \& Co. KGaA, Weinheim, Editor, A. Eftekhari, p. 117-186, 2007.

14. OHKOUCCHI, S., NAKAMURA, Y., IDEKA, N., SUGIMOTO, Y., ASAKAWA, K., Selective growth of ordered InGaAs quantum dots on patterned substrates with nano-hole arrays. J. Cryst. Growth 744, p. 301, 2007.

15.JI Q., Chen Y., JI L., JIANG X., LEUNG K.-N., Ion beam imprinting system for nanofabrication, Microelectron. Eng. 83, 796, 2006.

16. MIRAMOND C., FERMON C., ROUSSEAUX F., DECANINI D. and CARCENAC F., Permalloy cylindrical submicron size dot arrays, J. Magn. Magn. Mater. 165, 500, 1997.

17. MORALEJO S., CASTAÑO F.J., REDONDO C., JI R., NIELSCH K., ROSS C. A. and CASTAÑO F., Fabrication and magnetic properties of hexagonal arrays of NiFe elongated nanomagnets, J. Magn. Magn. Mater. 316, e44, 2007.

18. MASUDA H., KANEZAWA K. and NISHIO K., Fabrication of Ideally Ordered Nanohole Arrays in Anodic Porous Alumina Based on Nanoindentation Using Scanning Probe Microscope, Chem. Lett. 31, 1218, 2002.

19.ZHANG H., ZHANG D. and He Y., A novel atomic force microscope operating in liquid for in situ investigation of electrochemical preparation of porous alumina, Microsc. Res. Tech. 66, 126, 2005.

20. LIN M.-N., LIU C. Y., LIU N. W., LAI M. Y., PENG C. Y., WANG H. H., WANG Y. L. and LIN M.-T., Fabrication of an ordered nanoparticle array with a nanoaperture membrane used as a contact-mask, Nanotechnology 17, 315, 2006. 
21.SUN Z. and KIM H. K., Growth of ordered, single-domain, alumina nanopore arrays with holographically patterned aluminum films, Appl. Phys. Lett. 81, 3458, 2002.

22. COJOCARU C. S., PADOVANI J. M., WADE T., MANDOLI C., JASKIEROWICZ G., WEGROWE J. E., Fontcuberta i Morral A. and Pribat D., Conformal Anodic Oxidation of Aluminum Thin Films, Nano Lett. 5, 675, 2005.

23. YASUI K., NISHIO K. and MASUDA H., Fabrication of Nanocomposites by Filling Nanoholes in Highly Ordered Anodic Porous Alumina by Vacuum Deposition of Metal, Jpn. J. Appl. Phys. 44, L1181, 2005.

24. CHOI J., WEHRSPOHN R. B. and GOSELE U., Moiré Pattern Formation on Porous Alumina Arrays Using Nanoimprint Lithography, Adv. Mater. 15, 1531, 2003.

25. LEE W., JI R., ROSS C. A., GOSELE U. and NIELSCH K., Wafer-Scale Ni Imprint Stamps for Porous Alumina Membranes Based on Interference Lithography, Small 2, 978, 2006.

26. NISHIO K., FUKUSHIMA T., and MASUDA H., Control of Pitting Sites on Al for Electrolytic Capacitors Using Patterned Masking Film, Electrochem. Solid-State Lett. 9, B39, 2006.

27. MIKULSKAS I., JUODKAZIS S., TOMASIUNAS R. and DUMAS J. G., Aluminum Oxide Photonic Crystals Grown by a New Hybrid Method, Adv. Mater. 13, 1574, 2001.

28. MASUDA H., MATSUI Y., YOTSUYA M., MATSUMOTO F. and NISHIO K., Fabrication of Highly Ordered Anodic Porous Alumina Using Self-organized Polystyrene Particle Array, Chem. Lett. 33, 584, 2004.

29. MATSUI Y., NISHIO K. and MASUDA H., Highly ordered anodic porous alumina with 13-nm hole intervals using a $2 \mathrm{D}$ array of monodisperse nanoparticles as a template, Small 2, 522, 2006.

30. MASUDA H., and SATOH M., Fabrication of Gold Nanodot Array Using Anodic Porous Alumina as an Evaporation Mask, Jpn. J. Appl. Phys. 35, L126, 1996.

31.SULKA G. D., STROOBANTS S., MOSHCHALKOV V., BORGHS G. and CELIS J.-P., Synthesis of Well-Ordered Nanopores by Anodizing Aluminum Foils in Sulfuric Acid, J. Electrochem. Soc. 149, D97, 2002. 
32.DING G. Q., ZHENG M. J., Xu W. L., and SHEN W. Z., Fabrication of controllable free-standing ultrathin porous alumina membranes, Nanotechnology 16, 1285, 2005.

33. DING G. Q., SHEN W. Z., ZHENG M. J., and ZHOU Z. B., Integration of singlecrystalline nanocolumns into highly ordered nanopore arrays, Nanotechnology 17, 2590, 2006.

34. HOU K., TU J. P. and ZHANG X. B., Preparation of porous alumina film on aluminum substrate by anodization in oxalic acid, Chin. Chem. Lett. 13, 689, 2002.

35. ONO T., KONOMA CH., MIYASHITA H., KANAORI Y. and ESASHI M., Pattern Transfer of Self-Ordered Structure with Diamond Mold, Jpn. J. Appl. Phys. Part 1, 42, 3867, 2003.

36. SULKA G. D. and STEPNIOWSKI W. J., Structural features of self-organized nanopore arrays formed by anodization of aluminum in oxalic acid at relatively high temperatures, Electrochimica Acta 54, 3683, 2009.

37. YANG W.-B., and TANG X.-H., One-step anodization preparation and photoluminescence property of anodic aluminum oxide with nanopore arrays, Materials Science Forum 663, 272, 2011.

38. YANG W.-B., ZHOUA Y.-L., TANGA X.-H., ZHANGA B.-J., and LEIA G., Onestep anodization fabrication and morphology characterization of porous AAO with ideal nanopore arrays, Journal of Experimental Nanoscience 2, 207, 2007.

39. SORGENFRELI S., CHIU. C.-Y., GONZALEZ R. L., Yu Y-J., KIM P., NUCKOLLS C., and SHEPARD K. L., Label-free single-molecule detection of DNAhybridization kinetics with a carbon nanotube field-effect transistor, Nature Nanotechnology 6, 126, 2011.

40. LI C., FAN W., LEI B., ZHANG D., HAN S., TANG T., LIU X., LIU Z., ASANO S., MEYYAPPAN M., HAN J., and ZHOU C., Multilevel memory based on molecular devices, Applied Physics Letters 84(11), 1949, 2004.

41. FAVIER F., WALTER E. C., ZACH M. P., BENTER T., PENNER R. M., Hydrogen Sensors and Switches from Electrodeposited Palladium Mesowire Arrays, Science 293, 2227, 2001. 
42. NEUBRECH F., WEBER D., LOVRINCIC R., PUCCI A., LOPES M., TOURY T., and LAMY de La CHAPELLE M., Resonances of individual lithographic gold nanowires in the infrared, App. Phys. Lett. 93, 163105, 2008.

43. SCHLOGLM, R., and HAMID, S. B., A. Nanocatalysis: Mature Science Revisited or Something Really New? Angew. Chem. Int. Ed., 43, 1628, 2004.

44. AStRUC, D., LU, F., and ARANZAES, J. R., Nanoparticle Catalysis, Angew. Chem. Int. Ed., 44, 7852, 2005.

45. ROUCOUX, A., SCHULZ, J., and PATIN, H., Reduced transition metal colloids: A novel family of reusable catalysts? Chem. Rev., 102, 3757, 2002.

46. LIU, S. Q., LEECH, D., and JU, H. X., Application of colloidal gold in protein immobilization, electron transfer and biosensing, Anal. Lett. 36, 1, 2003.

47. RIBOH, C., HAES, A. J., MACFARLAND, A. D., Ranjit, C., and VAN DUYNE, R. P., A Nanoscale Optical Biosensor: Real Time Immunoassay and Nanoparticle Adhesion, J. Phys. Chem. B, 107, 1772, 2003.

48. KRASTEVA, N., BeSNARD, I., GUSE, B., BAUER, R. E., MULLEN, K., YASUDA, A., and VOSSMEYER, T., Self-assembled gold nanoparticle/dendrimer composite films for vapor sensing applications, Nano Lett., 2, 551, 2002.

49. VOSSMEYER, T., GUSE, B., BESNARD, I., BAUER, R. E., MULLEN, K., and YASUDA, A., Gold nanoparticle/polyphenylen dendrimer composite films: Preparation and vapor-sensing properties, Adv. Mater., 14, 238, 2002.

50. KRASTEVA, N., GUSE, B., BESNARD, I., YASUDA, A., and VOSSMEYER, T., Gold nanoparticle/PPI-dendrimer based chemiresistors: Vapor-sensing properties as a function of the dendrimer size, Sensors Actuat. B: Chem., 92, 137, 2003.

51.HU, W.-K., GAO, X.-P., NOREIUS, D., BURCHARDT, T., and NAKSTAD, N. K., Evaluation of nano-crystal sized a-nickel hydroxide as an electrode material for alkaline rechargeable cells, J. Power Sources, 160, 704, 2006.

52.DA SILVA, M. F., Quantification of maghemite nanoparticles, in Scientific and clinical applications of magnetic carriers, New York Plenum [s.l.]: Editor, W. Schutt et al., p. 171, 1997.

53. DIGGLE J. W., DOWNIE T. C. and GOULDING C. W., Anodic oxide films on aluminum, Chemical Review 69, 365, 1969. 
54. MARTIN C. R., Nanomaterials: A membrane-based synthetic approach, Science 266, 1961, 1994.

55. SHAWAQFEH A. T., BAITUS R., Fabrication and characterization of single layer and multi-layer anodic alumina membranes, Journal of membrane Science 157, 147, 1999.

56. KYOTANI T., XU W., YOKOYAMA Y., INAHARA J., TOUHARA H., TOMITA A., Chemical modification of carbon-coated anodic alumina films and their applications to membrane filter, Journal of membrane Science 196, 231, 2002.

57. SHINGUBARA S., Fabrication of nanomaterials using porous alumina templates, Journal of Nanoparticles Research 5, 17, 2003.

58. MIKULSKAS I., JUODKAZIS S., TOMASIUNAS R., DUMAS J. G., Aluminum oxide photonic crystals grown a new hybrid method, Advanced Materials 13, 1574, 2001.

59. SHEASBY P., COOKE W., The electrolytic colouring of anodized aluminum, Transaction of Intitute of Metal Finishing 52, 103, 1974.

60. BENGOUGH C., STUART G., Patente Britânica registrada em 1923.

61. CABONI, Patente Italiana registrada em 1936.

62. KELLER F., HUNTER M., ROBINSON D., Structural features of coating on aluminum, Journal of Electrochemical Society 100, 411, 1953.

63. SULKA G. D., Highly ordered anodic porous alumina formation by selforganized anodizing, c.1, in: Nanostructured Materials in Electrochemistry, [s.l.]: Ed. A. Efterkhari, Wiley - VCH, p.1-116, 2008.

64.THOMPSON G. E., WOOD G., Anodic films on aluminum, in: Treatise on Materials Science and Technology. v. 23, [s.I.] New York: Academic Press. 1983.

65. SHIMIZU K., KOBAYASHI K., THOMPSON G. E., WOOD G., A novel marker for the determination of transport number during anodic barrier oxide growth on aluminum, Philosophical Magazine B 64, 345, 1991.

66. WOOD G. C., SKELDON P., THOMPSON G. E., SHIMIZU K., A model for the incorporation of electrolyte species into anodic alumina, Journal of the Electrochemical Society 143, 74, 1996. 
67. O'SULLIVAN J. P., and WOOD G. C., Morphology and Mechanism of formation of porous anodic films on aluminum, Proceeding of the Royal Society of London Series A - Mathematical and Physics Science 317, 511, 1970.

68. HOAR T. P., MOTT N. F., A mechanism for the formation of porous anodic oxide films on aluminum, Journal of Physics and Chemical of Solids 9, 97, 1959.

69. PARKHUTIK V. P., SHERSHULSKY V., Theoretical modelling of porous oxide growth on aluminum, Journal of Physics D: Applied Physics 25, 1258, 1992.

70.PATERMARAKIS G., MOUSSOUTZANIS K., Electrochemical kinetic study on the growth of porous anodic oxide films on aluminum, Electrochimica Acta 40, 699, 1995.

71. MASUDA H., and FUKUDA K., Ordered metal nanohole arrays made by a twostep replication of honeycomb structure of anodic alumina, Science 268, 1466, 1995.

72. MASUDA H., MIZUNO T., BABA N., OHMORI T., Fabrication of Pt microporous electrodes from anodic porous alumina and immobilization of GOD into their micropores, Journal of Electroanalytical Chemistry 368, 33, 1994.

73. MASUDA H., YAMADA H., SATOH M., ASOH H., NAKAO M., TAMAMURA T., Highly ordered nanochannels-arrays architecture in anodic alumina, Applied Physics Letter 71, 2770, 1997.

74. MASUDA H., HASEGAWA F., ONO S., Self-ordering of a cell arrangement of anodic porous alumina formed in sulfuric acid solution, Journal of Electrochemical Society 144, L127, 1997.

75. MASUDA H., YADA K., and OSAKA A., Self-ordering of cell configuration of anodic porous alumina with large-size pores in phosphoric acid solution, Jpn. Journal of Applied Physics 37, L1340, 1998.

76. DESPIC A. R., A note on the effect of the electrolyte on the type of growth of anodic oxide on aluminum, J. Electroanal. Chem., 191, 417, 1985.

77.THOMPSON G. E., and WOOD G. C., Treatise on Materials Science and Technology, (ed. J.C. Scully), [s.I.]: Academic Press New York, Vol. 23, pp. 205329, 1983.

78.DESPIC A. and PARKHUTIK V. P., Modern Aspects of Electrochemistry, (eds. J. O'M. Bockris, R.E. White and B.E. Conway), [s.I.]: Plenum Press, New York and London, Vol. 20, pp. 401-503, 1989. 
79. TAKAHASHI H., FUJIMOTO K. and NAGAYAMA M., Effect of $\mathrm{pH}$ on the Distribution of Anions in anodic oxide films formed on aluminum in Phosphate solutions, J. Electrochem. Soc., 135, 1349, 1988.

80. ONO S., SAITO M., and ASOH H., Self-ordering of anodic porous alumina formed in organic acid electrolytes, Electrochim. Acta, 51, 827, 2005.

81. CHU S. Z., WADA K., INOUE S., ISOGAI M., KATSUTA Y., and Yasumori A., Large-scale fabrication of ordered nanoporous alumina films with arbitrary pore intervals by critical-potential anodization, J Electrochem. Soc., 153, B384, 2006.

82. MOZALEV A., MOZALEVA I., SAKAIRI M. and TAKAHASHI H., Anodic film growth on Al layers and Ta-Al metal bilayers in citric acid electrolytes, Electrochim. Acta, 50, 5065, 2005.

83. SHINGUBARA S., K. MORIMOTO, H. SAKAUE and TAKAHAGI T., Selforganization of a porous alumina nanohole array using a sulfuric/oxalic acid mixture as electrolyte, Electrochem. Solid- State Lett. 7, E15, 2004.

84.LE COZ F., ARURAULT L., and DATAS L., Chemical analysis of a single basic cell of porous anodic aluminum oxide templates, Materials Characterization 61, 283, 2010.

85. PALIBRODA E., Le mécanisme du développement de l'oxyde poreux de l'aluminium II. L'oxyde poreux et la tension électrique de la couche barrière, Surf. Technol., 23, 341, 1984.

86. NIELSCH K., CHOI J., SCHWIRN K., WEHRSPOHN R. B. and GOSELE U., Self-ordering Regimes of Porous Alumina: The 10\% Porosity Rule, Nano Lett., 2, 677, 2002.

87. EBIHARA K., TAKAHASHI H., and NAGAYAMA M., Structure and density of anodic oxide films formed on aluminum in oxalic acid solution, J. Met. Finish. Soc. Japan 34, 548, 1983.

88. EBIHARA K., TAKAHASHI H., and NAGAYAMA M., Structure and density of anodic oxide films formed on aluminum in sulfuric acid solutions, J. Met. Finish. Soc. Japan 33, 156, 1982.

89.ZHANG J., KIELBASA J. E., and CARROLL D. L., Controllable fabrication of porous alumina templates for nanostructures synthesis, Materials Chemistry and Physics 122, 295, 2010. 
90.HWANG S. K., JEONG S. H., HWANG H. Y., LEE O. J. and LEE K. H., Fabrication of highly ordered pore array in anodic aluminum oxide, Korean $\mathrm{J}$. Chem. Eng., 19, 467, 2002.

91.SULKA G. D. and PARKOLA K. G., Temperature influence on well-ordered nanopore structures grown by anodization of aluminium in sulphuric acid, Electrochim. Acta, 52, 1880, 2007.

92. WERNICK S., PINNER R. and SHEAASBY P. G., The Surface Treatment and Finishing of Aluminium and its Alloys, [s.I.]: ASM International, Finishing Publication Ltd., 5th edition, pp. 289, 1987.

93. SULKA G. D. and PARKOLA K., Anodising potential influence on well-ordered nanostructures formed by anodisation of aluminium in sulphuric acid, Thin Solid Films, 515, 338, 2006.

94. WOOD G. C. and O'SULLIVAN J. P., The anodizing of aluminium in sulphate solutions, Electrochim. Acta, 15, 1865, 1970.

95. BOCCHETTA P., SUNSERI C., BOTTINO A., CAPANNELLI G., CHIAVAROTTI G., PIAZZA S., and DI QUATO F., Asymmetric alumina membranes electrochemically formed in oxalic acid solution, J. Appl. Electrochem., 32, 977, 2002.

96. PAKES A., THOMPSON G. E., SKELDON P., MORGAN P. C. and SHIMIZU K., Anodizing of aluminum in Borax solution, Trans. IMF, 77, 171, 1999.

97. HAN J. K., KIM J., CHOI Y. C., CHANG K.-S., LEE J., YOUN H. J., BU S. D., Structure of alumina nanowires synthesized by chemical etching of anodic alumina membrane, Physica E 36, 140, 2007.

98. KIM J., CHOI Y. C. and Bu S. D., Formation Process of Dielectric Alumina Nanowires: Three Critical Steps Depending on Etching Rates of Oxide Layers in Anodic Aluminum Oxide Membrane, Journal of the Korean Physical Society 49, S529, 2006.

99.BURGOS N, PAULIS $M$, MONTES $M$. Preparation of $\mathrm{Al}_{2} \mathrm{O}_{3} / \mathrm{Al}$ monoliths by anodization of aluminum as structured catalytic supports, J Mater Chem. 13, 1458, 2003.

100. MELENDRES C. A, Van Gils S., TERRYN H. Toward a quantitative description of the anodic oxide films on aluminum, Electrochem Commun. 3, 737, 2001. 
101. THIBAULT S., and DUCHEMIN C., Optical reflectance method for analyzing anodic films formed on aluminum, Corros NACE 35 (11), 532, 1979.

102. FARNAN I., DUPREE R., JEONG Y., THOMPSON G. E., WOOD G. C., FORTY A. J., Structural chemistry of anodic alumina, Thin Solid Films 173, 209, 1989.

103. XU Y., THOMPSON G. E., WOOD G. C., and BETHUNE B., Anion incorporation and migration during barrier film formation on aluminum, Corros. Sci., 27, 83, 1987.

104. PATERMARAKIS G., MOUSSOUTZANIS $\mathrm{K}$. and NIKOLOPOULOS N., Investigation of the incorporation of electrolyte anions in porous anodic $\mathrm{Al}_{2} \mathrm{O}_{3}$ films by employing a suitable probe catalytic reaction, J. Solid State Electrochem. 3, 193, 1999.

105. SHIMIZU, K., HABAZAKI, H., SKELDON, P., THOMPSON, G. E. and WOOD, G. C., Comparison of depth profiling analysis of a thick, electrolytically-coloured porous alumina film by EPMA and GDOES, Surf. Interface Anal., 27, 1046, 1999.

106. SHIMIZU, K., BROWN, G. M., HABAZAKI, H., KOBAYASHI, K., SKELDON, P., THOMPSON, G. E. and WOOD, G. C., Glow discharge optical emission spectrometry (GDOES) depth profiling analysis of anodic alumina films-a depth resolution study, Surf. Interface Anal. 27, 24, 1999.

107. SHIMIZU, K., BROWN, G. M., HABAZAKI, H., KOBAYASHI, K., SKELDON, P., THOMPSON, G. E. and WOOD, G. C., Impurity distributions in barrier anodic films on aluminum: a GDOES depth profiling study, Electrochim. Acta, 44, 2297, 1999.

108. SHIMIZU, K., HABAZAKI, H., SKELDON, P., THOMPSON, G. E. and WOOD, G. C., Migration of sulphate ions in anodic alumina, Electrochim. Acta, 45, 1805, 2000.

109. THOMPSON G. E., FURNEAUX R. C., WOOD G. C., RICHARDSON J. A. and GOODE J. S., Nucleation and Growth of porous anodic films on aluminum, Nature, 272, 433, 1978.

110. ONO S. and MASUKO N., The high resolution observation of porous anodic films formed on aluminum in phosphoric acid solution, Corros. Sci., 33, 841, 92. 
111. ONO S., H. ICHINOSE and MASUKO N., Defects in Porous Anodic Films Formed on High Purity Aluminum, J. Electrochem. Soc., 138, 3705, 1991.

112. ONO S., ICHINOSE H. and MASUKO N., Lattice images of crystalline anodic alumina formed on a ridged aluminum substrate, J. Electrochem. Soc., 139, L80, 1992.

113. ZHU X.-F., SONG Y., LIU L., WANG C-Y., ZHENG J., JIA H.-B., and WANG X.L., Electronic currents and the formation of nanopores in porous anodic alumina, Nanotechnology 20, 475303, 2009.

114. MACDONALD D. D., On the Formation of Voids in Anodic Oxide Films on Aluminum, J. Electrochem. Soc., 140, L27, 1993.

115. LEE C. W., KANG H. S., CHANG Y. H. and HAHM Y. M., Thermotreatment and chemical resistance of porous alumina membrane prepared by anodic oxidation, Korean J. Chem. Eng., 17, 266, 2000.

116. YANG S. G., LI T., HUANG L. S., TANG T., ZHANG J. R., GU B. X., Du Y. W., SHI S. Z., and Lu Y. N., Stability of anodic aluminum oxide membranes with nanopores, Phys. Lett. A, 318, 440, 2003.

117. HOANG V. V., and Oh S. K., Simulation of structural properties and structural transformation of amorphous $\mathrm{Al}_{2} \mathrm{O}_{3}$, Physica B, 352, 73, 2004.

118. XU W. L., ZHENG M. J., Wu S. and SHEN W. Z., Effects of high-temperature annealing on structural and optical properties of highly ordered porous alumina membranes, Appl. Phys. Lett., 85, 4364, 2004.

119. BORCA-TASCIUC D. A., and CHEN G., Thermal Properties of Nanochanneled Alumina Templates, J. Appl. Phys. 97, 084303, 2005.

120. XIA Z., RIESTER L., SHELDON B. W., CURTIN W.A., LIANG J., YIN A., and $\mathrm{XU}$ J. M., Mechanical properties of highly ordered nanoporous anodic alumina membranes, Rev. Adv. Mater. Sci. 6, 131, 2004.

121. BROWN I. W. M., BOWDEN M. E., KEMMITT T. and MACKENZIE K. J. D., Structural and thermal characterization of nanostructured alumina templates, Curr. Appl. Phys., 6, 557, 2006.

122. CHEN C. C., CHEN J. H. and CHAO C. G., Post-treatment Method of Producing Ordered Array of Anodic Aluminum Oxide Using General Purity Commercial (99.7\%) Aluminum, Jpn. J. Appl. Phys. 44, 1529, 2005. 
123. CHEN C. H., TAKITA K., HONDA S. and AWAJI H., Fracture behavior of cylindrical porous alumina with pore gradient, J. Eur. Ceram. Soc., 25, 385, 2005.

124. THEODOROPOULOU M., KARAHALIOU P. K., GEÓRGIA S. N., KRONTIRAS C. A., PISANIAS M. N., KOKONOU M., and NASSIOPOULOU A. G., Thin Porous Anodic Alumina Films: Interface trap density determination, lonics, 11, 236, 2005.

125. KATO S., NIGO S., UNO Y., ONISI T. and KIDO G., Voltage-induced insulatormetal transition at room temperature in an anodic porous alumina thin film, J. Phys.: Conference Series, 38, 148, 2006.

126. FERNANDES J. C. S., PICCIOCHI R., DA CUNHA BELO M., MOURA E SILVA T., FERREIRA M. G. S., and FONSECA I. T .E., Capacitance and photoelectrochemical studies for the assessment of anodic oxide films on aluminum, Electrochim. Acta, 49, 4701, 2004.

127. KARAHALIOU P. K., THEODOROPULOU M., KRONTIRAS C. A., XANTHOPOULOS N., GEORGA S. N. and PISANIAS M. N., Transient and AC Conductivity of nanocrystalline porous Alumina Thin Films on Silicon with embedded Silicon nanocrystals, J. Appl. Phys., 95, 2776, 2004.

128. THEODOROPOULOU M., KARAHALIOU P. K., GEÓRGIA S. N., KRONTIRAS C. A., PISANIAS M. N., KOKONOU M. and NASSIOPOULOU A. G., Interface trap density of anodic porous alumina films of different thicknesses on $\mathrm{Si}$, J. Phys.: Conference Series, 10, 222, 2005.

129. ZABALA N., PATTANTYUS-ABRAHAM A. G., RIVACOBA A., GARCíA DE ABAJO F. J., and WOLF M. O., Relativistic effects in EELS of nanoporous alumina membranes, Phys. Rev. B, 68, 245407, 2003.

130. OH H.-J., PARK G-S., KIM J-G., JEONG Y., and CHI C.-S., Surface roughness factor of anodic oxide layer for electrolytic capacitors, Mater. Chem. Phys., 82, 331, 2003.

131. REDÓN R., VÁZQUEZ-OLMOS A., MATA- ZAMORA M. E., ORDOÑEZMEDRANO A., RIVERA-TORRES F. and SANIGER J. M., Contact angle studies on anodic porous alumina, Rev. Adv. Mater. Sci., 11, 79, 2006. 
132. THOMPSON D. W. , SNYDER P. G., CASTRO L. and YAN L., Optical characterization of porous alumina from vacuum ultraviolet to midinfrared, $\mathbf{J}$. Appl. Phys., 97, 113511, 2005.

133. XU W. L., CHEN H., ZHENG M. J., DING G. Q., and SHEN W. Z., Optical transmission spectra of ordered porous alumina membranes with different thicknesses and porosities, Optical Mater., 28, 1160, 2006.

134. HOHLBEIN J., REHN U., and WEHRSPOHN R. B., In-situ optical characterization of porous alumina, Phys. Stat. Sol. A, 201, 803, 2004.

135. KOKONOU M., NASSIOPOULOU A. G. and TRAVLOS A., Structural and photoluminescence properties of thin alumina films on silicon, fabricated by electrochemistry, Mater. Sci. Eng. B, 101, 65, 2003.

136. HUANG G. S., WU X. L., SIU G. G. and CHU P. K., On the Origin of Light Emission from Porous Anodic Alumina Formed in Sulfuric Acid, Solid State Commun. 137, 621, 2006.

137. CHEN J. H., HUANG C. P., CHAO C. G. and CHEN T. M., The investigation of photoluminescence centers in porous alumina membranes, Appl. Phys. A, 84, 297, 2006.

138. DU Y., CAI W. L., Mo C. M., CHEN J., ZHANG L. D. and ZHU X. G., Preparation and photoluminescence of alumina membranes with ordered pore arrays, Appl. Phys. Lett., 74, 2951, 1999.

139. HUANG G. S., WU X. L., KONG F., CHENG Y. C., SIU G. G. and CHU P. K., In situ fabrication of alumina nanotubes array and photoluminescence, Appl. Phys. Lett., 89, 073114, 2006.

140. STOJADINOVIC S., ZEKOVIC Lj., BELCA I., KASALICA B. and NIKOLIC D., The influence of anodizing conditions on the galvanoluminescence spectra of porous oxide films on aluminum formed in phosphoric acid solution, Electrochem. Commun. 6, 708, 2004.

141. KASALICA B., STOJADINOVIC S., ZEKOVIC Lj., BELCA I. and NIKOLIC D., The influence of aluminum treatment and anodizing conditions on the galvanoluminescence properties of porous oxide films formed in sulfuric acid solution, Electrochem. Commun. 7, 735, 2005. 
142. STOJADINOVIC S., BELCA I., KASALICA B., ZEKOVIC Lj. and TADIC M., The galvanoluminescence spectra of barrier oxide films on aluminum formed in inorganic electrolytes, Electrochem. Commun. 8, 1621, 2006.

143. PARKHUTIK V. P., The initial stages of aluminium porous anodization studied by auger electron spectroscopy, Corrosion Science 26, 295, 1986.

144. ZARASKA L., SULKA G. D., and JASKULA M., The effect of $n$-alcohols on porous anodic alumina formed by self-organized two-step anodizing of aluminium in phosphoric acid, Surf. Coat. Technol., 204, 1729, 2010.

145. LEE W. JI R. GOSELE U. and NIELSCH K., Fast fabrication of long-range ordered porous alumina membranes by hard anodization, Nature Materials 5 , 741, 2006.

146. THOMPSON G. E., Porous anodic alumina: fabrication, characterization and applications, Thin Solid films 297 192, 1997.

147. LI F. Y., ZHANG L. and METZGER R. M., On the Growth of Highly Ordered Pores in Anodized Aluminum Oxide, Chem. Mater. 10, 2470, 1998.

148. SU Z. X. and ZHOU W. Z., Formation Mechanism of Porous Anodic Aluminum and Titanium Oxides, Adv. Mater. 20, 3663, 2008.

149. SINGH S., FESTIN M., BARDEN W. R. T., XI L., FRANCIS J. T. and KRUSE P., Universal Method for the Fabrication of Detachable Ultrathin Films of Several Transition Metal Oxides, ACS Nano 2, 2363, 2008.

150. LEE W., SCHWIRN K., STEINHART M., PIPPEL E., SCHOLZ R. and GOSELE U., Structural engineering of nanoporous anodic aluminium oxide by pulse anodization of aluminium, Nat. Nanotechnol. 3, 234, 2008.

151. LEE W., SCHOLZ R., and GOSELE U., A Continuous Process for Structurally Well-Defined $\mathrm{Al}_{2} \mathrm{O}_{3}$ Nanotubes Based on Pulse Anodization of Aluminum, Nano Lett. 8, 2155, 2008.

152. SHINGUBARA S., OKINO O., SAYAMA Y., SAKAUE H. and TAKAHAGI T., Ordered Two-Dimensional Nanowires Array Formation Using Self-Organized Nanoholes of Anodically Oxidized Aluminum, Jpn. J. Appl. Phys. 36, 7791, 1997.

153. SHINGUBARA S., OKINO O., SAYAMA Y., SAKAUE H. and TAKAHAGI T., Two-dimensional Nanowires array formation on Si substrate using self-organized 
nanoholes of anodically oxidized aluminum, Solid-State Electron. 43, 1143, 1999.

154. JESSENSHY O., MULLER F., and GOSELE U., Self-organized formation of hexagonal pore arrays in anodic alumina, Appl. Phys. Lett. 72, 1173, 1998.

155. LI A. P., MULLER F., BIRNER A., NIELSCH K. and GOSELE U., Hexagonal pore arrays with a 50-420 nm interpore distance formed by self-organization in anodic alumina, J. Appl. Phys. 84, 6023, 1998.

156. LI F., ZHANG L. and METZGER R. M., On the Growth of Highly Ordered Pores in Anodized Aluminum Oxide, Chem. Mater. 10, 2470, 1998.

157. ZHANG L., CHO H. S., LI F., METZGER R. M. and DOYLE W. D., Cellular growth of highly ordered porous anodic films on aluminum, J. Mater. Sci. Lett. 17, 291, 1998.

158. LI A. P., MULleR F., BIRNER A., NIELSCH K., and GOSELE U., Polycrystalline nanopore arrays with hexagonal ordering on aluminum, J. Vac. Sci. technol. A 17, 1428, 1999.

159. LI D., ZHAO L., JIANG C. and LU J. G., Formation of Anodic Aluminum Oxide with Serrated Nanochannels, Nano Lett. 10, 2766, 2010.

160. ZARASKA L., SULKA G. D. and JASKULA M., Properties of nanostructures obtained by anodization of aluminum in phosphoric acid at moderate potentials, Journal of Physics: Conference Series 146, 012020, 2009.

161. LI Y., LING Z. Y., CHEN S. S., and WANG J. C., Fabrication of novel porous anodic alumina membranes by two-step hard anodization, Nanotechnology 19 , 225604, 2008.

162. HAN X. Y., and SHEN W. Z., Improved two-step anodization technique for ordered porous anodic aluminum membranes, Journal of Electroanalytical Chemistry 655, 56, 2011.

163. SCHWIRN K., LEE W., HILLEBRAND R., STEINHART M., NIELSCH K. and GOSELE U., Self-ordered Anodic Aluminum Oxide Formed by $\mathrm{H}_{2} \mathrm{SO}_{4}$ Hard Anodization, ACS Nano 2, 302, 2008.

164. ASOH H., NISHIO K., NAKAO M., YOKOO A., TAMAMURA T., and MASUDA $\mathrm{H}$., Fabrication of ideally ordered anodic porous alumina with $63 \mathrm{~nm}$ hole periodicity using sulfuric acid, J. Vac. Sci. Tech. B 19, 569, 2001. 
165. ASOH H., NISHIO K., NAKAO M., A., TAMAMURA T., and MASUDA H., Conditions for Fabrication of Ideally Ordered Anodic Porous Alumina Using Pretextured Al, Electrochem. Soc. 148, B152, 2001.

166. MASUDA H., ASOH H., WATANABE M., NISHIO K., NAKAO M., and TAMAMURA T., Square and Triangular Nanohole Array Architectures in Anodic Alumina, Adv. Mater., 13, 189, 2001.

167. MATSUI Y., NISHIO K., and MASUDA H., Highly Ordered Anodic Porous Alumina by Imprinting Using $\mathrm{Ni}$ Molds Prepared from Ordered Array of Polystyrene Particles, Jpn. J. Appl. Phys., 44, 7726, 2005.

168. MATSUI Y., NISHIO K., and MASUDA H., Highly Ordered Anodic Porous Alumina with 13-nm Hole Intervals Using a 2D Array of Monodisperse Nanoparticles As a Template, Small, 2, 522, 2006.

169. SULKA G. D., and JASKULA M., Defects Analysis in Self-Organized Nanopore Arrays Formed by Anodization o Aluminum at Various Temperatures, J. Nanosci. Nanotechnol. 6, 3803, 2006.

170. SCHONENBERGER C., VAN DER ZANDE B. M. I., FOKKINK L. G. J., HENNY M., SCHMID C., KRUGER M., BACHTOLD A., HUBER R., BIRK H., and STAUFER U., Template synthesis of nanowires in porous polycarbonate membranes: Electrochemistry and morphology. J. Phys. Chem. B, 101, 5497, 1997.

171. YANG X.-C., ZOU X., Liu Y., LI X.-N., Hou J.-W., Preparation and characteristics of large-area and high-filling $\mathrm{Ag}$ nanowires arrays in OPAA template, Materials Letters 64, 1451, 2010.

172. YIN A. J., LI J., JIAN W., BENNETT A. J., and XU J. M., Fabrication of highly ordered metallic nanowires arrays by electrodeposition. Appl. Phys. Lett., 79, 1039, 2001.

173. METZGER R. M., KONOVALOV V. V., SUN M., XU T., ZANGARI G., XU B., BENAKLI M., and DOYLE W. D., Magnetic nanowires in hexagonally ordered pores of alumina, IEEE Trans. Magn., 36(1), 30, 2000.

174. MENON L., LU W. T., FRIEDMAN A. L., BENNETT S. P., HEIMAN D., and SRIDHAR S., Negative index metamaterials based on metal-dielectric nanocomposites for imaging applications, Applied Physics Letters 93, 123117, 2008. 
175. NIELSCH K., MULLER F., LI A. P., GOSELE U., Uniform Nickel Deposition into Ordered Alumina Pores by Pulsed Electrodeposition, Adv. Mater. 12, 582, 2000. 176. SAUER G., BREHM G., SCHNEIDER S., NIELSCH K., WEHRSPOHN R. B., CHOI J., HOFMEISTER H., and GOSELE U., Highly ordered monocrystalline silver nanowires arrays, J. Appl. Phys. 91, 3243, 2002.

177. KONDO T., NISHIO K., and MASUDA H., Surface-Enhanced Raman Scattering in Multilayered Au Nanoparticles in Anodic Porous Alumina Matrix, Applied Physics Express 2, 032001, 2009.

178. KONDO T., NISHIO K., and MASUDA H., Multilayered Three-Dimensional Structures of Ag Nanoparticles in Anodic Porous Alumina, Japanese Journal of Applied Physics 49, 025002, 2010.

179. CHOI J., SAUER G., NIELSCH K., WEHRSPOHN R. B., and GOSELE U., Hexagonally Arranged Monodisperse Silver Nanowires with Adjustable Diameter and High Aspect Ratio, Chem. Mater., 15, 776, 2003.

180. WANGA X. W., YUANA Z. H., and FANG B. C., Template-based synthesis and magnetic properties of $\mathrm{Ni}$ nanotubes arrays with different diameters, Materials Chemistry and Physics 125, 1, 2011.

181. CHOU S. Y., WEI M. S., KRAUSS P. R., and FISHER P. B., Single-domain magnetic pillar array of $35 \mathrm{~nm}$ diameter and 65 Gbits/in. ${ }^{2}$ density for ultrahigh density quantum magnetic storage, J. Appl. Phys. 76, 6673, 1994.

182. YIN A. J., LI J., JIAN W., BENNETT A. J., and XU J. M., Fabrication of highly ordered metallic nanowires arrays by electrodeposition, Applied Physics Letters 79, 1039, 2001.

183. MARUTA R. H., KIM H. Y., HUANCA D. R., SALCEDO W. J., A New Correlation-Based Granulometry Algorithm with Application in Characterizing Porous Silicon Nanomaterials, ECS transactions 31, 273, 2010. 


\section{ANEXO A: Publicação durante o Programa de Mestrado}

BUSTAMANTE R. H.; RAIMUNDO D. S.; CHAMPI H. A. A.; KIN H. Y.; SALCEDO, W. J. Fabrication of porous anodic alumina by single-step anodization: Influence of the molar concentration and effect of chemical etching, ECS Transactions, 39(1), 401, 2011. 